University of São Paulo

Institute of Astronomy, Geophysics and Atmospheric Sciences

Department of Geophysics

Julia Carolina Rivadeneyra Vera

New measurements of crustal and

lithospheric thickness for the South

American platform using the receiver

function method, toward a 3D velocity

model

São Paulo 



\section{New measurements of crustal and lithospheric thickness for the South American platform using the receiver function method, toward a 3D velocity model}

Thesis presented at the Institute of Astronomy, Geophysics and Atmospheric Sciences of the University of São Paulo as partial requirement for obtaining the title of Doctor of Sciences.

Area of concentration: Geophysics

Advisor: Prof. Dr. Marcelo Belentani de Bianchi

Final version: The original copy is available at the library

São Paulo 

To my family, especially to my mom who always supported and encouraged me to achieve my dreams, no matter how far away they seem. 


\section{Acknowledgements}

The present work is the result of my studies during the last four years. During this time, I have had the support of several institutions, colleagues, and friends to whom I would like to say thank you.

First of all, I would like to thank my advisor, Ph.D. Marcelo Bianchi, for all the support, guidance, patience, constant encouragement, and friendship during all my $\mathrm{Ph} . \mathrm{D}$. Thank you for being the warm and critical person who I needed in the crucial moments, encouraging me to give my best. I also want to thank Professor Marcelo Assumpção for all his recommendations in the development of this work.

To the members of the Brazilian Seismographic Network (RSBR) for the data provided and used in this work. A special thanks to the Seismology group of the University of São Paulo and the "3-Basins Project" team, who are in charge of the installation of the BL and XC subnets stations; and quality control of the data.

To the San Calixto Observatory (OSC) and the Geophysics Institute of Peru (IGP), especially to their executive directors Gonzalo Fernández and Hernando Tavera respectively, for the data provided from the Bolivian and Peruvian stations, which have been processed in this work.

To the Institute of Astronomy, Geophysics and Atmospheric Science, and all its staff, for the opportunity to realize my Ph.D. in its facilities as well as for the experience to develop an international internship in France.

I thank Ph.D. Yvonne Font who I worked with the final part of this work, in the Geoázur Laboratory in Valbonne-France. Thanks to Hans Agurto-Detzel who introduced me to Yvonne and for all his support when I was in France.

To CNPq, CAPES, and FAPESP for the financial support to develop this research.

A special thank to the most important person in my life, my Mom, for the constant encouragement and presence despite the distance, for teaching me not to surrender despite the circumstances. Thanks Mom for all your support and love.

To all my IAG colleagues for the good moments shared, especially the coffee afternoons and barbecues. A special thanks to the Seismology group for all the support during these years, specially to Jackson Calhau, Bruno Collaço, Leonardo Fabricius, Mariana Lion, Estevão Tadeu, Jaime Convers, Lucas Schirbel, Nathalya Shimomura, Lúcio Quadros and its honorary member Jamisson Assunção; for their priceless friendship, support and patience in difficult times, and for the fun and relaxed moments.

To all the friends that I met during this time, thanks for being with me in the good and not-so-good moments. To Olivia, with whom I lived for two years, for her patience, generosity, and kindness whatever the situation; and for giving me the opportunity to take care of an adorable kitten, Kiwi. To Veronique and Juan for their hospitality and to make me miss home a little less. To Anamaría for the support, patience, and cares during the final stage of this work. 



\section{Abstract}

Rivadeneyra-Vera, J.C. (2021) New measurements of crustal and lithospheric thickness for the South American platform using the receiver function method, toward a 3D velocity model. Thesis (Ph.D)-Instituto de Astronomia, Geofísica e Ciências Atmosféricas, Universidade de São Paulo, São Paulo.

Using the Permanent Brazilian Network and a temporary deployment, we studied the Moho discontinuity and the Lithosphere-Asthenosphere Boundary (LAB) in the stable South American platform. From P-wave receiver functions processed with a modified, low uncertainty, H-k stacking method, we obtained the Moho depth; that together with previous results permitted to updated the crustal thickness map of South America, with improved resolution in the Amazon and western part of Brazil, and better delimiting the narrow belt of thinner Sub-Andean crust. The average crustal thickness in the stable continental region is $40.5 \mathrm{~km}$. Paraná and Parnaíba intracratonic Basins, the western part of Pantanal Basin and Amazon Craton present a thicker crust up to $\sim 44 \mathrm{~km}$. The eastern edge of Pantanal Basin, Borborema, and Mantiqueira Provinces present a thinner crust, up to $36 \mathrm{~km}$. $V_{p} / V_{s}$ ratios were estimated for the first time on a large scale in the South American platform. Values ranged between 1.68 and 1.80, being higher in the Paraná Basin and coastal margin (up to 1.79) and lower in cratonic areas $(<1.74)$. Nevertheless, regional patterns are hard to establish due to the scattered estimations.

The LAB was estimated using the S-wave receiver function method, also analyzing some local international stations. At the Borborema and Mantiqueira Provinces, we confirm a thinner lithosphere of $\sim 90 \mathrm{~km}$ that also characterizes the Chaco and Pantanal Basins. The Amazon Craton, the São Francisco Craton, and Paranapanema block present a thicker, greater than $120 \mathrm{~km}$ lithosphere; in these older and colder areas, we also interpreted a mid-lithospheric discontinuity at $\sim 90 \mathrm{~km}$, which tends to correlate with the heat flow. Nevertheless, we do not observe a clear correlation between the heat flow and deeper LAB measurements. On the other hand, the seismicity follows areas with thinner observed lithosphere.

Finally, due to the need of using 3D velocity models for regional accurate epicenter locations, that improves neotectonic and seismic hazard studies, we have built a 3D apriori velocity model for the South American Platform including the Central Andes area. The model is based on previous velocity relationships and structural information, being the most important the obtained crustal thickness. The horizontal resolution is $0.5^{\circ}$, and the vertical varies from $1 \mathrm{~km}$ at shallower depths to $5 \mathrm{~km}$ in the upper mantle. The travel time difference between the $3 \mathrm{D}$ and $1 \mathrm{D}$ velocity models is larger than $\sim 8$ seconds for a station on the stable platform predicting an Andean event travel time. To test the model reliability, we relocated the well-known Aiquile 1998 earthquake (Bolivia) and recent platform events, obtaining successful results when compared with the best epicenters.

Keywords: P-wave receiver function, S-wave receiver function, crustal thickness, Lithosphere-Asthenosphere boundary, 3D velocity model, South America platform. 


\section{Resumo}

Rivadeneyra-Vera, J.C. (2021) Novas estimativas de espessura crustal e litosférica na plataforma Sul-Americana usando o método de função do receptor, para um modelo de velocidade 3D. Tese (Doutorado)-Instituto de Astronomia, Geofísica e Ciências Atmosféricas, Universidade de São Paulo, São Paulo.

Utilizando a Rede Sismográfica Brasileira e as estações temporárias XC, estudamos a descontinuidade de Moho e o limite litosfera-astenosfera (LAB - Lithosphere-Asthenosphere Boundary) na plataforma Sul-Americana. A espessura crustal foi obtida a partir das funções do receptor da onda $\mathrm{P}$, empilhadas com o método $\mathrm{H}-\mathrm{k}$ modificado, que fornece incertezas menores; estas estimativas junto com dados previamente publicados permitiram atualizar o mapa de espessura crustal para a América do Sul, melhorando a resolução na região Amazônica e no oeste do Brasil e delimitando melhor a faixa estreita de crosta fina da região Sub-Andina. A média da espessura crustal na plataforma do continente é de $40.5 \mathrm{~km}$. As bacias do Paraná e Parnaíba, a parte oeste da bacia do Pantanal e o Cráton Amazônico apresentam uma crosta espessa de até $\sim 44 \mathrm{~km}$. A borda leste da bacia do Pantanal, e as províncias de Borborema e Mantiqueira apresentam uma crosta mais fina de $\sim 36 \mathrm{~km}$. As razões de $V_{p} / V_{s}$ foram estimadas pela primeira vez em grande escala na plataforma Sul-Americana; os valores obtidos variam entre 1,68 e 1,80, sendo mais altos na Bacia do Paraná e na margem costeira (até 1,79), e menores em áreas cratônicas $(<1,74)$. Entretanto, é difícil estabelecer padrões regionais devido às estimativas dispersas.

A LAB foi estimada a partir das funções do receptor da onda $\mathrm{S}$ e também foram analisadas estações internacionais locais. Nas províncias da Borborema e Mantiqueira foi confirmada uma litosfera mais fina de $\sim 90 \mathrm{~km}$, assim como nas Bacias do Chaco e Pantanal. Nos crátons Amazônico, São Francisco e no bloco Paranapanema foi observada uma litosfera mais espessa que $120 \mathrm{~km}$; nestas áreas mais antigas e com um fluxo térmico menor foi identificada uma outra descontinuidade litosférica em $\sim 90 \mathrm{~km}$, que tende a se correlacionar com o fluxo térmico. No entanto, não foi observada uma correlação clara entre o fluxo térmico e as medidas da LAB mais profundas. Por outro lado, a sismicidade parece ser maior em áreas que apresentam uma litosfera mais fina.

Devido à necessidade de se utilizar modelos de velocidade 3D para localizações precisas em escala regional, e poder melhorar os estudos neotectônicos e de ameaça sísmica, foi construído um modelo de velocidade a-priori 3D para a plataforma Sul-Americana que também inclui os Andes Centrais. O modelo está baseado em relações de velocidades e informações estruturais previamente publicadas, sendo uma das mais importantes a espessura crustal obtida com as funções do receptor da onda P. A resolução horizontal é de $0.5^{\circ}$, e a vertical varia de $1 \mathrm{~km}$ na região mais superficial até $5 \mathrm{~km}$ no manto superior. A diferença dos tempos de percurso quando usamos modelos de velocidade 3D e 1D é de até 8 segundos para estações na plataforma estável que preveem tempos de percurso de eventos andinos. Para testar a confiabilidade do modelo, relocalizamos o sismo de Aiquile (Bolívia) e dois eventos mais recentes da plataforma estável, obtendo resultados satisfatórios.

Palavras-chave: Função de receptor da onda P e S, espessura crustal, Limite litosferaastenosfera, modelo de velocidade 3D, Plataforma Sul-Americana. 



\section{List of Figures}

1.1 Relocation of Aiquile earthquake, 1998 (Bolivia) using the iLoc algorithm of Bondár and Storchak (2011) and global 3D RSTT model (Myers et al.,

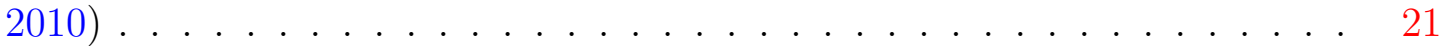

1.2 Main geological provinces in the South American plate . . . . . . . . . . 23

1.3 Stations from Brazilian Seismographic Network (RSBR), XC temporary deployment and Brazilian seismicity from the uniform catalog, from 1955 to

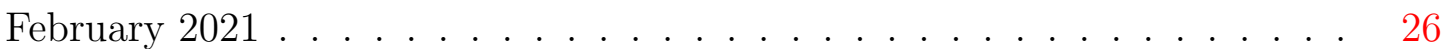

1.4 Evolution of the number of stations and networks in Brazil . . . . . . . . 27

$2.1 \quad$ P-wave receiver function scheme . . . . . . . . . . . . . . . . . . 30

2.2 Stations and distribution of events used in P-wave receiver function . . . . 34

2.3 Receiver function traces before and after correlation at AMBA station . . . 37

2.4 Incidence angle vs. epicentral distances for deep regional events . . . . . . 39

2.5 Model of P-wave triplication for regional deep events . . . . . . . . . . . . 39

2.6 Histograms of the 200 estimates of crustal thickness $(\mathrm{H})$ and $V_{p} / V_{s}(\mathrm{k})$ ratios at AMBA station. ratios and uncertainties at AMBA station . . . . . . . . 40

2.7 Comparison between good and regular stations . . . . . . . . . . . . . . 41

2.8 Comparison of receiver function traces of teleseismic and deep regional events 43

2.9 Crustal thickness $(\mathrm{H})$ and $V_{p} / V_{s}$ ratios for additional stations . . . . . . 45

2.10 Comparison of $\mathrm{H}$ and $\mathrm{k}$ results at IQT0 and PUC0 Peruvian stations, between Condori et al. (2017) and the present work . . . . . . . . . . . 46

2.11 Receiver function section for IQT0 and PUC0 Peruvian stations . . . . . . 47

2.12 Receiver function section of SIV station . . . . . . . . . . . . . . . . . 48

2.13 Crustal thickness and $V_{p} / V_{s}$ averages by geological provinces . . . . . . . 49 
3.1 S-wave receiver function scheme . . . . . . . . . . . . . . 78

3.2 Stations and distribution of events used in S-wave receiver function . . . . 80

3.3 Stacking and bootstraping at NBLA and NBTA stations . . . . . . . . 82

3.4 Different low-pass filters tested to stack S-wave receiver function traces . . 83

3.5 Comparison of Moho depth obtained using P-wave receiver function (RivadeneyraVera et al., 2019) and using S-wave receiver function (present work) . . . . 85

3.6 Comparison with Heit et al. (2007) . . . . . . . . . . . . . . . . 86

3.7 Lithospheric thickness map in central South America . . . . . . . . . . . . 87

3.8 Average and standard variation $(\sigma)$ lithospheric thickness by geological

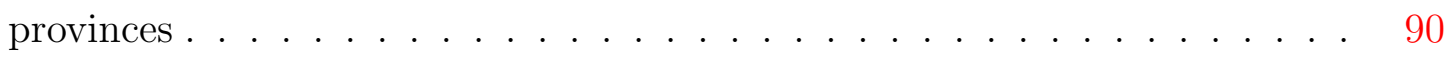

3.9 SRF section and thickness lithosphere map from Borborema Province . . . 91

3.10 SRF section and thickness lithosphere map from Mantiqueira Province . . 92

3.11 SRF section and thickness lithosphere map from Amazon Craton . . . . . . 94

3.12 SRF section and thickness lithosphere map from São Francisco craton . . . 95

3.13 SRF section and thickness lithosphere map from Pantanal, Paraná and Chaco Basins . . . . . . . . . . . . . . . . . . . . 97

3.14 Areas delimited for stacking by piercing points . . . . . . . . . . . . 99

3.15 Stacked traces by piercing points in each box . . . . . . . . . . . . 100

3.16 Lithospheric thickness in Pantanal, Paraná, and Chaco Basins . . . . . . . 101

3.17 Seismicity vs lithospheric thickness . . . . . . . . . . . . . . . 103

3.18 Heat flow vs. lithospheric thickness . . . . . . . . . . . . . . . . . 104

3.19 Heat flow and lithospheric thickness correlation . . . . . . . . . . . 105

3.20 Schema for lithospheric structure in areas with lower and higher heat flow . 107

4.1 Delimitation of a 3D velocity model area and seismicity of South American platformn and Central Andes region . . . . . . . . . . . . . 111

4.2 Topography and Sedimentary thickness map of the South American platform113

4.3 Velocity laws for sediments, platform crust and Andean crust . . . . . . . . 116

4.4 Mantle velocity profile at $68^{\circ} \mathrm{W} \ldots \ldots \ldots$. . . . . . . . . 117

4.5 Theoretical P-wave ray paths for regional events up to $30^{\circ}$ distance and up

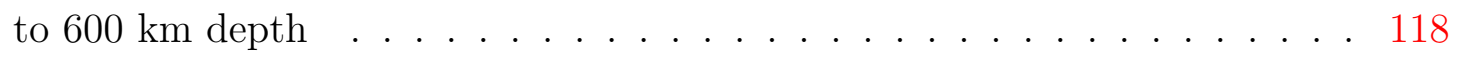

4.6 3D representation of the study area and the discretization in blocks . . . . 119 
4.7 Vertical cross-section at $12^{\circ} \mathrm{S}$ and $20^{\circ} \mathrm{S}$, from $7 \mathrm{~km}$ a.m.s.l to $80 \mathrm{~km}$ depth . 121

4.8 Horizontal section at $4 \mathrm{~km}$ a.m.s.l., $4 \mathrm{~km}, 36 \mathrm{~km}$ and $55 \mathrm{~km}$ depth . . . . . 122

4.9 Regional travel time using 1D AK135 velocity model and a 3D velocity model, at 0 and $20 \mathrm{~km}$ depth . . . . . . . . . . . . . . . 124

4.10 Travel time difference using 1D global and 3D regional velocity models . . 124

4.11 Aiquile earthquake relocation using NLLoc routine and the 3D velocity model126

4.12 Amargosa earthquake relocation using NLLoc method and the 3D velocity model ............................. 127

4.13 Guyana earthquake relocation using NLLoc method and the 3D velocity

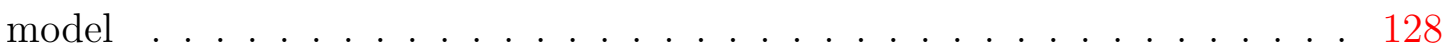





\section{List of Tables}

2.1 Number of events (teleseismic and deep regional) and good receiver function traces $($ FR's) by station . . . . . . . . . . . . . . . 35

2.2 Results of $\mathrm{H}$ and $\mathrm{K}$ for additional stations . . . . . . . . . . . . . . 44

3.1 Number of good S-wave receiver function (SRF) traces in each processed

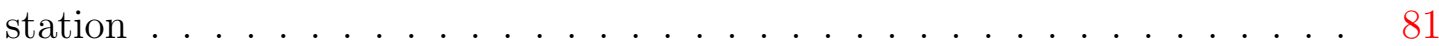

3.2 Lithospheric thickness at NBLA station using different low-pass filters . . . 83

3.3 Lithospheric thickness in Central South America . . . . . . . . . . . . . 88

3.4 Average lithospheric thickness by geological provinces . . . . . . . . . . . . 90

3.5 Number of events stacked by boxes . . . . . . . . . . . . . . . . . . . 99 



\section{Contents}

1. Introduction . . . . . . . . . . . . . . . . . . . 17

1.1 Seismic discontinuities studied . . . . . . . . . . . . . . . . . . 17

1.1.1 Discontinuity of Mohorovičić . . . . . . . . . . . . . 17

1.1.2 Lithosphere-Asthenosphere Boundary (LAB) . . . . . . . . . . . . 19

$1.23 \mathrm{D}$ regional velocity models . . . . . . . . . . . . . . . . . 20

1.3 Geological setting . . . . . . . . . . . . . . . . 21

1.4 The Brazilian Seismographic Network (RSBR - Rede Sismográfica Brasileira) 24

1.4.1 XC temporary deployment . . . . . . . . . . . . 25

1.4.2 The Brazilian seismic Catalog . . . . . . . . . . . . . 27

2. Crustal thickness in the South American platform . . . . . . . . . . . . . . . 29

$2.1 \quad \mathrm{P}$-wave receiver function . . . . . . . . . . . . . . . . . . . 29

2.1.1 Crustal thickness $(\mathrm{H})$ and $V_{p} / V_{s}(\mathrm{k})$ from PRF . . . . . . . . 32

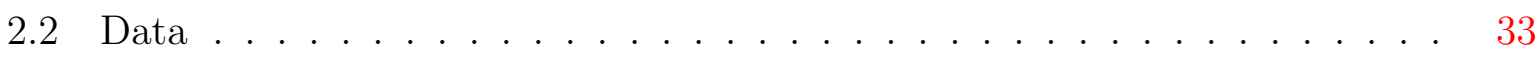

2.3 Data processing . . . . . . . . . . . . . . . . . . . 35

2.3.1 Deconvolution and stacking . . . . . . . . . . . . 35

2.3.2 Deep regional event processing . . . . . . . . . . . . . . . 38

2.4 Results and discussion . . . . . . . . . . . . . . . . . . . 40

2.4.1 Deep events . . . . . . . . . . . . . . . . . . 42

2.4.2 Additional stations . . . . . . . . . . . . . . . . . . . . . . 43

2.4.2.1 Peruvian stations . . . . . . . . . . . . . . . 45

2.4.2.2 SIV station - Bolivia . . . . . . . . . . . . 47

2.4.3 Regional patterns . . . . . . . . . . . . . . . . . . . . 48 
2.5 Paper published in the Journal American Geophysical Union: An updated crustal thickness Map of Central South America Based on Receiver Function Mesasurements in the Region of the Chaco, Pantanal, and Paraná Basins, Southwestern Brazil . . . . . . . . . . . . . . . . . . 51

3. Lithosphere-Asthenosphere boundary under Brazil . . . . . . . . . . . . . . 77

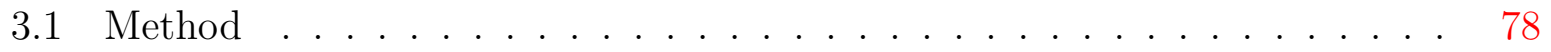

3.2 Data . . . . . . . . . . . . . . . . . . . . 79

3.3 Data processing . . . . . . . . . . . . . . . 80

3.4 Results and discussion . . . . . . . . . . . . . . . . 86

3.4.1 Regional patterns . . . . . . . . . . . . . . . . . . 89

3.4.2 LAB vs. seismicity . . . . . . . . . . . . . . . . 102

3.4 .3 LAB vs. heat flow . . . . . . . . . . . . . . . . . 104

4. 3D a-priori velocity model for South American Platform . . . . . . . . . . . . . 109

4.1 Introduction . . . . . . . . . . . . . . . . . . . . . . . . 109

4.2 Model Construction . . . . . . . . . . . . . . . . . . . 112

4.2 .1 Structural data . . . . . . . . . . . . . . . . . . . 112

4.2.2 Sedimentary and Crustal velocities . . . . . . . . . . . . 113

4.2 .3 Mantle velocities . . . . . . . . . . . . . . . . . . 116

4.2.4 Parametrization and Model construction . . . . . . . . . . . 117

4.3 Travel Time computation . . . . . . . . . . . . . . . . . . . . 123

4.4 Example of earthquakes location . . . . . . . . . . . . . . 125

4.4.1 Aiquile Andean earthquake . . . . . . . . . . . . 125

4.4 .2 Platform earthquakes . . . . . . . . . . . . . . 126

5. Conclusions . . . . . . . . . . . . . . . . . . . . . . . 129

5.1 Crustal thickness in the South America platform . . . . . . . . . . . . . . 129

5.2 Lithosphere-Asthenosphere boundary under Brazil . . . . . . . . . . . . 130

5.3 3D velocity model for South American platform . . . . . . . . . . . . 130

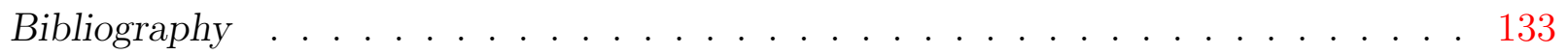


Chapter 1

\section{Introduction}

The knowledge of the crustal and upper mantle structure is a key part of geodynamic and Earth's evolution studies, as well as for the construction of better regional velocity models to be used in the epicenter location routines. Throughout the study of the wave travel times generated by earthquakes, seismology studies the Earth's interior, dividing it into layers that have different composition and structure. At the limits between layers occur important seismic velocity changes, hence these limits are named seismic discontinuities.

Using the receiver function method for $\mathrm{P}$ - and S-waves we studied the two most important global first-order seismic discontinuities in the upper mantle, in the major part of continental South-American platform: Mohorovičić discontinuity that marks the crustmantle limit (Chapter 2) and the Lithosphere-Asthenosphere boundary (Chapter 3). Using the results obtained during this work, and other published data, we assembled and tested a 3D velocity model for the South American platform, presented in Chapter 4, which will help to improve the monitoring of Brazilian and Andean seismicity. In each chapter we present an introduction to the topic covered, the methodology followed in detail, as well as the results obtained and we discuss them. Finally, in Chapter 5 we summarize the most important findings of each topic.

\subsection{Seismic discontinuities studied}

\subsubsection{Discontinuity of Mohorovičić}

This discontinuity, also named Moho, separates the continental crust (rich in silica) or oceanic crust (rich in gabbros) from the mantle (peridotites, rich in magnesium silicates) (Fowler, 2005; Lutgens et al., 2012). Therefore, due to the chemical composition change, 
this discontinuity has an important seismic velocity jump from an average crustal P-wave velocity of $\sim 6.4 \mathrm{~km} / \mathrm{s}$ to $\sim 8.04 \mathrm{~km} / \mathrm{s}$, the expected velocity for mantle rocks.

The crust is the most complex region of the Earth because of the cyclic sedimentation, metamorphism, and igneous activity which process and reprocess its materials and lead to extreme differentiation of the chemical elements (Brown and Mussett, 1993). Determining the seismic properties, especially in continental crust, is essential to understand the continental evolution, as well as to improve velocity models.

In general terms, the average continental crustal thickness is $40.5 \mathrm{~km}$ and the oceanic one is $7 \mathrm{~km}$. However, in the continental part, the Moho depth varies according to the tectonic provinces due to its different evolution. Christensen and Mooney (1995) compiled global seismic studies and presented average thicknesses by environments, as follows: 30.5 $\mathrm{km}$ in extended crusts, $36.2 \mathrm{~km}$ for rifts, $38.7 \mathrm{~km}$ in areas of continental arcs, $41.5 \mathrm{~km}$ in shields and platforms, and $46.3 \mathrm{~km}$ in orogens. Despite having considered global data, the constraint points in South America were few, mainly localized in the active margin (western border).

In the last 20 years, with the increase of seismic stations in South America, many studies have been carried out to characterize the crustal structure in regional (Lloyd et al., 2010; Chulick et al., 2013) and local scale (Assumpção et al., 2002; França and Assumpção, 2004; Bianchi, 2008; Julià et al., 2008; Luz et al., 2015; Albuquerque et al., 2017). Most of these studies have been compiled by Pavão et al. (2012) to present a map of crustal thickness in Brazil, and Assumpção et al. (2013) presented a first crustal thickness map for South America; nevertheless, some areas remained poorly sampled because of the lack of seismic stations, these gaps were filled with gravity data that does not have a good resolution as seismic techniques.

We updated the crustal thickness map for the South American platform, using data of new seismic temporary stations in southwest Brazil and parts of Bolivia, Paraguay, Argentina, and Uruguay (XC subnet); filling important gaps and improving the resolution mostly in the Amazon region and west of Brazil, compared with the last model of Assumpção et al. (2013). 


\subsubsection{Lithosphere-Asthenosphere Boundary (LAB)}

The LAB is a transition that separates the outermost rigid, cold, mechanically strong, and conductive lithosphere from the ductile, weak, and convective asthenosphere (Sun et al., 2018), its study is fundamental for understanding the processes of continental evolution and interaction with plate tectonics. The lithosphere comprises the crust and uppermost mantle, being thinner in oceanic regions and thicker in continental ones, where its bottom depth is poorly understood and studied (Marshak and Van Der Pluijm, 2004; Fowler, 2005; O’Reilly and Griffin, 2010).

There are different ways to define the LAB: (a) thermally is defined by an isotherm of $\sim 1300{ }^{\circ} \mathrm{C}$ due to at this temperature the dominant mineral in the mantle (olivine) becomes weak (Marshak and Van Der Pluijm, 2004), (b) chemically the LAB divides the mantle depleted in basaltic components from a more fertile asthenosphere (O'Reilly and Griffin, 2010), (c) seismologically, marks a seismic velocity inversion of $\sim 5 \%$, indicating the limit between the rigid lithosphere and the asthenosphere.

Lithospheric thickness varies with age, mineralogy, stress, strain rate, etc; and the estimated LAB depth considering different properties (e.g. elastic, thermal, electrical, petrological, and seismic velocities), being the seismological LAB, associated with a lowvelocity zone in the upper mantle, normally deeper than other ones. Between seismological methods, surface-wave tomography provides robust constraints about lithospheric structure, nevertheless it cannot distinguish if a velocity change is abrupt or occurs over tens of kilometers (Fischer et al., 2010). On the other hand, the high frequencies used in bodywave tomographies do not permit to detect the LAB if it is not sharp enough (Rychert and Shearer, 2009).

The S-wave receiver function method provides powerful complementary constraints of the LAB and its velocity gradient because of these converted phases are sensitive to changes in shear-wave structure. Previous seismological studies have characterized the LAB at different geological units, varying between 60 and $120 \mathrm{~km}$ in younger continental and tectonically altered regions, $70 \pm 4 \mathrm{~km}$ at oceanic island stations, and deeper than $150 \mathrm{~km}$ under cratonic areas (Anderson, 1995; Feng et al., 2007; Sun et al., 2018), where also was found a midlithospheric discontinuity at $\sim 100 \mathrm{~km}$ (Fischer et al., 2010; Kind and Yuan, 2018; Sun et al., 2018). 
Many works dealing with S-wave receiver functions have reported the difficulty to interpret a proper LAB conversion in stable areas and especially associated with the cratonic regions. Such difficulties normally arise from the fact that there is more than one possible phase to be interpreted and a choice has to be made between the options. Other stations, normally associated with younger regions present a sharp and clear LAB phase on S-wave receiver functions.

Using data of the permanent Brazilian Network (RSBR) and the XC temporary deployment in the eastern and central-west part of Brazil, we have estimated the seismological LAB, in most of the South American platform. We compared our results with those of Heit et al. (2007) that also studies the LAB in South America, as well as explored the correlation of our lithospheric thickness estimates with heat flow measurements and observed seismicity in the stable South American platform.

\section{$1.23 D$ regional velocity models}

The accuracy of hypocenter location improves tectonic studies, e.g. determining fault geometry and earthquake migration (Cleveland and Ammon, 2013), as well as the evaluation of seismic hazard. Nevertheless, the determination of hypocenters using regional and teleseismic stations presents uncertainties greater than $20 \mathrm{~km}$, due to noisy seismograms, unfavorable geometries of stations, and the use of $1 \mathrm{D}$ velocity models that do not take into account crustal and upper mantle heterogeneities (Bondár et al., 2004).

Considering that 3D velocity models have already been developed for some regions of the world, Myers et al. (2010) developed the global 3-D RSTT (Regional Seismic Travel Time) model, which considers the effects of the crust and upper mantle structure in regional travel times for Pn waves, in stations with a maximum distance of $15^{\circ}$. The global 3D RSTT model has been refined with tomography to adjust the average crustal and mantle velocities in Eurasia and North Africa, showing epicenter accuracies of $5 \mathrm{~km}$ or better (Myers et al., 2010). The most common way of validating and calibrating the 3D models is using well-known hypocenters calculated independently (Neves et al., 2018), named ground-truth (GT) events, which are very rare in stable platforms.

In South America, the RSTT model (Myers et al., 2010) and the iLoc algorithm developed by Bondár and Storchak (2011) were used to relocate the well-known Andean Aiquile, 
1998 earthquake determined by InSAR (Funning et al., 2005). The initial results so far obtained were not satisfactory, as shown in Figure 1.1, probably because the RSTT model is not yet well-calibrated for South America. Due to the need to use 3D velocity models in the location of events, we built one for the stable region of South America, integrating the topography of the Moho determined in this study, a compilation of velocity information for the crust and sedimentary basins, and recent mantle 3D velocity profiles.

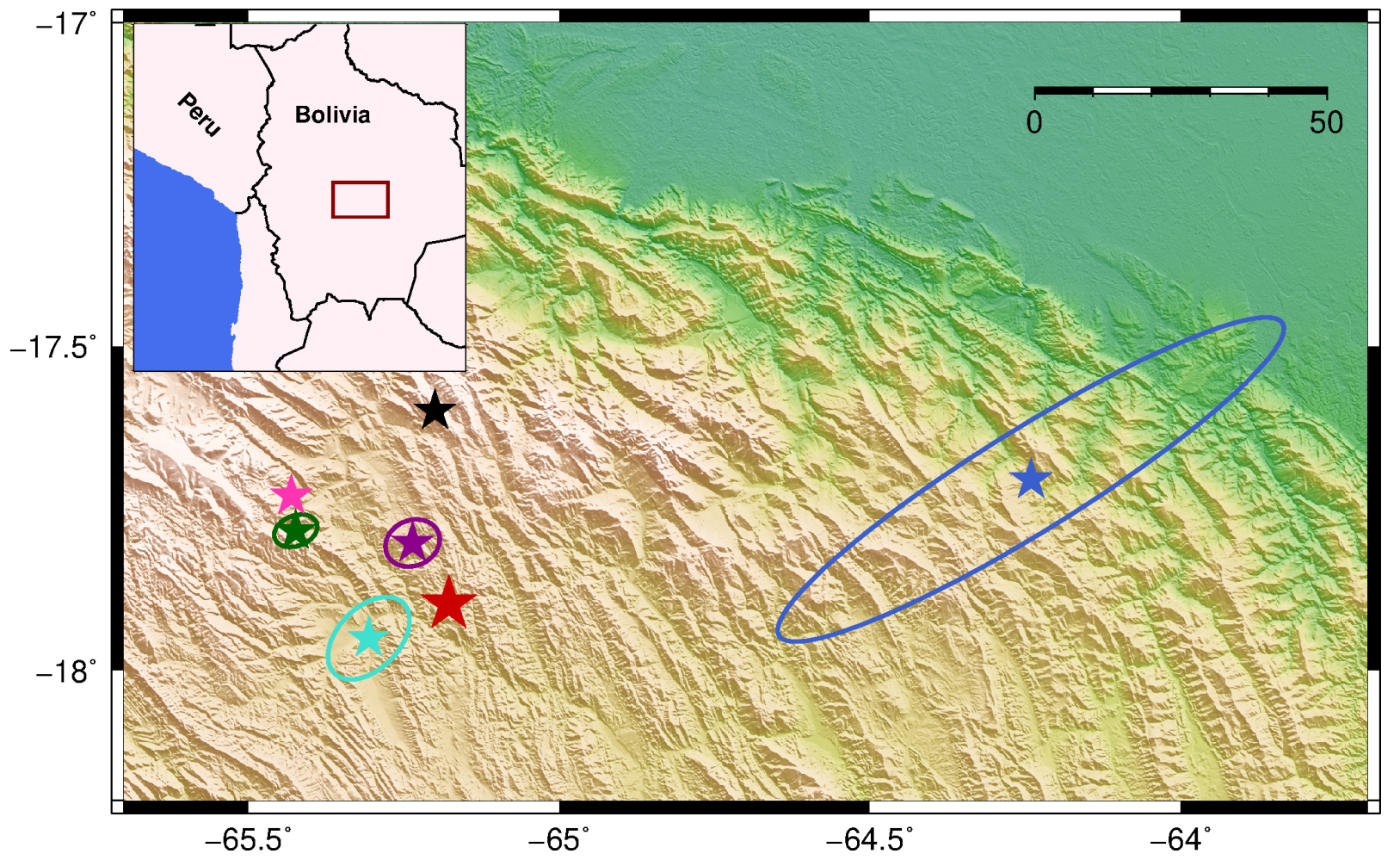

Figure 1.1: Relocation of Aiquile earthquake, 1998 (Bolivia) using the iLoc algorithm of Bondár and Storchak (2011) and global 3D RSTT model (Myers et al., 2010). Red star: well-known epicenter determined by Funning et al. (2005). Epicenters given by different agencies: ISC (green star), NEIC (pink star) and Harvard (black star). Epicenter determined using the $i L o c$ algorithm and stations up to $90^{\circ}$ (blue star). Epicenter determined using iLoc algorithm and stations corrected with RSTT model up to $15^{\circ}$ (turquoise star). Epicenter determined using $i L o c$ algorithm and station up to $90^{\circ}$ and corrected with RSTT model up to $15^{\circ}$ (purple star).

\subsection{Geological setting}

The study area comprises the South American Platform (SAP) that represents the oldest and stable continental part of the South American plate, which has not been affected by the Caribbean and Andean orogeny, being the Patagonian block and Andean belt the unstable counterparts. SAP is the result of the collage of Archean and Proterozoic nuclei 
cratons (pink areas in Figure 1.2). Guyana and Central Brazilian Shields occupy the most northern part of the South American platform and have ages between 2.2 Ga and 1.9 Ga, being separated by the Amazon Basin. São Francisco Craton is located in the central-eastern part of SAP and is presumed to have become stable at least $1.8 \mathrm{Ga}$ ago (Alkmim, 2004). In the southern part of the Central Brazilian Shield is located a Paleozoic block named Rio Apa Block, which is part of the cratonic basement of the Neoproterozoic Paraguay belt, different authors consider these segments as part of Amazon Craton (Filho et al., 2020). Finally, there is geophysical and geological evidence of a possible cratonic nucleus under the Paraná Basin, named Paranapanema cratonic block (Cordani, 1984; Mantovani et al., 2005; Julià et al., 2008). While this block has been proposed by many different authors, most of them disagree on its form, unity, and size under the basin.

The cratonic nucleus was joined by mobile belts during the Brasiliano-Pan African cycle (Almeida et al., 2000). The Tocantins Province was formed by the convergence of the Amazon, São Francisco, and Paranapanema cratonic blocks, the basement was established during the orogeny of Brasilian/Pan-Africano (900 Ma to 500 Ma). The Mantiqueira Province is a major and highly complex province deformed during the Neoproterozoic/Early Paleozoic (900 - $480 \mathrm{Ma}$ ). It extends from the southern border of Bahia state to Uruguay being parallel to a part of the South American Atlantic coast, reaching nearly $3000 \mathrm{~km}$ long and an average of $200 \mathrm{~km}$ wide (Almeida et al., 2000; Silva et al., 2005). The Borborema Province is located in the northeast of Brazil bordering the passive margin of the South American platform, it was the result of convergence and collision of West Africa and São Francisco Craton, and during the Mesozoic suffered extensional events, and after the continental breakup there were episodes of volcanism (Luz et al., 2015). 


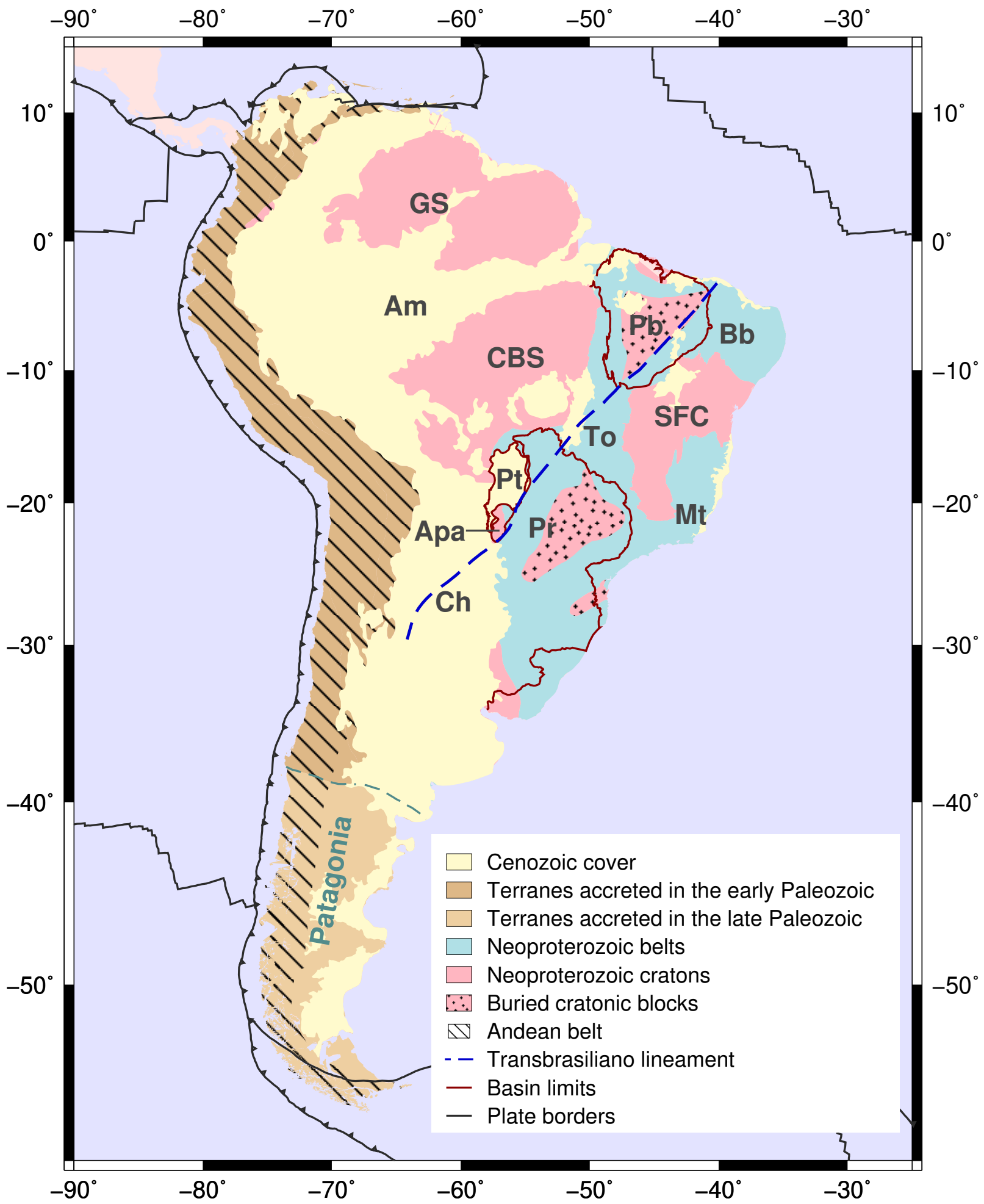

Figure 1.2: Main geological provinces in the South American plate taken from (Cordani et al., 2016). Black lines: Plate borders (Bird, 2003). Green dotted line: Suture of Patagonia. Main geological provinces: Pink= cratons and cratonic blocks beneath basins (GS: Guyana Shield, CBS: Central Brazilian shield, SFC: São Francisco craton; and Apa rio Block). Blue $=$ Neoproterozoic foldbelts (Bb: Borborema Province, To: Tocantins Province and Mt: Mantiqueira Province). Yellow=Cenozoic cover (Am: Solimões-Amazonas, and Ch: ChacoParaná Basins). Dark red line delimits large intracratonic basins (Pb: Parnaíba, Pr: Paraná; and Pt: Pantanal Basins). Blue dotted line: Transbrasiliano Lineament. 
After the SAP formation, most of the cratons and fold belts were covered by three large intracratonic Paleozoic basins and at the last stage, the platform was little affected by tectonic and magmatic events, partly caused by the Atlantic ocean opening in the Lower Cretaceous (130 Ma ago). Paraná Basin is a typical intracratonic sedimentary basin whose subsidence was initiated during the middle to late Ordovician times in the interior of Gondwana (Milani and Ramos, 1998; Almeida et al., 2000; Julià et al., 2008). The sediment cover has a tick up to $7 \mathrm{~km}$ with the presence of an extensive volume of flood basalt volcanism intercalated with the basin's sediments and is underlain by a predominantly cratonic nucleus. Parnaíba Basin presents up to $3.5 \mathrm{~km}$ of sediments, the sedimentation probably started in the Cambrian $(\sim 100$ Ma before that of the Paraná Basin) and has a high correlation with analogous basins in the African continent (Milani and Thomaz Filho, 2000). Amazon Basin covers Amazonian craton, dividing it between the Guyana Shield and Central Brazilian Shield, and has sediments up to $5 \mathrm{~km}$ thick; despite all the efforts made to be studied by the seismology, it is still the most poorly understood region.

Other important, but smaller, intracratonic sedimentary basins are: The ChacoParaná Basin located west from the narrower southern end of the Paraná Basin, with which it has a close relationship throughout most of its evolutionary history, and has an average sedimentary thickness of $4 \mathrm{~km}$ (Rosa et al., 2016; Dragone, 2018); and the relatively younger Pantanal Basin with less than $500 \mathrm{~m}$ deep and presently subsiding, whose origin is still debated between either a Miocene (Assine et al., 2016) or Quaternary origin (Ussami et al., 1999).

\subsection{The Brazilian Seismographic Network (RSBR - Rede Sismográfica Brasileira)}

The first seismographic stations in Brazil began to operate in early 1900, recording important events such as 1906 San Francisco and the 1922 São Paulo (5.1 mb) earthquakes. However, seismographic recordings were discontinued in 1944, and after two unregistered important Brazilian earthquakes, one station restarted its operation in 1957. During the 1960 decade were installed some stations over the Brazilian territory due to national and international projects, because of the need for seismic hazard studies several permanent 
stations were installed from 1970, forming four research groups at: University of Brasilia (UnB), University of São Paulo (USP), Federal University of Rio Grande do Norte (UFRN), and the National Observatory (ON). These groups worked independently in research activities to study earth structure in addition to studying local seismicity (Bianchi et al., 2015, 2018).

Since 2009 with the initial support by Petrobras, and later by CPRM these institutions formed the Brazilian Seismographic Network (RSBR), composed of four FDSN registered subnets, each one operated by one institution:

- ON network operates stations mainly along the coastline from the south of the northeast region to the south region of Brazil and on specific oceanic islands (National Observatory).

- NB network covers most of the northeast of Brazil, interacting with the BR and ON stations to the north and south of the northeast (UFRN).

- BR network monitors the north and central area of Brazil. It borders the BL network stations to the south and NB network stations to the east (UnB).

- BL network stations are located in the south, southeast, and part of the central region of Brazil (USP).

Until 2018, the RSBR had 84 broadband stations (120s - $150 \mathrm{~Hz})$ in operation, recording at 100 samples/seconds, whose data is freely open to anyone (Bianchi et al., 2018). The stations are distributed according to different needs, as better monitoring areas with higher seismicity. Unfortunately, in the northern part of Brazil still there are few stations because of logistical difficulties in the Amazon region. Figure 1.3 shows the distribution of the RSBR stations.

\subsubsection{XC temporary deployment}

Additionally to the RSBR stations, the seismological group of University of São Paulo (USP) operated a total of 38 temporary seismic stations (XC registered networks codes) in the western part of Brazil, Bolivia, Paraguay, Argentina, and Uruguay since 2016; as part of the 3-Basins Project funded by FAPESP (Grant 2013/24215-6). The goal of this 
project is to study the crust and upper mantle seismic structure including the evolution of the Pantanal, Chaco, and Paraná Basins (Figure 1.3). The XC data are still restricted to the project participants, and they were processed alongside RSBR stations during the course of this work. Those stations are helping to fill an important gap of the stable South American RSBR stations toward the Andean region.

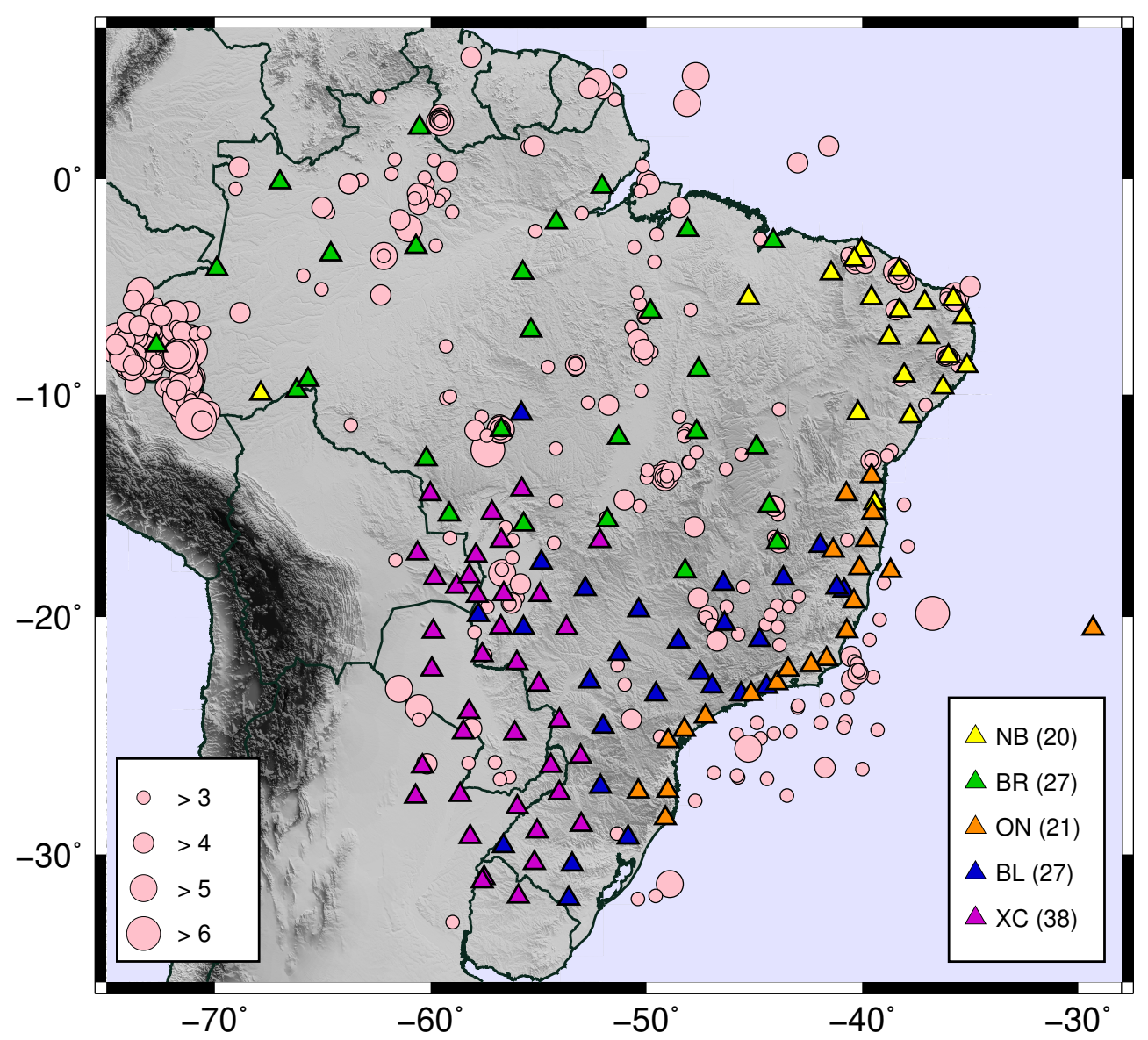

Figure 1.3: Stations from Brazilian Seismographic Network (RSBR) composed of four subnets: BL (blue triangles), ON (orange triangles), BR (green triangles) and NB (yellow triangles). XC temporary deployment (purple triangles) and Brazilian seismicity (pink circles) from the uniform catalog, from 1955 to February 2021.

Even considering all the difficulties, RSBR stations have accumulated between 8 and 10 years of continuous data so far, making it a reference network for the Stable South American Platform. Figure 1.4 shows the increase in stations and networks in Brazil since 2007; also, the red arrows indicate the number of available stations in Brazil when previous works of LAB (20 stations) and Moho (60 stations) were carried out. During this work, which goes from 2016 to 2020, the number of available stations was approximately 160, which allowed to improve the coverage of the studies and filled important gaps. 


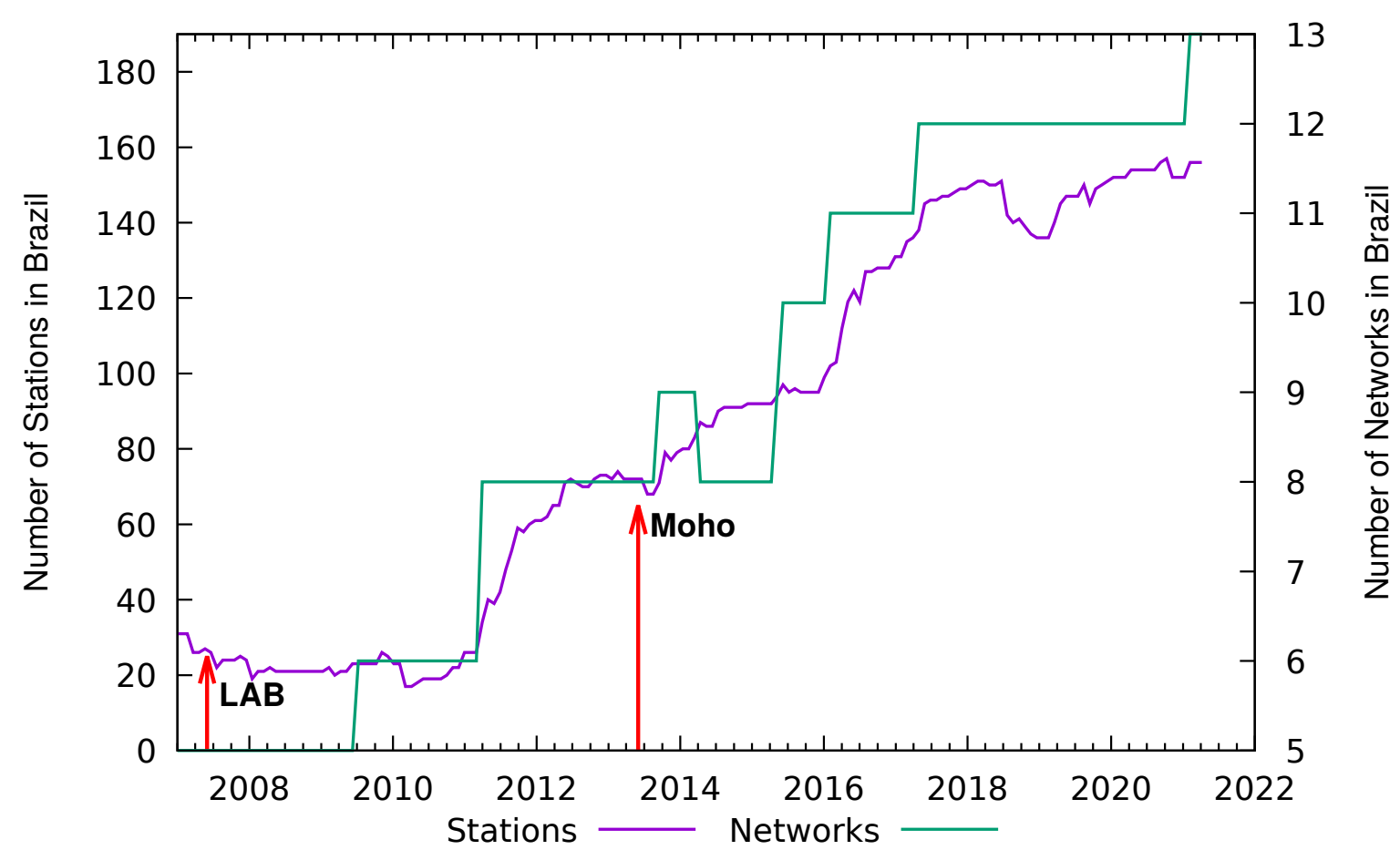

Figure 1.4: Evolution of the number of stations and networks in Brazil. Red arrows indicate the number of available stations when previous works of LAB (2007) and Moho (2013) were carried out.

\subsubsection{The Brazilian seismic Catalog}

Together with the installation of seismographic stations in Brazil, it has been possible to study the Brazilian seismicity with the compilation of all historical and instrumental seismic activity. The completeness of the Brazilian Catalog varies in space and time, during the 1940s and 1950s the Brazilian stations were capable to detect any event of magnitude 6 in Brazil, in early 1960 it was possible to detect events above $5.0 \mathrm{mb}$, improving the detectability up to $3.5 \mathrm{mb}$ in the 1980s. With the installation and growth of the RSBR, it is now possible to detect events with a magnitude lower than $3.5 \mathrm{mb}$ for Brazil. In regions with a higher density of stations, such as the SE and NE, were detected twice as many events with magnitudes between 3.5 -4.0 mb per year, and the detectability has improved near to $3.0 \mathrm{mb}$ or less (Bianchi et al., 2018).

Historically, the four institutions that form the RSBR collaborate to establish the Brazilian Seismic Bulletin (http://www.moho.iag.usp.br/eq/bulletin/), which has recently received the support of the CPRM while trying the assembly and publishes the information in a coherent way for most of the main earthquakes in South America. Figure 1.3 
shows the Brazilian seismicity obtained from the most recent Seismic Bulletin Information obtained from the IAG/USP web page (http://www.moho.iag.usp.br/eq/bulletin/). The Catalog was filtered considering the detection limit thresholds discussed by Bianchi et al. (2018), and it gives a reasonable overview of the seismicity observed in the South America platform. 
Chapter 2

\section{Crustal thickness in the South American platform}

In this chapter we complement the explanation of the methodology used to obtain the crustal thickness $(\mathrm{H})$ and $V_{p} / V_{s}(\mathrm{k})$ ratios at the analyzed stations in the South American platform, most of them located in Brazil, as well as the detailed processing of deep events. Most of these results were published in the paper An Updated Crustal Thickness Map of Central South America Based on Receiver Function Measurements in the Region of the Chaco, Pantanal, and Paraná Basins, Southwestern Brazil, presented in Section 2.5.

We also present new measurements at Peruvian and Bolivian stations that were not included in the paper because the data were obtained after the manuscript submission. These results helped us to better characterize the Sub-Andean region, which has been poorly studied due to the lack of stations and data restrictions.

\section{$2.1 \quad P$-wave receiver function}

$\mathrm{P}$-wave receiver function $(\mathrm{PRF})$ is a time series obtained from the deconvolution, in the frequency- or time-domain, of the vertical component from the radial and tangential components, isolating the structure response from other factors, and getting the most important crustal and upper mantle discontinuities (Owens et al., 1984; Langston, 1979; Cassidy, 1992).

In receiver function traces (RF's) it is possible to identify the direct P-wave arrival, as well as $\mathrm{P}$ to $\mathrm{S}$ converted phase $($ Ps) and multiples: Ppps and Psps + Ppss (Ppss) at different discontinuities (Figure 2.1). The dominant energy at radial receiver function generally comes from $P s$ conversion at Moho discontinuity, being the biggest signal after 
the direct P-wave, because of the high velocity contrast between the crust and upper mantle (Zhu and Kanamori, 2000; Ligorría and Ammon, 1999). Reflections can also be observed when the crustal structure is not too complex with strong lateral variations.

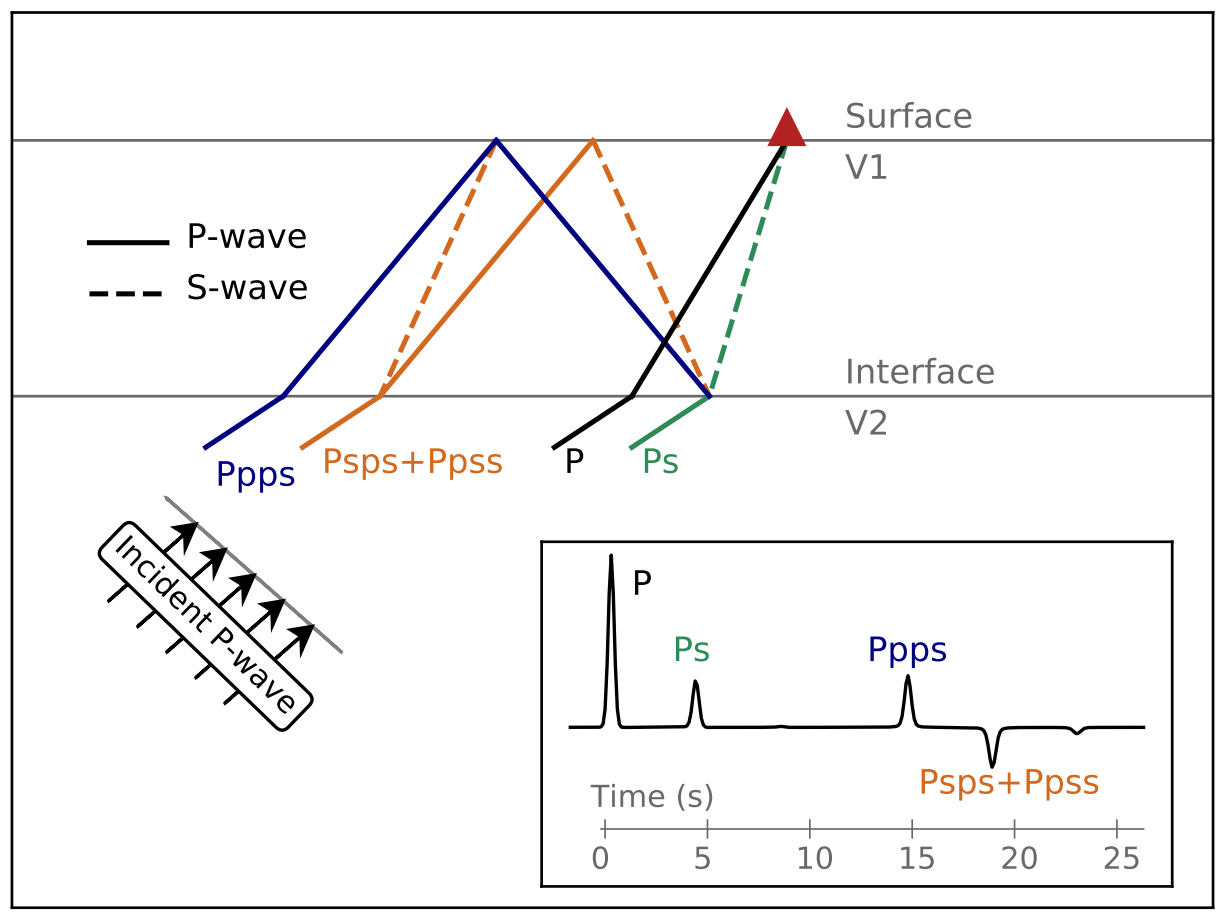

Figure 2.1: Simplified scheme of direct P-wave path, converted phase $(P s)$ and reverberated multiples (Ppps and Ppss) refracted at an interface. Synthetic receiver function trace is showed in the embedded picture.

When there is a good quantity of available data and the signal-noise ratio (SNR) is high, either approach (frequency- or time-domain) can be equally used, otherwise, it is necessary to choose one of them to get the best results. Ligorría and Ammon (1999) have obtained good results using the deconvolution in time-domain, the stability of the method for long periods is noticeable in the first arrival amplitudes, and the frequency-domain noise does not appear in the time-domain approach.

In the time-domain source equalization method (Langston, 1979), the theoretical displacement of the ground, in vertical $\left(D_{V}\right)$, radial $\left(D_{R}\right)$, and tangential $\left(D_{T}\right)$ directions, in response to the incident $\mathrm{P}$-wave in several layers can be represented by: 


$$
\begin{aligned}
& D_{V}(t)=I(t) * S(t) * E_{V}(t) \\
& D_{R}(t)=I(t) * S(t) * E_{R}(t) \\
& D_{T}(t)=I(t) * S(t) * E_{T}(t)
\end{aligned}
$$

where $S(t)$ is the source time function, $I(t)$ is the instrument response, and $E_{V}(t)$, $E_{R}(t)$, and $E_{T}(t)$ are the structure impulsive responses in the vertical, radial, and tangential components. The asterisks represent the convolution operator.

Because of the small incidence angle, the $P s$ conversion point is assumed to be close to the station (less than $20 \mathrm{~km}$ of lateral distance), ensuring that estimates are less affected by lateral variations in shallower layers (Zhu and Kanamori, 2000). When the P-wave arrives with an almost vertical incidence angle, the structure response in the vertical component and tangential components, $E_{V}(t)$ and $E_{T}(t)$, can be considered as $\delta(t)$ (Dirac's delta) and 0 respectively. Then the equations above are turned in:

$$
\begin{aligned}
& D_{V}(t) \approx I(t) * S(t) \\
& D_{R}(t)=I(t) * S(t) * E_{R}(t) \\
& D_{T}(t) \approx 0
\end{aligned}
$$

Assuming that the instrument response is the same at the three components, the seismogram of the vertical component represents the source and effects throughout the path minus the structure close to the station. Then the crustal structure response at horizontal components $\left(E_{R}(t)\right.$ e $\left.E_{T}(t)\right)$ can be isolated deconvolving the vertical from radial records: 


$$
\begin{aligned}
& E_{R}(t)=\frac{D_{R}(t)}{I(t) * S(t)} \simeq \frac{D_{R}(t)}{D_{V}(t)} \\
& E_{T}(t)=\frac{D_{T}(t)}{I(t) * S(t)} \simeq \frac{D_{T}(t)}{D_{V}(t)}
\end{aligned}
$$

The deconvolution procedure described in Equation 2.3 is numerically unstable due to the limited band signals and the presence of noise. In order to avoid these limitations, the estimated deconvolution is multiplied by the transform of a Gaussian pulse to limit the frequency bands and excludes high frequencies that were not in the original data (Langston, 1979). The aperture of this filter is represented by a Gaussian parameter, that normally takes the value of 5 , corresponding to a frequency of $\sim 2.5 \mathrm{~Hz}$, when we are interested in imaging the Moho depth (Ligorría and Ammon, 1999).

\subsubsection{Crustal thickness $(H)$ and $V_{p} / V_{s}(k)$ from PRF}

Knowing the arrival time difference between the direct $\mathrm{P}$-wave and $P s$ converted phase, crustal average velocity $\left(V_{p}\right.$ or $V_{s}$ ), and the $V_{p} / V_{s}$ ratio (also known as k) it is possible to estimate the crustal thickness using the Equation 2.4 (Zandt et al., 1995; Zhu and Kanamori, 2000).

$$
H=\frac{T_{P s}}{\sqrt{\frac{1}{V_{s}^{2}}-p^{2}}-\sqrt{\frac{1}{V_{p}^{2}}-p^{2}}}
$$

Where $T_{P s}$ is the direct $\mathrm{P}$-wave and $P s$ difference arrival time, $V_{p}$ is the average crustal $\mathrm{P}$-wave velocity, $V_{s}$ is the average crustal $\mathrm{S}$-wave velocity and $p$ is the ray parameter of the incident wave. The dependence of crustal thickness $(\mathrm{H})$ with $\mathrm{P}$-wave velocity $\left(V_{p}\right)$ is not as strong as $\mathrm{k}$; so for a variation of $0.1 \mathrm{~km} / \mathrm{s}$ in $V_{p}$, an $\mathrm{H}$ variation is less than $0.5 \mathrm{~km}$; while for a variation of $0.1 \mathrm{in} \mathrm{k}$, the $\mathrm{H}$ variation is up to $4 \mathrm{~km}$. To reduce this uncertainty, later converted phases, that provide additional information, are used as shown in equations 2.5 and 2.6 (Zhu and Kanamori, 2000), which considers the multiple phases travel times $T_{P p p s}$ and $T_{\text {Psps+Ppss. }}$. 


$$
\begin{gathered}
H=\frac{T_{\text {Ppps }}}{\sqrt{\frac{1}{V_{s}^{2}}-p^{2}}+\sqrt{\frac{1}{V_{p}^{2}}-p^{2}}} \\
H=\frac{T_{\text {Ppss }+ \text { Psps }}}{2 * \sqrt{\frac{1}{V_{s}^{2}}-p^{2}}}
\end{gathered}
$$

Equation 2.7 is used to calculate the value of $\mathrm{k}$. The advantage is that it is independent of the crustal thickness $(\mathrm{H})$ and has a small dependency on the $V_{p}$. For a $V_{p}$ variation of $0.5 \mathrm{~km} / \mathrm{s}, \mathrm{k}$ varies in 0.03 (Zandt et al., 1995).

$$
\frac{V_{p}}{V_{s}}=\left\{\left(1-p^{2} V_{p}^{2}\right)\left[2\left(\frac{T_{P s}}{T_{P p p s}-T_{P s}}\right)+1\right]^{2}+p^{2} V_{p}^{2}\right\}^{\frac{1}{2}}
$$

Generally, estimating $\mathrm{H}$ and $\mathrm{k}$ in only one receiver function can be difficult due to the noise interference, presence of other layers, crustal heterogeneities, etc. Zhu and Kanamori (2000) proposed to stack a group of receiver functions at the same station, with different ray-parameter, to maximize the objective function shown by Equation 2.8:

$$
s(H, k)=\omega_{1} r\left(t_{1}\right)+\omega_{2} r\left(t_{2}\right)-\omega_{3} r\left(t_{3}\right)
$$

where $r(t)$ is the radial component of receiver function, $t_{1}, t_{2}$, and $t_{3}$ are the predicted arrival times for Ps, Ppps, and Ppss phases for a crustal thickness $=\mathrm{H}$ and $V_{p} / V_{s}=\mathrm{k}$, calculated from the equations $2.4,2.5$ and 2.6. The weights $\omega_{1}, \omega_{2}$, and $\omega_{3}$ vary between 0 and 1, and should sum to one. Normally the Ps phase must have a higher weight due to its bigger amplitude.

The best value of $\mathrm{H}$ and $\mathrm{K}$ maximize the function $s(H, k)$, as the Moho is not the only discontinuity in the crust and upper mantle, this function has multiple local maximums for each discontinuity, e.g. sedimentary basement and Conrad discontinuity at crustal scale.

\subsection{Data}

We used data recorded at stations belonging to the Brazilian Seismographic Network (RSBR) (Bianchi et al., 2018) from 2010 to 2018 and 35 temporary stations (XC network of the FAPESP 3 Basins Project) from 2016 to 2018. Additionally were obtained data from 
2014 to 2018 from six Peruvian stations, provided by the Geophysical Institute of Peru (IGP) through the Executive Director Hernando Tavera; and from SIV station located in Bolivia, provided by San Calixto Observatory (OSC) through the director Gonzalo Fernández. All stations are displayed in Figure 2.2a.

To use the PRF method, are needed events that have a small incidence angle (close to the vertical) and high signal-noise ratio (SNR), that are teleseismic events with epicentral distances between $35^{\circ}$ and $90^{\circ}$ and magnitude $\geq 5.5 \mathrm{mb}$; or deep regional events with epicentral distances $\leq 30^{\circ}$, depth $\geq 300 \mathrm{~km}$ and magnitude $\geq 4.5 \mathrm{mb}$, that contain higher frequencies and SNR than teleseismic events. Most of the teleseismic events are distributed between the NW (Central America) and the South Sandwich Islands, while the SW and NW azimuths have reduced coverage. On the other hand, the deep regional events mostly come from the west coast of South America (Figure 2.2b). In total, 2571 different events were registered at analyzed stations with a total of 71256 receiver functions processed.

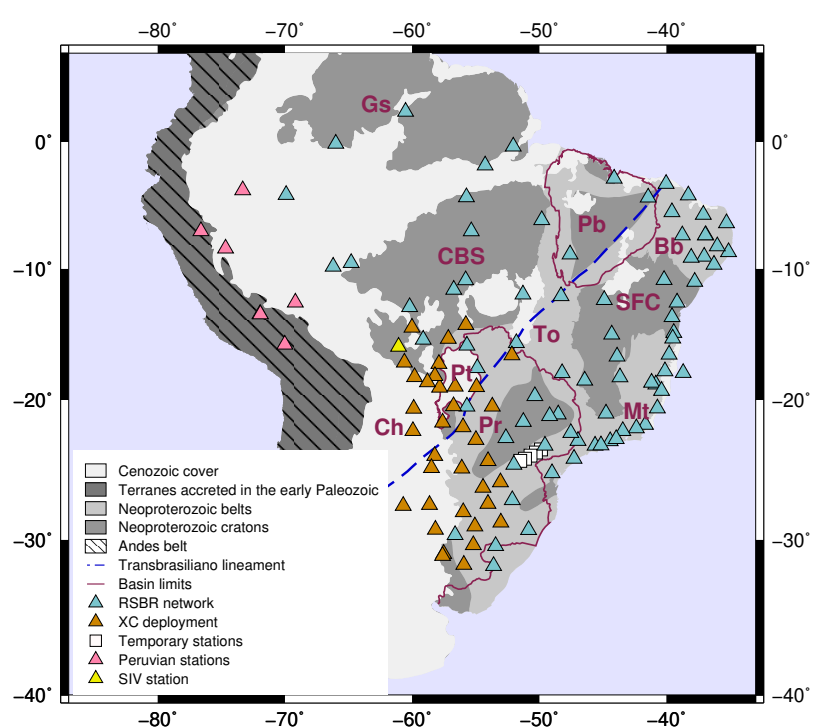

(a)

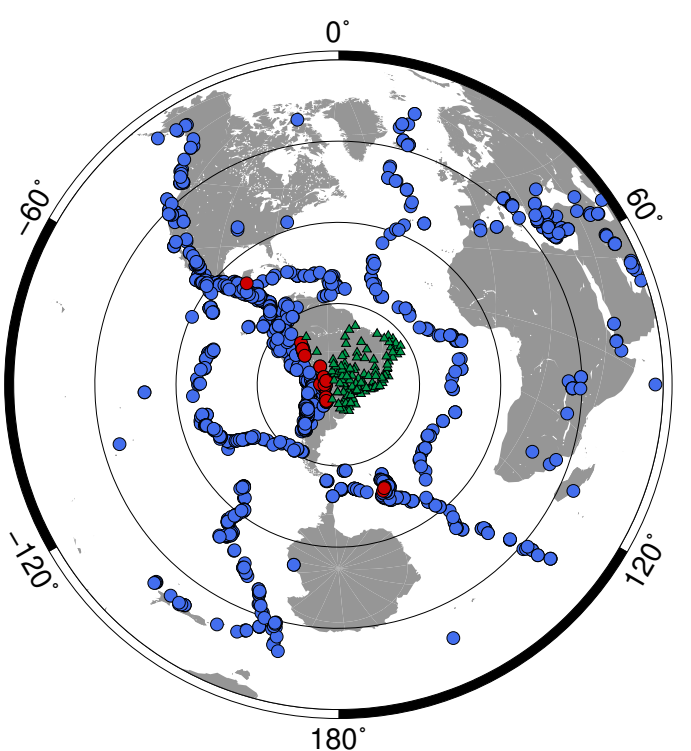

(b)

Figure 2.2: (a) Distribution map of stations used in P-wave receiver function analysis. Light blue triangles: RSBR stations, orange triangles: XC temporary deployment stations, open squares: temporary RSBR station, pink triangles: Peruvian stations and yellow triangle: SIV station (Bolivia). Blue dotted line: Transbrasiliano Lineament. Purple line: large intracratonic basin limits (Pb: Parnaíba, Pr: Paraná, and Pt: Pantanal). Gs: Guyana shield, CBS: Central Brazilian shield, SFC: Craton Sao Francisco, Am: Amazonian Basin, Ch: Chaco-Paraná basin. To, Mt and Bb: Tocantins, Mantiqueira and Borborema Neoproterozoic foldbelts. Shaded areas refer to the geological provinces shown in Figure 1.2.. (b) Distribution of events used in P-wave receiver function analyses. Blue circles: teleseismic events, red circles: Deep regional events, and green triangles: seismic stations. Concentric circles are distances every $30^{\circ}$. 


\subsection{Data processing}

To obtain the crustal thickness $(\mathrm{H})$ and $V_{p} / V_{s}(\mathrm{k})$ ratio, receiver functions in the timedomain were obtained for each station. The standard H-k stacking (Zhu and Kanamori, 2000) was initially used; and later, a modified version as proposed by (Heit et al., 2014) was also tested, after the traces were moved out to a reference ray parameter and stacked.

\subsubsection{Deconvolution and stacking}

The data collected were windowed 10 seconds before and 120 seconds after the P-wave arrival, detrended, tapered at the edges using a 1\% Hanning window, filtered between 0.5 and $4 \mathrm{~Hz}$, and finally rotated into ZRT components using the back azimuth angle. Receiver functions (RF's) were obtained from the iterative deconvolution in time-domain (Ligorría and Ammon, 1999), in a 40 seconds window after the direct P-wave arrival, using a Gaussian width parameter of 5 , that corresponds to a low-pass filter of $\sim 2.5 \mathrm{~Hz}$.

Inspecting the RF's, some of them are unstable and noisy being difficult to identify the converted phases (Figure 2.3a). For each station, one good RF was visually selected, considering that at least the direct $\mathrm{P}$ and $P s$ phases were clear. After, the other RF's of the same station were correlated to discard bad traces, selecting those with a correlation higher than $65 \%$ for the first 12 seconds after the direct $\mathrm{P}$ arrival (Figure 2.3b). Retained good traces represent approximately $30 \%$ of the total, as shown in Table 2.1 where stations that only present results when deep events were considered are in blue, and stations that do not present stable results, despite having good data quantity, are in red. (To obtain good coherent arrivals, at least for the $P s$ conversion, are necessary at least 100 good traces).

Table 2.1 - Number of events (teleseismic and deep regional) and good receiver function traces (FR's) by station.

\begin{tabular}{|c|c|c|c|c|c|c|c|c|}
\hline Station & Events & RF's & Station & Events & RF's & Station & Events & RF's \\
\hline BL.AQDB & 950 & 274 & BR.SDBA & 1153 & 484 & XC.BBLB & 120 & 113 \\
BL.BB19B & 1011 & 33 & BR.SGCB & 406 & 119 & XC.BBPS & 31 & 25 \\
BL.BSCB & 1165 & 274 & BR.SMTB & 1048 & 298 & XC.BBRB & 71 & 80 \\
BL.BSFB & 681 & 208 & BR.SNDB & 1079 & 449 & XC.BBRT & 30 & 13 \\
BL.CLDB & 992 & 497 & BR.TBTG & 956 & 44 & XC.BBSD & 219 & 181 \\
BL.CNLB & 1015 & 45 & BR.VILB & 862 & 197 & XC.BDQN & 157 & 63 \\
\hline
\end{tabular}

Continued on the next page... 
Table 2.1 - Continuation

\begin{tabular}{|c|c|c|c|c|c|c|c|c|}
\hline Station & Events & RF's & Station & Events & RF's & Station & Events & RF's \\
\hline BL.CPSB & 955 & 360 & NB.NBAN & 409 & 265 & XC.CCRS & 210 & 33 \\
\hline BL.DIAM & 1180 & 252 & NB.NBCA & 75 & 30 & XC.CRSM & 233 & 123 \\
\hline BL.ESAR & 206 & 89 & NB.NBCL & 327 & 274 & XC.DVLD & 141 & 98 \\
\hline BL.FRTB & 1004 & 259 & NB.NBCP & 98 & 75 & XC.EDMB & 180 & 17 \\
\hline BL.IBTB & 63 & 86 & NB.NBIT & 400 & 247 & XC.ESFA & 358 & 44 \\
\hline BL.ITAB & 955 & 201 & NB.NBLA & 463 & 178 & XC.FDPY & 239 & 25 \\
\hline BL.ITQB & 943 & 150 & NB.NBLI & 293 & 233 & XC.FRBT & 132 & 66 \\
\hline BL.ITRB & 997 & 111 & NB.NBLV & 71 & 46 & XC.MAPY & 238 & 105 \\
\hline BL.PARB & 1040 & 133 & NB.NBMA & 462 & 292 & XC.MCR1 & 133 & 44 \\
\hline BL.PCMB & 892 & 245 & NB.NBMO & 273 & 165 & XC.MECA & 176 & 57 \\
\hline BL.PEXB & 210 & 292 & NB.NBPA & 337 & 189 & XC.MURT & 195 & 74 \\
\hline BL.PLTB & 988 & 165 & NB.NBPB & 390 & 333 & XC.NBRS & 132 & 40 \\
\hline BL.PMNB & 986 & 315 & NB.NBPN & 447 & 269 & XC.PANT & 184 & 106 \\
\hline BL.PP1B & 888 & 389 & NB.NBPS & 412 & 118 & XC.PAPY & 241 & 15 \\
\hline BL.PTGB & 950 & 229 & NB.NBPV & 351 & 302 & XC.PSAL & 283 & 24 \\
\hline BL.RCLB & 1000 & 25 & NB.NBRF & 273 & 203 & XC.PTET & 126 & 32 \\
\hline BL.SJI1 & 29 & 221 & NB.NBTA & 413 & 325 & XC.RODS & 234 & 36 \\
\hline BL.SJMB & 1215 & 140 & ON.ABR01 & 205 & 62 & XC.ROIB & 59 & 19 \\
\hline BL.TRCB & 900 & 191 & ON.ALF01 & 1258 & 103 & XC.ROSB & 785 & 91 \\
\hline BL.VABB & 1003 & 75 & ON.CAM01 & 1203 & 53 & XC.RPRD & 241 & 31 \\
\hline BR.AGBLB & 89 & 330 & ON.CMC01 & 1211 & 53 & XC.RVDE & 168 & 93 \\
\hline BR.ARAG & 821 & 246 & ON.DUB01 & 1183 & 153 & XC.SCCA & 156 & 19 \\
\hline BR.BOAV & 1048 & 202 & ON.GDU01 & 1217 & 275 & XC.SICB & 63 & 47 \\
\hline BR.ETMB & 852 & 25 & ON.GUA01 & 1203 & 254 & XC.SJPY & 150 & 64 \\
\hline BR.IPMB & 1068 & 234 & ON.MAN01 & 1091 & 92 & ХC.TBOT & 161 & 34 \\
\hline BR.ITTB & 1013 & 402 & ON.NAN01 & 1218 & 125 & XC.TLMB & 15 & 6 \\
\hline BR.JANB & 1151 & 285 & ON.PET01 & 971 & 115 & XC.UNIS & 140 & 33 \\
\hline BR.MALB & 902 & 204 & ON.RIB01 & 1160 & 410 & XC.VACA & 427 & 11 \\
\hline BR.MARB & 66 & 11 & ON.SLP01 & 906 & 104 & XC.VBST & 280 & 144 \\
\hline BR.MC01 & 320 & 177 & ON.TIJ01 & 940 & 25 & BX.JIR01 & 80 & 38 \\
\hline BR.MCPB & 1077 & 255 & ON.VAS01 & 1125 & 160 & BL.TRIB & 5 & 5 \\
\hline BR.NPGB & 1004 & 311 & XC.ALGR & 225 & 31 & BR.MACA & 19 & 8 \\
\hline BR.PDRB & 943 & 41 & XC.AMBA & 284 & 117 & BL.C2SB & 728 & 0 \\
\hline BR.PRPB & 962 & 335 & XC.ANTJ & 61 & 28 & BR.CZSB & 876 & 0 \\
\hline BR.PTLB & 914 & 479 & XC.ARAP & 173 & 24 & BR.TEFE & 654 & 0 \\
\hline \multirow[t]{2}{*}{ BR.SALB } & 970 & 261 & XC.AZCA & 185 & 39 & BR.TMAB & 1150 & 0 \\
\hline & & & & & & XC.POCN & 203 & 0 \\
\hline
\end{tabular}

Blue: Stations that only present results with deep regional events

Red: Stations that do not present stable results

The arrival time of the converted phases is controlled by the slowness (a horizontal component of the velocity of a seismic phase), which depends on the incidence angle mainly governed by the epicentral distance, focal depth, and velocities under the station. The dependence of the arrival time on the slowness is called move-out (Kind et al., 2012). 
As each event has different source parameters, the slowness is different as well as the arrival times of the converted phases in all of them (Figure 2.3b). If we stack the receiver functions as they are, the converted phases are still destructively superimposed due to different arrival times, being this effect minor at Moho Ps conversion, and larger for multiple reflected phases (Figure 2.3b).

To avoid these problems, the arrival time of each converted phase was corrected using a fixed reference slowness ( $p$ parameter) of $6.4 \mathrm{~s} /{ }^{\circ}$ and the IASP91 model (Kennett and Engdahl, 1991). This correction consists of stretching or compressing the time scale to parallelize travel time curves of converted phases, remembering that each phase needs its own move-out correction. Figure 5a of Section 2.5 shows an example of the move-out correction of one good RF trace at the AMBA station.

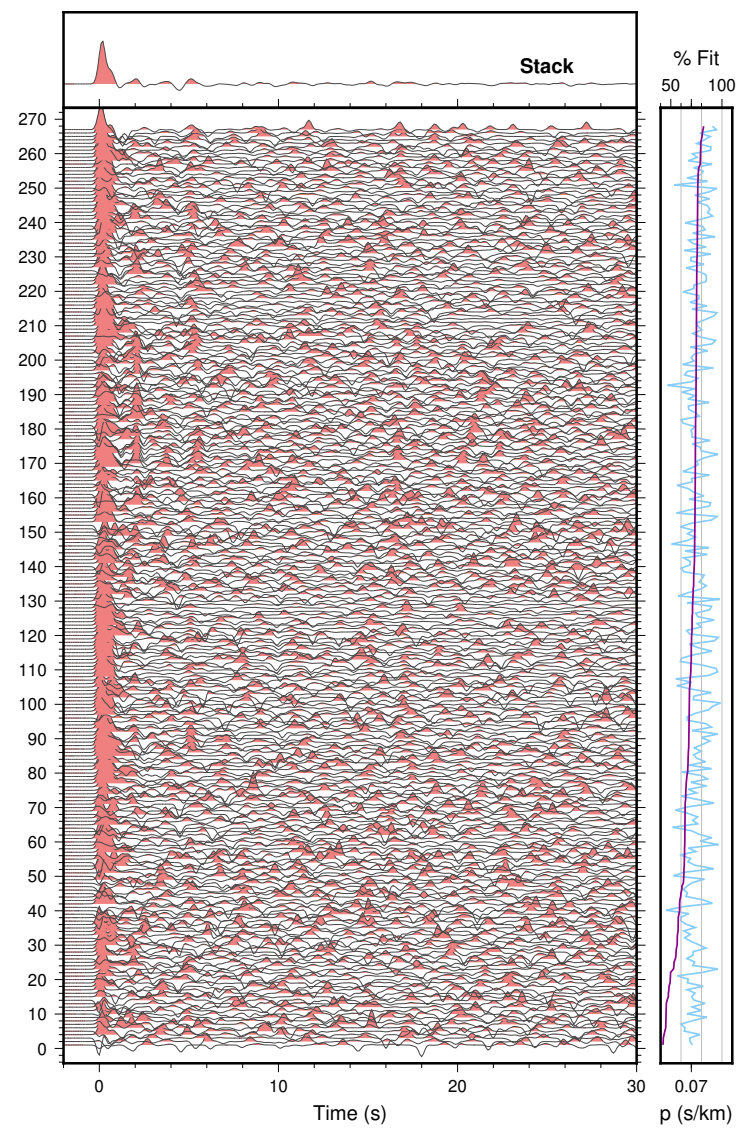

(a)

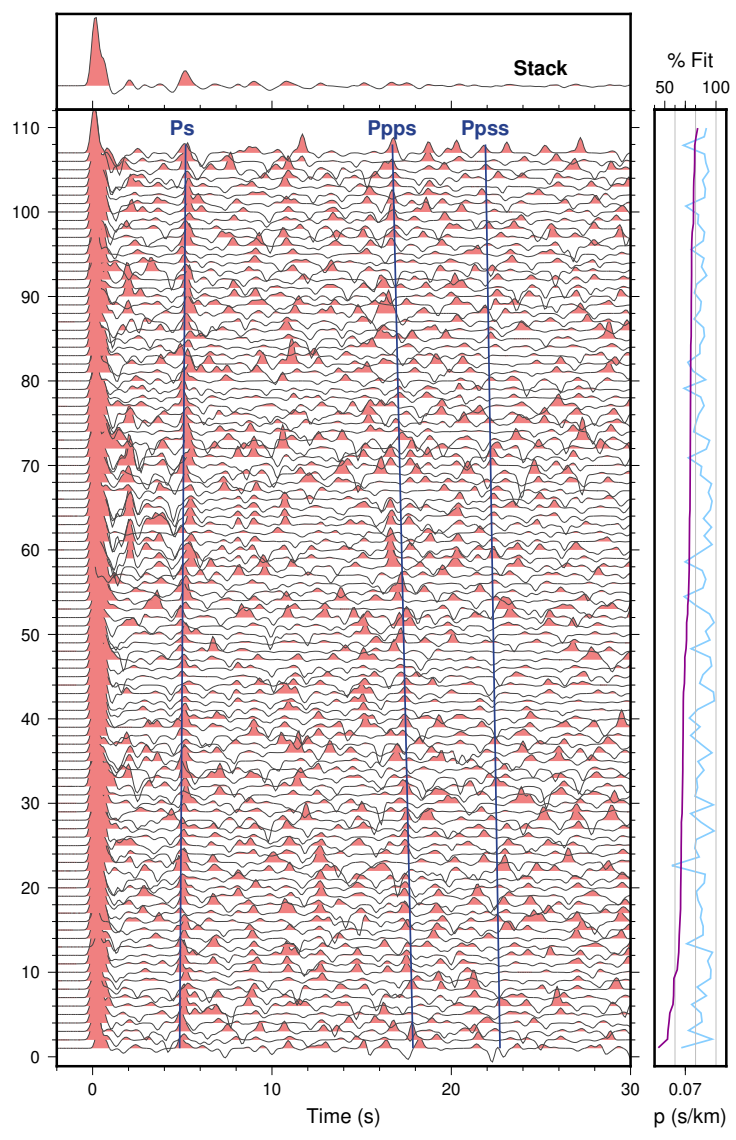

(b)

Figure 2.3: RF's traces at AMBA station sorted by ray parameter (purple line), and showing the fit percentage of the deconvolution (light blue line). (a) before the correlation and (b) after the correlation. Blue lines in (b) are the expected arrival times of Ps, Ppps and Ppss phases.

Heit et al. (2014) presented a modification of Zhu and Kanamori (2000) method, in 
which the receiver function traces are stacked by move-out corrected phases (Ps, Ppps, and Ppss) enhancing each one, reducing noise interferences from other incoherent arrivals, and agreeing with the arrival times predicted with the model. We used this approach to stack our move-out corrected traces (Figure 5b of Section 2.5).

To estimate the uncertainties we used a bootstrap resampling, that consists of creating a random sample with replacement (30\% in this work) from the original sample, and with the same size, by $\mathrm{N}$ times (200 in this work). This method is one of the most important to estimate the variation and estimate errors, given by the standard deviation.

\subsubsection{Deep regional event processing}

Owing that in some stations the data were noisy and it was difficult to identify the $P s$ conversion and other converted multiples, we also analyzed regional deep events that have higher frequencies and signal-to-noise ratio than teleseismic events, mainly because of the shorter paths and the fact that these waves cross just one time the asthenosphere (at the station side). Similar incidence angles in relation to standard teleseismic events RF's are ensured because of their deep hypocenter, as shown in Figure 2.4. One disadvantage of deep regional events is that the interference of the $\mathrm{P}$-wave with upper mantle discontinuities causes a P-wave triplication (Zhang and Langston, 1995; Costa, 2006), arriving more than one $\mathrm{P}$-wave per distance, each one with a different incidence angle, as observed in Figure 2.4 for events with epicentral distances between $10^{\circ}$ and $17^{\circ}$.

As the first arrival always is used to calculate the receiver function, it is not possible to use data that present $\mathrm{P}$-wave triplication since they present more than one $\mathrm{P}$-wave arrival, with different slowness. Using the IASP91 velocity model, which considers a linear velocity gradient in the mantle and better represents the velocity structure and arrival times for seismic waves (Kennett and Engdahl, 1991), we elaborated the model shown in Figure 2.5, which indicates for what distances and depths the $\mathrm{P}$-wave presents triplication. This model helped us to discard these data allowing us to select traces to be processed by the receiver function methodology. 


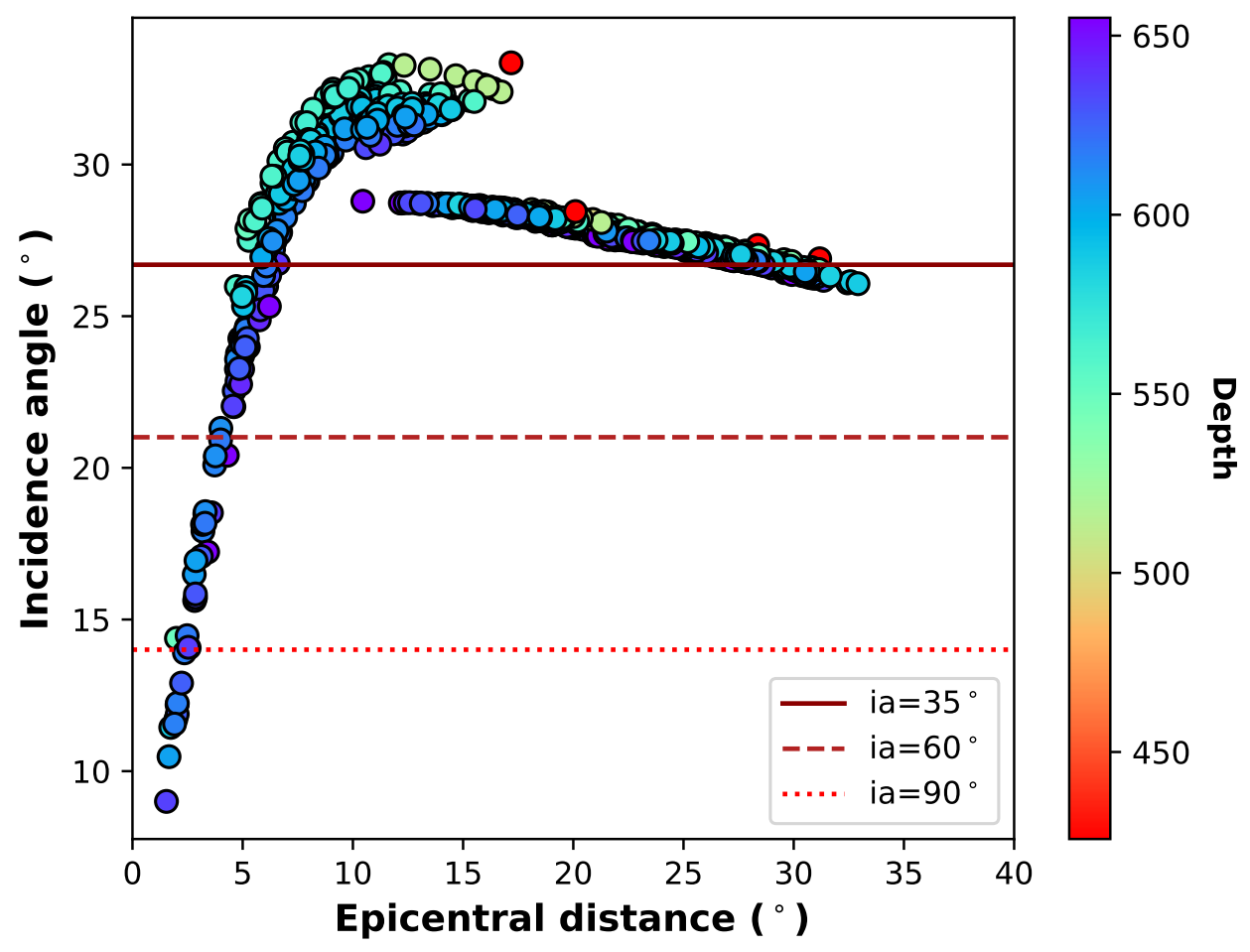

Figure 2.4: Theoretical incidence angle of first arrival for deep regional events recorded at Brazilian stations, compared with theoretical incidence angle (ia) of events at $35^{\circ}, 60^{\circ}$ and $90^{\circ}$. At distances between $10^{\circ}$ and $17^{\circ}$ it is observed the $\mathrm{P}$-wave triplication.

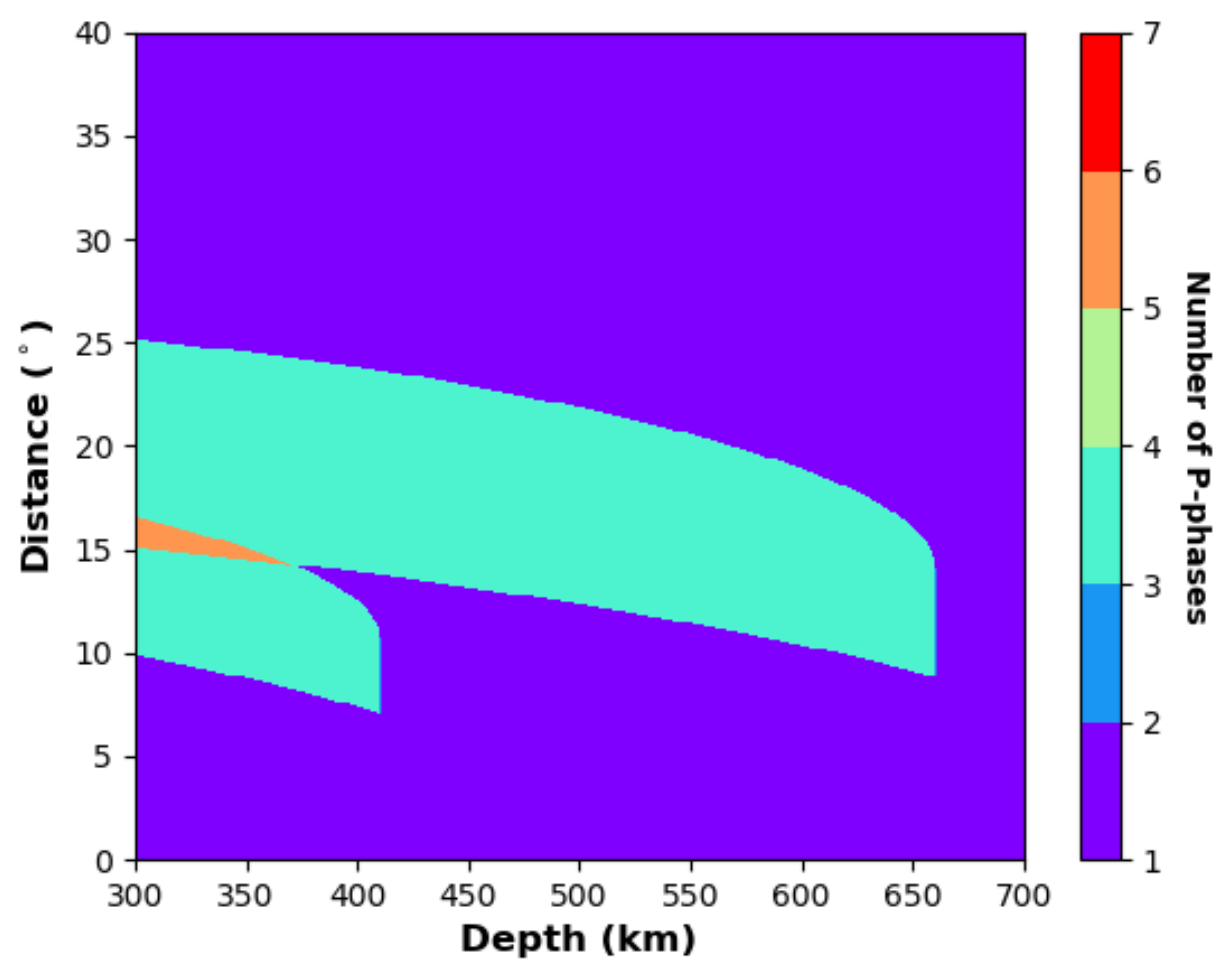

Figure 2.5: Model of $\mathrm{P}$-wave triplication for deep regional events, which shows the number of $\mathrm{P}$-wave arrivals at a given depth and distance. 


\subsection{Results and discussion}

In the published paper (Section 2.5), we presented the results obtained from the RSBR stations and $35 \mathrm{XC}$ temporary deployment. In this chapter, we explain more details not discussed in the paper and we present additional results from six Peruvian and one Bolivian stations processed.

To estimate $\mathrm{H}$ and $V_{p} / V_{s}(\mathrm{k})$ ratio using the modified H-k stacking method (Heit et al., 2014), as indicated in Section 2.3.1; we considered weights of 0.6 for Ps phase, 0.2 for Ppps, and 0.2 for Ppss. We first used a fixed average P-wave velocity $\left(V_{p}\right)$ of $6.4 \mathrm{~km} / \mathrm{s}$ (Christensen and Mooney, 1995). As we have 200 stacked traces for each phase, at each station, we have estimated 200 values for $\mathrm{H}$ and $\mathrm{k}$ at each one (Figure 4c of Section 2.5). The median of these estimates represents the crustal thickness and $\mathrm{k}$ ratio, and the uncertainties are given by the standard deviation (Figure 2.6).
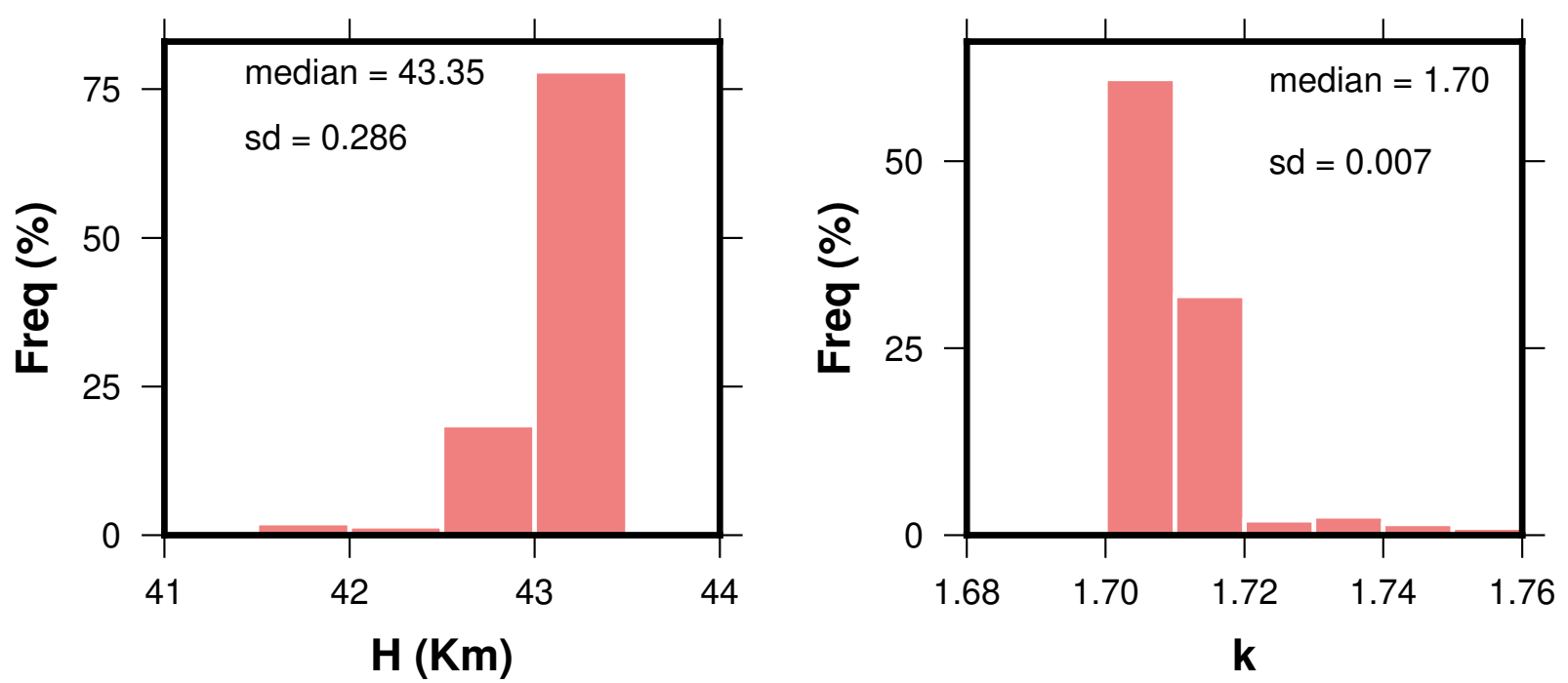

Figure 2.6: Histograms of the 200 estimates of crustal thickness $(\mathrm{H})$ and $V_{p} / V_{s}(\mathrm{k})$ ratios at AMBA station. The median of the estimates gives the $\mathrm{H}$ and $\mathrm{k}$ values, while the uncertainties are given by the standard deviation.

When each H-k grid was visually inspected, we realized that some stations showed more than one peak, probably due to heterogeneities in the crust (named as a regular station) as shown in Figure 2.7. In these cases, to constraint the crustal thickness we used a consistent $V_{p} / V_{s}$ crustal value between the range given by (Christensen, 1996). 

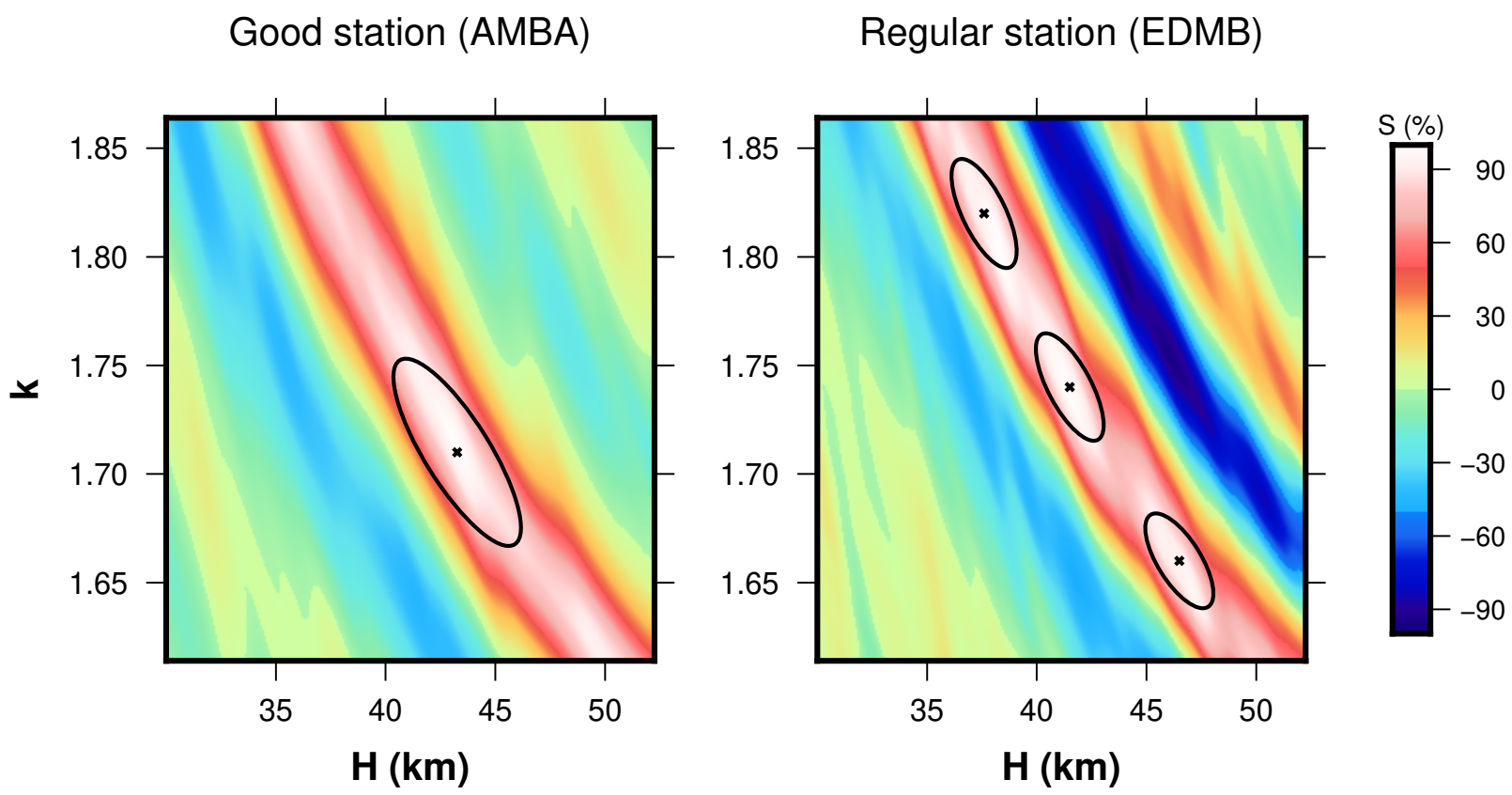

Figure 2.7: Comparison between good and regular stations. (a) Good station (AMBA) that shows only one maximum peak of objective function at $\mathrm{H}-\mathrm{k}$ grid searching. (b) regular station (EDMB) that shows three possible maximum peaks. Hot colors represent the percentage of the objective function $s(H, k)$ of Equation 2.8.

Results comparison between the modified Heit et al. (2014) and traditional (Zhu and Kanamori, 2000) H-k stacking are shown in Figure 5 of Section 2.5, both results are close to each other, being the uncertainties of modified method smaller. These results were also compared with previous studies for common stations (Figure 6 of Section 2.5), being the difference smaller for crustal thickness; due to $V_{p} / V_{s}$ values are more difficult to stabilize, they show a higher difference when compared with results of other works. For more details consult Section 2.5.

In the area of Pantanal, Paraná, and Chaco-Paraná Basins, we also used an average $V_{s}$, from the regional S-wave velocity model of Shirzad et al. (2020), instead of a fixed $V_{p}$. Both results are consistent for $\mathrm{H}$ and $V_{p} / V_{s}$ (Figure 8 and $\mathrm{S} 1$, Section 2.5), being the $\mathrm{k}$ uncertainties larger when $V_{s}$ is used because the H-k stacking method is more sensitive to $V_{s}$ than $V_{p}$ variations. However, the main characteristics are maintained.

Using these new measurements and previously published data we updated the previous model of crustal thickness of South America presented by Assumpção et al. (2013), details of its construction are mentioned in the paper. It is important to highlight that important areas poorly studied before, as the Amazon region and central part of the South American 
platform, are now covered and improved as shown in Figure 9 of Section 2.5. In this new version, there is an increase of $\sim 55 \%$ in different measurement points in relation to the 2013 model.

\subsubsection{Deep events}

For this dataset, the deconvolution procedure and H-k stacking was the same one described for teleseismic data and were used the same parameters. In most of the analyzed stations, the results were consistent with those obtained with teleseismic data (Figure S1 of Section 2.5). Using deep regional data was possible to obtain results at BL.TRIB, BR.MACA and XC.PSAL stations that had not been possible to resolve with teleseismic data.

Figure 2.8 shows the receiver function sections using teleseismic and deep regional data at BL.TRIB station. Using teleseismic data, an arrival close to $\sim 2$ seconds is observed, which is probably a $P s$ conversion of sediment basement. Nevertheless, the Ps conversion at Moho ( 6 seconds) and multiple reverberations are not clear, making it impossible to estimate $\mathrm{H}$ and $\mathrm{k}$ values from these traces.

On the other hand, looking at the section of the deep regional data, it is possible to distinguish an arrival at $\sim 6$ seconds, that would be the $P s$ conversion at Moho; another arrival is clear at $\sim 4$ seconds that could represent a $P s$ conversion of another crustal interface (Conrad discontinuity) with a depth of $31 \mathrm{~km}$ or a positive multiple for the sediment basement. Anyway, it is difficult to make any affirmation because of the limited amount of available data. 


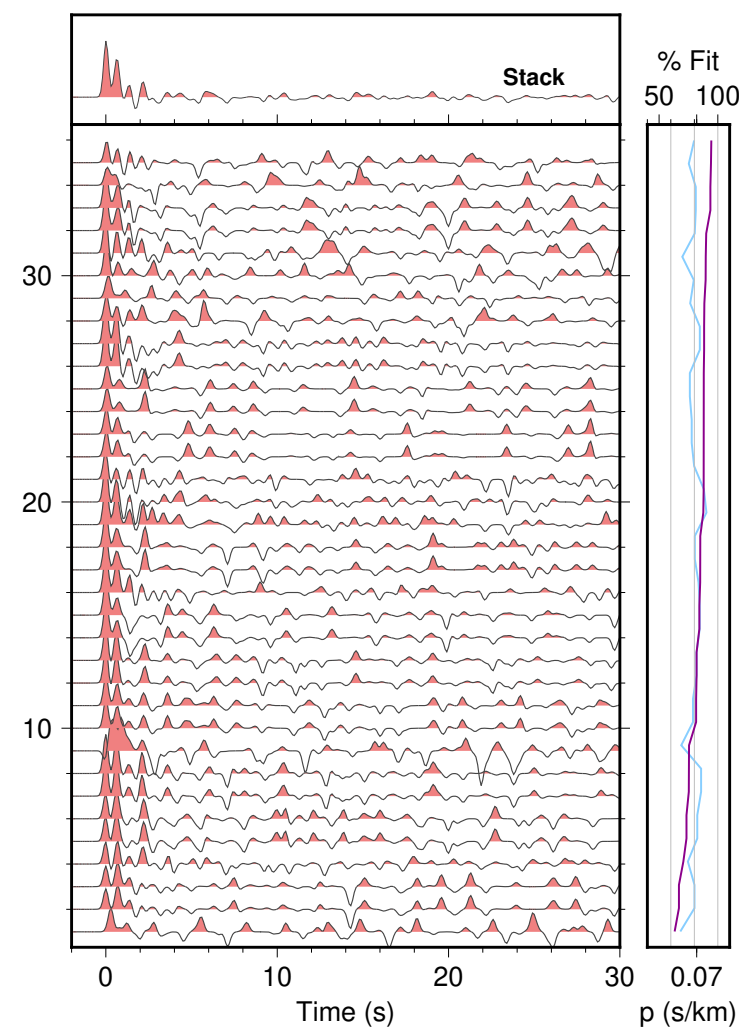

(a)

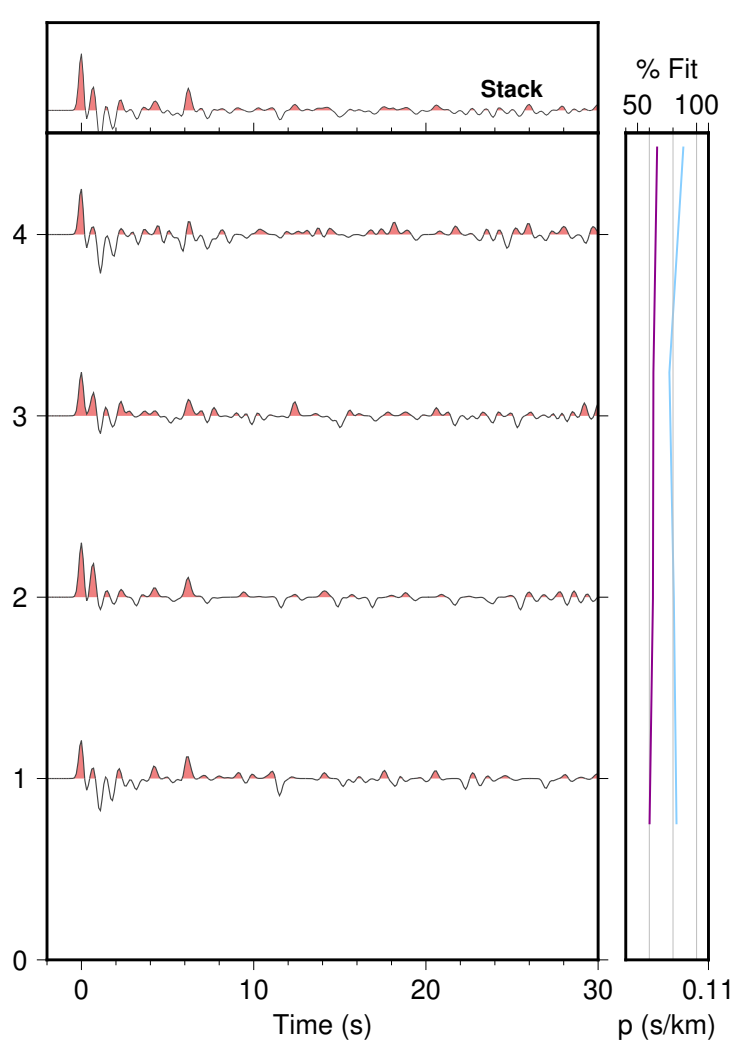

(b)

Figure 2.8: Comparison of receiver function traces of teleseismic (a) and deep regional events (b) for BL.TRIB station sorted by ray parameter (purple line) and showing the fit percentage of the deconvolution(light blue line). When using teleseismic data neither the $P s$ conversion can be recognized, despite it should be the clearest signal after direct $\mathrm{P}$ arrival. When deep regional data is used it is possible to observe the $P s$ arrival at $\sim 5$ seconds, and earlier arrival at $\sim 4$ seconds that could be a crustal interface or a positive multiple for sediment basement.

The results obtained from deep and teleseismic data compare well, within the uncertainties of each estimate. Although results using deep events show larger uncertainties due to the few events available, similar patterns are observed comparing both results (Figure S1 of Section 2.5). It is important to highlight that in the southern part of the Amazon Craton there is a larger discrepancy for crustal thickness up to $6 \mathrm{~km}$.

\subsubsection{Additional stations}

Apart from the RSBR and XC temporary deployment stations, we have analyzed one Bolivian and six Peruvian stations, the average number of events obtained is almost 200; considering both teleseismic and deep regional data.

Peruvian stations (green triangles in Figure 2.2a) are located in the Sub-Andean region, which borders Andes highland to the west, South American platform to the east, and has 
200 km width approximately (Ward et al., 2013; Rocha and Cristallini, 2015; Condori, 2016). This area is still poorly studied by seismological tools due to the few stations, although some crustal studies with low resolution have been carried out, identifying a narrower belt of thinner crust $(\sim 35 \mathrm{~km})$ along this area (Assumpção et al., 2013; Van der Meijde et al., 2013). Results obtained from RBSR also showed a thinner crust and suggest a narrower Sub-Andean belt than previous works.

On the other hand, the SIV station (yellow triangle in Figure 2.2a) helped us to confirm the results from some close XC temporary stations, which due to their short operating time do not have enough available data for reliable results.

Figure 2.9 and Table 2.2 show the additional results, where new processed stations are squares, and stations belonging to the RSBR network are circles. Stations located in the Andes highlands have a crust thicker than $45 \mathrm{~km}$. The IQT0 station, located in the Amazon Basin, also presents a thicker crust of $\sim 45 \mathrm{~km}$, agreeing with the results of other RSBR stations already analyzed in the area. Otherwise, the SIV station has a crustal thickness of $37.2 \mathrm{~km}$, confirming previous results from temporary $\mathrm{XC}$ deployment.

Values obtained for $V_{p} / V_{s}$ ratio are scattered, even in nearby stations, being difficult to correlate with geological features. Most of the estimated values are between the expected range according to Christensen (1996); however, we found extreme values at some Peruvian stations that will be discussed later.

Table 2.2 - Results of $\mathrm{H}$ and $\mathrm{K}$ for additional stations.

\begin{tabular}{|c|c|c|c|c|c|c|}
\hline Network & Station & $\mathbf{H} \mathbf{( k m})$ & Error & Vp/Vs & Error & Num. of RF \\
\hline PE & BVTA & 50.3 & 3.16 & 1.76 & 0.05 & 35 \\
PE & CUS0 & 55.0 & 3.84 & 1.71 & 0.05 & 9 \\
PE & IQT0 & 44.7 & 0.33 & 1.78 & 0.01 & 74 \\
PE & PTM0 & 40.0 & 2.42 & 1.81 & 0.05 & 16 \\
PE & PUC0 & 40.28 & 1.97 & 1.79 & 0.04 & 47 \\
PE & UNAP & 41.6 & 3.74 & 1.82 & 0.07 & 15 \\
BO & SIV & 37.2 & 0.17 & 1.79 & 0.05 & 99 \\
\hline
\end{tabular}




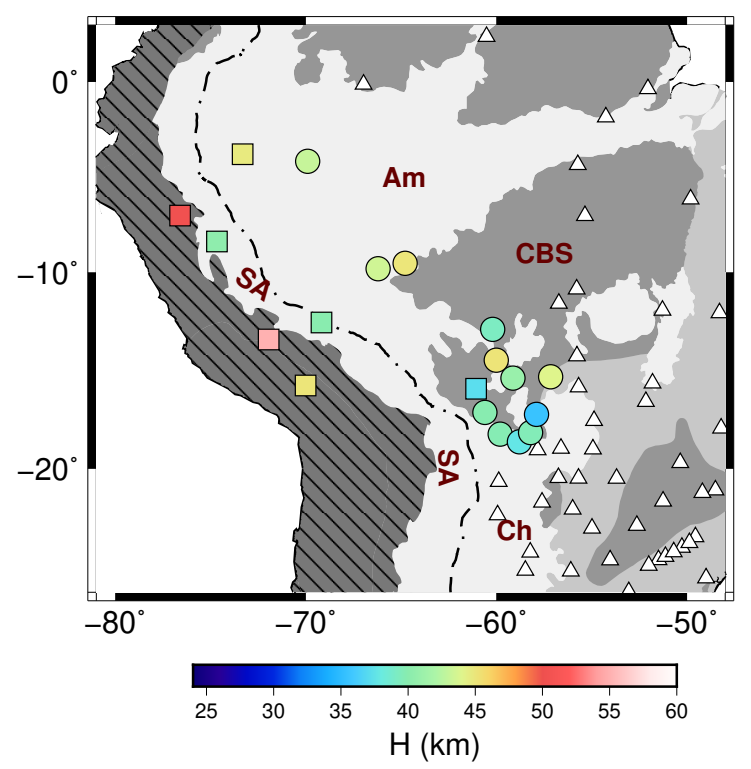

(a)

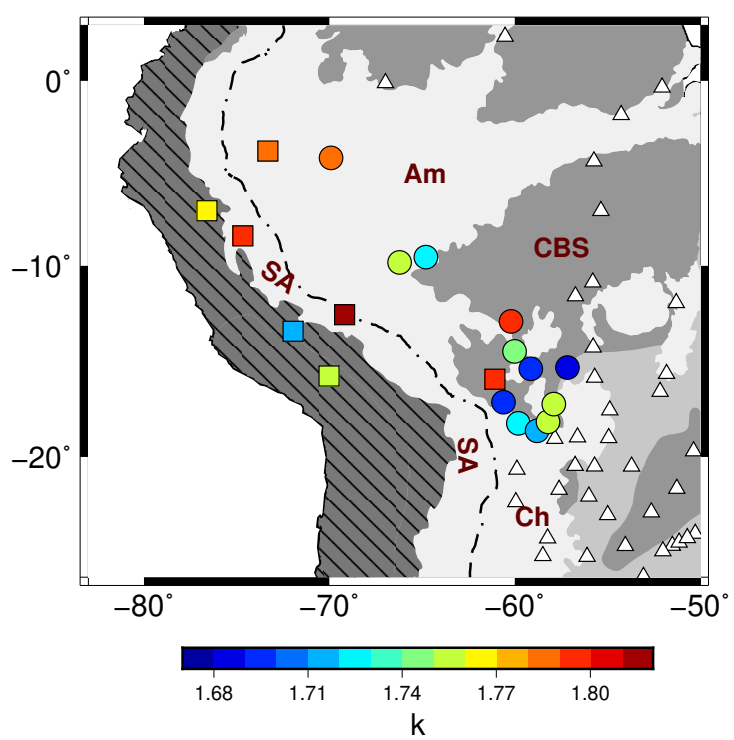

(b)

Figure 2.9: Crustal thickness (a) and $V_{p} / V_{s}$ ratios (b) results for additional stations processed (squares) and closest Brazilian stations results (circles). Open triangles: Other Brazilian stations processed. Am: Amazonian basin, Ch: Chaco-Paraná basin, SA: Sub-Andean region. Shaded areas refer to the geological provinces shown in Figure 1.2.

\subsubsection{Peruvian stations}

Receiver functions sections of Peruvian stations show noisy data, making it possible to adopt different values of $\mathrm{H}$ and $\mathrm{k}$, which were restricted according to Christensen (1996). The crustal structure of northern Peru was studied by Condori (2016); Condori et al. (2017) through also receiver function method, analyzing two common stations with the present work: IQT0 and PUCO, finding thinner crustal thicknesses (squares at Figure 2.10), although it presents greater uncertainties. Values of $V_{p} / V_{s}$ also are different, being the values reported by Condori et al. (2017) less scattered.

Small differences may occur because of different adopted values during data processing, e.g. Condori et al. (2017) uses a $V_{p}$ of $6.1 \mathrm{~km} / \mathrm{s}$ (we used a $V_{p}=6.4 \mathrm{~km} / \mathrm{s}$ ) and different weights in the H-k staking. Nevertheless, we observe significant differences in crustal thicknesses, while we estimated values of $\sim 45 \mathrm{~km}$, they reported values lesser than $38 \mathrm{~km}$. Regardless, we obtained RFs that show a clearer Ps arrival (Figure 2.11), resulting in an H-k stack that converges to a stable solution, even with a more open search grid. Other previous works as Assumpção et al. (2013); Van der Meijde et al. (2013); Lloyd et al. (2010) reported values of $\sim 40 \mathrm{~km}$ of crustal thickness in this area. 


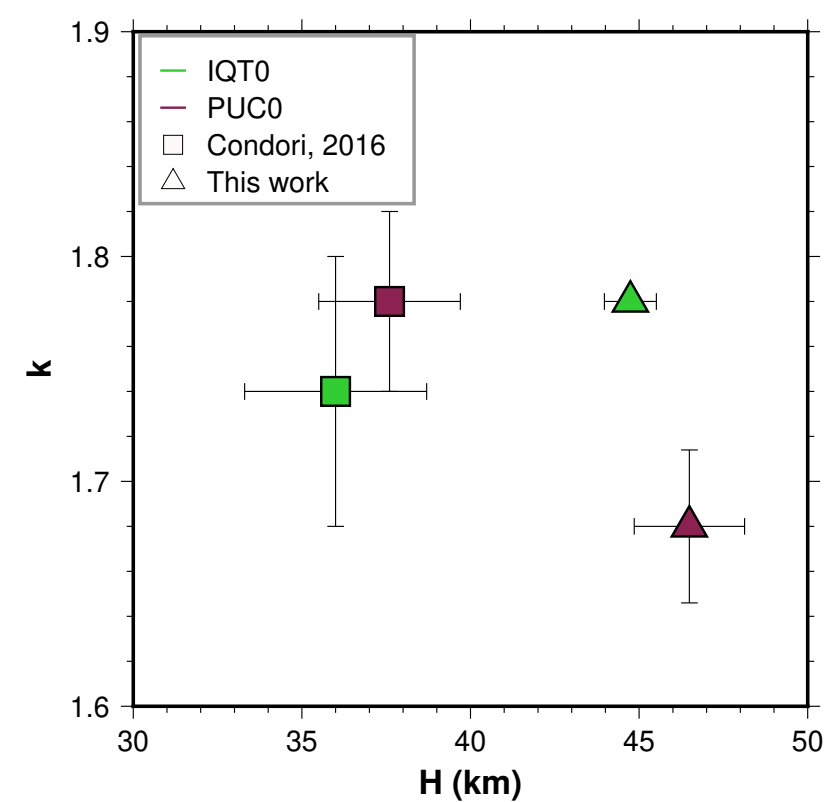

Figure 2.10: Comparison of $\mathrm{H}$ and k results at IQT0 and PUC0 Peruvian stations, between Condori et al. (2017) and the present work. Green symbols: IQT0 station, purple symbols: PUC0 station, squares: Condori et al. (2017) and triangles: present work.

In the Andean region, because of its complexity, it is difficult to obtain clear receiver function traces. However, we observed a crustal thickness notably thicker than the SubAndean area, which has a slightly thinner crust than Amazon Basin, as pointed in previous works. Most of $V_{p} / V_{s}$ values are within the normal range according to Christensen (1996), being higher in the Sub-Andean region and Amazon Basin, as expected for areas with a thicker sediment layer.

Figure 2.11 shows the RF section at IQT0 and PUC0 Peruvian stations, located in the Sub-Andean area, a delay of direct P-wave is observed (arrival time different than 0), this characteristic is observed in stations located on thick low-velocity sedimentary layers, where the $P s$ conversion at bottom of sedimentary layer is higher, masking the direct $\mathrm{P}$ arrival (Zelt and Ellis, 1999; Zheng et al., 2005; Yu et al., 2015). Another important effect of sediment layers is that reverberating phases may overprint $P s$ converted phases from interesting discontinuities, as Moho in this case (Zheng et al., 2005). If the converted phase at Moho is not masked, this one arrives later and it leads to estimate a greater depth if the sediment layer is not accounted for (Yeck et al., 2013); since we did not take into account this correction for our estimates, it could explain our thicker crust in comparison with previous studies. 


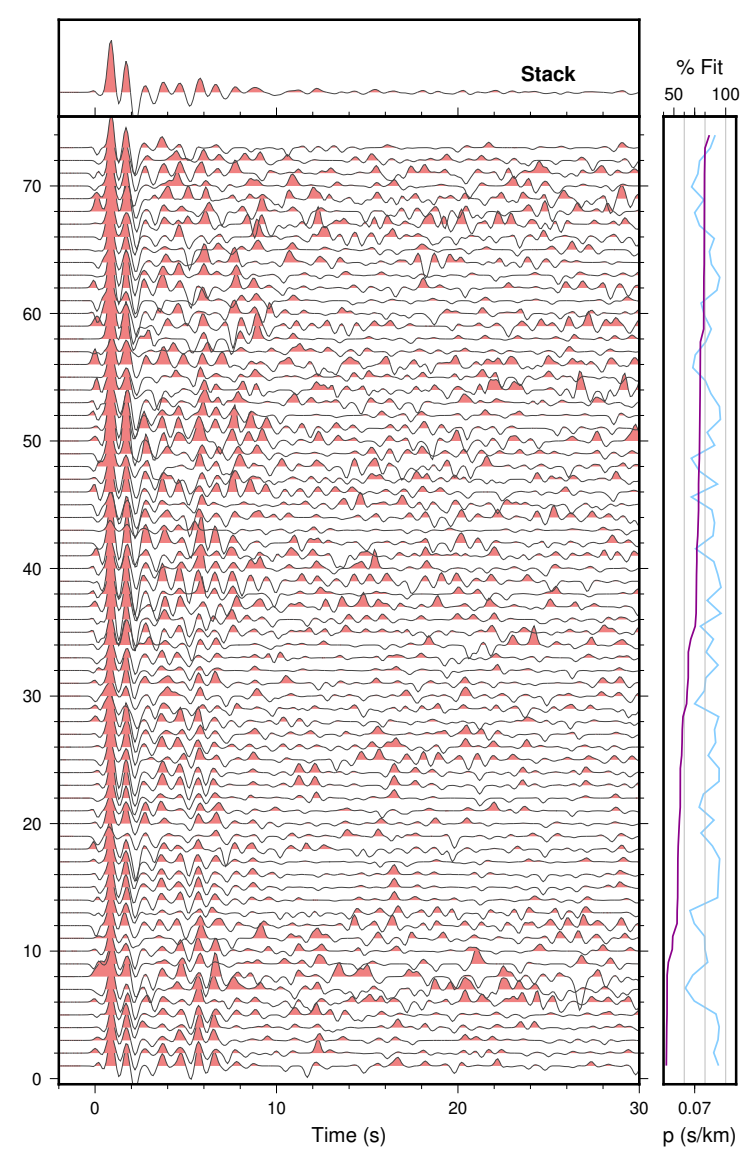

(a) IQT0 station

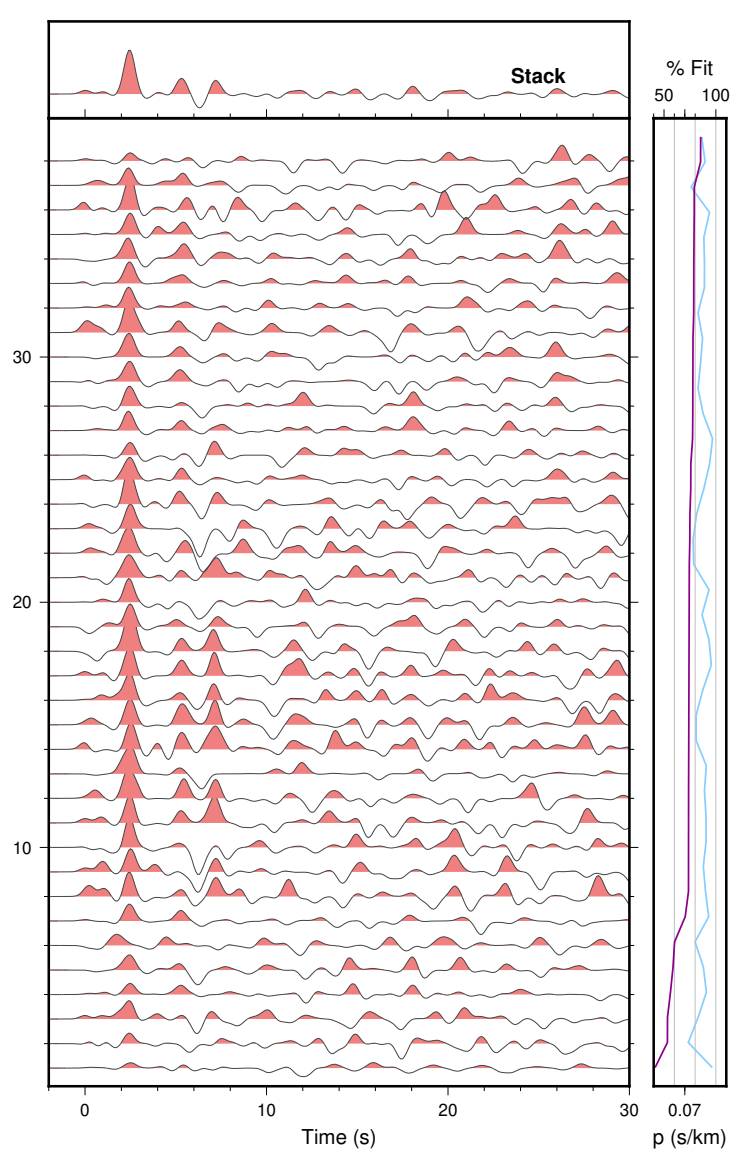

(b) PUC0 station

Figure 2.11: Receiver function sections for (a) IQT0 and (b) PUC0 Peruvian stations. In both there is a delay of direct $\mathrm{P}$-wave, that is the effect of an important sediment layer with low velocity. Ps conversion is not clear and multiplies are masked by sediment basement reverberations. They are sorted by ray parameter (purple line), and also is showed the fit percentage of the deconvolution (light blue line).

Despite the results presented here, it is clear that those estimates need further verification.

\subsubsection{SIV station - Bolivia}

At the SIV station, a great amount of consistent RF's traces were obtained and considered to obtain the $\mathrm{H}$ and $\mathrm{k}$ values. We observe that for events with back azimuths between $100^{\circ}$ and $200^{\circ}$ it is not possible to identify a clear arrival of $P s$ at expected time of $\sim 5$ seconds, despite having been selected as good traces in the correlation. However at $\sim 10$ seconds appears an arrival (Figure 2.12a), that could be a conversion at $\sim 100 \mathrm{~km}$, according to the IASP91 velocity model, or a positive multiple of the shallower crustal interface. This station is installed over an area without an important sediment layer, then the effect of a possible sediment layer is excluded. 
According to the model proposed by Portner et al. (2020), the Nazca slab has a depth of $\sim 600 \mathrm{~km}$ in this region, then a possible conversion due to the slab is discarded. Anyway, excluding these traces, $P s$ conversion is clearer in the stack of the remaining events; nevertheless, the reverberated phases are not recognizable (Figure 2.12b).

From the RF traces of Figure 2.12b, we estimated a crustal thickness of $37.2 \mathrm{~km}$, which correlates well with close XC stations, in which fewer events were used due to their availability. The $V_{p} / V_{s}$ value (1.79) is higher than in nearby stations, this parameter is more difficult to stabilize even more when the multiplies are not clear, as in this station.

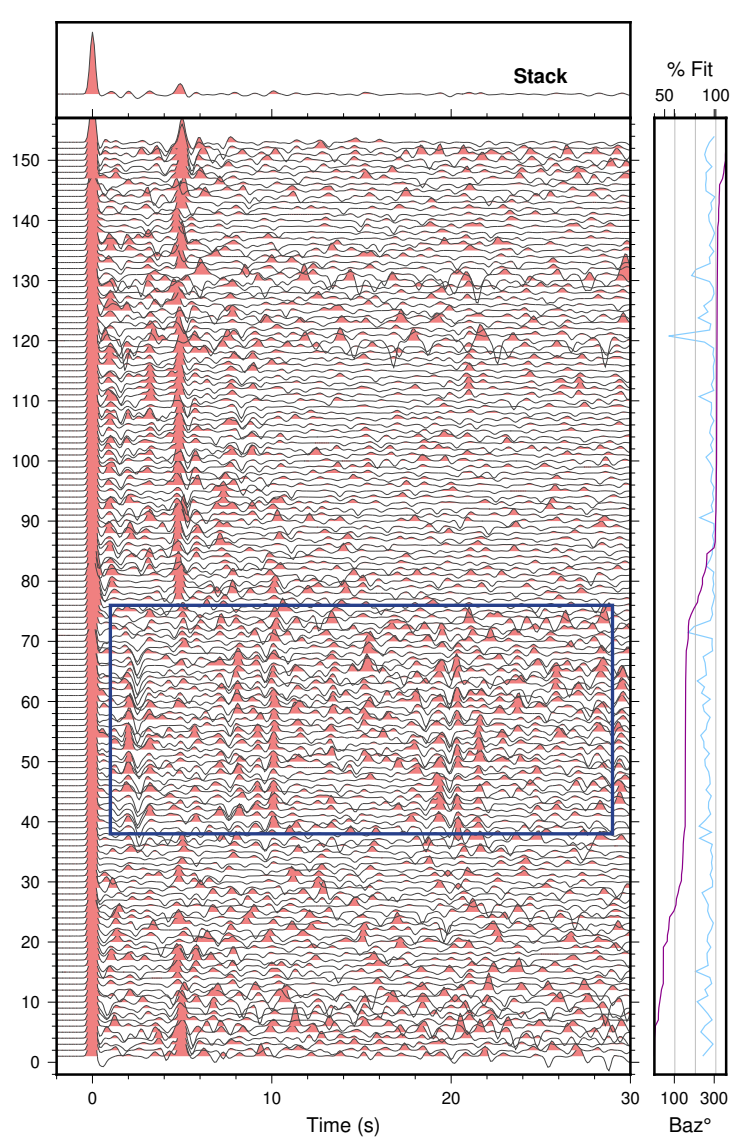

(a)

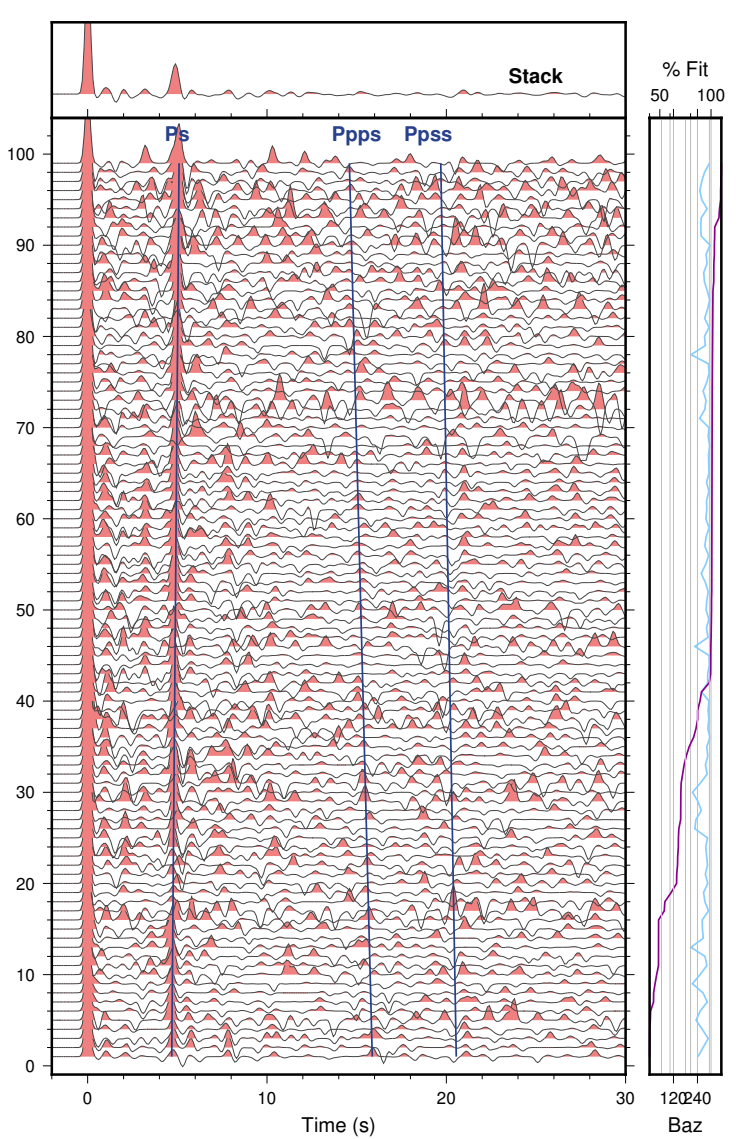

(b)

Figure 2.12: Receiver function section of SIV station (a) sorted by back azimuth (purple line), between $100^{\circ}$ and $200^{\circ}$ back azimuth the expected arrival of $P s$ conversion at $\sim 5$ seconds is not recognizable (blue square). (b) RF section sorted by ray parameter (purple line), with the predicted arrival time of Ps, Ppps and Ppss phases, using a $\mathrm{H}=37.2 \mathrm{~km}, k=1.79$ and IASP91 model. In both sections are shown, in the lateral pictures, the fit percentage of the deconvolution(light blue line).

\subsubsection{Regional patterns}

Crustal thickness and $V_{p} / V_{s}$ ratio vary according to the geology and evolution of the area, e.g. sedimentary basins and regions affected by magmatism present higher $k$ val- 
ues. To observe how these parameters change, we calculated average values of the crustal thickness $(\mathrm{H})$ and $V_{p} / V_{s}(\mathrm{k})$ ratios at different geological provinces analyzed. Figure 2.13 shows these average values and the standard deviation $(1 \sigma)$ as error bars, the red dotted line represents the average crustal thickness of $41.5 \mathrm{~km}$ for shields and platforms according to Christensen and Mooney (1995) and the reference value of $V_{p} / V_{s}$ of 1.73 .

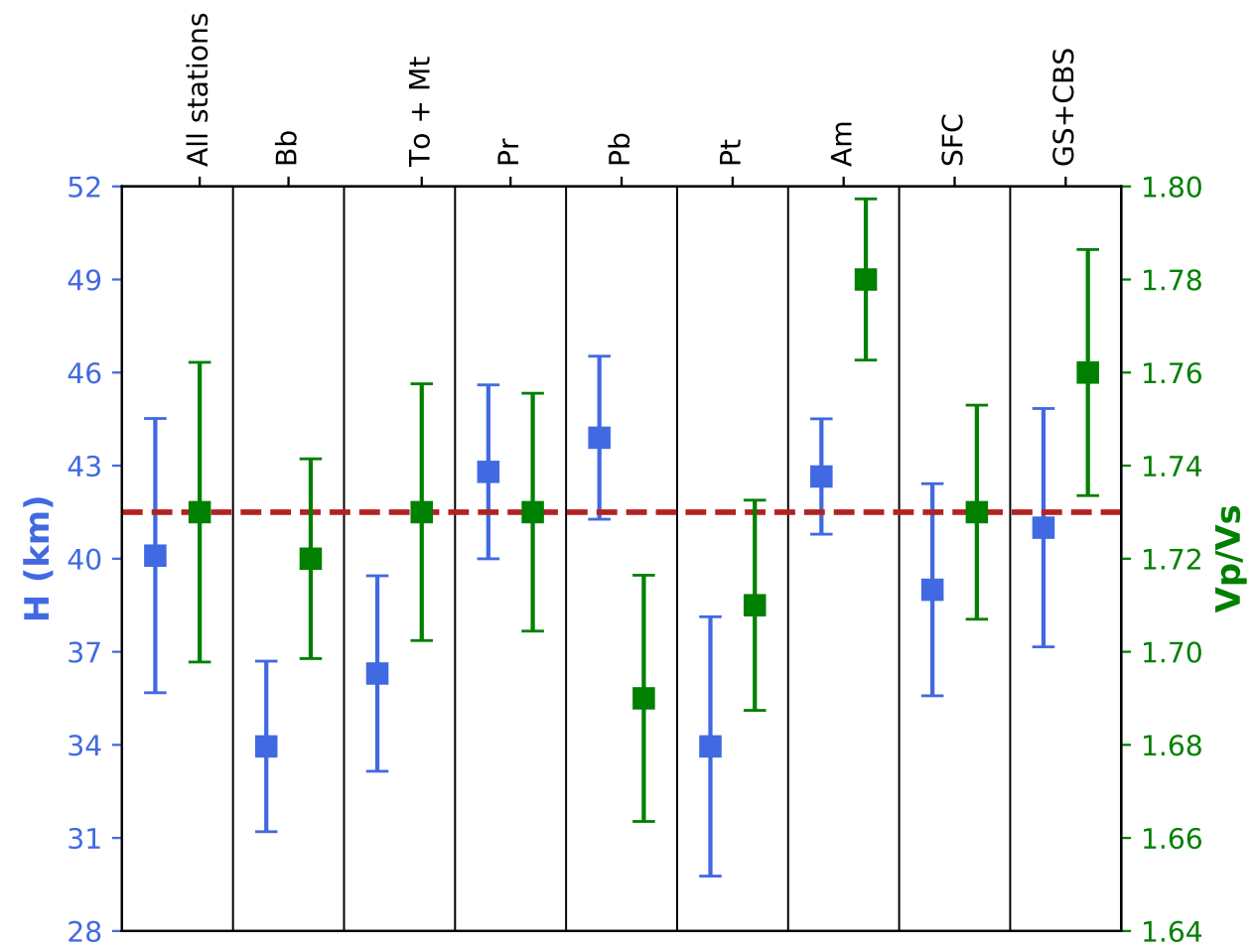

Figure 2.13: Crustal thickness and $V_{p} / V_{s}$ averages by geological provinces. Bb, To and Mt: Borborema, Tocantins and Mantiquiera Provinces. Pr, Pb, Pt and Am: Paraná, Paranaíba, Pantanal and Amazon Basins. SFC: São Francisco Craton. GS: Guapore Shield. CBS: Central Brazilian Shield. Crustal thickness averages are blue squares and $V_{p} / V_{s}$ averages are green squares. Red dotted line represents the average global crustal thickness of $41.5 \mathrm{~km}$ estimated by Christensen and Mooney (1995) for shields and platforms and $V_{p} / V_{s}$ reference value of 1.73. Left $y$ axis: Crustal thickness and right $y$ axis: $V_{p} / V_{s}$ ratios.

Regular stations with higher or lower inconsistent values of $V_{p} / V_{s}$ were discarded. The average crustal thickness value for all stations analyzed is $40.5 \mathrm{~km}$, very close to the average for platforms reported by Christensen and Mooney (1995). Average $V_{p} / V_{s}$ is also the same as the adopted reference of 1.73. Error bars for $V_{p} / V_{s}$ are higher because this parameter is more difficult to stabilize.

The Neoproterozoic fold belts, Borborema, Tocantins, and Mantiqueira Provinces; present lower values of crustal thickness $(<36 \mathrm{~km})$ and slightly lower values of $V_{p} / V_{s}$, 
being lower, in both parameters, at Borborema Province as previously pointed by Luz et al. (2015). It is also important to note that those regions concentrate the seismicity in the stable part of the continent.

Paraná (Pr) and Parnaíba (Pb) Basins have an average crustal thickness of $\sim 44 \mathrm{~km}$, the thicker crust in these areas is explained by the presence of a cratonic block in both. These higher values are consistent with previous studies, as Julià et al. (2008) for Paraná Basin and Coelho et al. (2018); Soares et al. (2018) for Parnaíba Basin. $V_{p} / V_{s}$ average value for Paraná Basin agreed with the reference value of 1.73, while in Parnaíba Basin this value is significantly lower; however, in this region, only three stations were analyzed, obtaining scattered values. Amazonian Basin (Am) presents also an average crust of $\sim 44 \mathrm{~km}$, and higher values of $\mathrm{k}$ ratios, as expected for a region with sediments. As well as in Parnaíba Basin, in the Amazon Basin, only four stations were analyzed, two of them belonging to the Peruvian network, that as commented before, presented inconclusive results due to the sediment layer. Finally, at Pantanal Basin (Pt) was found an average thinner crust of $\sim 34$ $\mathrm{km}$ and a low $V_{p} / V_{s}$ value of 1.71 .

The cratonic areas present an average crustal thickness very close to the average value reported by Christensen and Mooney (1995). São Francisco Craton has an average $V_{p} / V_{s}$ value very close to 1.73, while at Guapore Shield (GS) and Central Brazilian Shield (CBS), $V_{p} / V_{s}$ value is higher (1.76).

Further results and discussions are presented in the Manuscript published as part of this work, presented in the next Section 2.5. 
Section 2.5. Paper published in the Journal American Geophysical Union: An updated crustal thickness Map of Central South America Based on Receiver Function Mesasurements in the Region of the Chaco, Pantanal, and Paraná Basins, Southwestern Brazil

2.5 Paper published in the Journal American Geophysical Union: An updated crustal thickness Map of Central South America Based on Receiver Function Mesasurements in the Region of the Chaco, Pantanal, and Paraná Basins, Southwestern Brazil 


\section{JGR Solid Earth}

\author{
RESEARCH ARTICLE \\ 10.1029/2018JB016811 \\ Key Points: \\ - New crustal thicknesses are \\ estimated for a large region of \\ midplate South America, not \\ previously sampled before \\ - The active Pantanal Basin has strong \\ lateral variation: thick crust and \\ high $V p / V s$ in the west and thin \\ crust and low $V p / V s$ in the east \\ - A new, updated model of crustal \\ thickness for South America is \\ presented
}

Supporting Information:

- Supporting Information S1

Correspondence to:

C. Rivadeneyra-Vera,

carolina.vera@iag.usp.br

\section{Citation:}

Rivadeneyra-Vera, C., Bianchi, M., Assumpção, M., Cedraz, V., Julià, J., Rodríguez, M., et al. (2019). An updated crustal thickness map of central South America based on receiver function measurements in the region of the Chaco, Pantanal, and Paraná Basins, southwestern Brazil. Journal of Geophysical Research: Solid Earth, 124 8491-8505. https://doi.org/10.1029/ 2018JB016811

Received 3 OCT 2018 Accepted 3 JUL 2019

Accepted article online 9 JUL 2019 Published online 13 AUG 2019

(C)2019. American Geophysical Union All Rights Reserved.

\section{An Updated Crustal Thickness Map of Central South America Based on Receiver Function Measurements in the Region of the Chaco, Pantanal, and Paraná Basins, Southwestern Brazil}

\author{
Carolina Rivadeneyra-Vera ${ }^{1}$ iD, Marcelo Bianchi ${ }^{1}$ iD, Marcelo Assumpção ${ }^{1}$ iD, Victoria Cedraz $^{2}$, \\ Jordi Julià $^{2}$ iD, Martín Rodríguez ${ }^{3}$, Leda Sánchez ${ }^{3}$ iD, Gerardo Sánchez ${ }^{4}$, Luciana Lopez-Murua ${ }^{4}$, \\ Gonzalo Fernandez", Rafael Fugarazzo", and The “3-Basins” Project Team" \\ ${ }^{1}$ Departmento de Geofísica, Instituto de Astronomia, Geofísica e Ciências Atmosféricas, Universidade de São Paulo, São \\ Paulo, Brazil, ${ }^{2}$ Departmento de Geofísica, Universidade Federal do Rio Grande do Norte, Natal, Brazil, ${ }^{3}$ Observatorio \\ Geofísico del Uruguay Universidad de la República, Montevideo, Uruguay, ${ }^{4}$ INPRES, San Juan, Argentina, ${ }^{5}$ Observatorio \\ San Calixto, La Paz, Bolivia, ${ }^{6}$ Laboratorio de Sismología, Facultad de Ciencias Exactas y Naturales, Universidad Nacional \\ de Asunción, Asunción, Paraguay
}

Abstract Previous compilation of crustal structure in South America had large unsampled areas including the thin crust in the Sub-Andean lowlands, largely estimated by gravity data, and the sparsely sampled Amazon Craton. A deployment of 35 seismic stations in Brazil, Bolivia, Paraguay, Argentina, and Uruguay improved the coverage of the Pantanal Basin in Western Brazil, the intracratonic Paraná and the Chaco Basins. Crustal thicknesses and $V p / V s$ ratios were estimated with a modified $\mathrm{H}-\mathrm{k}$ method by producing three stacked traces to enhance the three Moho conversions (the direct $P s$ and the two multiples Ppps and Ppss). This modified method gives lower uncertainties than previous studies and shows more regional consistency between nearby stations. The temporary stations and the Brazilian Network (RSBR) have characterized the crustal structure as follows. The Paraná Basin has a thick crust $40-45 \mathrm{~km}$ and average $V p / V s$ ratio (1.71-1.77), while the Chaco Basin has a slightly thinner crust (35-40 km) and higher $V p / V s$ ratio (1.75-1.79). This confirms the lack of widespread magmatic underplating in the Paraná Basin that could be related to the origin of the flood basalts during the South Atlantic opening. A belt of thin crust (30-35 km) with low $V p / V s(<1.74)$ is confined to the eastern edge of the Pantanal Basin. Normal crust $(38-43 \mathrm{~km})$ is observed along the western edge of the Pantanal, from the southern part of the Amazon craton to the Rio Apa cratonic block. This study, combined with other published data, provides an updated crustal thickness map of South America.

\section{Introduction}

Determining the seismic properties of the continental crust is essential in global and regional tectonic studies to decipher and understand the geological evolution of the continents (e.g., Artemieva \& Meissner, 2012), as well as defining velocity models for better monitoring of regional and global seismicity (e.g., Myers et al., 2010). Since the early 1990s many seismic studies have focused on the details of the crust and upper mantle in the Andean region by using mostly receiver functions (RFs), compiled by Chulick et al. (2013) and Assumpção, Feng, et al. (2013). However, most of the stable continent remains poorly sampled.

To overcome the sparse distribution of seismic data and derive crustal thickness maps, previous studies made use of surface wave tomography or gravity data, combined with a few control points with known crustal thickness. Feng et al. (2007) and Lloyd et al. (2010) used joint inversion of surface wave waveforms (with the Partitioned Waveform Inversion of van der Lee \& Nolet, 1997), group-velocity dispersion, and point constraints of crustal thickness from RFs. However, uncertainties of the crustal thickness away from the control points are very large. Assumpção, Feng, et al. (2013) tested the predictions of those two earlier crustal models using newly derived crustal thicknesses and showed that the misfits had standard deviations of 5 and $6 \mathrm{~km}$, respectively, for the stable part of the continent, and 9 and $10 \mathrm{~km}$ when the Andean region is included. Considering that the stable area of South America has a mean crustal thickness of $38 \mathrm{~km}$ and a standard deviation of $5 \mathrm{~km}$, one concludes that the crustal thickness predictions using surface wave tomography inversions are not as accurate as expected and do not provide a gain of information. 
Gravity satellite data (GOCE) have also been used to fill significant gaps in seismic data in South America, as done by Meijde et al. (2013) and Uieda and Barbosa (2017). Besides fitting only wavelengths longer than about $200 \mathrm{~km}$ (so that strong, short-scale lateral variations are smoothed out), both models assume a constant density contrast across the Moho, which may not be a valid assumption. For this reason, misfits between Moho gravity models and observed seismic data have a standard deviation of about $5 \mathrm{~km}$ in the stable part of the continent (Meijde et al., 2013; Uieda \& Barbosa, 2017), similar to the variability of the actual crustal thickness (crustal thickness in the stable part of the continent has a mean value of $\sim 40 \mathrm{~km}$ and a standard deviation of $5 \mathrm{~km}$ ). This means we do not reduce the error in estimating crustal thickness by using gravity data in the stable part of the continent. In fact, it is the misfit between the gravity-derived Moho depth and the seismic data (likely more reliable) that may provide information on anomalous density contrast or dynamic topography. From this discussion, it is clear that information about crustal structure from seismic methods is necessary for any local/regional tectonic study. Gravity modeling and surface wave tomography can only provide a large-scale first order picture.

The most complete crustal thickness map of continental South America was a compilation by Assumpção, Feng, et al. (2013) and Assumpção, Bianchi, et al. (2013) of all published seismological data, roughly the same data set used by CRUST1.0 model of South America (Laske et al., 2013). This map showed the long belt of thin crust $(\sim 35 \mathrm{~km})$ along most of the Sub-Andean region between the thick crust of the Andes (up to 70 $\mathrm{km}$ ) and the average $\sim 40 \mathrm{~km}$ crust of the stable platform further to the east; however, it had poor resolution in the Sub-Andean region due to the lack of seismic data. In that region, gravity-derived estimates (model of Tassara \& Echaurren, 2012) had been used as a first approximation. Meijde et al. (2013) also observed it with gravity satellite data.

To help fill the large gap in the midcontinent, between the highly sampled Andean chain and southeast Brazil, 35 temporary stations were deployed in part of the Chaco-Paraná Basin, the Pantanal Basin, and the western part of the Paraná Basin ("3-Basins" Project funded by FAPESP, Brazil), as shown in Figure 1. Here we determine crustal thicknesses and $V p / V s$ ratios with an improved version (Heit et al., 2014) of the $H-k$ stacking method of Zhu and Kanamori (2000). A narrow N-S zone of thin crust near the Quaternary/Cenozoic Pantanal Basin is now better delimited. A thin crust in the Chaco Basin is confirmed in the present study, although not in a zone as wide as previously thought. We also analyzed all stations of the permanent Brazilian Seismic Network (RSBR), slightly improving the coverage in the Amazon region. An analysis of $V p / V s$ patterns for the various geological provinces is presented. Finally, a compilation of additional published data, both in Brazil and in the Andes, provided an updated version of the crustal thickness map of South America.

\section{Geological Setting}

The stable continental interior of South America (Figure 1) resulted from the Neoproterozoic/Paleozoic amalgamation of several Archean and Early Proterozoic cratonic nuclei, divided into two major domains: the Amazonian and the Atlantic, roughly separated by the Transbrasiliano Lineament (TBL; Figure 1; Almeida et al., 2000; CPRM, 2016). The Amazonian domain (older then than $1700 \mathrm{Ma}$ ) is mainly composed of the Amazon Craton (Guyana Shield, Amazon Basin, and Central Brazil Shield), a postulated cratonic block beneath the Phanerozoic Parnaíba Basin in the north (Cordani et al., 1984) and the Rio Apa block in the south. The Atlantic domain is composed of the Archean São Francisco Craton and a postulated cratonic block beneath the Paraná Basin (Cordani et al., 1984; Zalán et al., 1990), joined by Brasiliano/PanAfrican foldbelts (distributed in the Borborema, Tocantins and Mantiqueira fold belt provinces).

Thick sedimentary cover accumulated in three major intracratonic basins, with subsidence initiated in the Paleozoic: Amazonas, Parnaíba, and Paraná Basins. During their evolution, Jurassic (130 Ma) basaltic magmatism occurred, with extensive continental flood basalts ("Paraná Magmatic Province"), related to the opening of the South Atlantic. Finally, marginal basins have been forming along the coast and the continental shelf since 130 Ma, after the Atlantic rifting (Milani \& Thomaz Filho, 2000).

The Paraná Magmatic Province is one of the world's largest continental flood basalt. Its origin is attributed to the upwelling of hot mantle, which contributed to the breakup of western Gondwana. The exact mechanism for the extrusion of the magma is not known in detail; it could be related to a central source in the middle of the Paraná Basin or multiple sources spread throughout the entire province. Gravity data show a NE-SW 


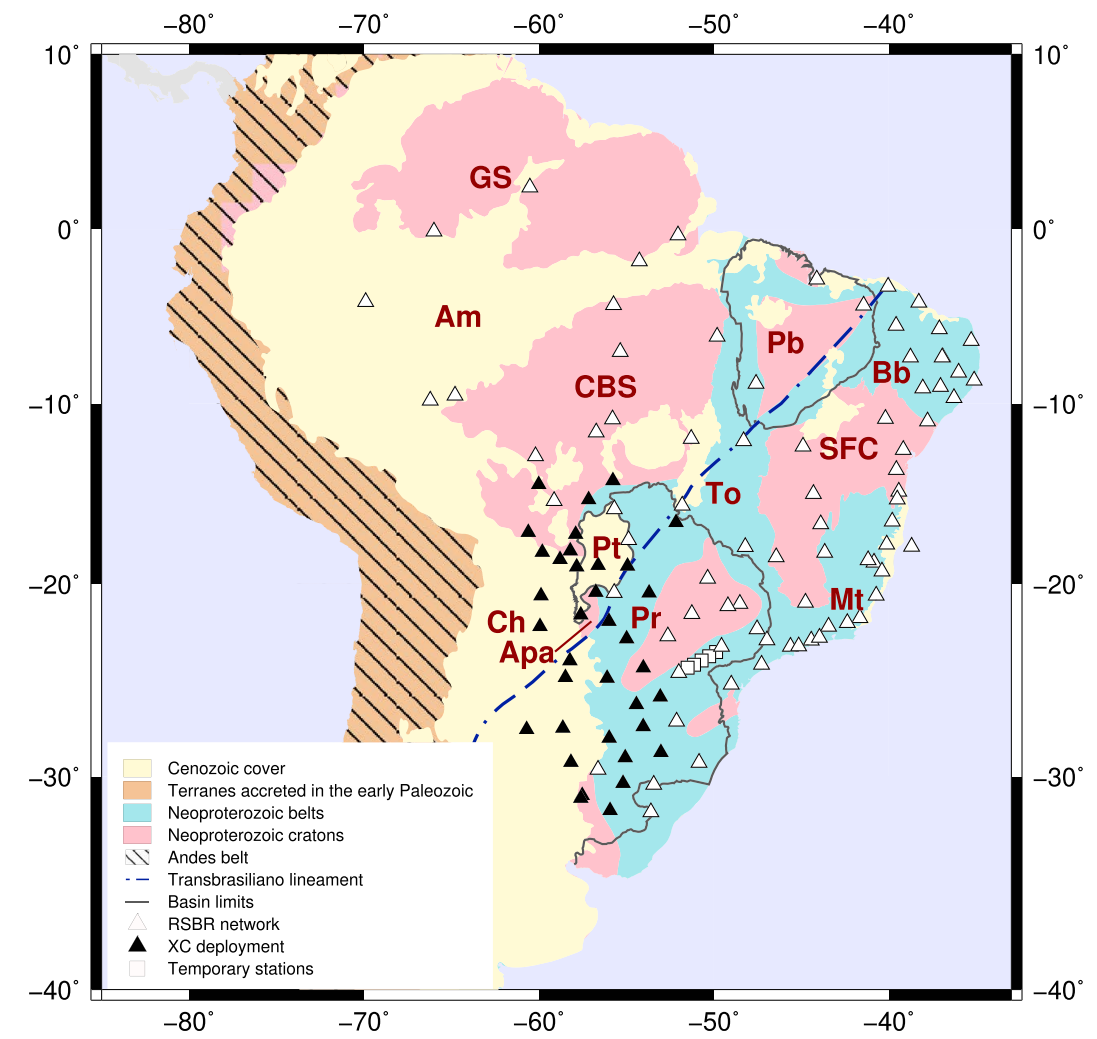

Figure 1. Stations used for receiver function analysis and main geologic provinces. Open triangles are the permanent Brazilian Seismic Network (RSBR), black triangles are the temporary XC network deployment, and squares are other temporary stations. Main geological provinces: Pink = cratons and cratonic blocks beneath basins (GS: Guyana shield, CBS: Central Brazilian shield, SFC: São Francisco craton; and Apa: Rio Apa block). Blue = Neoproterozoic foldbelts (Bb: Borborema Province, To: Tocantins Province, and Mt: Mantiqueira Province). Yellow = Cenozoic covers (Am: Solimões-Amazonas, and Ch: Chaco-Paraná Basins). Gray line delimits large intracratonic basins (Pb: Parnaíba, Pr: Paraná, and Pt: Pantanal). Blue dotted line: Transbrasiliano Lineament. Geology units are taken from CPRM (2016).

trending Bouguer high along the central axis of the Paraná Basin (e.g., Dragone et al., 2017), which had been interpreted as due to magmatic underplating in the lower crust related to the extrusion process. However, attempts to detect an underplated lower crust by seismic methods (An \& Assumpção, 2004, 2006; Julià et al., 2008; Shirzad et al., 2019) have not identified significantly higher velocities beneath the Paraná Basin. Perhaps the high Bouguer anomalies are due to a higher density (and high velocity) lithospheric lid as proposed by Chaves et al. (2016) and Rocha et al. (2018).

Long after the initiation of rifting in the South Atlantic, a Cenozoic reactivation of the South American platform caused a system of continental rifts along the southeast onshore margin (Cogné et al., 2012; Riccomini et al., 2004). One of the most interesting geologic features in our study area is the presently subsiding Pantanal Basin. The origin of the relatively new Pantanal Basin, which is less than $500 \mathrm{~m}$ deep, is still widely debated (Assine et al., 2016) between either a Miocene origin, related to extensional stresses similar to other rift basins in southeast Brasil, or a Quaternary origin, due to long-range extensional flexural stresses from load of the Andean chain (Ussami et al., 1999). Our RF study will provide more information on crustal properties to help better understand these debated issues. For example, gravity modeling, constrained by seismic data could reveal if subsidence is due to dynamic topography or crustal stretching.

\section{Data and Methodology}

We used teleseismic events (distances between $35^{\circ}$ and $90^{\circ}$ and magnitudes $>5.5 \mathrm{mb}$ ) and deep regional events (magnitudes $>4.5 \mathrm{mb}$, depths $>300 \mathrm{~km}$, and distances less than $30^{\circ}$, provided they are outside 


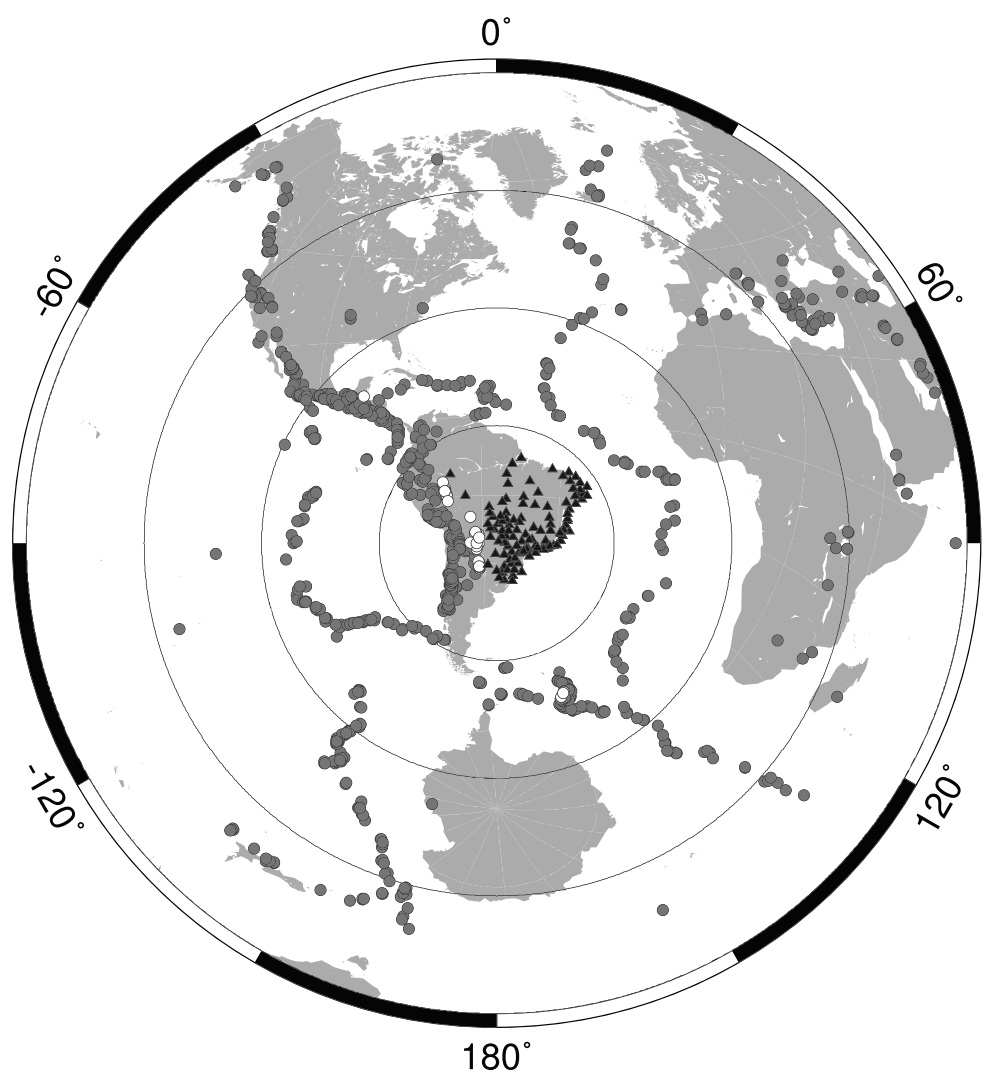

Figure 2. Distribution of events. Gray circles: teleseismic events; White circles: deep events; Black triangles: seismic stations. Concentric circles are distances every $30^{\circ}$.

triplication range). These events were recorded at 93 stations of the Brazilian permanent network, RSBR (Bianchi et al., 2018), from 2010 to 2018, and 35 temporary stations (FDSN registered XC network of the FAPESP “3-Basins Project”) since 2016 (Figure 2).

\subsection{RF}

A widely used method to locate the main discontinuities of the crust and upper mantle is RF (e.g., Owens et al., 1984). The RF is obtained by the deconvolution of the vertical component from the radial (and transverse) component of the seismograms, thus isolating the structural response below the station from the more distant source and upper mantle path effects.

Due to the high-velocity contrast between the crust and upper mantle, usually the $P$ to $S$ wave conversion at the Moho is the largest signal after the direct $P$ wave, as shown in the example of Figure 3. Multiple reflections and conversions, such as Ppps and Ppss (here we refer to the combination of both PpSs + PsPs as simply "Ppss") can also be seen when the crustal structure is not too complex with strong lateral variations. The arrival time of these three phases, knowing the average crustal $P$ or $S$ velocity, gives the crustal thickness $(H)$ and $V p / V s(k)$ ratio beneath the station (Zandt et al., 1995).

As the $P$ waves from teleseismic events arrive with steep incidence at the Moho, the $P$ to $S$ wave conversion point is close to the station (lateral distance of about $20 \mathrm{~km}$ or less) and is less affected by lateral variations in the crustal layers than the multiply reflected waves (Zhu \& Kanamori, 2000). The multiple phases (Ppps and $P p s s)$ travel a longer lateral distance in the crust, thus are more affected by lateral variations and interference from $P$ to $S$ conversions at other intra crustal discontinuities. This means that identifying the reverberated phases in a single RF is more difficult. This problem is usually solved by stacking the amplitudes of the three converted phases in the RFs obtained from many different earthquakes. One of the commonly used stacking 


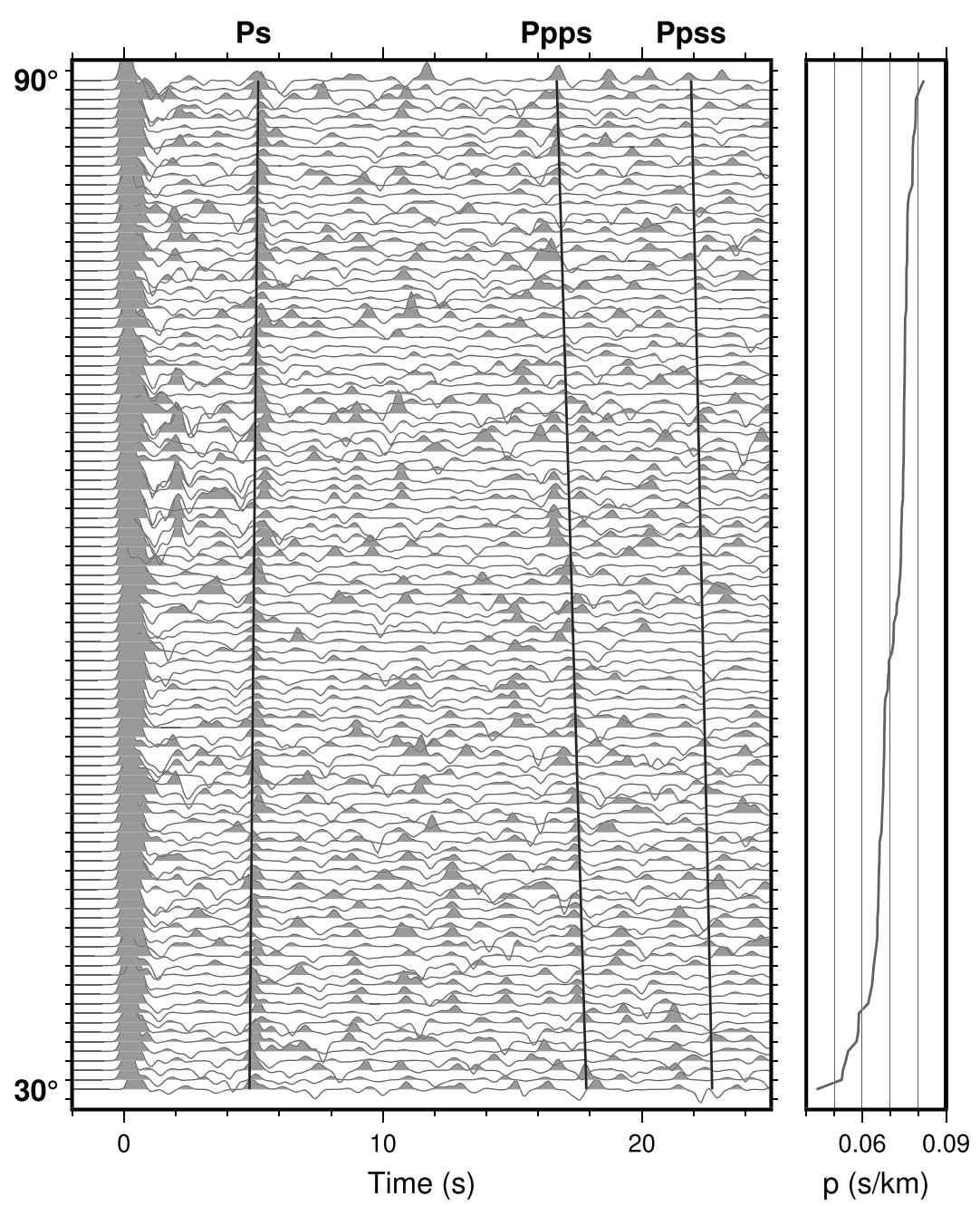

Figure 3. Section of selected receiver functions with gauss 5 for AMBA station, sorted by ray parameter, $p$ (shown in the righthand plot). Main plot black lines indicate the approximate arrival times of the $P s$ conversion (about $5 \mathrm{~s}$ after the direct $P$ ), the first positive multiple (about 17 to $18 \mathrm{~s}$ ), and the second negative multiple (about $22 \mathrm{~s}$ ). Event distances range from $30^{\circ}$ to $90^{\circ}$.

techniques, proposed by Zhu and Kanamori (2000), does a grid search for the best $H$ and $k$ that produce the highest stacked amplitude of the Ps, Ppps, and Ppss phases using equation (1).

$$
s(H, k)=w 1(A 1)+w 2(A 2)-w 3(A 3)
$$

where $A 1, A 2$, and $A 3$ are the sums of RF amplitudes at the expected arrival times of the Ps, Ppps, and Ppss phases, for a given value of $H$ and $k$. The weights $w 1, w 2$, and $w 3$ are chosen according to the quality of the RFs, but typical values are $0.7,0.2$, and 0.1 . The best values of $H$ and $k$ maximize the function $s(H, k)$.

A modified H-k method was proposed by Heit et al. (2014). Instead of summing the three amplitudes of all RFs directly, the traces are first corrected for normal moveout for each of the converted phases and stacked to produce three traces with enhanced Ps, Ppps, and Ppss phases each one, as shown in Figure 4. In this study we corrected all traces to a normal moveout corresponding to a reference slowness ( $p$ parameter) of $6.4 \mathrm{~s} /{ }^{\circ}$, equivalent to an epicentral distance of $66^{\circ}$. The amplitudes of the three stacked traces are then summed to obtain $s(h, k)$ using weights of $0.6,0.2$, and 0.2 for the Moho converted phase $(P s)$ and the other two multiples (Ppps and Ppss), respectively. Initial stacking of normal moveout corrected RFs, focused on each phase, reduces noise and interference from other incoherent arrivals. 

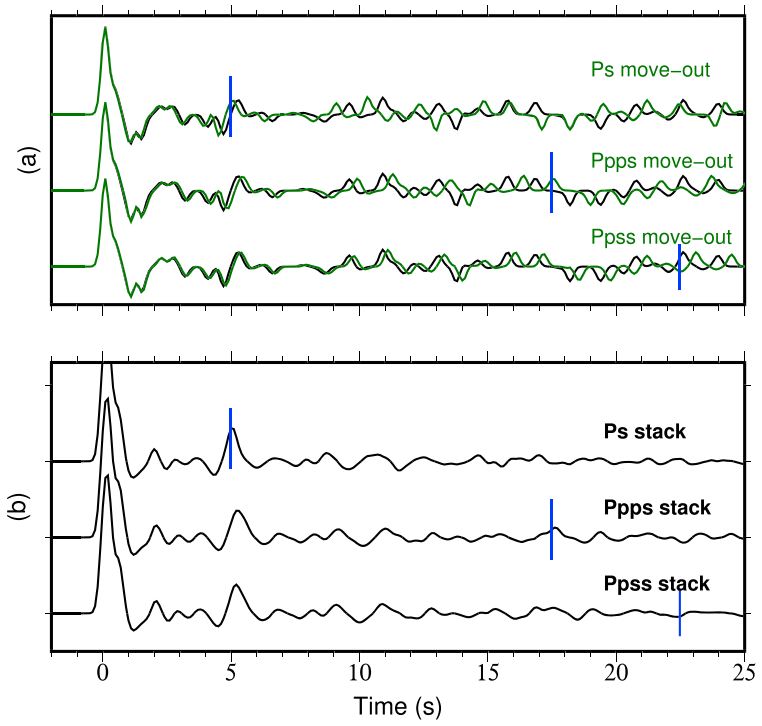

(c)

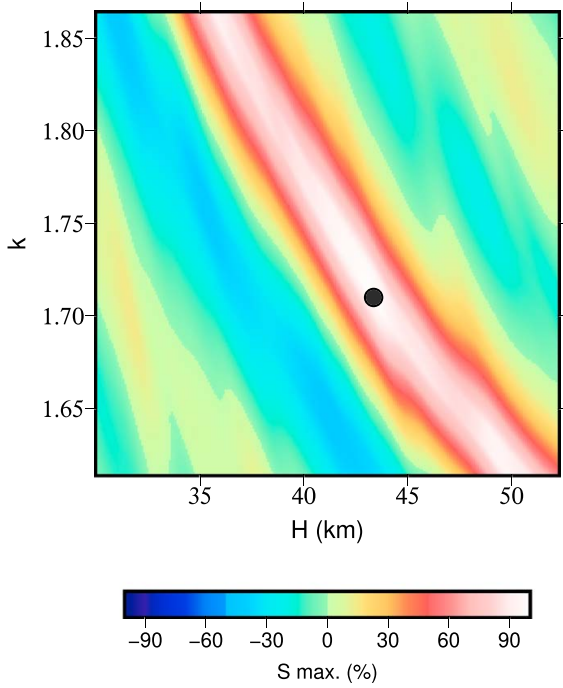

Figure 4. Modified H-k stacking for AMBA station. (a) Moveout of each phase for one event. Black: original trace; green: corrected trace; blue marks: expected arrival time for each phase. (b) Stacked trace of all events after moveout correction for each phase. Blue marks: expected arrival time for each phase.

(c) Modified H-k stacking method using the three traces from (b). Warm colors show the best values of $\mathrm{H}$ and $\mathrm{k}$ for the arrival times marked on (a) and (b). Estimated bootstrap uncertainties have the same value of the circle size.

\subsection{Data Processing}

The $P$ wave trains were windowed $10 \mathrm{~s}$ before and $120 \mathrm{~s}$ after the $P$ wave arrival, detrended, tapered at the edges using a $1 \%$ Hanning window and finally filtered between 0.5 and $4 \mathrm{~Hz}$. Final preprocessed traces were rotated to ZRT components.

RFs were obtained with the time domain deconvolution, of a 40-s window after the $P$ wave arrival, applying the iterative procedure of Ligorría and Ammon (1999) with a Gaussian width parameter of 5 (roughly corresponding to a low-pass filter of $2.5 \mathrm{~Hz}$ ). This Gaussian parameter was used instead of 2.5 because the resulting RFs showed a clearer Ps conversion, especially for stations over thick and soft sediment layers. For each station, one good RF trace was selected, considering that at least the $P$ wave and $P$ s phase were clear, to correlate with all other traces for that station in order to discard unstable and noisy traces. We retained all traces with a correlation higher than $65 \%$ for the first $12 \mathrm{~s}$ after the $P$ wave arrival (Figure 3 ). Teleseismic and deep events were processed in the same way, using the same parameters and procedures.

We used the modified H-k stacking method with an average crustal $V p=6.4 \mathrm{~km} / \mathrm{s}$. To estimate the uncertainties (standard deviations), 200 bootstrap resamplings were done, discarding $30 \%$ of the traces, before the normal moveout correction. We compared the modified H-k method of Heit et al. (2014), with the traditional method (Zhu \& Kanamori, 2000). Figure 5 shows that the results are similar, within the uncertainties of each other. However, the uncertainties of the modified method tend to be lower, both for the crustal thickness and the $V p / V s$ ratio, as shown by the histogram insets in Figure 5. For the crustal thickness, $50 \%$ of the estimates have uncertainties less than $0.61 \mathrm{~km}$ in the modified method, compared with $2.65 \mathrm{~km}$ in the traditional method. Most importantly, uncertainties in $V p / V s$ also are lower using the modified method, more than $50 \%$ have uncertainties $\leq 0.01$, whereas the normal H-k stacking has a median uncertainty of 0.051 .

We also compared our modified H-k results with those of other authors for common RSBR stations (Figure 6). Crustal thicknesses compare well in most cases, within the uncertainties of each estimate, as expected. Especially good agreement is seen for the Borborema Province (Luz et al., 2015a) where the slight bias is probably due to a difference in the average crustal $V p(6.5 \mathrm{~km} / \mathrm{s}$ by Luz et al., 2015a, compared with our $6.4 \mathrm{~km} / \mathrm{s}) . V p / V s$ ratios are generally more scattered and subject to artifacts from interference with other phases, lateral variations, and noise. Interestingly, our $V p / V s$ values rarely fall outside the 1.67-1.80 range. Extreme values $(<1.65$ or $>1.85)$ are not observed with our modified H-k method, which would be difficult to interpret in terms of petrological composition in stable continental crust (Christensen, 1996). 
(a) Crustal Thickness

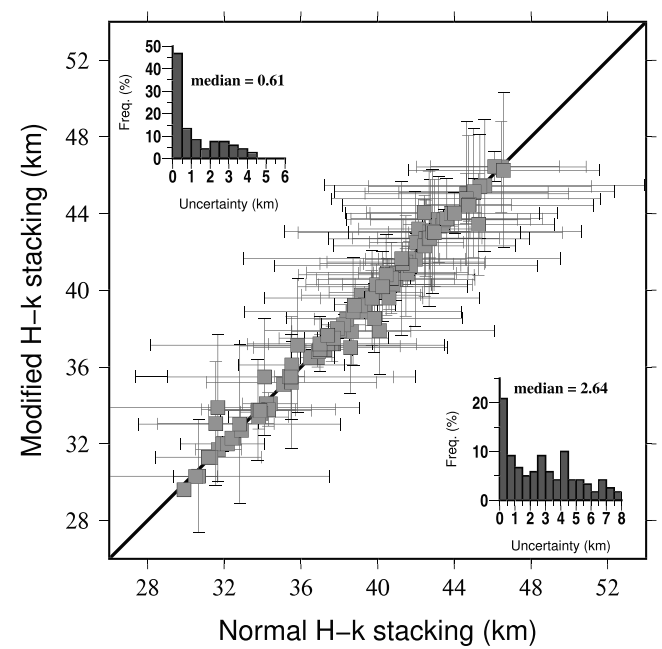

(b) $\mathrm{Vp} / \mathrm{Vs}$ ratio

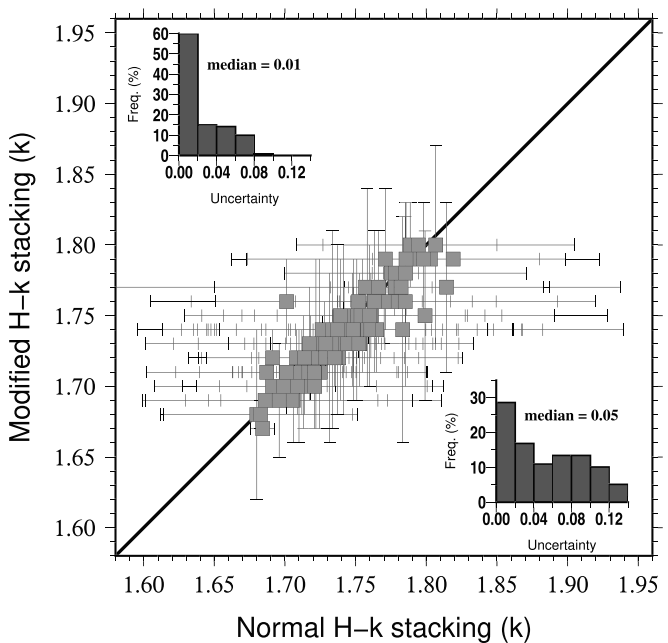

Figure 5. Comparison between normal and modified H-k stacking methods for (a) crustal thickness $\mathrm{H}$ and (b) $V p / V s$ ratio k. Black line is a 1:1 relation. Uncertainty histograms of each method are shown as insets. Median values for the modified method are 4 to 5 times smaller than the normal stacking method.

\section{Results and Discussion}

Crustal thickness $(H)$ and $V p / V s$ ratio $(k)$ estimated with our modified H-k method are shown in Figure 7. Good and regular stations are indicated by circles and rectangles, respectively. Regular stations are those that show more than one peak in the modified $\mathrm{H}-\mathrm{k}$ grid and the $V p / V s$ value was selected to be within limits given by Christensen (1996). The average crustal thickness of all our observations is $39.6 \mathrm{~km}$, similar to the reported average of $38 \mathrm{~km}$ for the stable part of the South American continent (Assumpção, Feng, et al., 2013) and the worldwide average of $40.5 \mathrm{~km}$ for continental platforms (Christensen \& Mooney, 1995).

Some crustal thickness patterns, observed in previous studies (e.g., Assumpção, Bianchi, et al., 2013; Luz et al., 2015a) are confirmed, such as the thick crust (40-45 km) in the northern part of the Paraná Basin, thinned crust along the coastal margin (due to stretching at the continent-ocean transition), and generally thin $(<35 \mathrm{~km})$ crust in the Borborema Province, NE Brazil.

The most interesting new findings, regarding crustal thicknesses, are the following:

a Thin crust is observed only along the eastern edge of the Pantanal Basin ( $\leq 35 \mathrm{~km})$. Previous studies had shown thin crust in this area, but there was no resolution to delimit this narrow N-S crustal thinning.

b Normal to thick crust $(\sim 42 \mathrm{~km})$ just to the west of the Pantanal Basin, from the southern tip of the Amazon Craton to the Rio Apa Block, south of the Pantanal Basin. This is consistent with the continuation of the Amazonian domain down to the Rio Apa block bordering the TBL.

c Normal to thin crust (35-40 km) in Chaco Basin (roughly west of $58^{\circ} \mathrm{W}$ ), significantly different from the Paraná Basin. However, the average thickness in the Chaco Basin is not as low as had been predicted by Assumpção, Feng, et al. (2013), Rosa et al. (2016), Feng et al. (2007), and Lloyd et al. (2010). Feng et al. (2007) and Lloyd et al. (2010) had estimated an average crustal thickness about $30 \mathrm{~km}$, while Assumpção, Feng, et al. (2013) and Rosa et al. (2016) had proposed a crust thinner than $35 \mathrm{~km}$. These previous studies had used mainly surface waves to estimate crustal thicknesses in this region previously devoid of seismic stations.

$V p / V s$ ratios tend to be more scattered and regional patterns are not easily recognized (e.g., Lloyd et al., 2010). However, Figure $7 \mathrm{~b}$ does show interesting patterns as the narrow belt of thin crust along the eastern part of the Pantanal Basin that is characterized by low ratios $(<1.74)$. Slightly higher values $(1.75-1.78)$ are seen in the western part of the basin.

The northern part of the Paraná Basin has variable ratios but mostly within the normal range of 1.71 to 1.77 (average of 1.74). This agrees with previous estimates of Julià et al. (2008) who did not observe any systematically high ratios that could be related to widespread mafic underplating in the lower crust. 
$\mathrm{H}(\mathrm{km})$

(a)

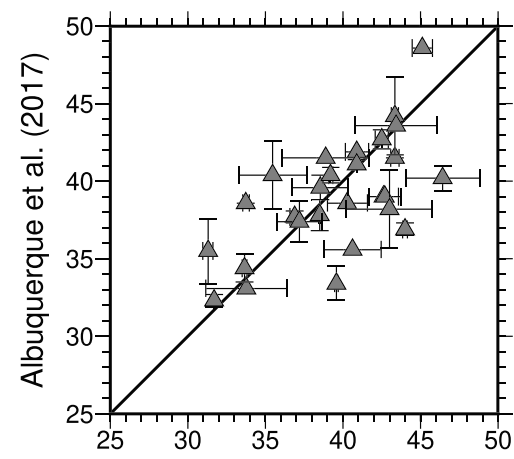

(b)

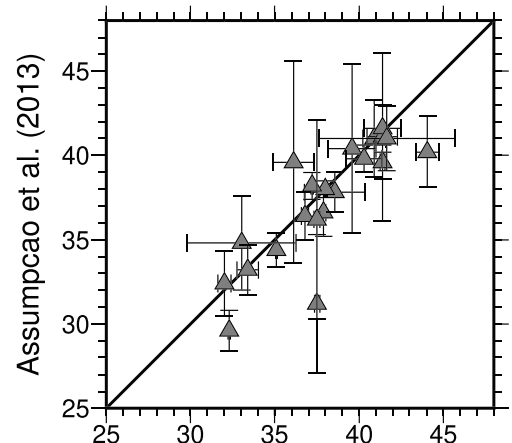

(c)
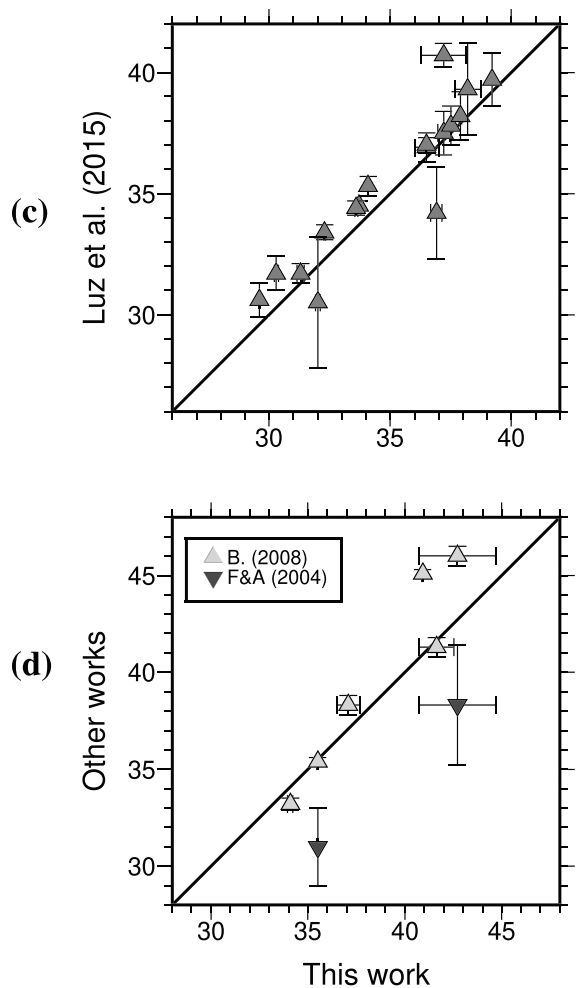
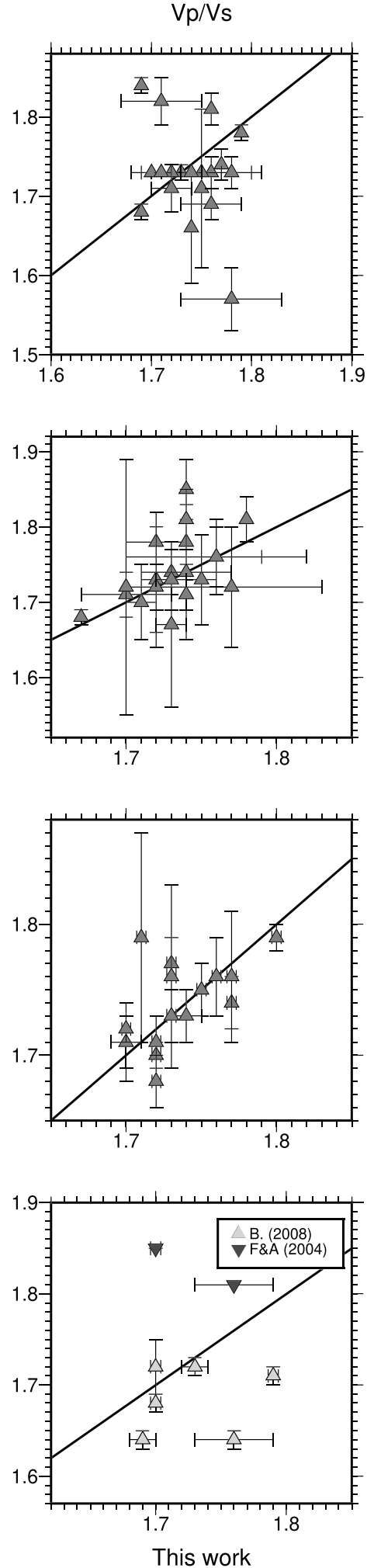

Figure 6. Comparison with other studies at common seismic stations. Crustal thickness $(H)$ is shown in the left column and $V p / V s$ ratio in the right column. (a) Albuquerque et al. (2017) for Amazonian stations. (b) Assumpção, Bianchi, et al. (2013) for Brazil. (c) Luz et al. (2015a) for northeastern Brazil. (d) Bianchi (2008) for all of Brazil, and França and Assumpção (2004) for southeastern Brazil. Black lines show the 1:1 relation. 
(a) Crustal Thickness

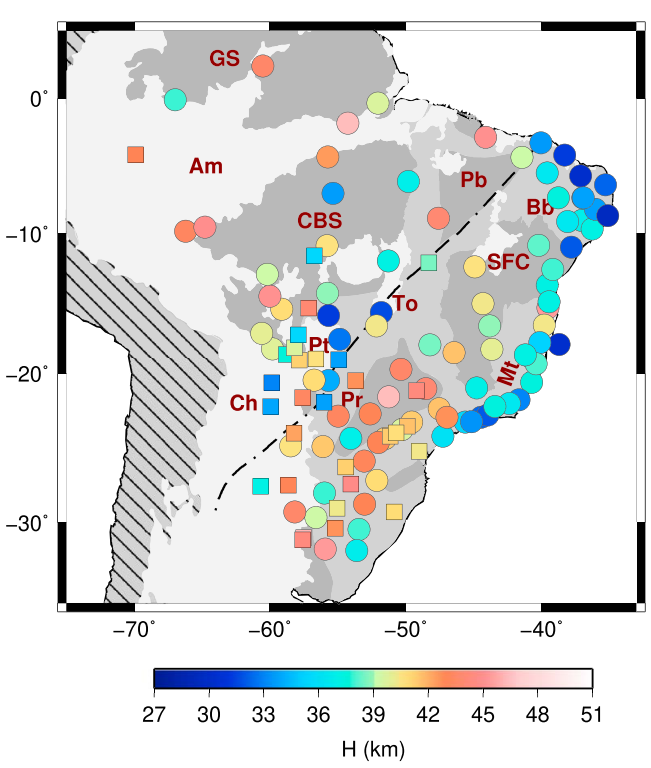

(b) $\mathrm{Vp} / \mathrm{Vs}$ Ratio

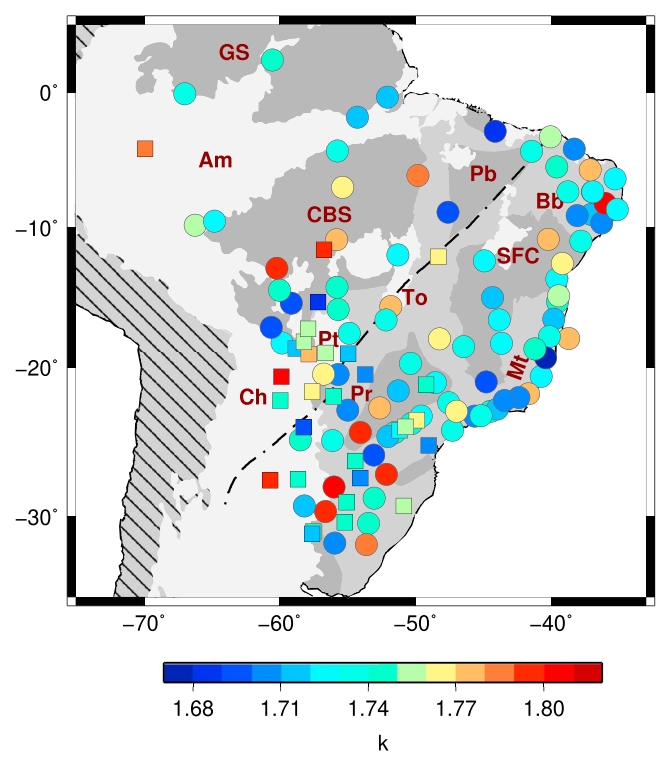

Figure 7. Individual (a) crustal thicknesses and (b) $V p / V s$ ratios obtained with the modified H-k stacking method, using a fixed crustal $V p=6.4 \mathrm{~km} / \mathrm{s}$, for all stations. Circles and squares are good and regular results, respectively. Shaded areas refer to the geological provinces shown in Figure 1.

However, high $k$ values in a few stations show that localized underplating is not ruled out, as pointed out by Julià et al. (2008). A trend of slightly higher ratios is seen in the southern part of the basin toward the ChacoParaná Basin.

Finally, low to normal values are seen in the southern part of the Amazon Craton (older than $1.7 \mathrm{Ga}$ ), similar to most of the São Francisco Craton (older than $2.0 \mathrm{Ga}$ ), with an average of 1.71 (indicative of a felsic bulk crustal composition; Christensen, 1996). This would agree with the early models of Durrheim and Mooney $(1991,1994)$ for the evolution of the Archean and Proterozoic continental crust. However, other cratonic areas seem to have different pattern of $V p / V s$ ratios, such as a trend of higher $V p / V s$ ratios that seems to characterize the rest of the Central Brazil Shield in the Amazon Craton $(k>1.75)$, but the few available stations are not enough to establish a regional pattern.

\subsection{Using Crustal Average Vs From ANT}

The results of the H-k method, shown above, were obtained using a fixed average crustal velocity of $V p=6.4$ $\mathrm{km} / \mathrm{s}$ (close to the worldwide average for continental platforms; Christensen \& Mooney, 1995). For the region of the XC temporary deployment (Chaco, Pantanal, and Paraná Basins), $S$ wave velocities have been mapped by inverting Rayleigh and Love wave dispersion curves in the period range 4 to $80 \mathrm{~s}$ obtained with ambient noise tomography (ANT; Shirzad et al., 2019). We have made a second estimate of crustal thickness and $V p / V s$ ratio in the area of our project, with the H-k stacking method, using the average crustal $S$ wave velocity obtained under each station, instead of using a fixed $P$ wave velocity. The average crustal $V s$ was obtained using a preliminary map of crustal thicknesses.

Results, for both $H$ and $k$, are consistent with those obtained with fixed $P$ wave velocity, as shown in Figures $8 \mathrm{a}$ and $8 \mathrm{~b}$. Maps with these results are shown in Figure S1 of the supporting information. Crustal thicknesses using the $S$ velocity from ANT tend to be slightly larger (by $\sim 1 \mathrm{~km}$ ) than using the standard $6.4 \mathrm{~km} / \mathrm{s}$, which may be due to a slight bias in estimating crustal velocities from smoothed inversions of surface wave dispersion. Uncertainties are slightly larger for the $k$ value when $S$ wave velocity is used, due to the H-k stacking method being more sensitive to $S$ wave than $P$ wave velocity variations (Figures $8 \mathrm{a}$ and $8 \mathrm{~b}$ ).

Despite the slightly larger uncertainties, the $H$ and $k$ results should be more accurate when using the locally determined $S$ wave velocities. The main characteristics of crustal thickness are maintained in the Pantanal Basin. In the east there is a very distinct thin crust $(\leq 35 \mathrm{~km})$ and low $V p / V s(<1.74)$, while in the west the crust is thicker $(40-45 \mathrm{~km})$ and has higher $V p / V s(1.75-1.78)$, as seen in Figure $S 1$. In the Chaco Basin the 
(a) $\mathrm{H}(\mathrm{km})$

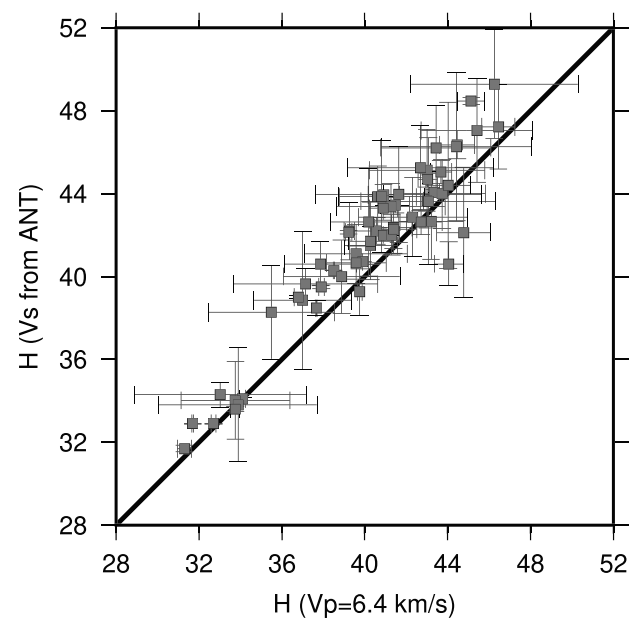

(b) $\mathrm{Vp} / \mathrm{Vs}$

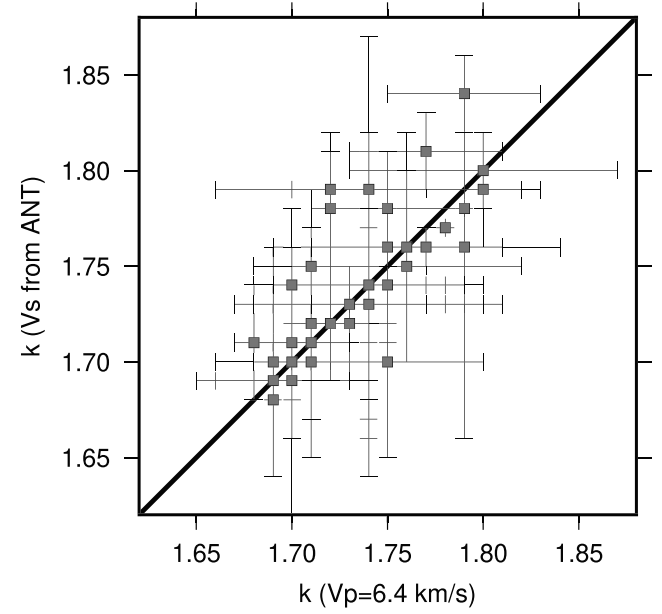

(c) $\mathrm{H}(\mathrm{km})$

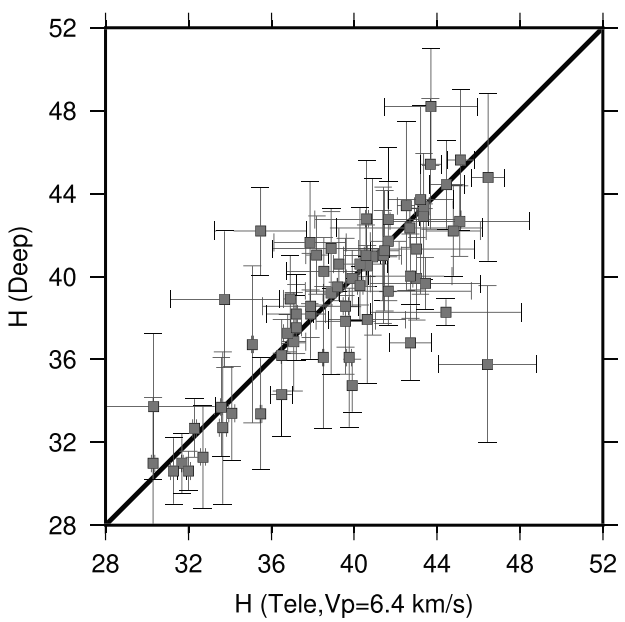

(d) $\mathrm{Vp} / \mathrm{Vs}$

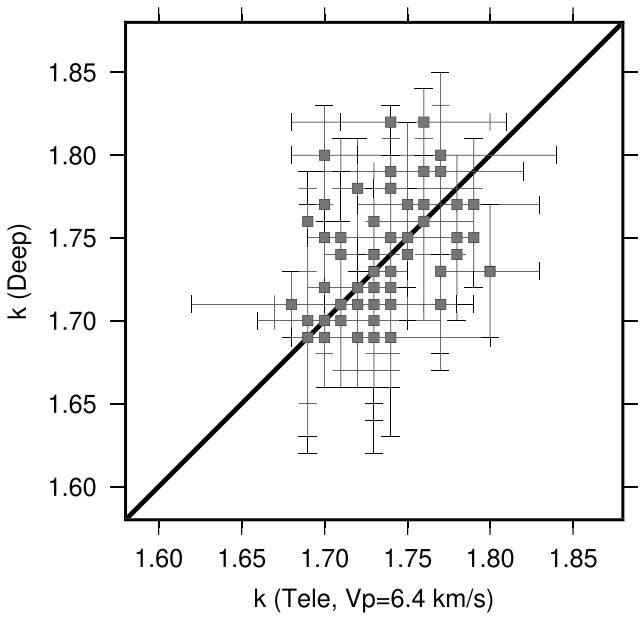

Figure 8. Comparison of crustal thickness $(H)$ and $V p / V s$ ratio $(k)$ using teleseismic events and fixed crustal $V p=6.4 \mathrm{~km} / \mathrm{s}$ (horizontal axes) with the values using crustal $V s$ obtained from ambient noise tomography, $\operatorname{ANT}(\mathrm{a}, \mathrm{b})$, and the values using regional deep earthquakes (c, d).

average crust is $38 \mathrm{~km}$ thick as in the previous use of a fixed $V p$ (Figure 7a). In the Paraná Basin a thicker crust is seen in the center, thinning toward the border with the Tocantins Province. Crustal thicknesses at the southern part of the Amazonian Craton (west of the Pantanal Basin) present large variations but has the same average value of $40-44 \mathrm{~km}$ thick.

\subsection{Deep Earthquakes}

Some stations of the XC temporary deployment in the Chaco and Pantanal Basins were installed in areas with soft sediments due to the lack of hard rock outcrop. These stations tend to be noisy. Additionally, reverberations in the low-velocity surface layers make it more difficult to identify the Ps conversion and even more so the converted multiples.

To increase the data set and get more robust $H$ and $k$ averages, we also analyzed regional deep Andean events (distances $<30^{\circ}$, depth $>300 \mathrm{~km}$ ) recorded at the temporary stations and some of the permanent RSBR stations. These deep regional events have a higher-frequency content and arrive with compatible incidence angles when compared with teleseismic events. Figures 8c and 8d compare the $H$ and $k$ results using these deep events with those of the teleseismic data. There is a general agreement in crustal thickness within the uncertainties across all stations. Uncertainties from the deep events tend to be slightly larger, partly due to 
the smaller number of deep events occurred during the deployment. Values of $V p / V s$ are more scattered, even using the same modified H-k method. Again, $V p / V s$ from the few deep events tend to have larger uncertainties compared with the teleseismic data set. Despite the larger uncertainties, the maps of crustal thickness and $\mathrm{k}$ values show similar patterns (Figure $\mathrm{S} 1$ ), a thin crust with low $\mathrm{Vp} / \mathrm{Vs}$ at the eastern border of the Pantanal Basin and a thicker crust in the center and northern part of the Paraná Basin thinning toward the southeast. At the São Francisco Craton and Mantiqueira Province the results with both kinds of data are similar. The region that presents the largest discrepancy is the southwestern part of the Amazon Craton where differences up to $6 \mathrm{~km}$ were found in some stations. We used deep, regional events as additional information to complement and confirm the results from stations with poor resolution from teleseismic data and not as an independent estimate.

\subsection{Updated Crustal Thickness Map of South America}

The last model of crustal thickness of South America was the compilation of Assumpção, Feng, et al. (2013), which had large areas poorly sampled such as most of the Sub-Andean region and the Amazon Craton. Our results with the temporary XC deployment fills an important data gap in the central region of the South American continent and also improves the coverage in the Amazon region. In this updated model, our results were included with the following criteria: (a) preference for thicknesses derived from the local $S$ wave velocity; (b) for stations with larger uncertainties, we used the average of the result from teleseismic and deep events if they were consistent; (c) when possible, we cross-checked our crustal thickness estimates with those obtained from preliminary $S$ velocity models developed from the joint inversion of RFs and SW dispersion by Cedraz et al. (2018) to confirm our results for stations with poor records.

Besides the data analyzed in this study, other published results were included such as (a) the Moho models from active experiments in the Parnaíba Basin, northern Brazil (Daly et al., 2014; Soares et al., 2018), and the continental shelf in southern Brazil (Evain et al., 2015), (b) crustal thicknesses from RF studies in the Parnaíba Basin and Boborema Province (Coelho et al., 2018; Julià et al., 2018; Trindade et al., 2014), and (c) new RF results from the Andes in Bolivia, Peru, and Colombia (Condori et al., 2017; Poveda et al., 2015; Ryan et al., 2016). Stations with good results from Albuquerque et al. (2017) in the Amazon region were also included.

The 2013 crustal thickness map had 937 seismic data points and the present version has 1,564 points. Some stations have duplicated measurements since different authors processed them with different parameters. The previous 2013 map had 933 different measurement points and the present version has 1,443 different points, a $\sim 55 \%$ increase.

We followed the same procedure as Assumpção, Feng, et al. (2013) and used some gravity-derived crustal thicknesses to fill in large areas devoid of seismic data. This was especially important in the oceanic areas near the continent to make the transition across the continental shelf more realistic. In the sub-Andean region we used the model of Tassara and Echaurren (2012), which was constrained by seismic data in the Andes. In Ecuador, where few seismically determined crustal thicknesses have been published, we used the gravity-derived models of Araujo (2013) and Font et al. (2013). Gravity-derived crustal thicknesses were used only for points more than $70 \mathrm{~km}$ away from other seismic data. The map with all previous and new data points can be seen in Figure S2. The supporting information shows how to retrieve all data points and the final grid file shown in Figure 9.

The updated crustal thickness model for South America (Figure 9) contains three new features on a continental scale when compared with the 2013 version. First, we find a long N-S belt of normal to thick crust (>40 km) from the central Amazon Craton to the southern section of the Paraná Basin. Second, there is a belt of thin crust ( 35 to $40 \mathrm{~km}$ ) along the low-altitude Sub-Andean region, which is narrower than the previous version. Third, the eastern section of the Amazon Craton (the oldest section, according to Tassinari \& Macambira, 1999) appears to have a thin crust (35 to $40 \mathrm{~km}$ ), although more data need to be collected in this region for a definite conclusion.

An interesting observation is the confirmation of normal crust (average of about $40 \mathrm{~km}$ ) in the intracratonic Parnaíba Basin, compared with the thick crust (40-45 km) of the Paraná Basin, especially in the inferred cratonic nucleus (as shown in Figure 1). In the Parnaíba Basin thick crust is found only near its western and southern border probably related to the Neoproterozoic fold belts. Both basins had very similar evolution 


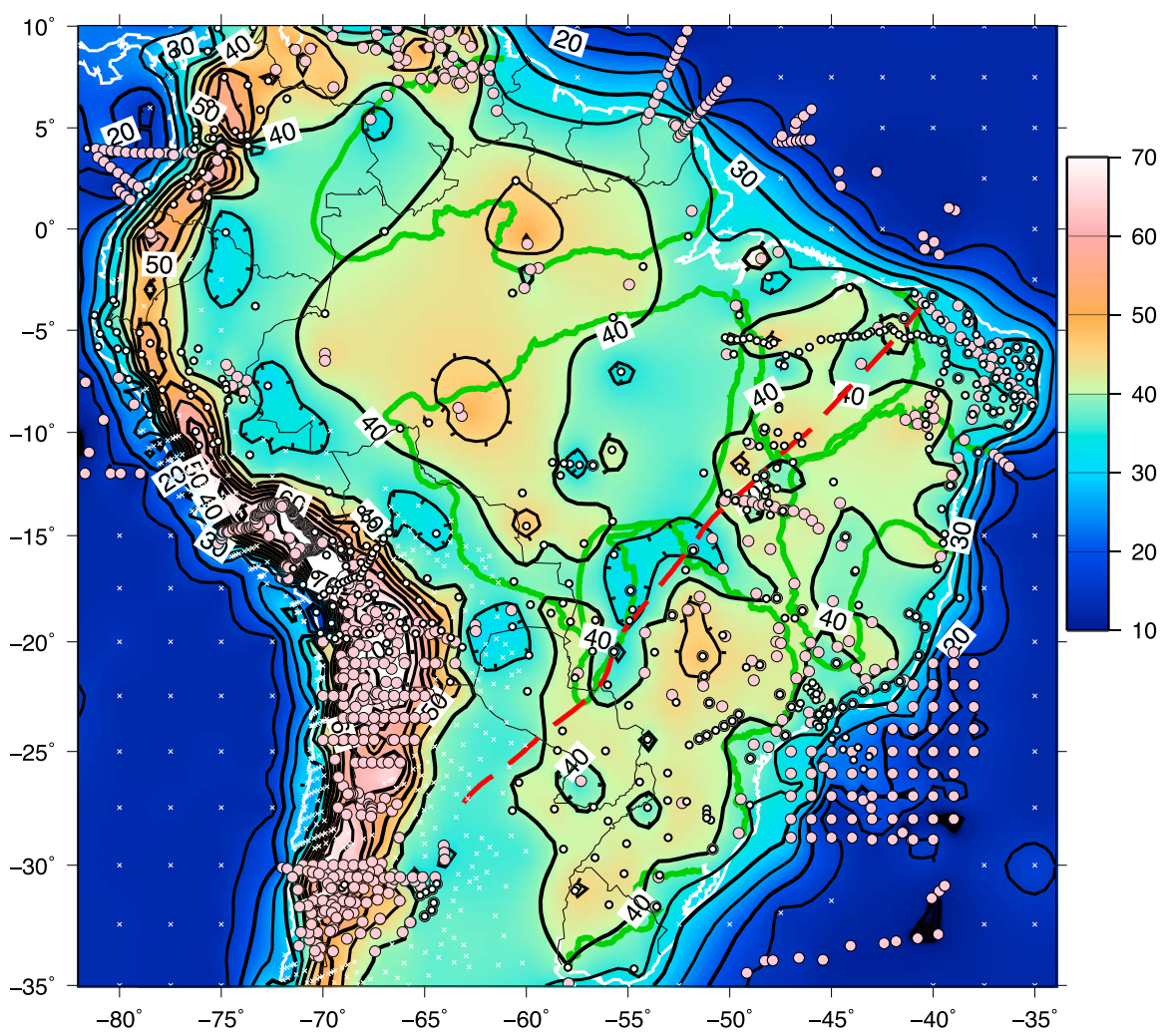

Figure 9. Updated crustal thickness map of northern and central South America. Red circles are previous data compiled by Assumpção, Feng, et al. (2013); white circles are the updated data processed in this study (XC and RSBR networks), as shown in Figure 1. Also included additional data published in other studies [see the supporting information for references].

with the first subsidence stage in the Paleozoic, and both had a significant magmatic event in the Mesozoic, producing large volumes of flood basalts. This difference in crustal thickness may be compensated by differences in the upper mantle, such as a thick lithospheric lid beneath the Paraná Basin with high velocities (Feng et al., 2007; Schaeffer \& Lebedev, 2013; Rocha et al., 2018) and high density (Chaves et al., 2016), whereas beneath the Parnaíba Basin high Pn velocities were found only along a small 400- to 500-km section in its center (Soares et al., 2018). This may imply that the cratonic block beneath the Parnaíba Basin is smaller and thinner compared with that of the Paraná Basin in the south. Interestingly, the crustal thickness in the Paraná Basin follows the elevated Moho expected in the Ponta Grossa and Rio Grande Arches $\left(25^{\circ} \mathrm{S}\right.$ and $31^{\circ} \mathrm{S}$, respectively, shown in Figure 1).

The TBL (Figure 1), a deep continental-scale feature (e.g., Fairhead \& Maus, 2003; CPRM, 2016) with continuation in Africa, is thought to divide the two major cratonic domains in South America: Amazonian to the NW and Atlantic domain to the SE (Figure 1). However, the crustal thickness map (Figure 9) does not show a sharp systematic difference across the TBL, except perhaps by a series of patches of thinner crust.

Regarding the Pantanal Basin, the thin crust inferred in the previous model is now restricted to a narrow NS belt along the eastern margin of the Basin and continuing southward between the Rio Apa block (part of the Amazonian domain) and the cratonic Paranapanema block beneath the Paraná Basin (part of the Atlantic domain). This implies that the thin crust in the central part of South America is not directly related to the origin of the Pantanal Basin but is just a result of the Gondwana amalgamation.

In the stable continental region (mainly Brazil) the average crustal thickness is $39.6 \mathrm{~km}$, with a standard deviation of $5 \mathrm{~km}$, close to the value of $38 \mathrm{~km}$ estimated previously (Assumpção, Bianchi, et al., 2013). These values are slightly lower than the global average of $41.5 \mathrm{~km}$ compiled by Christensen and Mooney (1995) for stable areas, but within the expected variability. 


\section{Conclusions}

A large temporary seismic study in southwest Brazil, including parts of Bolivia, Paraguay, northeast Argentina, and Uruguay, has provided valuable RF data in a previously unsampled region of South America. An improved H-k stacking technique was used to map crustal thicknesses and $V p / V s$ ratios, producing more consistent regional results.

In the northern part of the thick (40-45 km) Paraná Basin, with a large magmatic province of Early Cretaceous flood basalts, $V p / V s$ ratios are in the normal range (1.71-1.77) and do not imply significant widespread mafic underplating related to the flood basalt event. A few stations with higher $V p / V s$ ratios, however, do not exclude isolated areas with underplating, as found by Julià et al. (2008). The Chaco Basin and southern part of the Paraná Basin tend to have a normal thickness $(\sim 38 \mathrm{~km})$ and slightly higher $V p / V s$. The crust of the two basins seems to be systematically different, on average.

The active Pantanal Basin is characterized in the east by a thin crust (30-35 km), with felsic bulk composition $(V p / V s<1.74)$, and in the west by thick crust $(40-45 \mathrm{~km})$ with a high $V p / V s(1.75-1.78)$. West of the Pantanal Basin, the southern part of the Amazon Craton has a normal crustal thickness (40-42 km) with felsic composition $(V p / V s<1.73)$. Seismic stations in the Chaco Basin (northeastern Argentina and northern Paraguay) were noisy due to local soft sediments. Despite poor quality recordings at these local soft sediments, our preliminary results indicate that this region has normal crustal thickness. This makes the zone of thin crust along the Sub-Andean region narrower than previously indicated on past versions of the South America crustal thickness map.

The improved resolution of the updated map of crustal thickness in South America is useful for future regional studies of seismic wave propagation, crustal gravity modeling, and inferences on crustal evolution.

\section{Data and Resources}

The temporary deployment (XC stations) was part of the "3-Basins" Project funded by FAPESP, Brazil (Grant 2013/24215-6). The data are still restricted to the project participants, but the metadata is available at the www.sismo.iag.usp.br/mda/XC website. The data from the permanent Brazilian network (RSBR) are open and can be accessed via IRIS (www.iris.edu/mda/, last accessed on 29 March 2019) under the networks BL, BR, NB and ON or from www.rsbr.gov.br (last accessed on 29 March 2019). More details can be found in Bianchi et al. (2018). The publications used to compile recent results from the literature, since the previous compilation of 2013, are from Argentina (Ammirati et al., 2013; Perarnau et al., 2012), Brazil (Albuquerque et al., 2017; Assumpção et al., 2015; Berrocal et al., 2004; Coelho et al., 2018; Daly et al., 2014; Evain et al., 2015; Julià et al., 2018; Luz et al., 2015a; Luz et al., 2015b; Moreira, 2013; Soares et al., 2018; Trindade et al., 2014), Colombia (Monsalve et al., 2013; Poveda et al., 2015), Ecuador (Araujo, 2013; Font et al., 2013), Peru (Condori et al., 2017; James \& Snoke, 1994; Ryan et al., 2016), and Patagonia (Buffoni et al., 2019; Rodríguez \& Russo, 2016) and can be found in the supporting information. The database is available in the Zenodo platform (https://doi.org/10.5281/zenodo.2604359).

\section{References}

Albuquerque, D. F., França, G. S., Moreira, L. P., Assumpção, M., Bianchi, M., Barros, L. V., et al. (2017). Crustal structure of the Amazonian Craton and adjacent provinces in Brazil. Journal of South American Earth Sciences, 79, 431-442. https://doi.org/10.1016/j. jsames.2017.08.019

Almeida, F. F. M., de Brito Neves, B. B., \& Carneiro, C. D. R. (2000). The origin and evolution of the South American Platform. EarthScience Reviews, 50(1-2), 77-111. https://doi.org/10.1016/S0012-8252(99)00072-0

Ammirati, J.-B., Alvarado, P., Perarnau, M., Saez, M., \& Monsalvo, G. (2013). Crustal structure of the central Precordillera of San Juan, Argentina (31oS) using teleseismic receiver functions. Journal of South American Earth Sciences, 46, 100-109. https://doi.org/10.1016/j. jsames.2013.05.007

An, M., \& Assumpção, M. (2004). Multi-objective inversion of surface waves and receiver functions by competent genetic algorithm applied to the crustal structure of the Paraná Basin, SE Brazil. Geophysical Research Letters, 31, L05615. https://doi.org/10.1029/2003GL019179

An, M., \& Assumpção, M. (2006). Crustal and upper mantle structure in the intracratonic Paraná Basin, SE Brazil, from surface wave dispersion using genetic algorithm. Journal of South American Earth Sciences, 21(3), 173-184. https://doi.org/10.1016/j. jsames.2006.03.001

Araujo, S. (2013). The Ecuadorian Moho. La Granja (Univ. Salesiana Politecnica, Ecuador), 18(2), 43-47. ISSN: 1390-3799

Artemieva, I. M., \& Meissner, R. (2012). Crustal thickness controlled by plate tectonics: A review of crust-mantle interaction processes illustrated by European examples. Tectonophysics, 530-531, 18-49. https://doi.org/10.1016/j.tecto.2011.12.037

Assine, M. L., Merino, E. R., Pupim, F. N., Warren, L. V., Guerreiro, R. L., \& McGlue, M. M. (2016). Geology and geomorphology of the Pantanal Basin. In I. Biergie, \& M. L. Assine (Eds.), Dynamics of the Pantanal Wetlands (Chap. 2, pp. 23 -50). Springer. 
Assumpção, M., M. Bianchi, D.F. Albuquerque, G.S.L. França, and L.V. Barros, 2015. Crustal thickness map in South America: An updated version. 1st Symposium of Brazilian Seismology, University of Brasilia, DF, Brazil, abstract.

Assumpção, M., Bianchi, M. B., Julià, J., Dias, F. L., França, G. S., Nascimento, R. M., et al. (2013). Crustal thickness map of Brazil: Data compilation and main features. Journal of South American Earth Sciences, 43, 74-85. https://doi.org/10.1016/j.jsames.2012.12.009

Assumpção, M., Feng, M., Tassara, A., \& Julià, J. (2013). Models of crustal thickness for South America from seismic refraction, receiver functions and surface wave dispersion. Tectonophysics, 609, 82-96. https://doi.org/10.1016/j.tecto.2012.11.014

Berrocal, J., Marangoni, Y., Sá, N. C., Fuck, R., Soares, J. E. P., Dantas, E., et al. (2004). Deep seismic refraction and gravity crustal model and tectonic deformation in Tocantins Province, Central Brazil. Tectonophysics, 388(1-4), 187-199. https://doi.org/10.1016/j. tecto.2004.04.033

Bianchi, M. (2008). Variações da estrutura da crosta, litosfera e manto para a plataforma Sul Americana através de funções de receptor para ondas P e S. (PhD thesis), Universidade de São Paulo. https://doi.org/10.11606/T.14.2008.tde-22092008-121708

Bianchi, M. B., Assumpção, M., Rocha, M. P., Carvalho, J. M., Azevedo, P. A., Fontes, S. L., et al. (2018). The Brazilian Seismographic Network (RSBR): Improving seismic monitoring in Brazil. Seismological Research Letters, 89(2A), 452-457. https://doi.org/10.1785/ 0220170227

Buffoni, C., Schimmel, M., Sabbione, N. C., Rosa, M. L., \& Connon, G. (2019). Crustal structure beneath Tierra del Fuego, Argentina, inferred from seismic P-wave receiver functions and ambient noise autocorrelations. Tectonophysics, 751, 41-53. https://doi.org/ 10.1016/j.tecto.2018.12.013

Cedraz, V., J. Julià, M. Assumpção (2018), Crustal structure of the Pantanl Basin from joint inversion of receiver functions with Rayleighwave dispersion. 49th Brazilian Geol. Congr., Rio de Janeiro, Abstract.

Chaves, C., Ussami, N., \& Jeroen, R. (2016). Density and P-wave velocity structure beneath the Paraná Magmatic Province: Refertilization of an ancient lithospheric mantle. Geochemistry Geophysics Geosystems, 17, 3054-3074. https://doi.org/10.1002/2016GC006369

Christensen, N. I. (1996). Poisson's ratio and crustal seismology. Journal of Geophysical Research, 101(B2), 3139-3156. https://doi.org/ $10.1029 / 95 \mathrm{jb} 03446$

Christensen, N. I., \& Mooney, W. D. (1995). Seismic velocity structure and composition of the continental crust: A global view. Journal of Geophysical Research, 100(B6), 9761-9788. https://doi.org/10.1029/95jb00259

Chulick, G. S., Detweiler, S., \& Mooney, W. D. (2013). Seismic structure of the crust and uppermost mantle of South America and surrounding oceanic basins. Journal of South American Earth Scienci, 42, 260-276. https://doi.org/10.1016/j.jsames.2012.06.002

Coelho, D. L. O., Julià, J., Tribaldos, V. R., \& White, N. (2018). Deep crustal architecture of the Parnaiba basin of NE Brazil from receiver function analysis: Implications for basin subsidence, Geological Society of London, Special Publ., Lyell Collection, (Vol. 472). https://doi. org/10.1144/SP472.8

Cogné, N., Gallagher, K., Cobbold, P. R., Riccomini, C., \& Gautheron, C. (2012). Post-breakup tectonics in southeast Brazil from thermochronological data and combined inverse-forward thermal history modeling. Journal of Geophysical Research, 117, B11413. https://doi. org/10.1029/2012JB009340

Condori, C., França, G. S., Tavera, H. J., Albuquerque, D. F., Bishop, B. T., \& Beck, S. L. (2017). Crustal structure of north Peru from analysis of teleseismic receiver functions. Journal of South American Earth Sciences, 76, 11-24. https://doi.org/10.1016/j.jsames.2017.02.006

Cordani, U., Neves, B., Fuck, R., Porto, R., Thomaz Filho, A. \& Cunha. F. (1984). Estudo preliminar de integração do pré-cambriano com os eventos tectônicos das bacias sedimentares brasileiras. Petrobras.

CPRM (2016). Tectonic map of South America, 2nd edition, scale 1:5,000,000. Commission for the Geological Map of the World, published by CPRM (Brazilian Geological Survey)

Daly, M. C., Andrade, V., Barousse, C. A., Costa, R., McDowell, K., Piggott, N., \& Poole, A. J. (2014). Brasiliano crustal structure and the tectonic setting of the Parnaíba basin of NE Brazil: Results of a deep seismic reflection profile. Tectonics, 33, 2102-2120. https://doi.org/ $10.1002 / 2014 \mathrm{TC} 003632$

Dragone, G., Ussami, N., Gimenez, M., Lince, F., \& Chaves, C. (2017). Western Paraná suture/shear zone and the limits of Rio Apa, Rio Tebicuary and Rio de la Plata cratons from gravity data. Precambrian Research, 291, 162-177. https://doi.org/10.1016/j. precamres.2017.01.029

Durrheim, R. J., \& Mooney, W. D. (1991). Archean and Proterozoic crustal evolution: Evidence from crustal seismology. Geology, 19(6), 606-609. https://doi.org/10.1130/0091-7613(1991)019<0606:AAPCEE >2.3.CO;2

Durrheim, R. J., \& Mooney, W. D. (1994). Evolution of the Precambrain lithosphere: Seismological and geochemical constraints. Journal of Geophysical Research, 99(B8), 15,359-15,374. https://doi.org/10.1029/94JB00138

Evain, M., Afilhado, A., Rigoti, C., Loureiro, A., Alves, D., Klingelhoefer, F., et al. (2015). Deep structure of the Santos Basin-São Paulo Plateau System, SE Brazil. Journal of Geophysical Research: Solid Earth, 120, 5401-5431. https://doi.org/10.1002/2014JB011561

Fairhead, J. D., \& Maus, S. (2003). CHAMP satellite and terrestrial magnetic data help define the tectonic model for South America and resolve the lingering problem of the pre-break-up fit of the South Atlantic Ocean. The Leading Edge, 22(8), 779-783. https://doi.org/ $10.1190 / 1.1605081$

Feng, M., Van der Lee, S., \& Assumpção, M. (2007). Upper mantle structure of South America from joint inversion of waveforms and fundamental-mode group velocities of Rayleigh waves. Journal of Geophysical Research, 112, B04312. https://doi.org/10.1029/ 2006JB004449

Font, Y., Segovia, M., Vaca, S., \& Theunissen, T. (2013). Seismicity patterns along the Ecuadorian subduction zone: new constraints from earthquake location in a 3-D a priori velocity model. Geophysical Journal International, 193(1), 263-286. https://doi.org/10.1093/gji/ ggs083

França, G., \& Assumpção, M. (2004). Crustal structure of the Ribeira fold belt, SE Brazil, derived from receiver functions. Journal of South American Earth Sciences, 16(8), 743-758. https://doi.org/10.1016/j.jsames.2003.12.002

Heit, B., Bianchi, M., Yuan, X., Kay, S., Sandvol, E., Kumar, P., et al. (2014). Structure of the crust and the lithosphere beneath the southern Puna plateau from teleseismic receiver functions. Earth and Planetary Science Letters, 385, 1-11. https://doi.org/10.1016/j. epsl.2013.10.017

James, D. E., \& Snoke, J. A. (1994). Structure and tectonics in the region of flat subduction beneath central Peru: Crust and uppermost mantle. Journal of Geophysical Research, 99(B4), 6899-6912. https://doi.org/10.1029/93JB03112

Julià, J., Assumpção, M., \& Rocha, M. P. (2008). Deep crustal structure of the Paraná Basin from receiver functions and Rayleigh-wave dispersion: Evidence for a fragmented cratonic root. Journal of Geophysical Research, 113, B08318. https://doi.org/10.1029/ 2007jb005374

Julià, J.; Garcia, X. ; Nemocon, A. M., 2018. The Borborema Deep Electromagnetic and Seismic (BODES) experiment: Investigating basin inversion under Araripe. In: 49 Congresso Brasileiro de Geologia, 2018, Rio de Janeiro. Extended Abstract. 
Laske, G., Masters, G., Ma, Z. \& Pasyanos, M., 2013. Update on CRUST1.0-1-degree global model of Earth's crust, in EGU General Assembly Conference Abstracts, vol. 15, pp. EGU2013- 2658.

Ligorría, J., \& Ammon, C. (1999). Iterative deconvolution and receiver function estimation. Bulletin of the seismological society of America, 89(5), 1395-1400

Lloyd, S., van der Lee, S., França, G. S., Assumpção, M., \& Feng, M. (2010). Moho map of South America from receiver functions and surface waves. Journal of Geophysical Research, 115, B11315. https://doi.org/10.1029/2009JB006829

Luz, R., Julià, J., \& Nascimento, A. (2015a). Bulk crustal properties of the Borborema Province, NE Brazil, from P-wave receiver functions: Implications for models of intraplate Cenozoic uplift. Tectonophysics, 644-645(B6), 81-91. https://doi.org/10.1016/j.tecto.2014.12.017

Luz, R. M. N., Julià, J., \& Nascimento, A. F. (2015b). Crustal structure of the eastern Borborema Province, NE Brazil, from the joint inversion of receiver functions and surface wave dispersion: Implications for plateau uplift. Journal of Geophysical Research: Solid Earth, 120, 3848-3869. https://doi.org/10.1002/2015JB011872

Meijde, M., Julià, J., \& Assumpção, M. (2013). Gravity derived Moho for South America. Tectonophysics, 609, 456-467. https://doi.org/ 10.1016/j.tecto.2013.03.023

Milani, E. J., \& Thomaz Filho, A. (2000). Sedimentary basins of South America. In U. G. Cordani, E. J. Milani, A. Thomaz Filho, \& C. D. de Almeida (Eds.), Tectonic evolution of South American, 31st International Geological Congress, Rio de Janeiro, (pp. 389-449). Brazil.

Monsalve, H., Pacheco, J. F., Vargas, C. A., \& Morales, Y. A. (2013). Crustal velocity structure beneath the western Andes of Colombian using receiver-function inversion. Journal of South American Earth Sciences, 48, 106-122. https://doi.org/10.1016/j.jsames.2013.09.001

Moreira, L.D., 2013. Application of high-frequency receiver functions in seismographic stations in southern Brazil (in Portuguese). B.Sc. monograph, IAG-USP, São Paulo, Brazil, 2013, 60pp.

Myers, S. C., Begnaud, M. L., Ballard, S., Pasyanos, M. E., Phillips, W. S., Ramirez, A. L., et al. (2010). A crust and upper-mantle model of Eurasia and North Africa for Pn travel-time calculation. Bulletin of the seismological society of America, 100(2), 640-656. https://doi.org/ $10.1785 / 0120090198$

Owens, T. J., Zandt, G., \& Taylor, S. R. (1984). Seismic evidence for an ancient rift beneath the Cumberland Plateau, Tennessee: A detailed analysis of broadband teleseismic P waveforms. Journal of Geophysical Research, 89(B9), 7783-7795. https://doi.org/10.1029/ jb089ib09p07783

Perarnau, M., Gilbert, H., Alvarado, P., Martino, R., \& Anderson, M. (2012). Crustal structure of the Eastern Sierras Pampeanas of Argentina using high frequency local receiver functions. Tectonophysics, 580, 208-217. https://doi.org/10.1016/j.tecto.2012.09.021

Poveda, E., Monsalve, G., \& Vargas, C. A. (2015). Receiver functions and crustal structure of the northwestern Andean region Colombia. Journal of Geophysical Research: Solid Earth, 120, 2408-2425. https://doi.org/10.1002/2014JB011304

Riccomini, C., Sant'Anna, L. G., \& Ferrari, A. L. (2004). Evolução geológica do Rift Continental do Sudeste do Brasil. In V. Mantesso Neto, et al. (Eds.), Geologia do Continente Sul-Americano: Evolução da Obra de Fernando Flávio Marques de Almeida, (pp. 383-405). São Paulo, Brazil: Edições Beca.

Rocha, M.P.,Fuck, R.A., Assumpção, M., Azevedo, P.A., Affonso, G.M.P.C., Costa, I.S.L. \& Albuquerque D.F. (2018), Lithosphere expression of the boundary between the Amazonian and extra-Amazonian domains of the South American Platform from travel-time seismic tomography. AGU Fall Meeting, Abstract.

Rodríguez, E.E., \& R.M. Russo, 2016. Crustal thickness and structure in southern Chile: Patagonia plate assembly structures and continental arc modifications. AGU Fall Meeting, Abstract

Rosa, M. L., Collaço, B., Assumpção, M., Sabbione, N., \& Sánchez, G. (2016). Thin crust beneath the Chaco-Paraná Basin by surface-wave tomography. Journal of South American Earth Sciences, 66, 1-14. https://doi.org/10.1016/j.jsames.2015.11.010

Ryan, J., Beck, S., Zandt, G., Wagner, L., Minaya, E., \& Tavera, H. (2016). Central Andean crustal structure from receiver function analysis Tectonophysics, 682, 120-133. https://doi.org/10.1016/j.tecto.2016.04.048

Schaeffer, A. J., \& Lebedev, S. (2013). Global shear speed structure of the upper mantle and transition zone. Geophysical Journal International, 194(1). https://doi.org/10.1093/gii/ggt095

Shirzad, T., Assumpção, M., Bianchi, M., \& Collaço, B. (2019). Crustal structure using ambientseismic noise in west-central Brazil. In Bianchi, M., Assumpção, M. \& Chaves, C. (Orgs.), Reports from the 3rd Brazilian Seismology Symposium (78 pp.), Vinhedo, SP: IAG-USP. ISBN: 978-85-85047-21-4. https://doi.org/10.5281/zenodo.2656790

Soares, J. E., Stephenson, R., Fuck, R. A., De Lima, M. V., De Araújo, V. C., Lima, F. T., et al. (2018). Structure of the crust and upper mantle beneath the Parnaíba Basin, Brazil, from wide-angle reflection-refraction data. In M. C. Daly, R. A. Fuck, J. Julià, D. I. M. Macdonald, \& A. B. Watts (Eds.), Cratonic basin formation: A case study of the Parnaiba Basin of Brazil, Special Publications, (Vol. 472, pp. 67-82). London: Geological Society. https://doi.org/10.1144/SP472.9

Tassara, A., \& Echaurren, A. (2012). Anatomy of the Andean subduction zone: Three- dimensional density model upgraded and compared against global-scale models. Geophysical Journal International, 189(1), 161-168. https://doi.org/10.1111/j.1365-246X.2012.05397.x

Tassinari, C. C. G., \& Macambira, M. J. B. (1999). Geochronological provinces of the Amazonian Craton. Episodes, 22(3), 174-182.

Trindade, C. R., Soares, J. E., Fuck, R. A., Carmelo, A. C., \& Peixoto, C. L. O. (2014). Estrutura Crustal do Brasil Central. Laboratório Nacional de Energia e Geologia. Porto, Portugal. Comunicações Geológicas, Especial I, 101, 339-343.

Uieda, L., \& Barbosa, V. C. (2017). Fast nonlinear gravity inversion in spherical coordinates with application to the South American Moho. Geophysical Journal International, 208(1), 162-176. https://doi.org/10.1093/gji/ggw390

Ussami, N., Shiraiwa, S., \& Dominguez, J. (1999). Basement reactivation in a sub-Andean foreland flexural bulge: The Pantanal wetland, SW Brazil. Tectonics, 18(1), 25-39. https://doi.org/10.1029/1998TC900004

van der Lee, S., \& Nolet, G. (1997). Upper mantle S-velocity structure of North America. Journal of Geophysical Research, 102, 22,815-22,838. https://doi.org/10.1029/97jb0116

Wessel, P., \& Smith, W. H. F. (1998). New, improved version of generic mapping tools released. Eos, Transactions American Geophysical Union, 79(47), 579-579. https://doi.org/10.1029/98eo00426

Wessel, P., Smith, W. H. F., Scharroo, R., Luis, J., \& Wobbe, F. (2013). Generic Mapping Tools: Improved version released. Eos, Transactions American Geophysical Union, 94(45), 409-410. https://doi.org/10.1002/2013eo450001

Zalán, P., Wolfs, S., Conceição, J., Marques, A., Astolfi, M., Vieira, I., et al. (1990). Bacia do Paraná. Origem e evolução das bacias sedimentares, Petrobras, 135-168.

Zandt, G., Myers, S. C., \& Wallace, T. C. (1995). Crust and mantle structure across the Basin and Range-Colorado Plateau boundary at $37^{\circ} \mathrm{N}$ latitude and implications for Cenozoic extensional mechanism. Journal of Geophysical Research, 100(B6), 10,529-10,548. https://doi.org/ $10.1029 / 94 \mathrm{jb} 03063$

Zhu, L., \& Kanamori, H. (2000). Moho depth variation in southern California from teleseismic receiver functions. Journal of Geophysical Research, 105(B2), 2969-2980. https://doi.org/10.1029/1999jb900322 


\section{Journal of Geophysical Research: Solid Earth}

\section{Supplementary material}

\section{An updated crustal thickness map of central South America based on}

receiver function measurements in the region of the Chaco, Pantanal and Paraná Basins, southwestern Brazil

Carolina Rivadeneyra-Vera ${ }^{1}$, Marcelo B. Bianchi1, Marcelo Assumpção ${ }^{1}$,

Victoria Cedraz², Jordi Julià², Martin Rodríguez ${ }^{3}$, Leda Sánchez ${ }^{3}$, Gerardo Sánchez ${ }^{4}$, Luciana LopezMurua $^{4}$, Gonzalo Fernandez ${ }^{5}$, Rafael Fugarazzo ${ }^{6}$ and the "3-Basins" Project Team

${ }^{1}$ Dept. of Geophysics; Institute of Astronomy, Geophysics and Atmospheric Sciences; University of São Paulo; São Paulo, SP, 05508-090, Brazil.

${ }^{2}$ Dept. of Geophysics; Federal University of Rio Grande do Norte; Natal, RN, 84000, Brazil

${ }^{3}$ University of La República; Montevideo, Uruguay

${ }^{4}$ INPRES; San Juan, Argentina

${ }^{5}$ San Calixto Observatory; La Paz, Bolivia

${ }^{6}$ National University of Asunción; Asunción, Paraguay

We first compare the results of crustal thickness and $\mathrm{Vp} / \mathrm{Vs}$ ratios using different assumptions and data sets (Figure S1). We then describe the final database of crustal thicknesses used to update the South American map. 
(a) Crustal Thickness (Tele)

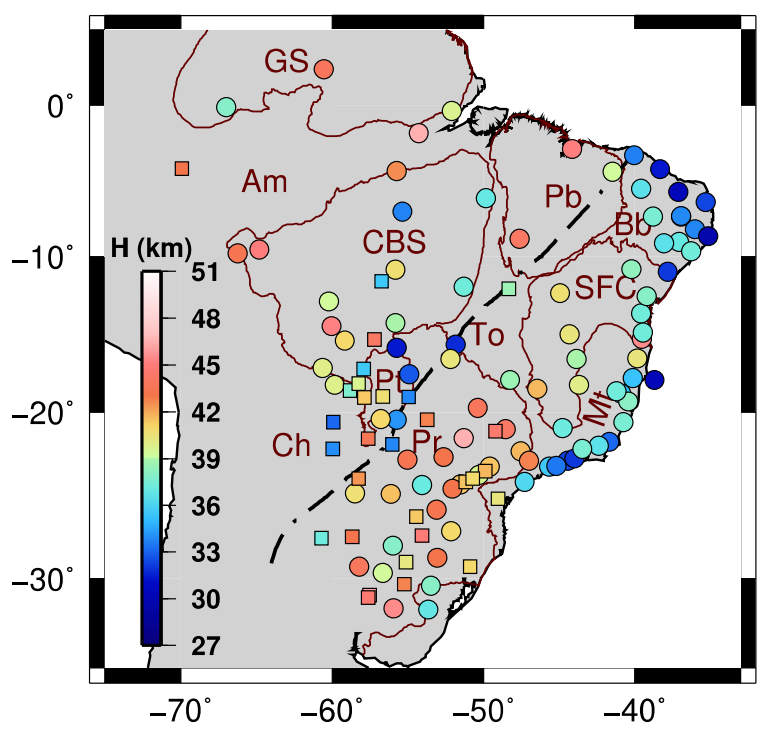

(c) Crustal Thickness (Deep)

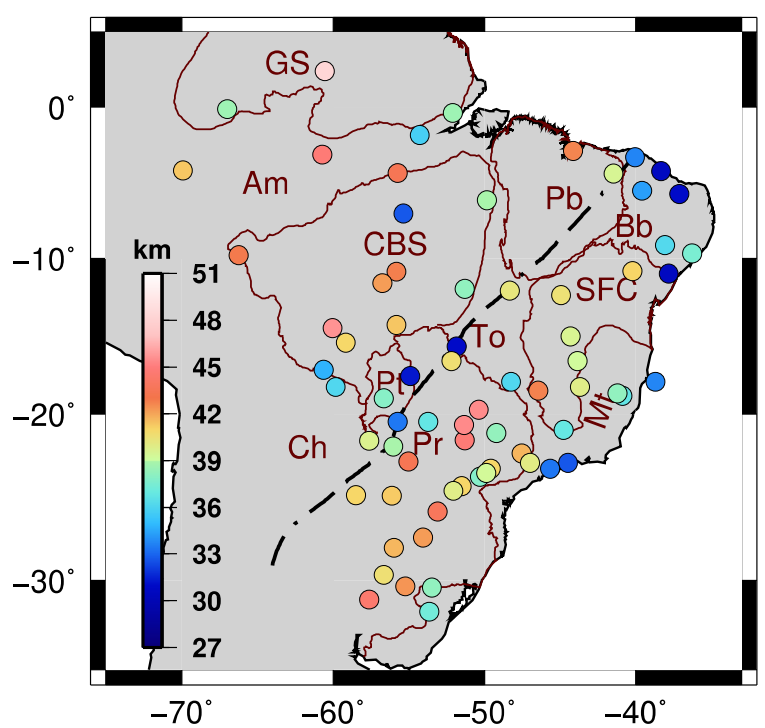

(e) Crustal Thickness (ANT)

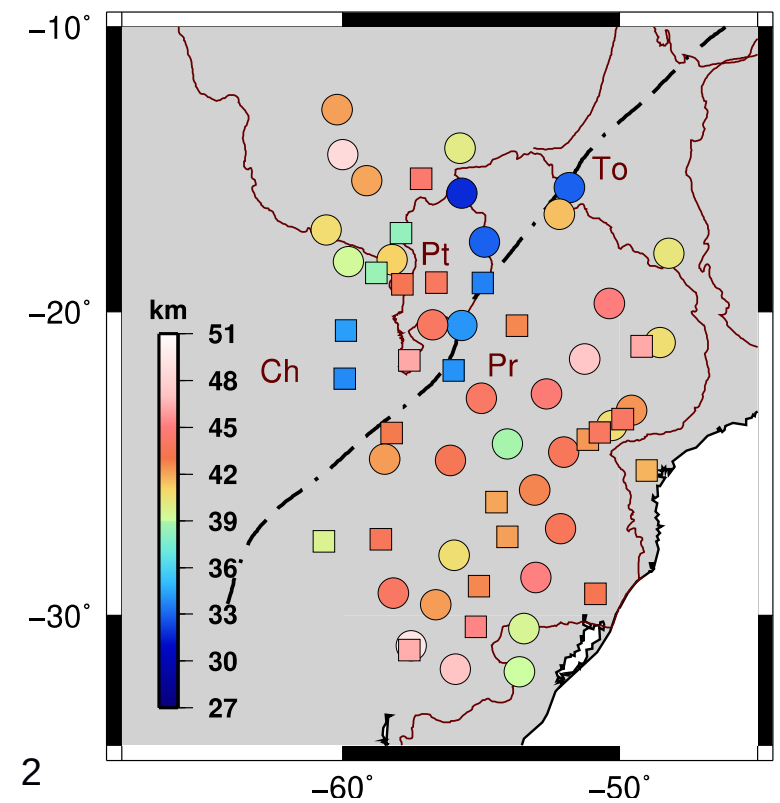

(b) $\mathrm{Vp} / \mathrm{Vs}$ Ratio (Tele)

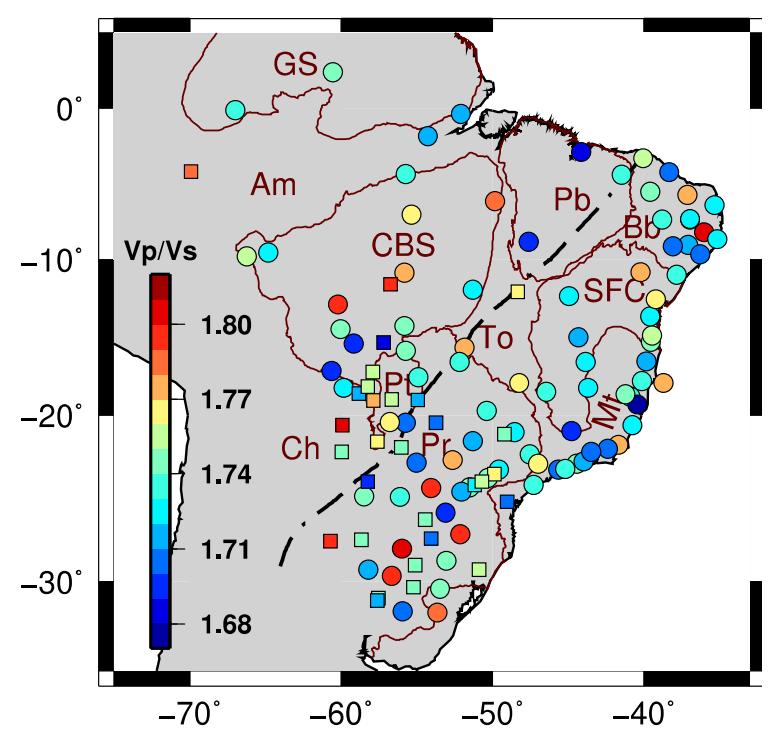

(d) Vp/Vs Ratio (Deep)

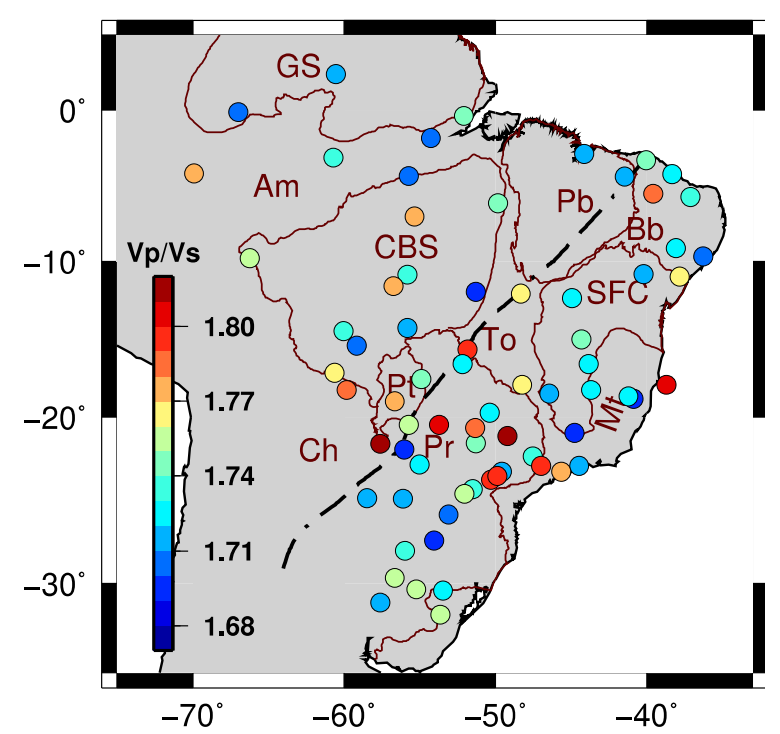

(f) $\mathrm{Vp} / \mathrm{Vs}$ Ratio (ANT)

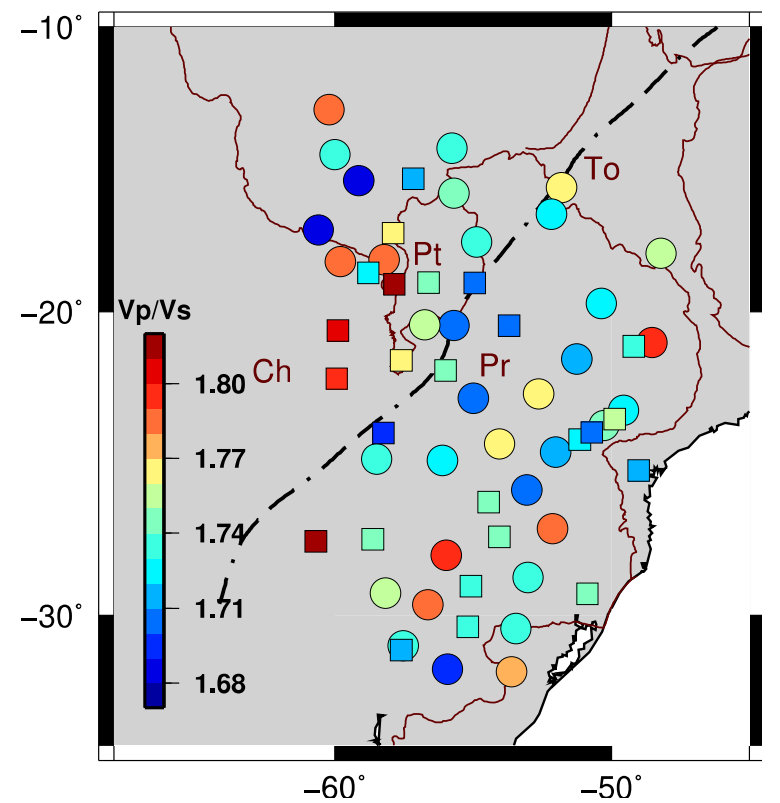


Figure S1: Crustal thickness (left column) and Vp/VS ratio (right column) for: $a, b)$ teleseismic events using a fixed crustal $V p=6.4 \mathrm{~km} / \mathrm{s}$. c,d) regional deep events with a fixed crustal $V p=6.4 \mathrm{~km} / \mathrm{s}$, $e, f)$ values obtained with the average crustal S-wave velocity given by the Ambient Noise Tomography of (Shirzad et al., 2019). Dashed line is the Transbrasiliano Lineament.

We now describe the database of crustal thicknesses used to update the previous Moho map of South America (Assumpção et al., 2013a,b). All data files can be downloaded from Zenodo platform: https://doi.org/10.5281/zenodo.2604359. Figure S2 shows all the data points used for this 2019 version.

The text files have columns named as I, X, Y, E, H, U:

$\mathrm{I}$ = point ID, usually the station name

$\mathrm{X}, \mathrm{Y}=$ longitude and latitude

$E=$ elevation (meters) above mean sea level.

$\mathrm{H}=$ Crustal Thickness $(\mathrm{km})$ - this includes the topography, i.e., $\mathrm{H}=$ depth to Moho + elevation

$\mathrm{U}=$ uncertainty estimate of $\mathrm{H}$, based on a) standard deviation from measurements of different authors, b) uncertainty from $\mathrm{H}-\mathrm{k}$ stacking, or c) ad-hoc estimate when not given in the original publication.

Other columns are comments (such as $\mathrm{Vp} / \mathrm{Vs}$ ratio, average crustal $\mathrm{Vp}$, when available) and reference.

Compilation_SAm2013.IXYEHU_ref_v2019Mar23.dat = 936 points used in the 2013 version (Assumpção et al., 2013a and Assumpção et al., 2013b). References are given in the 2013 publications. A couple of errors in the 2013 database were corrected.

Compilation_SAm2013-2018.IXYEHUku_ref_v2019Mar24.dat $=488$ points compiled from published literature in the last few years. References are given at the end of this Supplementary Material. Some stations are common to the previous compilation. RivadeneyraVera_etal_JGR2019Mar24.IXYEHU.dat $=124$ crustal thicknesses obtained in the present paper, mainly from the Brazilian network (RSBR) as well as the temporary deployment in central South America (XC network). At column 9 is specified from what type of data we obtained $\mathrm{H}$ and $\mathrm{k}$ :

$\mathrm{T}$ : Teleseismic data with a fixed $\mathrm{Vp}$

D: Deep, regional data with a fixed $V p$

Vs: We used Vs instead of Vp

Compilation_SAm2018_2019.IXYEHUku_ref_v2019Mar23.dat $=8$ new points, mostly unpublished, preliminary results. 
The distribution of the data points is shown in Figure S2 below.

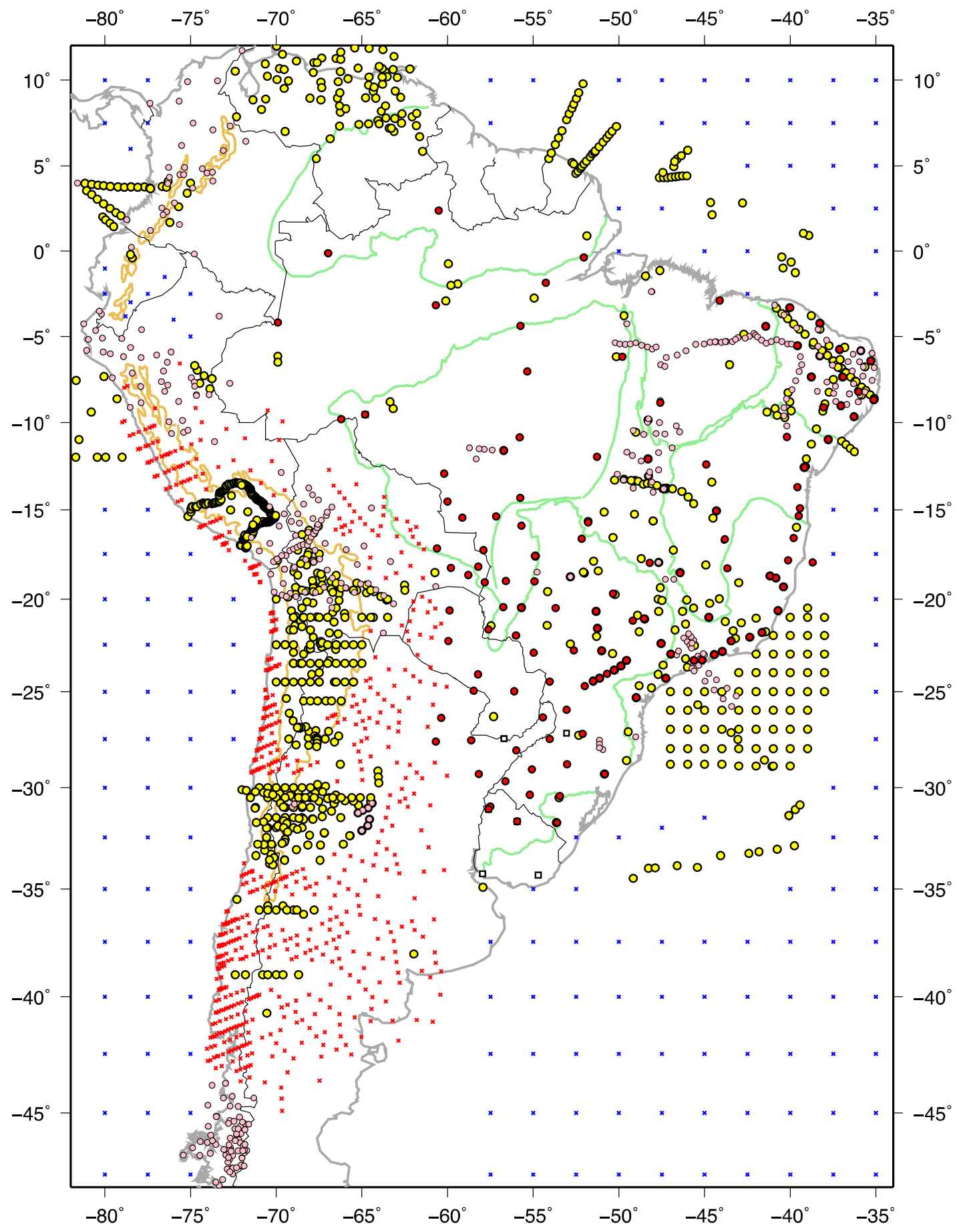


Figure S2: Distribution of crustal thickness measurements. Yellow dots = previous compilation of 2013 (file Compilation_SAm2013.IXYEHU_ref_v2019Mar23.dat above); pink dots = compilation from the literature (file Compilation_SAm2013-2018.IXYEHUku_ref_v2019Mar23.dat); red dots = data processed in the present paper (RivadeneyraVera_etal_JGR2019.IXYEHU.dat); open squares= preliminary unpublished data (Compilation_SAm2018_2019.IXYEHUku_ref v2019Mar23.dat). Crosses indicate crustal thicknesses based on gravity anomalies to fill in regions devoid of seismic data: blue = estimates based on Bouguer anomalies in the oceans (Assumpção et al., 2013a) and the crustal model for Ecuador (Font et al., 2013; Araujo, 2013); red = crustal model of Tassara and Echaurren (2012) using points more than $75 \mathrm{~km}$ from any seismic point.

The data shown in Figure S2 were gridded with GMT tool "surface" version 4.5.14, at every $0.5^{\circ}$ interval, after getting blockmean averages, with the options:

$$
\text { blockmean -I0.5 -Wi | surface -I0.5 - C๑.05 -T๑.5 }
$$

The gridded Crustal Thickness (Moho_SAm_2019Mar22.T0.5.grd) is shown in Figure S3. 


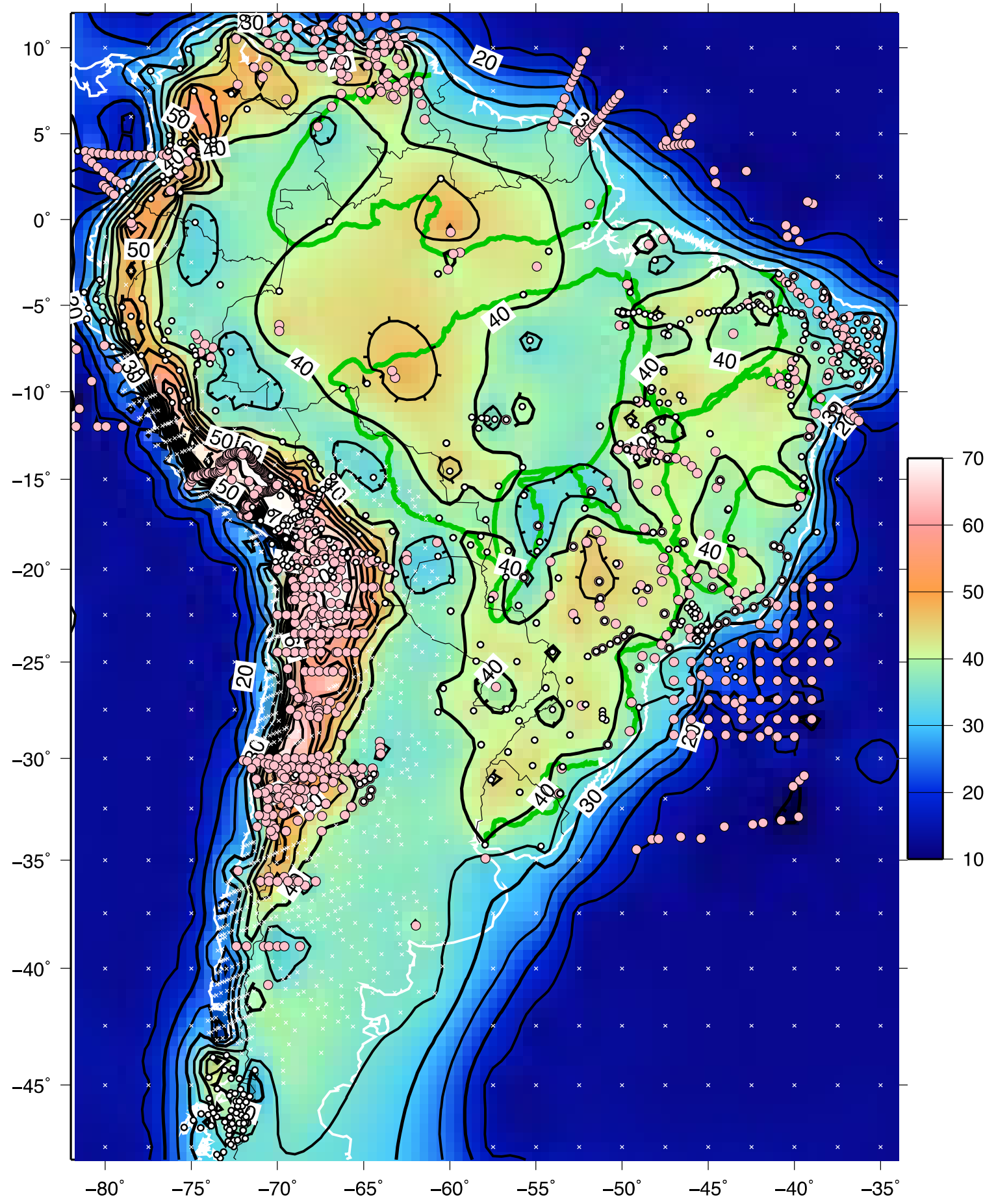

Figure S3. Crustal thickness map from grid file

Moho_SAm_Rivadeneyra_etal_JGR2019Mar24.grd. Pink dots are previous data compiled in 2013; open circles are all new data (Compilation_SAm2013-2018 + Compilation_SAm2018-2019 + RivadeneyraVera_etal_JGR2019 files). White crosses are gravity derived estimates to fill in empty regions near the Andes and in the oceans. 
References for the additional data compiled from the literature since the previous compilation of 2013:

\section{ARGENTINA}

Ammirati, J.-B., P. Alvarado, M. Perarnau, M. Saez, and G. Monsalvo, 2013. Crustal structure of the central Precordillera of San Juan, Argentina $\left(31^{\circ} \mathrm{S}\right)$ using teleseismic receiver functions. J. South Am. Earth Sci., 46, 100-109, doi: 10.1016/j.jsames.2013.05.007

Perarnau, M., Gilbert, H., Alvarado, P., Martino, R. and Anderson, M., 2012. Crustal structure of the Eastern Sierras Pampeanas of Argentina using high frequency local receiver functions. Tectonophysics,580, pp.208-217.

\section{BRAZIL:}

\section{SOUTHERN BRAZIL: LUCASDIOGOMOREIRA_TG2013}

Moreira, L.D., 2013. Application of high-frequency receiver functions in seismographic stations in southern Brazil (in Portuguese). B.Sc. monograph, IAG-USP, São Paulo, Brazil, 2013, 60pp.

\section{CENTRAL BRAZIL: PMP ALONG MINAÇU-BRASILIA AND MG PROFILES}

Berrocal J., Y. Marangoni, N.C. Sá, R. Fuck, J.E.P. Soares, E. Dantas, F. Perosi, and C.

Fernandes, 2004. Deep seismic refraction and gravity crustal model and tectonic deformation in Tocantins Province, Central Brazil. Tectonophys., 388, 187-199., doi:

10.1016/j.tecto.2004.04.033

Trindade, C.R., Soares, J.E., Fuck, R.A., Carmelo, A.C. and Peixoto, C.L.O., 2014. Estrutura Crustal do Brasil Central. Laboratório Nacional de Energia e Geologia. Porto, Portugal. Comunicações Geológicas, Especial I,101, pp.339-343.

\section{PARNAIBA BASIN}

Daly, M.C., V. Andrade, C.A. Barousse, R. Costa, K. McDowell, N. Piggott, and A.J. Poole, 2014. Brasiliano crustal structure and the tectonic setting of the Parnaíba basin of NE Brazil: Results of a deep seismic reflection profile. Tectonics, 33, 2102-2120, doi: 10.1002/2014TC003632

Coelho, D.L.O, J. Julià, V.R. Tribaldos \& N. White, 2018. Deep crustal architecture of the Parnaíba basin of NE Brazil from receiver function analysis: implications for basin subsidence. Geol. Soc., London, Special Publ., Lyell Collection, v. 472, p. SP472.8.

Soares, J.E., Stephenson, R., Fuck, R.A., De Lima, M.V., De Araújo, V.C., Lima, F.T., Rocha, F.A. and Da Trindade, C.R., 2018. Structure of the crust and upper mantle beneath the Parnaíba 
Basin, Brazil, from wide-angle reflection-refraction data. Geological Society, London, Special Publications,472(1), pp.67-82. From: DALY, M. C., FUCK, R. A., JULIÀ, J., MACDONALD, D. I. M. \& WATTS, A. B. (eds) 2018. Cratonic Basin Formation: A Case Study of the Parnaíba Basin of Brazil. Geological Society, London, Special Publications, 472, 67-82.

\section{BORBOREMA PROVINCE:}

Luz, R.M.N., J. julià, and A.F. Nascimento, 2015a. Bulk crustal properties of the Borborema Province, NE Brazil, from P-wave receiver functions: Implications for models of intraplate Cenozoic uplift. Tectonophys., 644-645, 81-91, doi: 10.1016/j.tecto.2014.12.017

Luz, R.M.N., J. julià, and A.F. Nascimento, 2015b. Crustal structure of the eastern Borborema Province, NE Brazil, from the joint inversion of receiver functions and surface wave dispersion: Implications for plateau uplift. J. Geophys. Res., 120, doi: 10.1002/2015JB011872.

Julià, J.; Garcia, X. ; Nemocon, A. M., 2018. The Borborema Deep Electromagnetic and Seismic (BODES) experiment: Investigating basin inversion under Araripe.. In: 49 Congresso Brasileiro de Geologia, 2018, Rio de Janeiro. Extended Abstract.

\section{SANTOS BASIN:}

Evain, M., A. Afilhado, C. Rigoti, A. Loureiro, D. Alves, F. Klingelhoefer, P. Schnurle, A. Feld, R. Fuck, J. Soares, M.V. Lima, C. Corela, L. Matias, M. Benabdellouahed, A. Baltzer, M. Rabineau, A. Viana, M. Moulin, and D. Aslanian, 2015. Deep structure of the Santos Basin São Paulo Plateau system, SE Brazil. Journal of Geophysical Research, Solid Earth, 120, doi: 10.1002/2014JB011561

\section{RSBR ("BIANCHI, 2015"):}

Assumpção, M., M. Bianchi, D.F. Albuquerque, G.S.L. França, and L.V. Barros, 2015. Crustal thickness map in South America: an updated version. $1^{\text {st }}$ Symposium of Brazilian Seismology, University of Brasilia, DF, Brazil, abstract.

\section{AMAZON CRATON:}

Albuquerque, D.F., França, G.S., Moreira, L.P., Assumpção, M., Bianchi, M., Barros, L.V., Quispe, C.C. and Oliveira, M.E., 2017. Crustal structure of the Amazonian Craton and adjacent provinces in Brazil. Journal of South American Earth Sciences, 79, pp.431-442.

\section{COLOMBIA: Stations BOL, PBLA, W Colombia:}

Monsalve, H., J.F. Pacheco, C.A. Vargas, and Y.A. Morales, 2013. Crustal velocity structure beneath the western Andes of Colombian using receiver-function inversion. J. South Am. 
Earth Sci., 48, 106-122.

Poveda, E., G. Monsalve, and C.A. Vargas, 2015. Receiver functions and crustal structure of the northwestern Andean region, Colombia. J. Geophys. Res., 120, doi: 10.1002/2014JB011304

\section{ECUADOR:}

Font, Y., M. Segovia, S. Vaca, and T. Theunissen, 2013. Seismicity patterns along the Ecuadorian subduction zone: new constraints from earthquake location in a 3-D a priori velocity model. Geophys.J.Int., xxx , doi: 10.1093/gji/ggs083

Araujo, S., 2013. The Ecuadorian Moho. La Granja (Univ. Salesiana Politecnica, Ecuador), 18(2), 43-47. ISSN: 1390-3799

\section{PERU:}

James, D.E. and Snoke, J.A., 1994. Structure and tectonics in the region of flat subduction beneath central Peru: Crust and uppermost mantle. Journal of Geophysical Research: Solid Earth, 99(B4), pp.6899-6912.

Condori, C., G.S. França, H.J. Tavera, D.F. Albuquerque, B.T. Bishop, S.L. Beck, 2017. Crustal structure of north Peru from analysis of teleseismic receiver functions. J. South American Earth Sci., 76, 11-24. Doi: 10.1016/j.jsames.2017.02.006

Ryan, J., Beck, S., Zandt, G., Wagner, L., Minaya, E. and Tavera, H., 2016. Central Andean crustal structure from receiver function analysis. Tectonophysics, 682, pp.120-133.

\section{PATAGONIA:}

Buffoni, C., M. Schimmel, N.C. Sabbione, M.L. Rosa, G. Connon, 2019. Crustal structure beneath Tierra del Fuego, Argentina, inferred from seismic P-wave receiver functions and ambient noise autocorrelations. Tectonophysics, 751, 41-53. DOI: 10.1016/j.tecto.2018.12.013

Rodríguez, E.E., \& R.M. Russo, 2016. Crustal Thickness and Structure in Southern Chile: Patagonia plate assembly structures and continental arc modifications. AGU Fall Meeting, Abstract. 
Chapter 3

\section{Lithosphere-Asthenosphere boundary under Brazil}

In addition to studying the crustal thickness and $V_{p} / V_{s}$ values, we also used the S-wave receiver function $(\mathrm{SRF})$ method to estimate the seismological lithosphere-asthenosphere boundary (LAB) in the South American platform, mainly in Brazil. This method is an alternative to identify lithospheric discontinuities since tomographies do not have enough resolution to directly define this boundary due to its sharpness (Rychert and Shearer, 2009). Since Farra and Vinnik (2000) proposed the SRF method, it has been carried out successfully to estimate the LAB depth over the world (Kumar et al., 2005a,b; Yuan et al., 2006; Kumar et al., 2007; Hansen et al., 2009; Kumar et al., 2012; Blanco et al., 2017).

Although several studies map the LAB on a global scale (Rychert and Shearer, 2009; Pasyanos et al., 2014; Priestley et al., 2018), South American LAB has been poorly studied because of the lack of seismic stations until a few years ago, and the large amount of data required (Bianchi, 2008). Due to the geographic location of South America, it is needed a database of several years, since the required events to use the SRF method are scarce $(\sim 25 /$ year $)$.

Despite these limitations, Heit et al. (2007) estimated the LAB depth under some South American stations finding a notably thicker lithosphere (up to $160 \mathrm{~km}$ ) under cratonic and surroundings areas, and a thinner one under coastal areas (passive continent-ocean margin). Nowadays, with the installation of some stations due to new projects, especially in Brazil, are possible more detailed studies for the lithospheric structure. 


\subsection{Method}

The S-wave receiver function was proposed for the first time by Farra and Vinnik (2000), and subsequently Yuan et al. (2006); Kind et al. (2012) have provided more details of the technique. The first step is the rotation of the three components into the ray coordinate system LQT, where each wave type is enhanced in one component, $S p$ converted phase is polarized on $\mathrm{L}$ component, $P s$ on $\mathrm{Q}$ component, and $\mathrm{SH}$ on $\mathrm{T}$ component (Kind et al., 2012). As it was commented in Chapter 2, the deconvolution is usually applied to eliminate the source and propagation effects, leaving only the response of local crustal and upper mantle structure. To obtain SRF traces, the L component is deconvolved by the $\mathrm{Q}$ component, transforming the S-wave train into a sharp spike on the Q component, and the resulting L component contains the impulsive response of converted waves, as shown in Figure 3.1a (Kumar et al., 2005a,b; Bianchi, 2008; Kind et al., 2012). SRF traces have the amplitude and time inverted compared to $\mathrm{P}$-wave receiver function (PRF) ones, therefore the time is reverted in reference to time $=0$, and the amplitude is multiplied by -1 . In this final trace, the amplitude of $S p$ conversion at LAB is negative and has a positive time (Figure 3.1b).

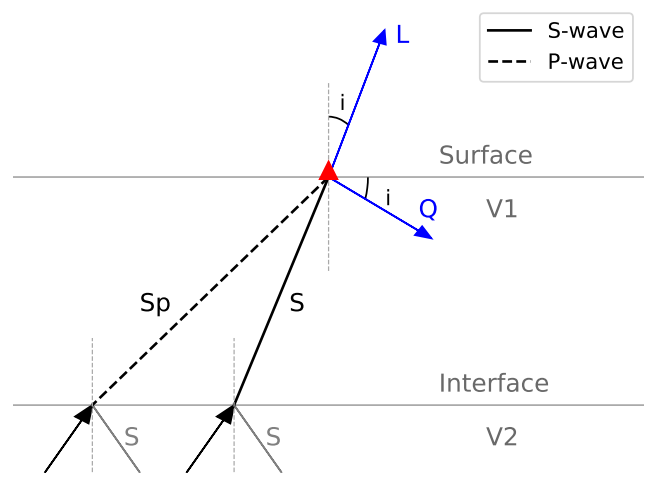

(a)

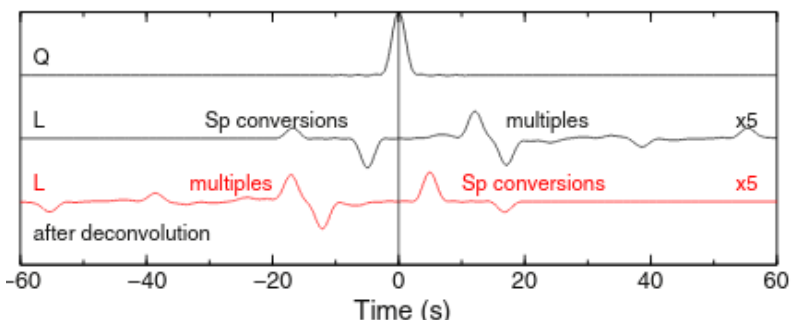

(b)

Figure 3.1: S-wave receiver function scheme. (a) $S$ and $S p$ paths, and LQT system. (b) L and Q components after deconvolution (black) and deconvolved L trace with time and amplitude reverted (red). Figure adapted from Kind et al. (2012).

As the $S p$ conversion is weak, it can be enhanced by stacking many records, previously corrected to a reference slowness (Kumar et al., 2005a,b; Yuan et al., 2006; Bianchi, 2008; Kind et al., 2012; Kind and Yuan, 2018). This move-out correction permits summation, in the time domain, of mantle signals from different epicentral distances; despite a velocity 
model is required, the influence of using any model is relatively weak for longer periods (Kind and Yuan, 2018). Finally, the time is converted into depth, also using a velocity model.

The advantage of this method is that the main $S p$ conversion does not interfere with crustal multiples that are generally mixed with the conversions at lithospheric depths in PRF. SRF method is very suitable for gradual transition zones in the upper mantle, such as the LAB, and it also can sample a broader area than PRF; for example, to expand the sampling area for oceanic island stations (Kind and Yuan, 2018).

It is important to remark that SRF tends to be noisier than PRF, having lower quality and depth resolution due to $\mathrm{S}$ waves present lower longer periods, then it is not possible to resolve fine crustal structures. Therefore are required earthquakes with a larger magnitude that results in a smaller number of available events.

\subsection{Data}

To estimate the LAB we analyzed the RSBR stations from 2010 to 2019, XC temporary deployment from the middle of 2016 to 2020, and some international stations (Figure 3.2a). We considered events with magnitude greater than $5.8 \mathrm{mb}$ and epicentral distances between $60^{\circ}$ and $85^{\circ}$ (Yuan et al., 2006; Heit et al., 2007), as shown in Figure 3.2b. 


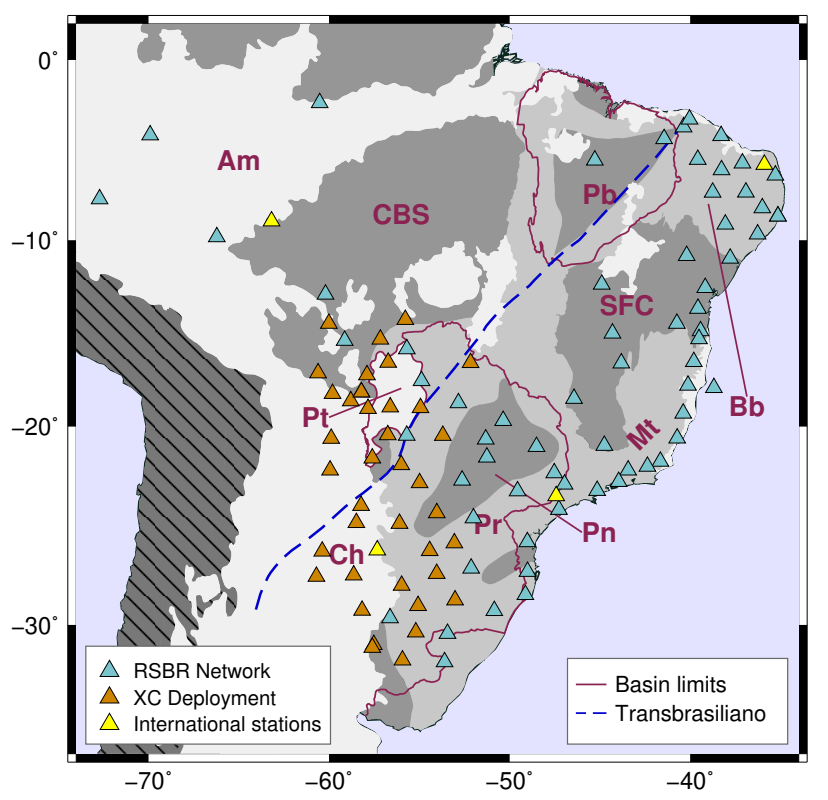

(a)

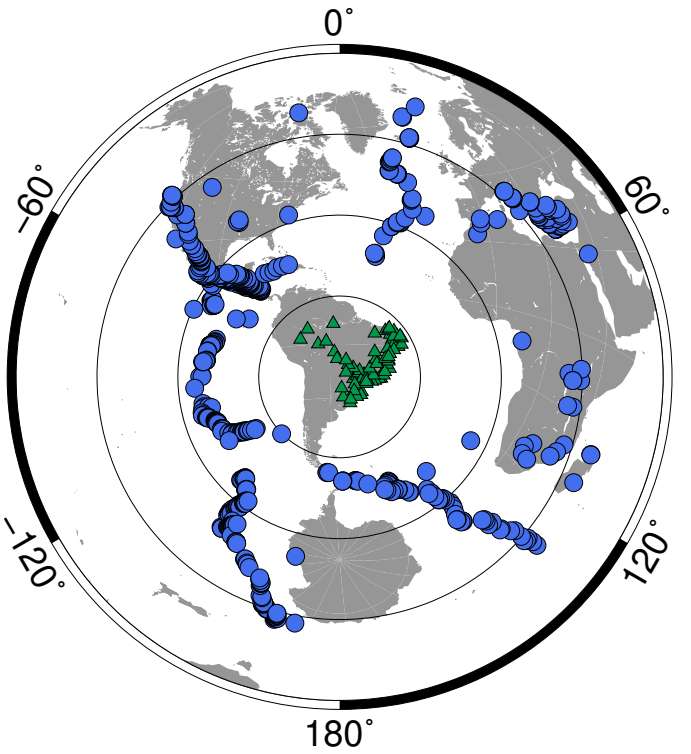

(b)

Figure 3.2: (a) Map of stations used in S-wave receiver function analysis. Light blue triangles: Permanent RSBR stations. Orange triangles: Temporary XC deployment. Yellow triangles: International stations. Blue dotted line: Transbrasiliano Lineament. Purple line: Basin limits (Pr: Paraná, Pb: Paraníba, Pt: Pantanal, Ch: Chaco, Am: Amazonian) SFC: São Francisco Craton, Bb: Borborema Province and Mt: Mantiqueira Province. Shaded areas refer to the geological provinces shown in Figure 1.2. (b) Distribution of events used in S-wave receiver function analyses. Blue circles: events selected, green triangles: seismic stations. Concentric circles are distances every $30^{\circ}$.

\subsection{Data processing}

Each selected seismogram was windowed 300 seconds before and 100 seconds after the S-wave arrival, rotated into ZRT using the back azimuth angle, and finally rotate to coordinate system LQT, considering the theoretical incidence angle according to IASP91 model (Kennett and Engdahl, 1991). Rotated traces were detrended and filter between 1.5 and $0.01 \mathrm{~Hz}$, finally they were deconvolved, mirrored, and cut between 20 seconds before and 150 seconds after $\mathrm{t}=0$. The $\mathrm{SRF}$ traces were visually inspected to do quality control and were discarded the noisy and unstable ones, Table 3.1 shows the number of good traces at each station. It is important to highlight that permanent stations (RSBR) have an average of more than 150 good traces, while the stations that belong to $\mathrm{XC}$ temporary deployment, blue ones, have less than 60 good traces. This is because of the short operating time of the XC network (since the middle of 2016), then considering an average of 25 suitable events per year, we have less than 100 ones in our analysis period. 
Table 3.1 - Number of good S-wave receiver function (SRF) traces in each station processed.

\begin{tabular}{|c|c|c|c|c|c|c|c|}
\hline Station & SRF & Station & SRF & Station & SRF & Station & SRF \\
\hline BL.AQDB & 206 & BR.SDBA & 143 & ON.GDU01 & 86 & XC.FDPY & 30 \\
\hline BL.BB19B & 258 & BR.VILB & 131 & ON.GUA01 & 271 & XC.FRBT & 58 \\
\hline BL.BSCB & 292 & NB.NBAN & 260 & ON.MAJ01 & 175 & XC.MAPY* & 36 \\
\hline BL.C2SB & 179 & NB.NBBL & 20 & ON.MAN01 & 326 & XC.MCR1 & 54 \\
\hline BL.CNLB & 282 & NB.NBCA & 99 & ON.NAN01 & 262 & XC.MECA & 37 \\
\hline BL.CPSB* & 278 & NB.NBCL & 251 & ON.PET01 & 304 & XC.MURT & 55 \\
\hline BL.FRTB & 328 & NB.NBCP & 25 & ON.RIB01 & 390 & XC.NBRS & 63 \\
\hline BL.ITAB & 174 & NB.NBIT & 139 & ON.SLP01 & 314 & XC.PANT & 37 \\
\hline BL.ITQB & 105 & NB.NBLA & 149 & ON.TER01 & 190 & XC.PAPY & 35 \\
\hline BL.ITRB & 174 & NB.NBLI/V & 119 & ON.TIJ01* & 101 & XC.POCN* & 44 \\
\hline BL.PCMB & 162 & NB.NBMA & 255 & ON.VAS01 & 377 & XC.PSAL* & 45 \\
\hline BL.PLTB & 310 & NB.NBMO & 270 & XC.ALGR & 58 & XC.PTET* & 46 \\
\hline BL.PMNB & 207 & NB.NBPA & 149 & XC.AMBA & 70 & XC.RODS & 63 \\
\hline BL.PP1B & 54 & NB.NBPB & 166 & XC.ANTJ* & 38 & XC.RPRD & 65 \\
\hline BL.PTGB & 268 & NB.NBPN & 148 & XC.ARAP* & 15 & XC.RVDE & 43 \\
\hline BL.RCLB & 313 & NB.NBPS & 240 & XC.AZCA & 34 & XC.SSCA* & 28 \\
\hline BL.TRCB & 219 & NB.NBPV & 270 & XC.BBLB & 35 & XC.SJPY & 39 \\
\hline BL.TRIB & 12 & NB.NBRF & 202 & XC.BBPS & 25 & XC.TBOT & 46 \\
\hline BL.VABB & 263 & NB.NBTA & 184 & XC.BBRB & 29 & XC.TICA* & 21 \\
\hline BR.BOAV & 130 & NB.PFBR* & 8 & XC.BBRT* & 23 & XC.UNIS* & 46 \\
\hline BR.CZSB & 119 & NB.SSBR* & 10 & XC.BBSD & 62 & XC.VACA* & 28 \\
\hline BR.ETMB & 77 & ON.ABR01 & 196 & XC.BDQN & 62 & XC.VBST & 54 \\
\hline BR.TBTG & 165 & ON.ALF01 & 196 & XC.CCRS & 58 & G.SPB & 283 \\
\hline BR.JANB/7 & 57 & ON.ANA01 & 65 & XC.CRSM & 59 & GT.CPUP & 186 \\
\hline BR.MC01 & 57 & ON.CAM01 & 394 & XC.DVLD & 74 & IU.RCBR & 78 \\
\hline BR.PTLB & 127 & ON.CMC01 & 121 & XC.EDMB* & 33 & IU.SAML* & 186 \\
\hline BR.SALB/V & 72 & ON.DUB01 & 382 & XC.ESFA & 26 & IU.TQRA & 237 \\
\hline
\end{tabular}

* Stations in which reliable results could not be obtained

Black: Stations belonging to permanent network (RSBR)

Blue: XC temporary deployment

Green: International stations

As every event has different source parameters, it is necessary to do a move-out correction to a reference value of $6.4 \mathrm{~s} /{ }^{\circ}$. Because of the low signal-to-noise ratio of SRF traces, it is necessary to stack several events to enhance the signal of $S p$ conversion at 
LAB, then corrected traces were stacked doing a bootstrap of 100 resamplings, to estimate uncertainties. Figure 3.3 shows the median stacked trace of the 100 resamplings (red line) and the standard deviation at each point (gray area) of the NBLA and NBTA stations, located in São Francisco Craton and Borborema Province respectively.
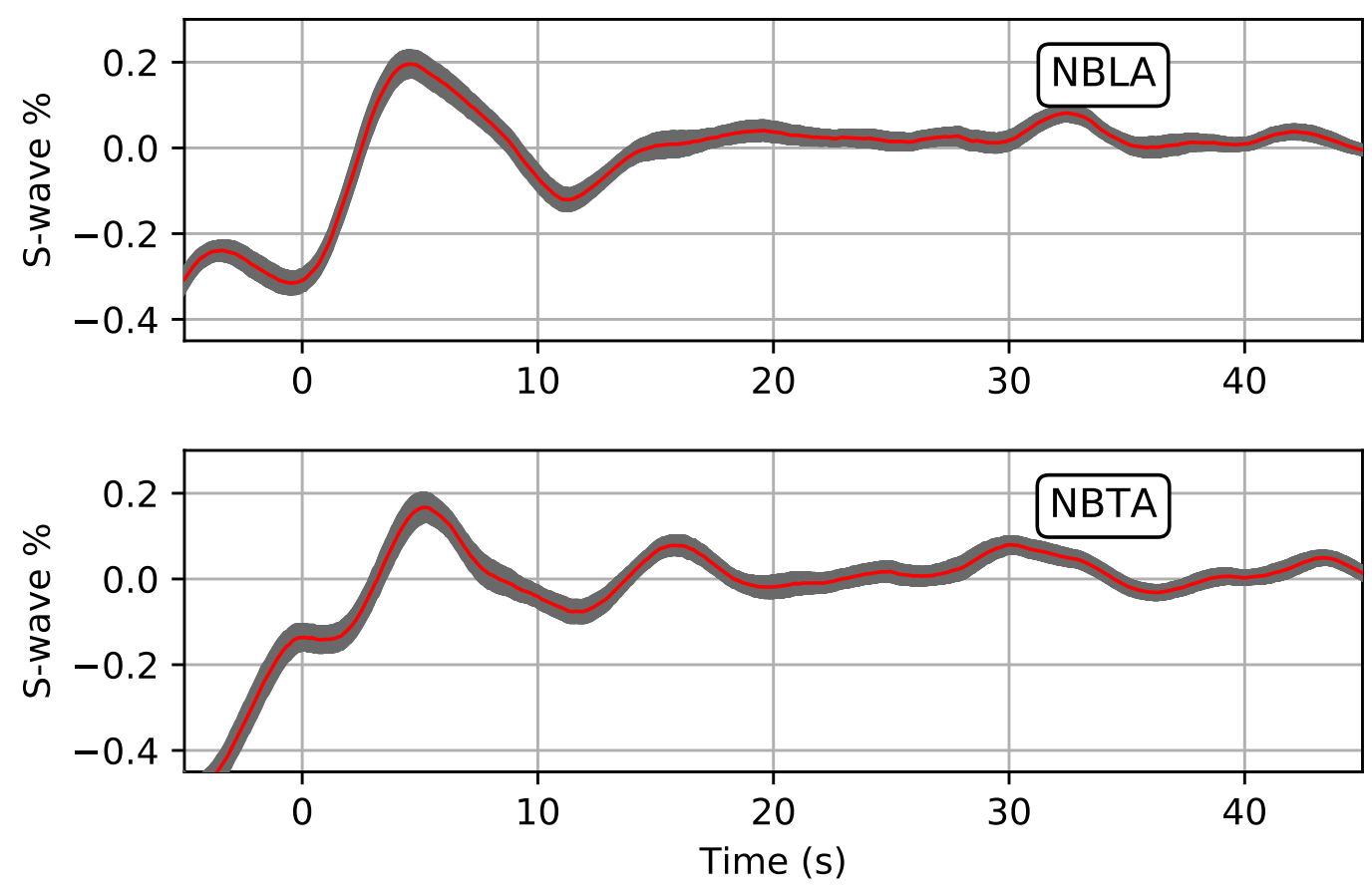

Figure 3.3: Stacking and bootstrapping of 100 repetitions at NBLA and NBTA stations. Red line: Median stacked trace of the 100 resamplings. Gray area: Standard deviation $(1 \sigma)$ at each point.

Because the conversion at LAB is weak and not very clear at all frequencies, we tested five different low-pass filters of $2,3,4,6$, and 8 seconds. The most noticeable effect of different filters is a less noisy trace as lower the filter is; however, all of them present compatible results with each other, as shown in Figure 3.4. At all frequencies, it is possible to distinguish a clear negative phase, close to $\sim 10$ seconds at NBLA station. At NBTA station, when using a low-pass filter of 2 seconds, the $S p$ conversion is not clear and has almost the same amplitude of the noise, while the converted phase is clearer when lower frequency bands are used; anyway, a coherent negative arrival at $\sim 12$ seconds is observed in all frequency bands used. 

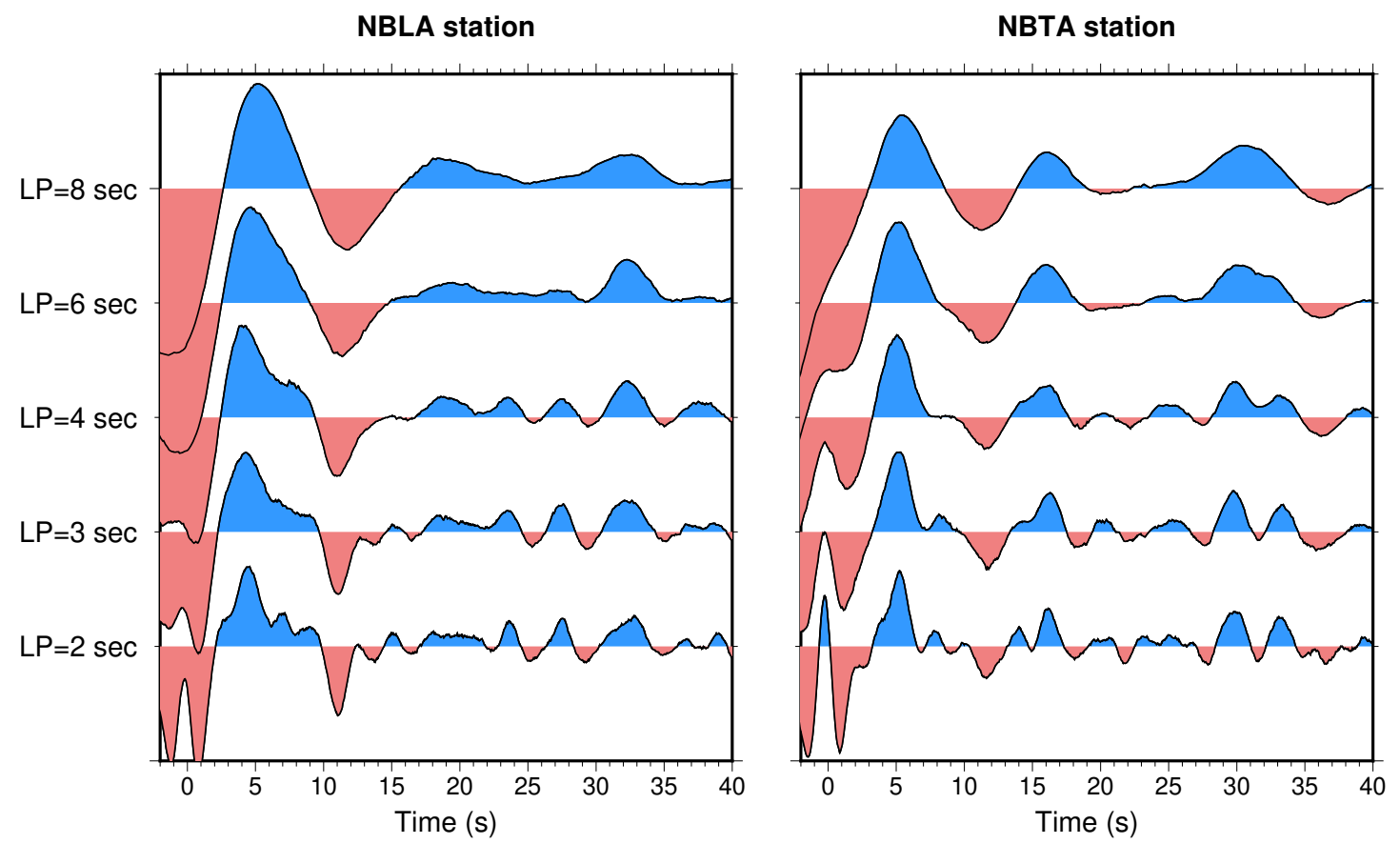

Figure 3.4: Stacked SRF traces using low-pass filters of 2, 3, 4, 6, and 8 seconds. In both stations is clear the $S p$ conversion arrival at $\sim 10$ and $\sim 12$ seconds in NBLA and NBTA stations respectively, in all frequencies tested. As expected, with lower filters, the stacked trace is less noisy making easier the identification of converted phases.

The arrival time of $S p$ conversion at LAB is obtained from the minimum position of the SRF trace that later is converted to depth using the IASP91 model (Kennett and Engdahl, 1991). Since we bootstrap the stacks, we assume the lithosphere thickness as the median of the estimates and the standard deviation as the uncertainty. Table 3.2 shows the lithospheric thickness using different low-pass filters, which varies from $98.5 \mathrm{~km}$ to 103 $\mathrm{km}$; these differences are within the uncertainties that go up to $\pm 4 \mathrm{~km}$. It is noticeable that the uncertainties are higher as lower the filter is, because the lobules become wider at lower frequencies (Figure 3.4), and the maximum of the negative arrival, assumed as the arrival of $S p$ conversion at the LAB, varies more in the bootstrapping.

Table 3.2 - Lithospheric thickness at NBLA station using different low-pass filters

\begin{tabular}{|c|c|c|}
\hline Low-pass filter & LAB $\mathbf{( k m )}$ & Standard deviation \\
\hline 2 seconds & 98.5 & 1.49 \\
3 seconds & 98.3 & 1.53 \\
4 seconds & 99.9 & 2.45 \\
6 seconds & 100.0 & 2.94 \\
8 seconds & 103.0 & 3.84 \\
\hline
\end{tabular}


Since it is also possible to estimate a crustal thickness using the SRF method, we estimated the Moho depth in permanent stations belonging to RSBR using the same lowpass filters mentioned above. These results were compared with the crustal thickness obtained through the $\mathrm{P}$-wave receiver function method presented by Rivadeneyra-Vera et al. (2019) and discussed in Chapter 2. The best correlation, and therefore the more reliable results are given when a low-pass filter of 6 seconds is used, as shown in Figure 3.5, despite obtaining systematically higher values with the SRF method, it is important to highlight that it gives higher uncertainties than the PRF method. According to the results obtained from Figure 3.5, we used a low-pass filter of 6 seconds to estimate the LAB depth.

In Figure 3.5d two stations are presenting a thick crust $(>40 \mathrm{~km})$ using the PRF method and a notably thinner one when using the SRF method. These are: TRIB station where were used few good data in both cases, only four deep regional events with the PRF method, and 12 with the SRF method; the other station is CNLB, which was selected as a regular station during the $\mathrm{PRF}$ processing (Chapter 2) and can have more than one value for crustal thickness. In both stations, the estimates obtained using the PRF method have a great uncertainty and could adopt smaller values in the H-k stacking.

We compared our results with those obtained by Heit et al. (2007) for common international stations, they also used the same method presented in this work. Figure 3.6 shows a good agreement at stations that present thinner lithosphere $(\sim 80 \mathrm{~km})$. The most remarkable difference between both studies is the number of events processed, while Heit et al. (2007) stacked an average of $20 \mathrm{SRF}$ traces at each station, in the present work we stacked up to 200 SRF traces. 


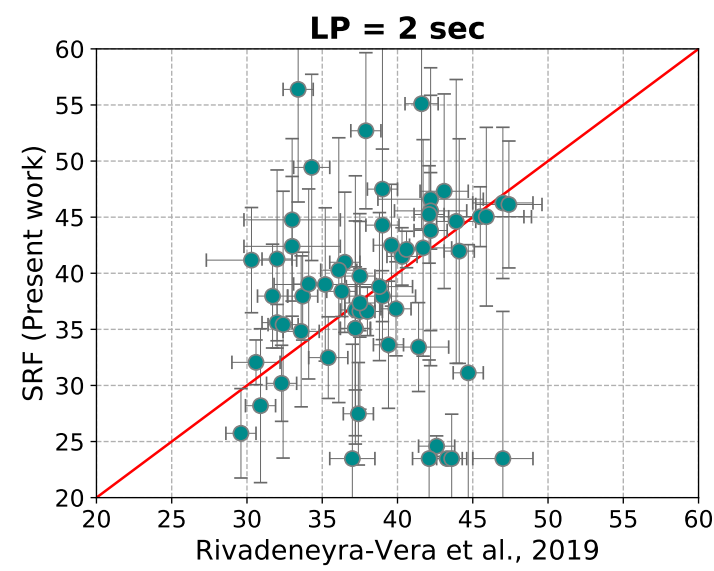

(a)

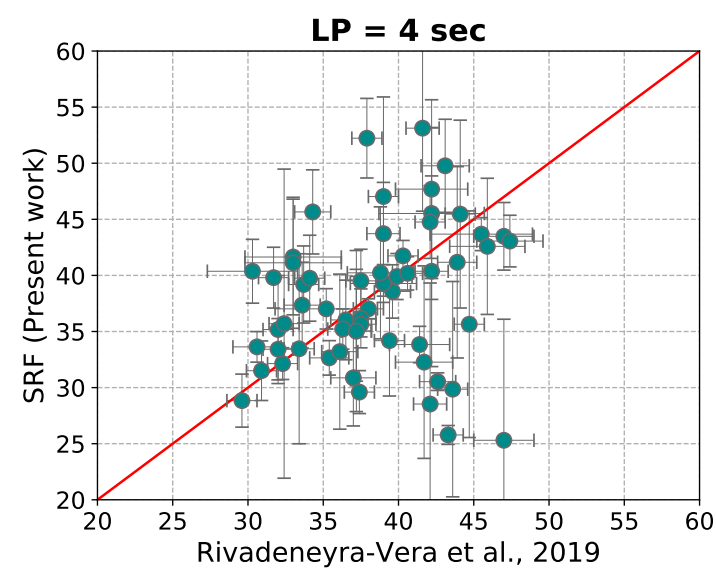

(c)

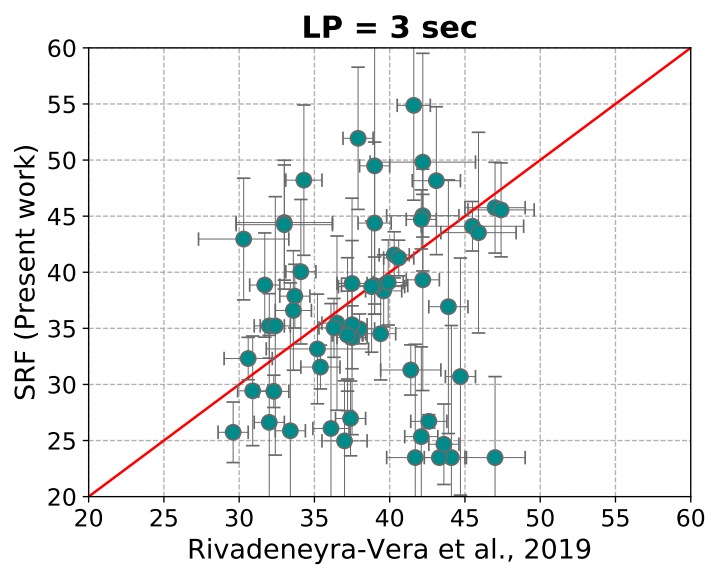

(b)

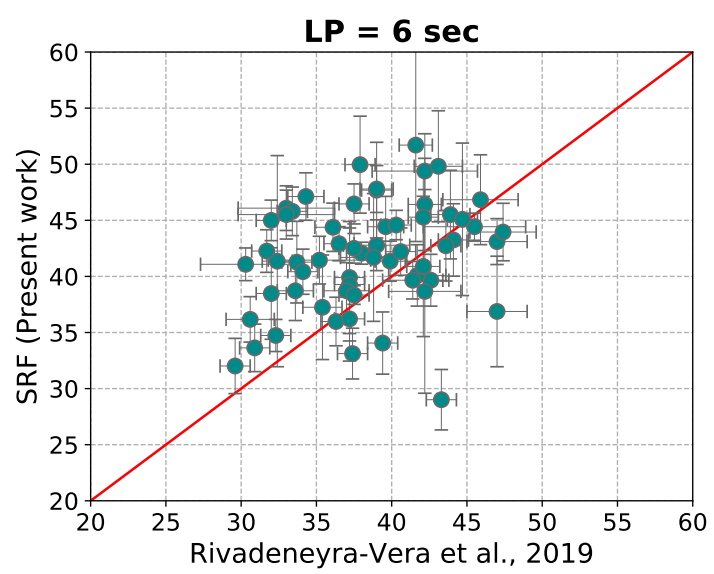

(d)

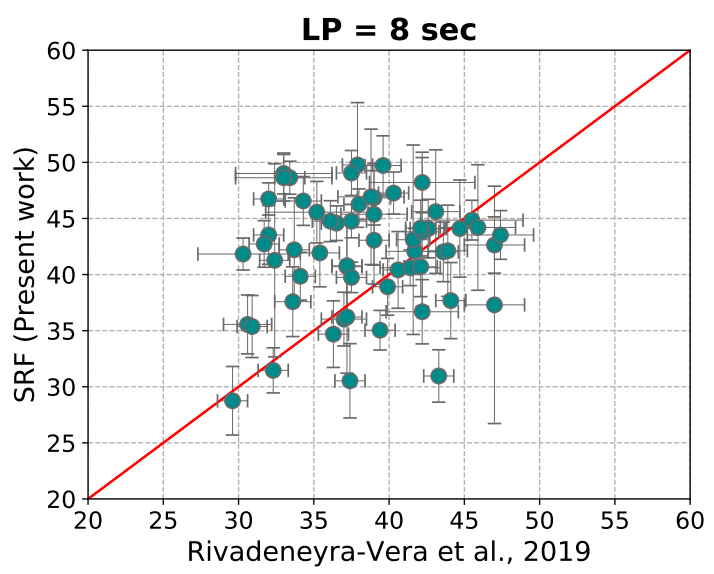

(e)

Figure 3.5: Comparison of Moho depth obtained using P-wave receiver function (Rivadeneyra-Vera et al., 2019) and using S-wave receiver function (present work). (a) Low-pass of 2 seconds, (b) Low-pass of 3 seconds (c) Low-pass of 4 seconds (d) Low-pass of 6 seconds (e) Low-pass of 8 seconds. The best correlation is given for a low-pass filter of 6 seconds. 


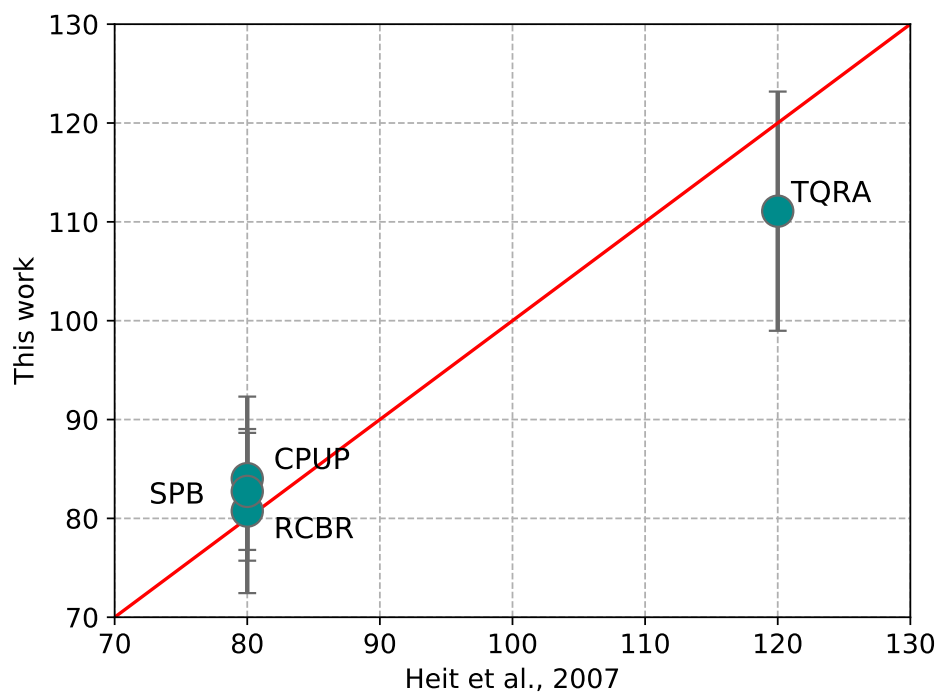

Figure 3.6: Comparison with Heit et al. (2007) at common seismic stations, using a low-pass filter of 6 seconds. Red line shows the 1:1 relation.

\subsection{Results and discussion}

The estimated lithospheric thickness in the South American platform is shown in Figure 3.7, where the size of the circles are according to the uncertainty of the estimate: Biggest circles have lower uncertainties $(\leq 10 \mathrm{~km})$, and the smallest one present higher uncertainty $(\geq 20 \mathrm{~km})$. Table 3.3 summarizes the LAB depth and uncertainty at each station. We confirmed a thinner lithosphere of $\sim 80 \mathrm{~km}$ at Borborema Province, observed previously by Heit et al. (2007) analyzing one international station, here we processed more than 10 stations, all with consistent results. Along the continent-ocean margin, at Mantiqueira Province, we found a LAB about $\sim 90 \mathrm{~km}$, being thicker in stations close to São Francisco Craton, which could indicate an extension of the craton toward the south in the coastal part.

Most stations located in the São Francisco Craton present a lithospheric thickness of $\sim 150 \mathrm{~km}$, being shallower $(\sim 100 \mathrm{~km})$ in some stations close to the coastal margin that seems to fit with a second-order midlithospheric discontinuity (MLD) between the Moho and LAB, also observed by different authors when using the SRF method to study the lithospheric structure in older regions (Rychert and Shearer, 2009; Fischer et al., 2010; Yuan and Romanowicz, 2018; Priestley et al., 2018; Kind and Yuan, 2018; Sun et al., 2018). 
In the Amazon Craton, which includes the Central Brazilian Shield (CBS) and Amazon Basin (Am), we observe a thicker lithosphere up to $200 \mathrm{~km}$, in agreement with the oldest cratonic areas of the world. The lithosphere sharply refines toward Pantanal and Chaco Basins that reach depths up to $100 \mathrm{~km}$. The Paraná Basin presents a thinner lithosphere of $\sim 100 \mathrm{~km}$ at some stations, and thicker estimates at Paranapanema cratonic block and the southwestern part of the basin.

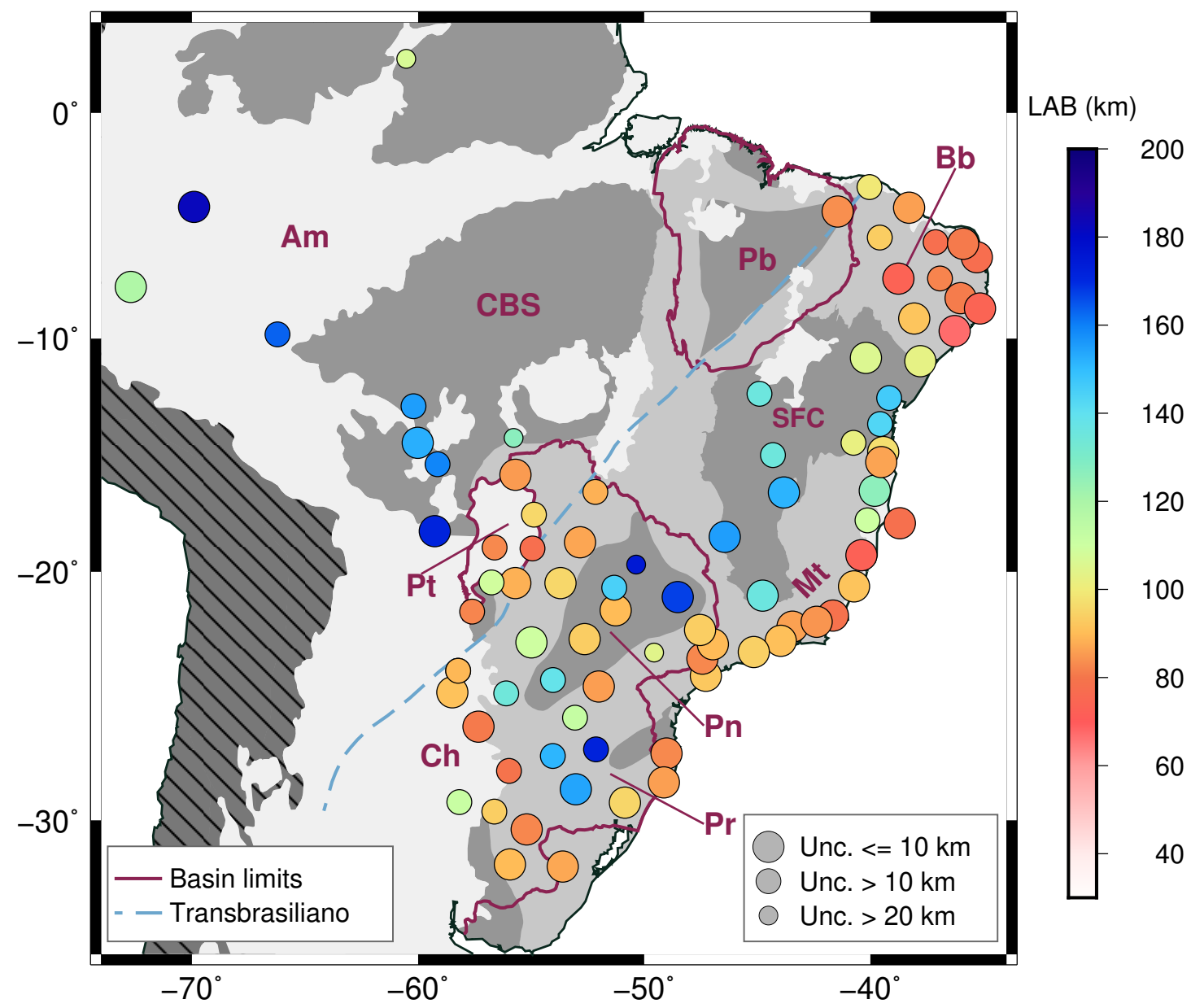

Figure 3.7: Lithospheric thickness map in Central South America, the size of circles represent the uncertainty of each estimation. CBS: Central Brazilian Shield, Pn: Paranapanema Cratonic Block, SFC: São Francisco Craton, Mt: Mantiqueira Province, Bb: Borborema Province, Ch: Chaco Basin, Am: Amazon Basin. Purple line delimits large intracratonic basins: Paraná (Pr), Parnaíba $(\mathrm{Pb})$ and Pantanal $(\mathrm{Pt})$. Light blue dotted line: Transbrasiliano Lineament. Shaded areas refer to the geological provinces shown in Figure 1.2. 
Table 3.3 - Lithospheric thickness in Central South America.

\begin{tabular}{|c|c|c|c|c|c|c|c|c|c|}
\hline Station & $\begin{array}{c}\text { Lon. } \\
\left(^{\circ}\right)\end{array}$ & $\begin{array}{c}\text { Lat. } \\
\left({ }^{\circ}\right)\end{array}$ & $\begin{array}{c}\text { LAB } \\
\text { km }\end{array}$ & $\begin{array}{c}\text { Error } \\
\text { km }\end{array}$ & Station & $\begin{array}{c}\text { Lon. } \\
\left(^{\circ}\right)\end{array}$ & $\begin{array}{l}\text { Lat. } \\
\left({ }^{\circ}\right)\end{array}$ & $\begin{array}{c}\text { LAB } \\
\text { km }\end{array}$ & $\begin{array}{c}\text { Error } \\
\text { km }\end{array}$ \\
\hline \multicolumn{10}{|c|}{ Borborema Province $(\mathrm{Bb})$} \\
\hline NBAN & -36.27 & -9.67 & 67.4 & 7.7 & NBTA & -38.06 & -9.12 & 91.7 & 3.5 \\
\hline NBCA & -36.01 & -8.22 & 81.0 & 3.3 & NBRF & -35.15 & -8.68 & 73.7 & 3.1 \\
\hline NBLI/V & -36.92 & -7.36 & 82.1 & 11.2 & NBCL & -38.29 & -4.22 & 86.0 & 8.4 \\
\hline NBPA & -37.11 & -5.75 & 77.7 & 12.6 & NBPV & -35.29 & -6.42 & 77.3 & 5.1 \\
\hline NBPS & -41.45 & -4.39 & 83.6 & 4.2 & NBMO & -40.04 & -3.31 & 99.1 & 11.4 \\
\hline NBPB & -39.58 & -5.55 & 93.3 & 10.1 & RCBR & -35.90 & -5.82 & 80.7 & 8.3 \\
\hline NBMA & -38.76 & -7.37 & 73.3 & 2.6 & & & & & \\
\hline \multicolumn{10}{|c|}{ Mantiqueira Province (Mt) } \\
\hline NAN01 & -40.13 & -17.84 & 110.0 & 15.1 & MAJ01 & -49.01 & -27.40 & 82.8 & 4.2 \\
\hline VAS01 & -43.44 & -22.28 & 86.1 & 3.7 & MAN01 & -43.96 & -22.90 & 90.7 & 1.7 \\
\hline ABR01 & -38.70 & -17.96 & 78.2 & 4.12 & PET01 & -47.28 & -24.29 & 92.4 & 2.4 \\
\hline CAM01 & -41.66 & -21.83 & 78.8 & 7.18 & RIB01 & -40.39 & -19.31 & 72.7 & 5.8 \\
\hline DUB01 & -42.37 & -22.08 & 84.5 & 2.9 & SLP01 & -45.16 & -23.32 & 94.0 & 2.7 \\
\hline ALF01 & -40.73 & -20.62 & 91.4 & 6.8 & TER01 & -49.13 & -28.53 & 85.9 & 2.3 \\
\hline GUA01 & -39.81 & -16.58 & 126.2 & 10.0 & & & & & \\
\hline \multicolumn{10}{|c|}{ São Francisco Craton (SFC) } \\
\hline NBIT & -39.43 & -14.93 & 97.2 & 6.3 & $\mathrm{JANB} / 7$ & -44.31 & -15.06 & 135.0 & 15.5 \\
\hline NBPN & -40.20 & -10.85 & 105.8 & 4.9 & MC01 & -43.82 & -16.66 & 151.61 & 9.8 \\
\hline NBLA & -37.79 & -10.99 & 103.0 & 3.9 & SDBA & -44.90 & -12.41 & 135.5 & 16.1 \\
\hline $\mathrm{NBCP}$ & -39.17 & -12.59 & 146.3 & 13.5 & CMC01 & -39.52 & -15.36 & 86.5 & 2.4 \\
\hline BSCB & -44.76 & -21.00 & 135.8 & 8.0 & ANA01 & -40.75 & -14.53 & 101.9 & 13.2 \\
\hline PMNB & -46.44 & -18.54 & 155.1 & 9.6 & GDU01 & -39.58 & -13.72 & 143.3 & 15.5 \\
\hline \multicolumn{10}{|c|}{ Amazon Craton (Am) } \\
\hline BOAV & -60.52 & -2.40 & 107.0 & 20.8 & VILB & -60.20 & -12.95 & 155.3 & 11.4 \\
\hline CZSB & -72.70 & -7.73 & 118.8 & 7.0 & VBST & -60.02 & -14.53 & 152.4 & 6.3 \\
\hline ETMB & -66.21 & -9.82 & 163.5 & 16.1 & BBSD & -59.27 & -18.30 & 171.5 & 9.7 \\
\hline TBTG & -69.91 & -4.19 & 182.3 & 9.3 & PTLB & -59.14 & -15.45 & 159.2 & 14.7 \\
\hline NBRS & -55.78 & -14.32 & 126.8 & 22.1 & & & & & \\
\hline \multicolumn{10}{|c|}{ Pantanal Basin $(\mathrm{Pt})$} \\
\hline PP1B & -54.88 & -17.60 & 95.6 & 13.5 & PANT & -56.62 & -18.99 & 82.8 & 14.3 \\
\hline AQDB & -55.70 & -20.48 & 88.4 & 3.1 & MURT & -57.61 & -21.66 & 82.3 & 12.0 \\
\hline SALV & -55.69 & -15.90 & 85.4 & 6.9 & BDQN & -56.75 & -20.45 & 108.9 & 15.8 \\
\hline RVDE & -54.94 & -19.03 & 77.6 & 12.9 & PAPY & -58.23 & -24.09 & 89.3 & 17.0 \\
\hline \multicolumn{10}{|c|}{ Chaco Basin (Ch) } \\
\hline MECA & -58.17 & -29.30 & 111.4 & 18.6 & ESFA & -58.49 & -24.96 & 91.0 & 7.9 \\
\hline AZCA & -55.98 & -28.08 & 79.37 & 12.3 & PAPY & -58.23 & -24.09 & 89.3 & 17.0 \\
\hline CPUP & -57.33 & -26.33 & 80.7 & 8.3 & & & & & \\
\hline \multicolumn{10}{|c|}{ Paraná Basin (Pr) } \\
\hline MCR1 & -54.04 & -24.46 & 138.5 & 12.3 & ITQB & -56.63 & -29.66 & 93.7 & 11.0 \\
\hline TRCB & -52.64 & -22.79 & 93.5 & 6.6 & DVLD & -52.16 & -16.64 & 88.3 & 12.7 \\
\hline PCMB & -51.26 & -21.61 & 89.9 & 2.8 & ALGR & -53.03 & -28.80 & 154.1 & 9.0 \\
\hline BB19B & -48.51 & -21.06 & 167.3 & 9.9 & FRBT & -53.06 & -25.98 & 112.5 & 14.2 \\
\hline
\end{tabular}

Continued on the next page... 
Table 3.3 - Continuation

\begin{tabular}{|c|c|c|c|c|c|c|c|c|c|}
\hline Station & $\begin{array}{c}\text { Lon. } \\
\mathbf{(}^{\circ}\end{array}$ & $\begin{array}{c}\text { Lat. } \\
\left.\mathbf{(}^{\circ}\right)\end{array}$ & $\begin{array}{c}\text { LAB } \\
\mathbf{k m}\end{array}$ & $\begin{array}{c}\text { Error } \\
\mathbf{k m}\end{array}$ & Station & $\begin{array}{c}\text { Lon. } \\
\mathbf{(}^{\circ}\end{array}$ & $\begin{array}{c}\text { Lat. } \\
\left.\mathbf{(}^{\circ}\right)\end{array}$ & $\begin{array}{c}\text { LAB } \\
\mathbf{k m}\end{array}$ & $\begin{array}{c}\text { Error } \\
\mathbf{k m}\end{array}$ \\
\hline TRIB & -51.33 & -20.67 & 144.8 & 14.8 & SJPY & -56.10 & -25.00 & 134.5 & 16.9 \\
ITRB & -50.36 & -19.70 & 175.2 & 27.6 & RPRD & -53.70 & -20.48 & 95.6 & 4.9 \\
FRTB & -49.56 & -23.34 & 104.2 & 27.7 & CRSM & -54.04 & -27.49 & 151.4 & 18.0 \\
CNLB & -50.85 & -29.31 & 95.4 & 6.2 & AMBA & -54.99 & -22.93 & 109.7 & 9.6 \\
PTGB & -52.01 & -24.72 & 85.8 & 3.4 & SPB & -47.43 & -23.59 & 82.7 & 5.9 \\
ITAB & -52.13 & -27.23 & 107.0 & 18.6 & RODS & -55.20 & -30.35 & 82.5 & 4.9 \\
C2SB & -52.84 & -18.77 & 86.8 & 6.0 & TBOT & -55.94 & -31.68 & 89.8 & 6.3 \\
PLTB & -53.60 & -31.76 & 87.1 & 3.6 & VABB & -46.97 & -23.00 & 89.7 & 3.4 \\
RCLB & -47.53 & -22.42 & 93.6 & 3.4 & & & & & \\
\hline
\end{tabular}

Blue: Stations located in the Paranapanema block

\subsubsection{Regional patterns}

Lithospheric thickness tends to vary according to tectonic units (Feng et al., 2007; Fischer et al., 2010; Kind and Yuan, 2018; Sun et al., 2018), then we estimated the average and standard variation $(\sigma)$ of our LAB estimates by geological provinces, shown in Figure 3.8 and Table 3.4. The shallowest LAB, between $80 \mathrm{~km}$ and $90 \mathrm{~km}$, is found at Borborema and Mantiqueira Provinces, and Pantanal and Chaco Basins, and it tends to have a smaller standard deviation $( \pm 20 \mathrm{~km})$, indicating less sparse values among the stations in these units.

Cratonic regions as Amazon, and São Francisco Craton, and Paranapanema block present a thicker lithosphere greater than 120 km; being consistent with Eaton et al. (2009) and Kind et al. (2012); finally, Paraná Basin presents an average lithosphere thickness of $\sim 100 \mathrm{~km}$, and a standard deviation greater than $30 \mathrm{~km}$. These provinces also present a high variation between the estimates, probably because of the misinterpreting between the LAB and MLD, discussed later. 


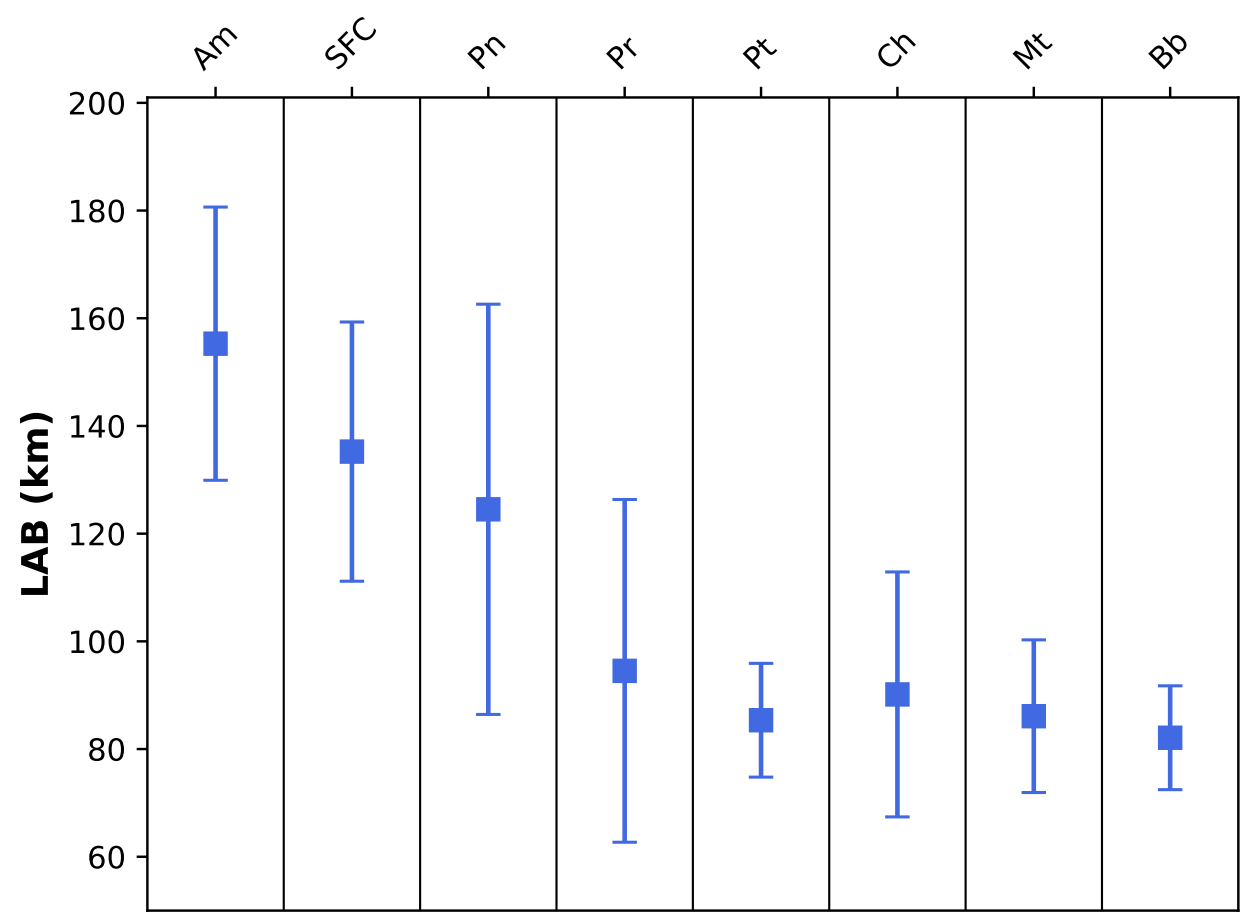

Figure 3.8: Average and standard variation $(\sigma)$ lithospheric thickness by geological provinces. Error bars represent one standard deviation $(\sigma)$. Am: Amazon craton, SFC: São Francisco Craton, Pn: Paranapanema Block, Pr: Paraná Basin, Pt: Pantanal Basin, Ch: Chaco Basin, Mt: Mantiqueira Province and Bb: Borborema Province.

Table 3.4 - Average lithospheric thickness by geological provinces.

\begin{tabular}{|c|c|c|}
\hline Tectonic unit & Average LAB (km) & Standard deviation \\
\hline Amazon Craton (Am) & 155.3 & 25 \\
São Francisco Craton (SFC) & 135.2 & 24 \\
Paranapanema block (Pn) & 124.5 & 38 \\
Paraná Basin (Pr) & 93.6 & 29 \\
Pantanal Basin (Pt) & 85.4 & 11 \\
Chaco Basin (Ch) & 90.1 & 23 \\
Borborema Province (Bb) & 82.1 & 10 \\
Mantiqueira Province (Mt) & 86.1 & 14 \\
\hline
\end{tabular}

Despite the patterns discussed, we analyze separately each one of the following geological provinces: (a) Borborema Province, (b) Mantiqueira Province, (c) Amazon Craton, (d) São Francisco Craton and (e) Pantanal, Paraná, and Chaco Basins, to better discuss the differences within each region. We present the SRF section of the stacked traces at each station, where the green mark indicates which negative arrival was considered as $S p$ conversion at LAB; and a lithospheric thickness map which also indicates the stations with unstable results (black triangles), where it was not possible to estimate the LAB. 
The stacked traces are reliable in most analyzed stations, showing a clear positive peak at $\sim 5$ seconds that represents the Moho discontinuity, and later negative peaks. When there was more than one negative arrival, we choose the one most consistent with nearby stations; and considering that in cratonic and older areas the LAB conversion arrives as a smaller second negative peak (Fischer et al., 2010; Kind and Yuan, 2018).

\section{- Borborema Province $(\mathrm{Bb})$}

Figure 3.9a shows a coherent negative arrival close to $\sim 9$ seconds $(\sim 80 \mathrm{~km})$, a slightly deeper LAB of $\sim 90 \mathrm{~km}$ is observed at inland stations: NBTA, NBPB. The deepest LAB $(\sim 100 \mathrm{~km})$ is observed at NMBO station, located on the Transbrasiliano Lineament; and the shallowest LAB $(\sim 70 \mathrm{~km})$ is found at NBAN station, in the coastal region of the Province (Figure 3.9b). On average, this region presents a thin LAB between $80 \mathrm{~km}$ and $100 \mathrm{~km}$, as reported by Heit et al. (2007), based on their results at RCBR station, also analyzed in the present work, in both cases this station presented a lithosphere about $80 \mathrm{~km}$ thick.

In the southern (NBAN, NBTA, and NBRF) and northern stations (NBPS, NBCL, and NBMO) it is observed a second later arrival between 15 and 20 seconds that could indicate some structure related to the closer cratons. Besides, some stations, as NBMO, NBPS, and NBPA present a wider LAB arrival, which can indicate a greater LAB transition area, instead of an abrupt velocity decrease.

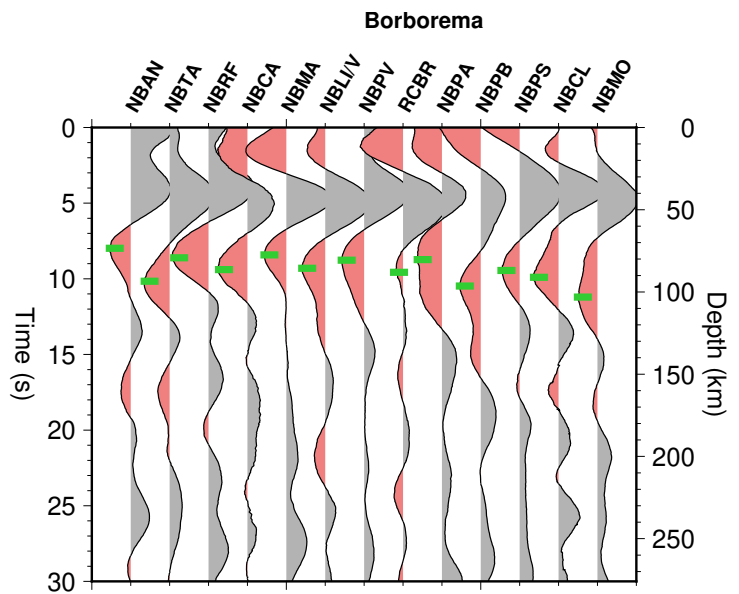

(a)

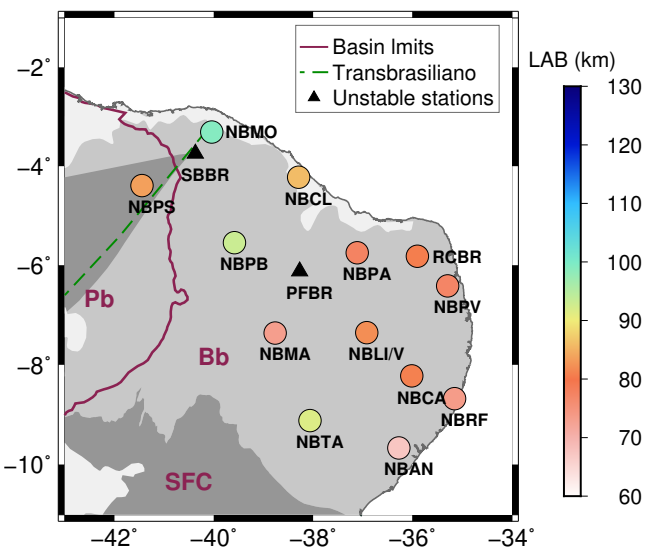

(b)

Figure 3.9: (a) SRF section sorted from south to north and (b) thickness lithosphere map for Borborema Province. Black triangles represent unstable stations with not reliable results. Shaded areas refer to the geological provinces shown in Figure 1.2. 


\section{- Mantiqueira Province}

The analyzed stations of this area are located at the ocean-continent margin, the arrival of the converted phase at LAB of most of them occurs close to $\sim 10$ seconds ( 100 km), however GUA01 and NAN01 stations, closest to São Francisco Craton, present later weaker phases between 12 and 15 seconds (Figure 3.10a), and therefore a thicker lithosphere.

As expected for a transition area, we found a thinner lithosphere that varies between $80 \mathrm{~km}$ and $100 \mathrm{~km}$, being thicker close to the border with São Francisco Craton where the LAB is up to $110 \mathrm{~km}$, as shown in Figure 3.10b.

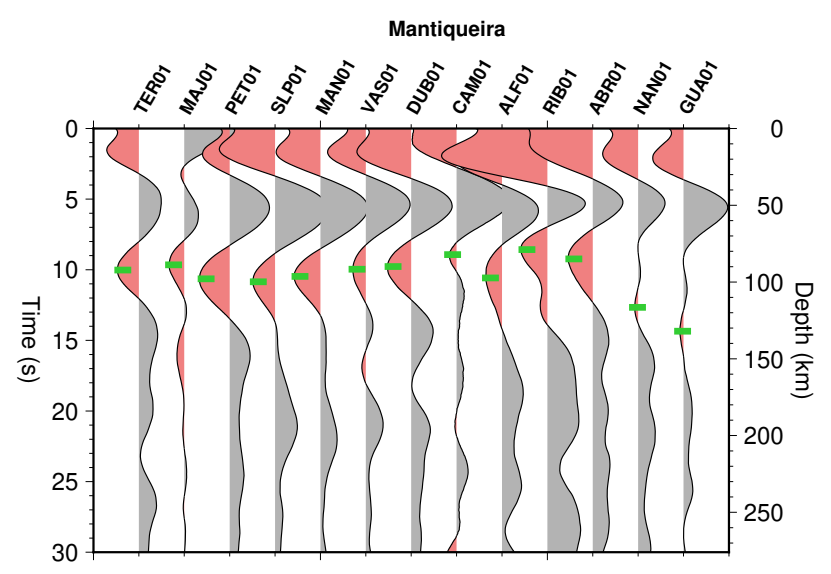

(a)

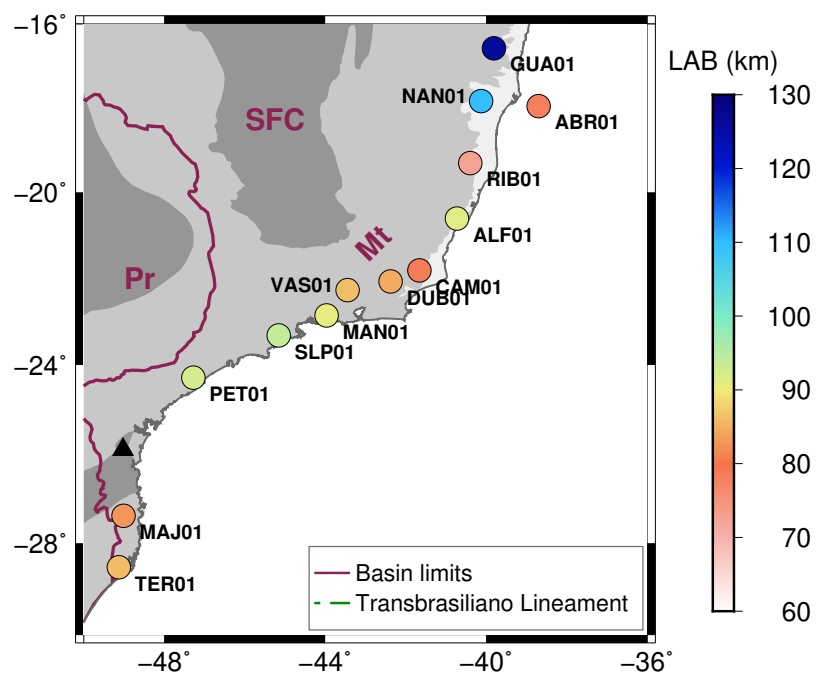

(b)

Figure 3.10: (a) SRF section sorted from south to north and (b) thickness lithosphere map for Mantiqueira Province. Shaded areas refer to the geological provinces shown in Figure 1.2. 


\section{- Amazon Craton}

In this region, we considered the Central Brazilian Shield (CBS) and Amazon Basin (Am), Figure 3.11a shows the SRF section. We have joined four stations in the BBSD trace, due to its proximity and the few good SRF traces at each one. Most of the stations present a first negative arrival at $\sim 10$ seconds $(\sim 100 \mathrm{~km})$, which could be interpreted as a midlithospheric discontinuity (MLD), widely reported in cratonic areas (Rychert and Shearer, 2009; Fischer et al., 2010; Yuan and Romanowicz, 2018; Priestley et al., 2018; Kind and Yuan, 2018; Sun et al., 2018), and defined as a second-order discontinuity between the Moho and LAB. This discontinuity would correspond to the base of the most chemically depleted layer indicated by xenoliths (Fischer et al., 2010; O’Reilly and Griffin, 2010).

The LAB conversion, second negative arrival according to Fischer et al. (2010); Kind and Yuan (2018), arrives at $\sim 19$ seconds $(172 \mathrm{~km})$ at the southernmost part of the CBS and is slightly refined to the north up to $\sim 150 \mathrm{~km}$ in VILB station. Most of the stacked traces show a clear LAB phase; however, NBRS and VILB stations show a weak signal that could indicate a small or gradual velocity change at the discontinuity.

The stacked traces at Amazon Basin show a less clear LAB phase, as pointed by previous works in cratonic areas, in the SRF traces the MLD generally is the highest negative signal, and later there is a weaker one at times corresponding to depths greater than $150 \mathrm{~km}$, associated with the LAB (Fischer et al., 2010; Kind and Yuan, 2018), as it is observed at ETMB and TBTG stations. In some cases, any deeper phase is recognizable or the lobule is wide, which indicates a gradual velocity gradient (O'Reilly and Griffin, 2010), as in BOAV station.

Figure 3.11b shows that the lithospheric thickness varies between $100 \mathrm{~km}$ and $200 \mathrm{~km}$ depth, in agreement with previous observations in other cratonic areas over the world (Eaton et al., 2009), the thinner lithosphere at NBRS station is probably due to its proximity with the Pantanal and Paraná Basins. Feng et al. (2004) also estimated a thick lithosphere deeper than $150 \mathrm{~km}$ in the Amazon Craton, based on anomalies of S-wave velocities. Unfortunately, at SAML international station and the other three 
stations belonging to XC deployment, it was not possible to obtain reliable results.

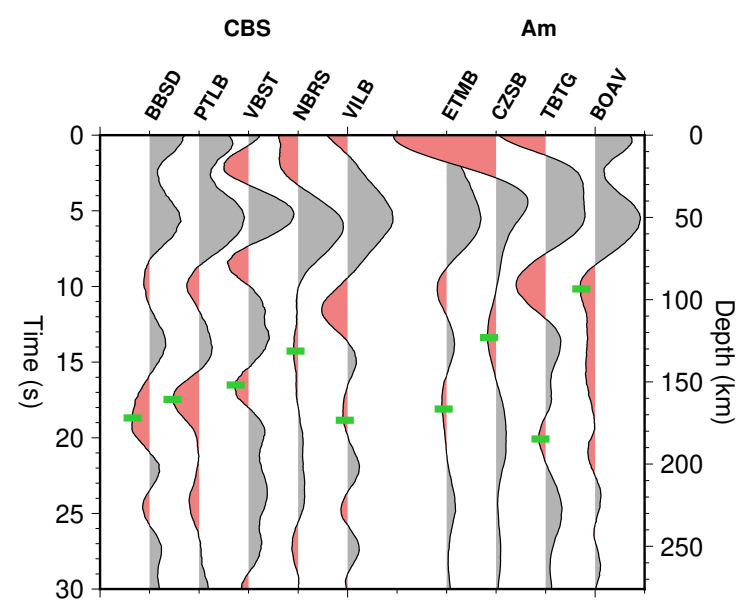

(a)

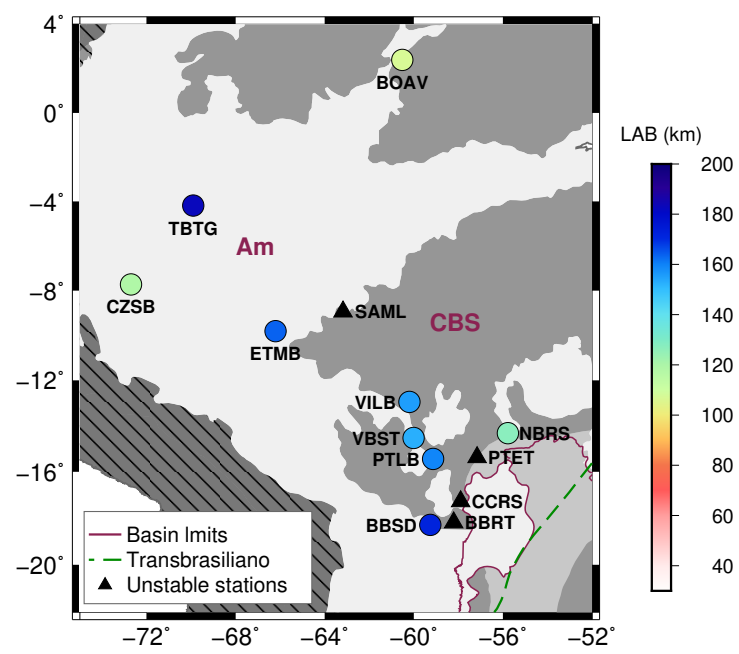

(b)

Figure 3.11: (a) SRF section for Amazon Craton, grouped in Central Brazilian Shield (CBS) and Amazon Basin (Am), green marks show LAB phases. (b) Lithospheric thickness map for the Amazon Craton. Shaded areas refer to the geological provinces shown in Figure 1.2.

\section{- São Francisco craton (SFC)}

In this area, all stations present a first and greater negative arrival at $\sim 10$ seconds (Figure 3.12a); as commented before, this phase is related to the MLD in cratons (Rychert and Shearer, 2009; Fischer et al., 2010; Yuan and Romanowicz, 2018; Priestley et al., 2018; Kind and Yuan, 2018; Sun et al., 2018). When there is a second arrival, even weak, we tend to interpret it as the LAB phase; and also taking care to maintain the consistency with nearby stations. An interesting pattern is observed in the two southernmost stations, where there is a third coherent arrival later than 20 seconds, which also appears in the stations of the middle part (NBIT, ANA01, GDU01, NBCP, and SDBA) between 20 and 26 seconds, thickening toward the north.

The inland stations present a lithosphere up to $150 \mathrm{~km}$ (Figure 3.12b) in concordance with several previous studies at global cratonic areas, that suggest a thick lithosphere greater than $120 \mathrm{~km}$ (Eaton et al., 2009). Heit et al. (2007) estimated a LAB depth of $160 \mathrm{~km}$ at one station close at the southwestern edge of the SFC, and Assumpção et al. (2017) also suggest a thicker lithosphere up to $200 \mathrm{~km}$ in the central and southern pasts, which correlates well with our results. 
The stations located in the central coastal part also present a thick lithosphere of $\sim 150 \mathrm{~km}$; however, at the south and north limits the LAB is shallower $(>120$ $\mathrm{km}$ ), probably due to the Atlantic opening. It is important to highlight that coastal stations from SFC craton present a deeper LAB than coastal stations from Borborema and Mantiqueira Provinces.

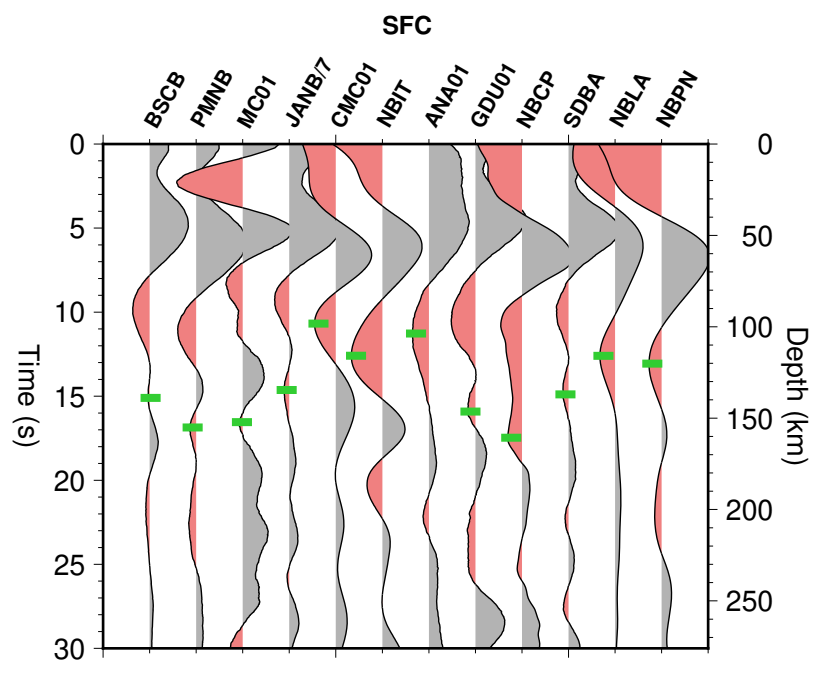

(a)

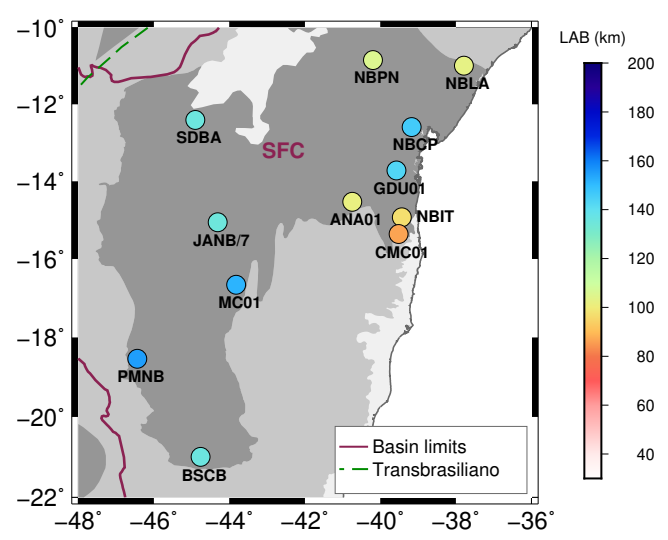

(b)

Figure 3.12: (a) SRF section sorted from south to north and (b) thickness lithosphere map for São Francisco craton. Shaded areas refer to the geological provinces shown in Figure 1.2.

\section{- Paraná, Pantanal and Chaco Basins}

The stations in the Paraná Basin were divided into two groups: those located in the area without a presence of a cratonic nucleus, and those located in the Paranapanema cratonic block according to Milani and Thomaz Filho (2000); Julià et al. (2008). In the first group (Figure 3.13a), most traces present a first negative arrival at $\sim 10$ seconds, coherent with the MLD phase, discussed before; nevertheless, when a later negative arrival is recognizable, even weak, this was interpreted as LAB conversion, in agreement with Fischer et al. (2010) for stable and older areas. In some stations, these negative arrivals are weak (e.g. TBOT and FRTB), which could indicate gradual velocity changes at both MLD and LAB depths.

The SRF section of the stations located in the Paranapanema block is shown in Figure $3.13 \mathrm{~b}$, four of the six stations present a strong arrival at $\sim 10$ seconds that could be interpreted as the MLD, already reported in other world cratonic areas. As in previous cases, some stations (BB19B, TRIB, ITRB) present two negative phases 
that would correspond to the MLD and LAB, interpreting the latter one as the LAB. The lack of a second arrival, later than $\sim 10$ seconds, in the other stations could be caused by the low velocity contrast at the LAB, and therefore cannot be identified with the SRF method.

Stations from Pantanal Basin (Figure 3.13b) show a LAB arrival at $\sim 9$ seconds $(\sim 80 \mathrm{~km})$. Despite the coherency in most stations, at AQDB and MURT stations this arrival is weaker and presents a later higher signal at $\sim 19$ seconds $(\sim 170 \mathrm{~km})$ and $\sim 23$ seconds $(\sim 210 \mathrm{~km})$ respectively, in both cases we choose the earlier arrival due to its consistent with nearby stations. RVDE station also presents two negative arrivals with similar amplitudes, interpreting the earlier one as the LAB. Finally, the few stations with reliable results at Chaco Basin show a consistent negative arrival at $\sim 10$ seconds, in this area we only processed one permanent station (CPUP) with several years of operation, also processed by (Heit et al., 2007), and both results are consistent.

The eastern edge of Pantanal Basin presents a thinner LAB of $\sim 80 \mathrm{~km}$; however, the BDQN station, located on the Rio Apa block, has a deeper LAB of $\sim 110 \mathrm{~km}$. Rocha et al. (2019) also founded a positive anomaly of $1 \%$ of P-wave velocity at 100 $\mathrm{km}$ depth in the Pantanal Basin, which reinforces our results. Toward Chaco Basin, the lithosphere is slightly thinned to $\sim 100 \mathrm{~km}$ (Figure 3.13c).

In the middle of Paraná Basin, we observed a lithospheric thickness of $\sim 100 \mathrm{~km}$, while in the Paranapanema block and in the southeastern part of the basin is notably a thicker one, up to $180 \mathrm{~km}$. Besides, there are significant differences between close stations due to the interpretation of the LAB or MLD; as commented before, if the $\mathrm{SRF}$ trace presents two negative arrivals, we considered the second one as the LAB phase. However, some stations only present one negative arrival probably related to the MLD, and the LAB phase is not present (Kind and Yuan, 2018). 


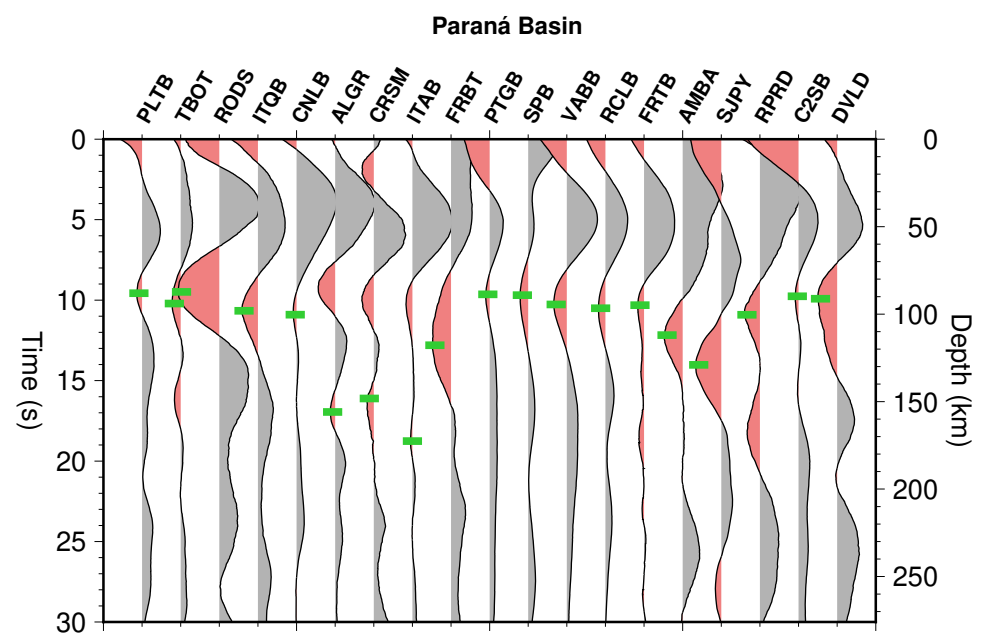

(a)

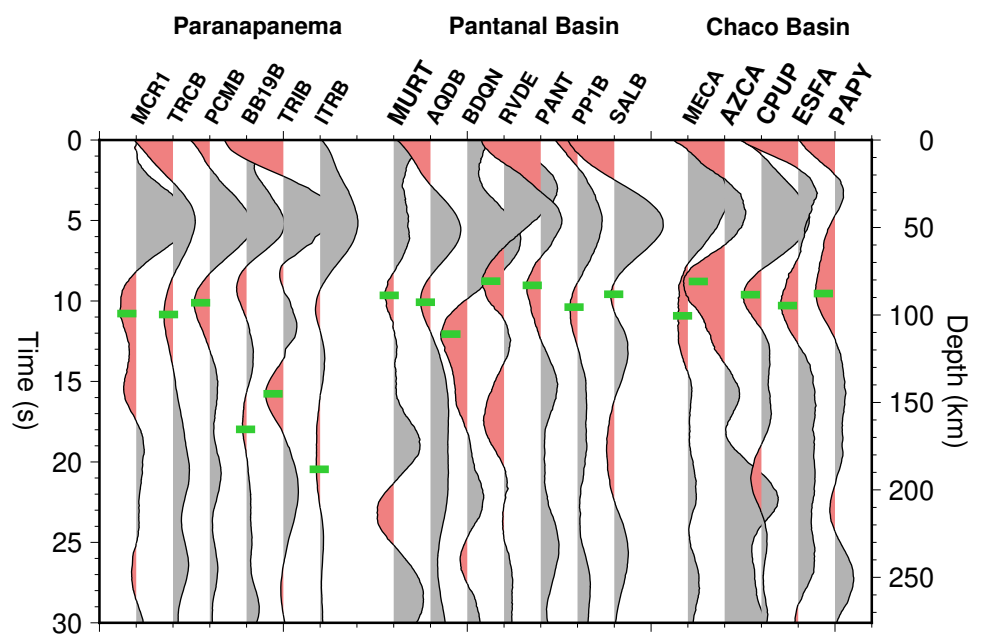

(b)

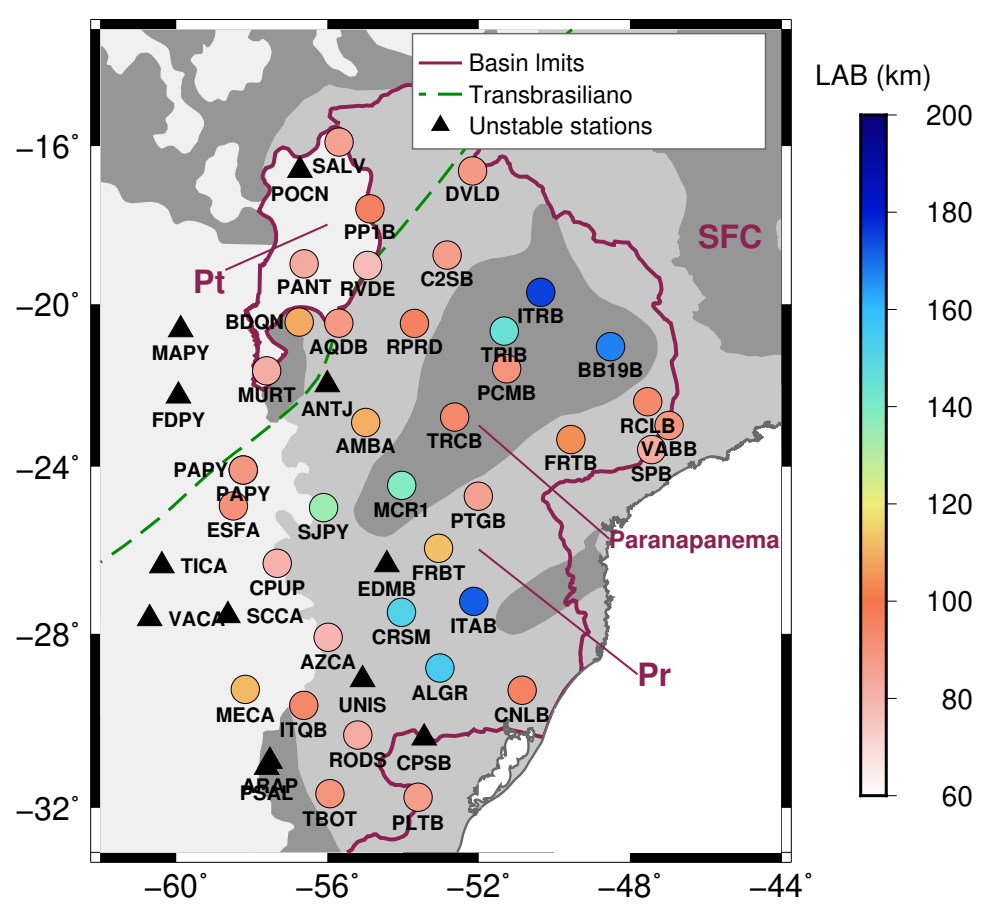

(c)

Figure 3.13: (a) SRF section of Paraná Basin, (b) SRF section of Paranapanema block, Pantanal and Chaco Basins (c) Lithospheric thickness map for Pantanal, Paraná and Chaco Basins. Shaded areas refer to the geological provinces shown in Figure 1.2. 
Extending the discussion of the Paraná basin, Dragone (2018) estimated a lithosphere of $\sim 80 \mathrm{~km}$ from magnetotelluric (MT) data, and knowing that the most likely causes of the MLD are the radial anisotropy and the presence of hydrous minerals, the MT method could not identify this discontinuity (Selway, 2018). These results lead us to wonder if the first arrival observed in Figure 3.13a would be the MLD or LAB? Some authors interpreted the first arrival close to $\sim 10$ seconds as the LAB in younger areas, and as the MLD in older and more stable regions Rychert and Shearer (2009); Fischer et al. (2010); Kind and Yuan (2018) which leads us to believe that our interpretation of the second arrival as the LAB is correct. Besides, tomographies of S-wave (Feng et al., 2007) and P-wave (Rocha et al., 2019) do not show negative velocity anomalies at $100 \mathrm{~km}$ depth in the Paraná Basin. Only with SRF, it is harder to establish a clear distinction of the LAB and MLD conversions, we believe that it is necessary to do more geophysical studies to reach a conclusion.

Because of the lower amount of available data in the area, mostly in the XC stations (Table 3.1), and the lack of clarity to distinguish between MLD and LAB; we also stacked the SRF traces by piercing points at a depth of $120 \mathrm{~km}$, in areas of $2^{\circ} \times 2^{\circ}$ (Figure 3.14). This stacking method is widely used to resolve mantle discontinuities due to it groups all the events that have a phase conversion in the same area Shen et al. (2003); Sun et al. (2007); Liu et al. (2016). The piercing point is defined as a position in a given depth (imaginary interface) where a seismic wave is converted from $\mathrm{S}$ to $\mathrm{P}$ (in this case). When this interface is shallower (e.g Moho) most of the piercing points are close to the station, but the deeper it is they move further away from the station.

The density of piercing points in the Paraná Basin reaches up to 200 traces per box (Table 3.5), decreasing toward the Chaco Basin and north of the basin. In some boxes, there were no available traces, or the staked one was noisy due to the few piercing points (cells highlighted in Table 3.5). 
Table 3.5 - Number of events stacked by boxes. One box is indicated by using a letter (column) and a number (row) as shown by the table, and enhanced in Figure 3.14.

\begin{tabular}{|c|c|c|c|c|c|c|c|c|}
\hline & $\mathbf{A}$ & $\mathbf{B}$ & $\mathbf{C}$ & $\mathbf{D}$ & $\mathbf{E}$ & $\mathbf{F}$ & $\mathbf{G}$ & $\mathbf{H}$ \\
\hline $\mathbf{1 2}$ & 11 & 6 & 0 & 1 & 0 & 0 & 0 & 0 \\
$\mathbf{1 1}$ & 37 & 17 & 14 & 3 & 0 & 0 & 0 & 0 \\
$\mathbf{1 0}$ & 53 & 34 & 36 & 29 & 20 & 0 & 1 & 1 \\
$\mathbf{9}$ & 79 & 38 & 67 & 72 & 51 & 73 & 14 & 5 \\
$\mathbf{8}$ & 30 & 86 & 104 & 113 & 106 & 117 & 46 & 15 \\
$\mathbf{7}$ & 27 & 83 & 152 & 194 & 210 & 243 & 84 & 24 \\
$\mathbf{6}$ & 31 & 66 & 118 & 190 & 178 & 214 & 149 & 46 \\
$\mathbf{5}$ & 14 & 28 & 102 & 132 & 73 & 123 & 78 & 11 \\
$\mathbf{4}$ & 44 & 49 & 66 & 158 & 57 & 18 & 0 & 0 \\
$\mathbf{3}$ & 17 & 75 & 107 & 96 & 86 & 30 & 4 & 0 \\
$\mathbf{2}$ & 7 & 81 & 105 & 76 & 62 & 38 & 5 & 0 \\
$\mathbf{1}$ & 5 & 3 & 39 & 54 & 26 & 0 & 1 & 0 \\
\hline
\end{tabular}

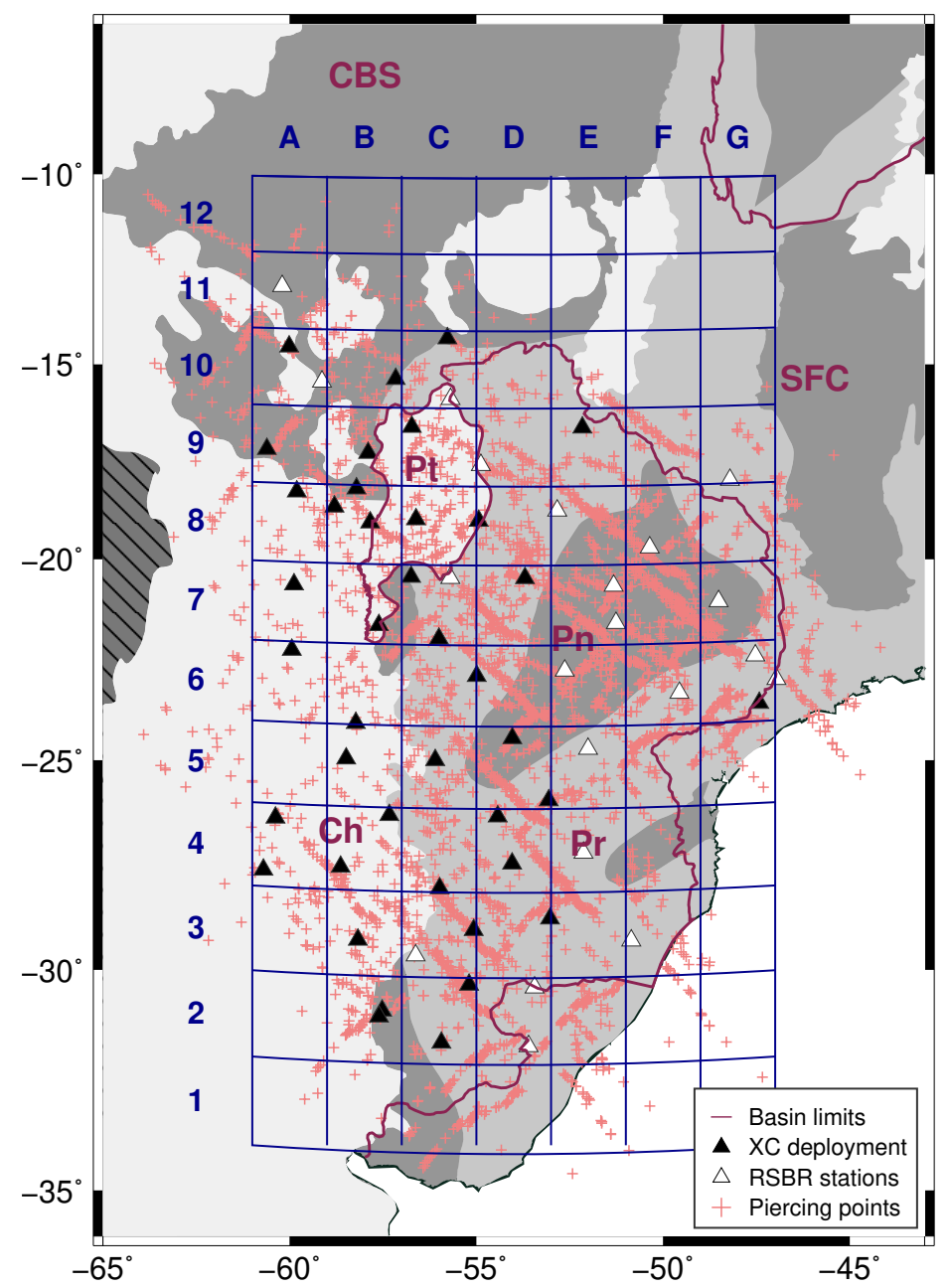

Figure 3.14: Areas delimited for stacking by piercing points. Pink crosses: piercing points at $120 \mathrm{~km}$ depth according to the IASP91 model. 

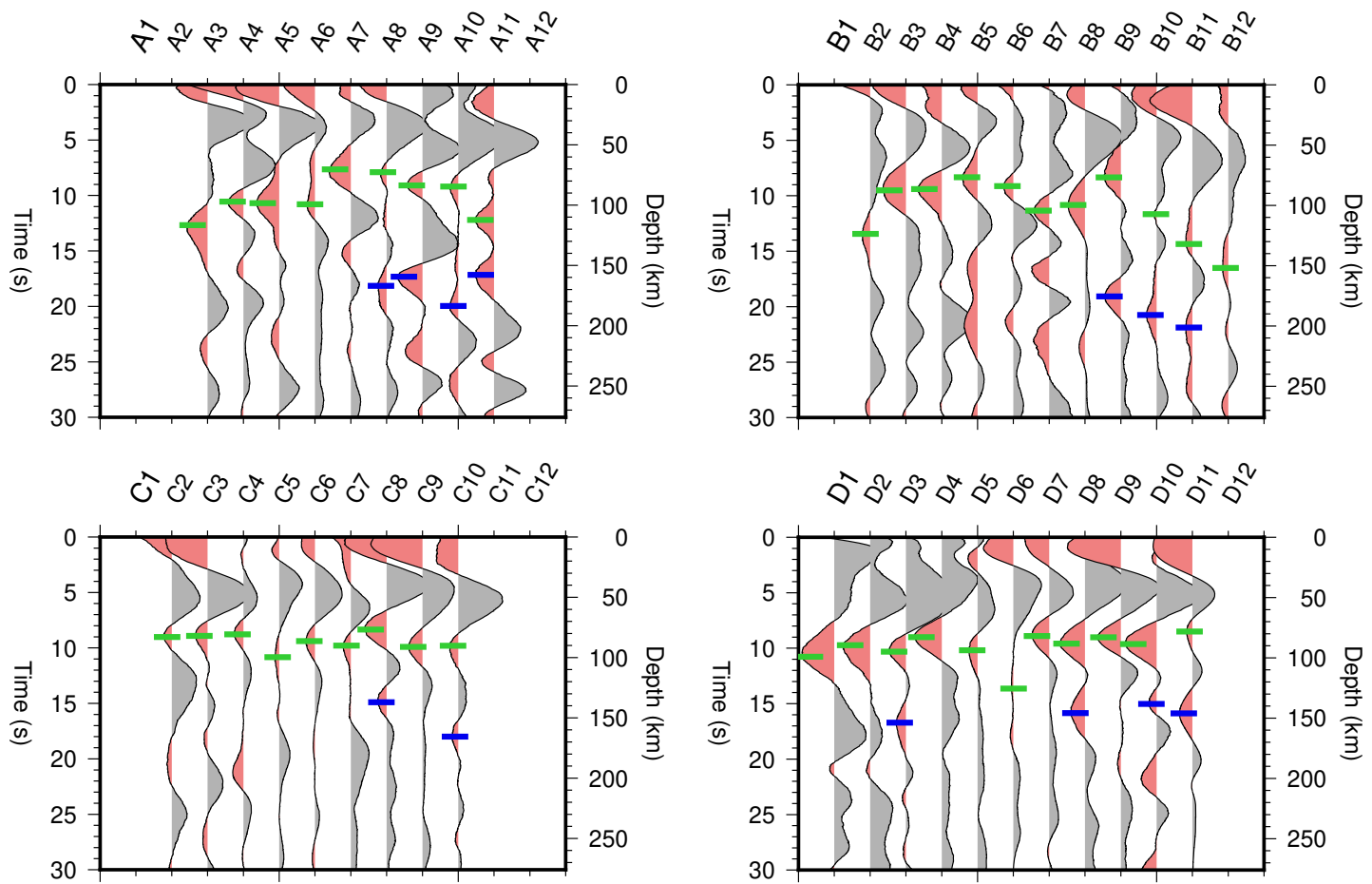

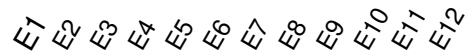

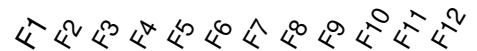
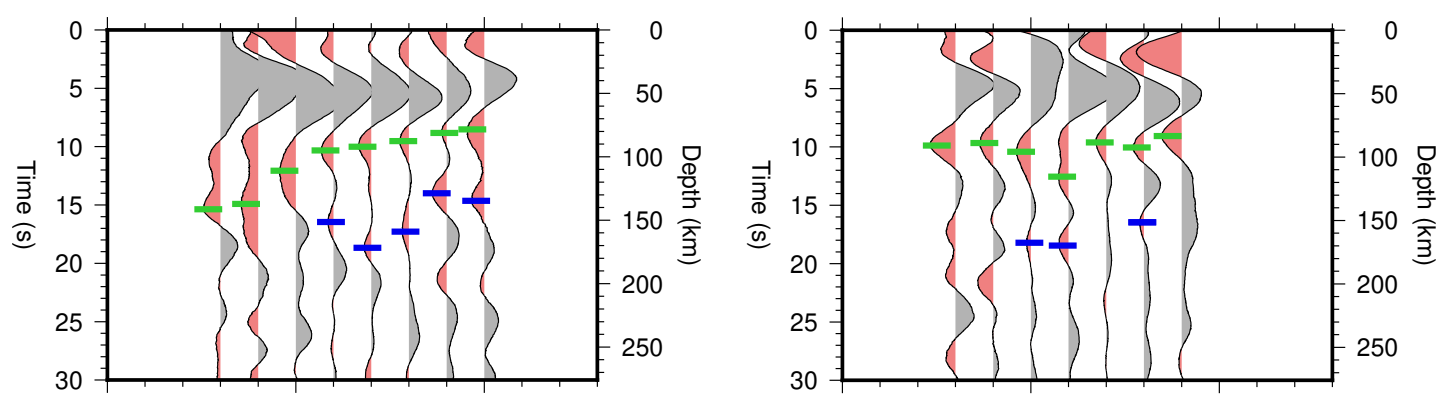

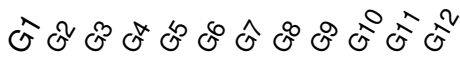

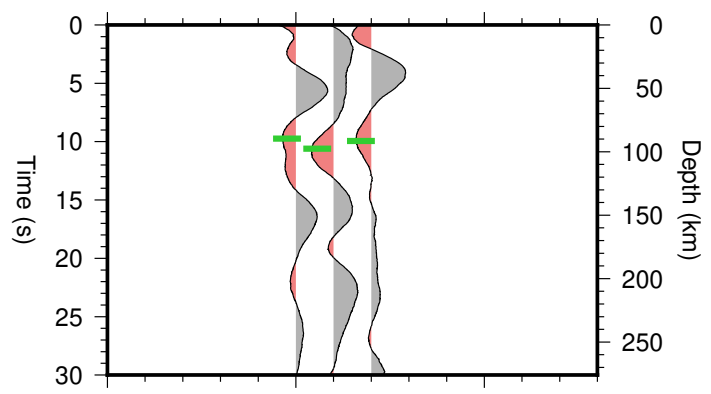

Figure 3.15: Stacked traces by piercing points in each box. Green mark is the first negative arrival and blue mark the second one.

Figure 3.15 shows the stacked trace at each box, the green mark is the first negative arrival and the blue mark the second one, which also could represent the LAB. For boxes that cover part of the Amazon craton (A8 to A11, B9 to B11, C10, D10, and D11) we observe two negative arrivals, also observed in the stacking by station. The 
same pattern is observed in the northern part of the Paraná basin, including the Paranapanema block (D6 to D9, E6 to E10, and F6 to F8).

The two negative arrivals are consistent with the results obtained stacking by stations, toward the Amazon Craton it is observed a thickening of the lithosphere, as well as in the northern and southernmost part of the Paraná Basin. Figure 3.16 compares the results obtained stacking by stations and by piercing points. In Figure 3.16b we present a LAB depth obtained from stacking by areas (piercing points), considering the first negative arrival (circles) and the second one, if exist (squares). The most general characteristics are conserved: a thicker lithosphere in the Amazon Craton, southeast and north part of the Paraná Basin, and a shallower LAB of $\sim 90$ $\mathrm{km}$ in the Pantanal and Chaco Basins.

The larger difference is observed to the south of Paranapanema block, that the stacking by piercing points looks to miss the second conversion, making the LAB at the Paraná Basin more uniform.

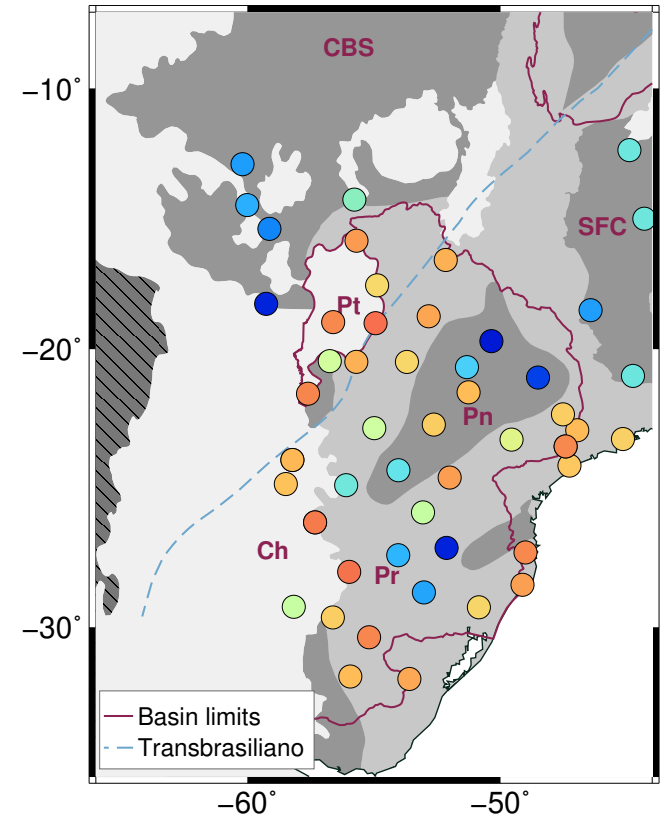

(a)

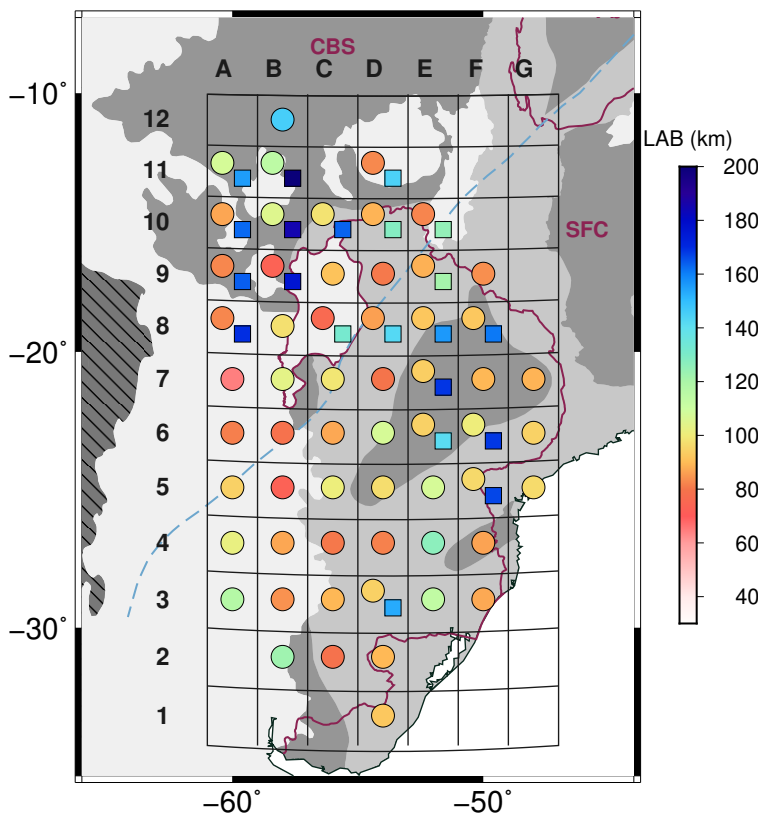

(b)

Figure 3.16: Lithospheric thickness in Pantanal, Paraná, and Chaco Basins from stacking by stations (a) and stacking by areas (b). Circles are the depth at first negative arrival and squares at the second one.

The most remarkable findings from analyzing the SRF sections are: 
- In order to obtain good results using the S-wave receiver function method it is necessary a good amount of available data, at least 100 good SRF traces to stack. Temporary deployment stations, mostly located at Pantanal, Paraná, and Chaco Basins, have reliable results despite their short operating time, and therefore little available data (Table 3.1).

- Several stations analyzed show a wide and weak LAB arrival, which could indicate that this boundary is often gradual instead of a sharp velocity change, being better described as a transition (Eaton et al., 2009; Kind et al., 2012; Sun et al., 2018), or that the impedance contrast is low. When the transition to the asthenosphere is gradual and extends more than $30 \mathrm{~km}$, the $S$ to $P$ conversion is not efficient and does not appear in the SRF traces (Fischer et al., 2010; Kind and Yuan, 2018).

- At cratonic and older areas we observed a greatest negative arrival close to $\sim 10$ seconds, which corresponds to a depth of $\sim 90 \mathrm{~km}$, several studies have correlated this feature with a midlithospheric discontinuity (MLD), located between depths of $80 \mathrm{~km}$ and $120 \mathrm{~km}$, beneath cratons around the world (Sun et al., 2018). Its nature and formation, still in discussion, involve compositional and thermal factors, as well as anisotropy. Fischer et al. (2010) propose that the MLD could reflect an alteration of the cratonic lithosphere by melt migration; however, only partial melt is ruled out because the cratonic lithosphere is cold (Sun et al., 2018).

\subsubsection{LAB vs. seismicity}

Even though most earthquakes occur at tectonic plate borders, e.g. subduction zone at the west limit of South America; intraplate earthquakes represent almost $15 \%$ of the global seismicity (Fowler, 2005). Agurto-Detzel et al. (2015) correlated the distribution of intraplate seismicity with geophysical parameters and founded that seismicity tends to occur in areas with higher heat flow $\left(>80 \mathrm{~W} / \mathrm{m}^{-2}\right)$ and negative S-wave anomalies in the lithosphere, that are properties related to the lithospheric thickness. Assumpção et al. (2004) and Rocha et al. (2016) also correlated Brazilian intraplate seismicity with a thinning of the lithosphere.

We qualitatively compared our LAB results with the Brazilian seismicity obtained 
from the most recent Seismic Bulletin Information (http://www.moho.iag.usp.br/eq/ bulletin/) and filtered considering the detection limit thresholds discussed by Bianchi et al. (2018). Areas with thinner lithosphere, such as Borborema and the coastal part of Mantiqueira Province, have higher seismicity. In the south of SFC also is observed seismic activity, despite the thicker lithosphere, as shown in Figure 3.17.

The thinner lithosphere estimated at the eastern edge of the Pantanal Basin correlates well with the high seismicity of the area. Paraná Basin, which presents a thicker lithosphere, seems to be a stable area, with very few events. Unfortunately, we do not have LAB estimates over all the Amazonian craton; however, close to the areas with thicker lithosphere there is no high seismicity. To the north of the craton, where the estimated LAB is $120 \mathrm{~km}$ depth some events of magnitude up to 4 were reported; the high seismicity reported at the west of the craton is related to the Nazca plate subduction and cannot be associated with any shallow structure like the lithosphere thickness.

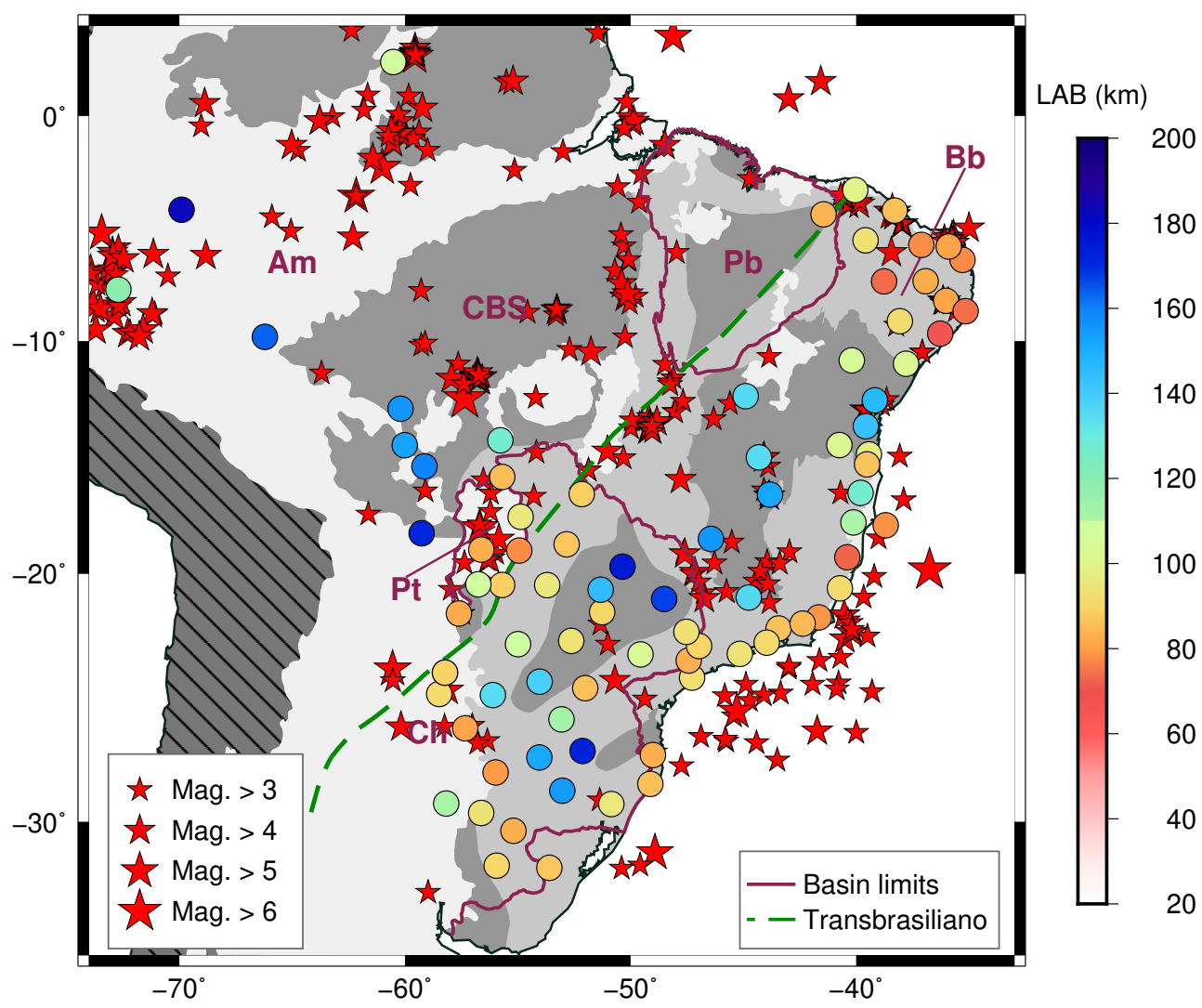

Figure 3.17: Seismicity vs Lithospheric thickness. Bb: Borborema Province, Am: Amazon Basin, CBS: Central Brazilian Shield, SFC: São Francisco Craton, Ch: Chaco Basin. Purple line delimits large intracratonic basins: Paraná $(\mathrm{Pr})$, Pantanal $(\mathrm{Pt})$ and Parnaíba $(\mathrm{Pb})$. Red stars: Events with magnitude $>3$. Green dashed line: Transbrasiliano Lineament. Shaded areas refer to the geological provinces shown in Figure 1.2. 


\subsubsection{LAB vs. heat flow}

Heat flow reflects the thermal structure, evolution, and geochemistry of the lithosphere, and therefore it is highly correlated with its thick, e.g. old cratonic areas present low heat flow and thicker lithosphere (Fischer et al., 2010). The latest compilation of world heat flow data was presented by Davies (2013); unfortunately, it has a very sparse distribution of constraint points in South America. Figure 3.18 shows the heat flow map in South America, as well as the lithospheric thickness estimated in the present work. Despite the low resolution of the heat flow grid of $2^{\circ} \times 2^{\circ}$, we observe a good overall agreement: areas with greater heat flow present thinner lithosphere, as Borborema, most of Mantiqueira Province, and Pantanal Basin. On the other hand, cratonic colder and older areas, such as Amazonian, São Francisco Craton, and Paranapanema block present a deeper LAB.

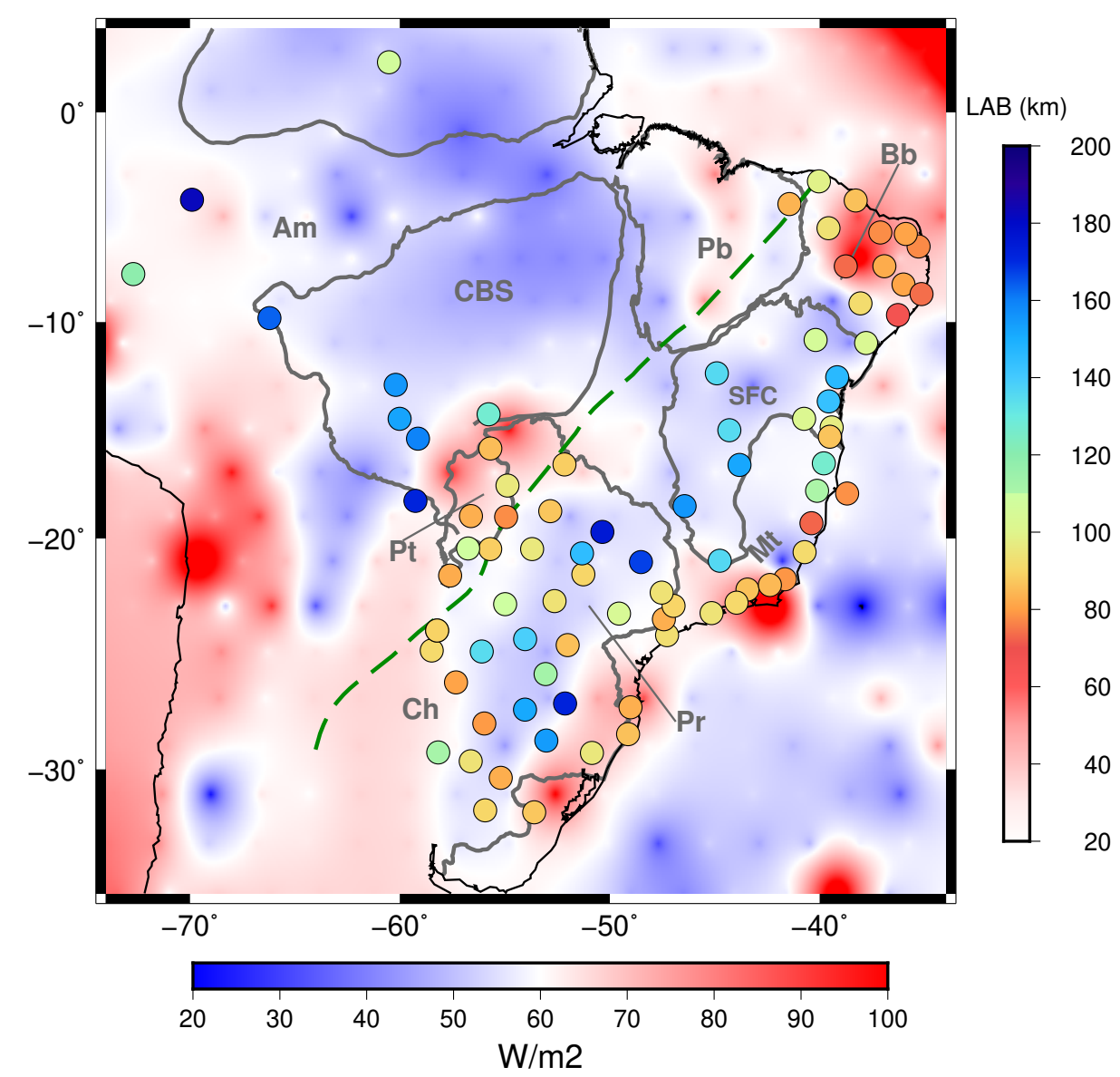

Figure 3.18: Heat flow (Davies, 2013) vs lithospheric thickness. Grey line delimits main geological provinces shown in Figure 1.2, Am: Amazonian Basin, CBS: Central Brazilian Shield, Pt: Pantanal Basin, Pr: Paraná Basin, Ch: Chaco Basin, SFC: São Francisco Craton, Pb: Parnaíba Basin, Mt: Mantiqueira Province and Bb: Borborema Province. Green dotted line: Transbrasiliano Lineament. 
In cratonic areas, where the LAB depth was estimated about $\sim 100 \mathrm{~km}$, it is possible that we misinterpreted the LAB with MLD, if this midlithospheric discontinuity is related to a migration of partial melting, as proposed by Fischer et al. (2010), it is expected that these areas present greater values of heat flow which is not observed in Figure 3.18.

Additional to the manual readings presented in Figures 3.7 and 3.18, we prepared a second set of automatic measurements, with the objective of not being biased by the interpreter. The automatic procedure searched for the largest negative peak between 0 and 20s. Those time values were converted to depth, and Figure 3.19 presents a plot of heat flow versus automatic measurements, where we can observe that, to some degree, part of the measurements are linearly correlated to each other.

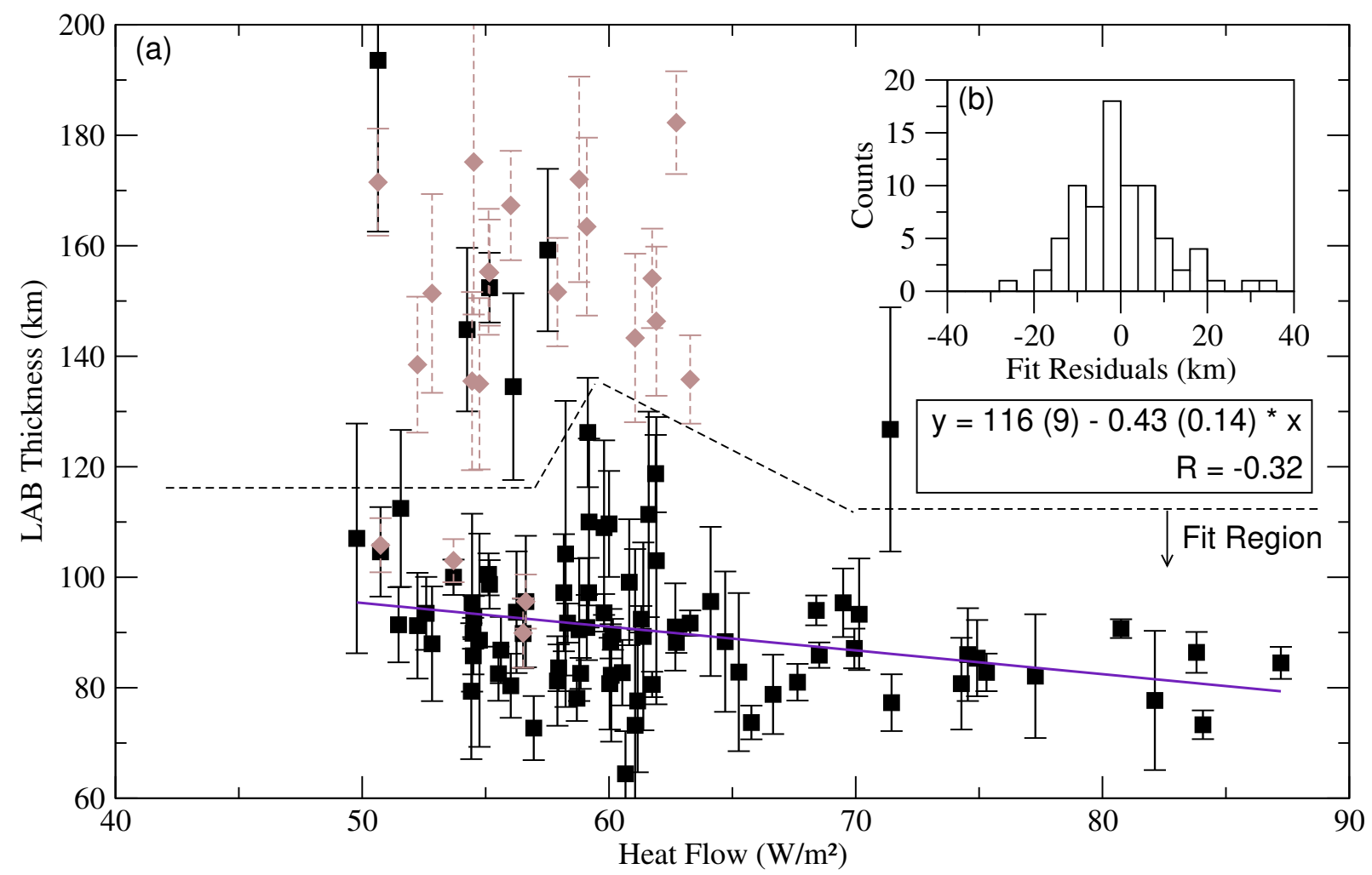

Figure 3.19: Heat flow and lithospheric thickness correlation. Black squares: automatic dataset. Brown diamonds: manual readings that have different values than the automatic dataset. Purple line: linear regression of the automatic dataset for the points inside the fit region. Picture embedded: histogram of the regression residuals.

We made a linear regression between the heat flow and lithospheric thickness from automatic picks, remembering that the highest negative arrival could be the MLD or LAB, as interpreted in the manual set. The regression only considered lithospheric thicknesses smaller than $\sim 130 \mathrm{~km}$, area below the dotted line in Figure 3.19, and indicates a linear 
trend between the values. Despite the low correlation coefficient (0.32), the residuals tend to have a normal distribution, indicating that the observed variations can be due to noise measurements or other non-systematic fluctuations in the observed values. We observe a possible variation of $0.43 \mathrm{~km} / \mathrm{W} / \mathrm{m}^{2}$ and a minimum expected conversion depth of $116 \mathrm{~km}$.

While the fit presented in Figure 3.19 can accommodate the readings below the $\sim 130$ $\mathrm{km}$ depth, it is unequivocal that the SRF traces show double negative phases located in a region of low heat flow $\left(<65 \mathrm{~W} / \mathrm{m}^{2}\right)$, even for the automatic measurements. Another way to interpret the data presented by this figure is that both readings are showing different features, and they should not be mixed.

The first, shallower, and mostly clear negative conversion should be interpreted as the MLD; and the second and deeper conversion should be attributed to the LAB. While for regions with higher heat flow the LAB is not observable, probably because the velocity structure of the lithosphere does not permit that the low-velocity transition from the LAB be evident anymore, being clear only the low-velocity transition associated to the MLD, that is reinforced by the high heat flow and melt migration or other compositional processes.

A schematic diagram for this idea is presented in Figure 3.20, where we reinforce the idea that the high heat flow changes the velocity structure of the upper mantle (reducing the velocity of the lithosphere as a whole) making impossible the detection of the LAB by the SRF; in these cases, the only negative arrival should be attributed to the proposed MLD. Of course, if this is the real case, the maps shown in Figures 3.7 and 3.18 should be split into two maps, one with the thickness of the LAB, and another with the thickness of the MLD. However, going further, when we observe the brown diamonds in Figure 3.19 (manual different lecture) we do not observe any correlation with the heat flow. This could be due to the amount of data, or just because the LAB thickness, as originally proposed by the seismological methods, is not dependent on temperature in the interval that it can be detected by the SRF method.

It is clear that while SRF alone will not be able to resolve this problem, the MLD or another low-velocity discontinuity should be proposed to explain the observed data. Meanwhile, the seismological LAB continues as an important matter in the frontier of the seismological methods, while our results indicate that it is present in some cratonic regions 
and absent (or not detectable) in high heat flow areas. On the other hand, the MLD is present in all regions and shows a trend with the observable heat flow values. Finally, we don't observe any trend with LAB depth and heat flow in cratonic and older regions.

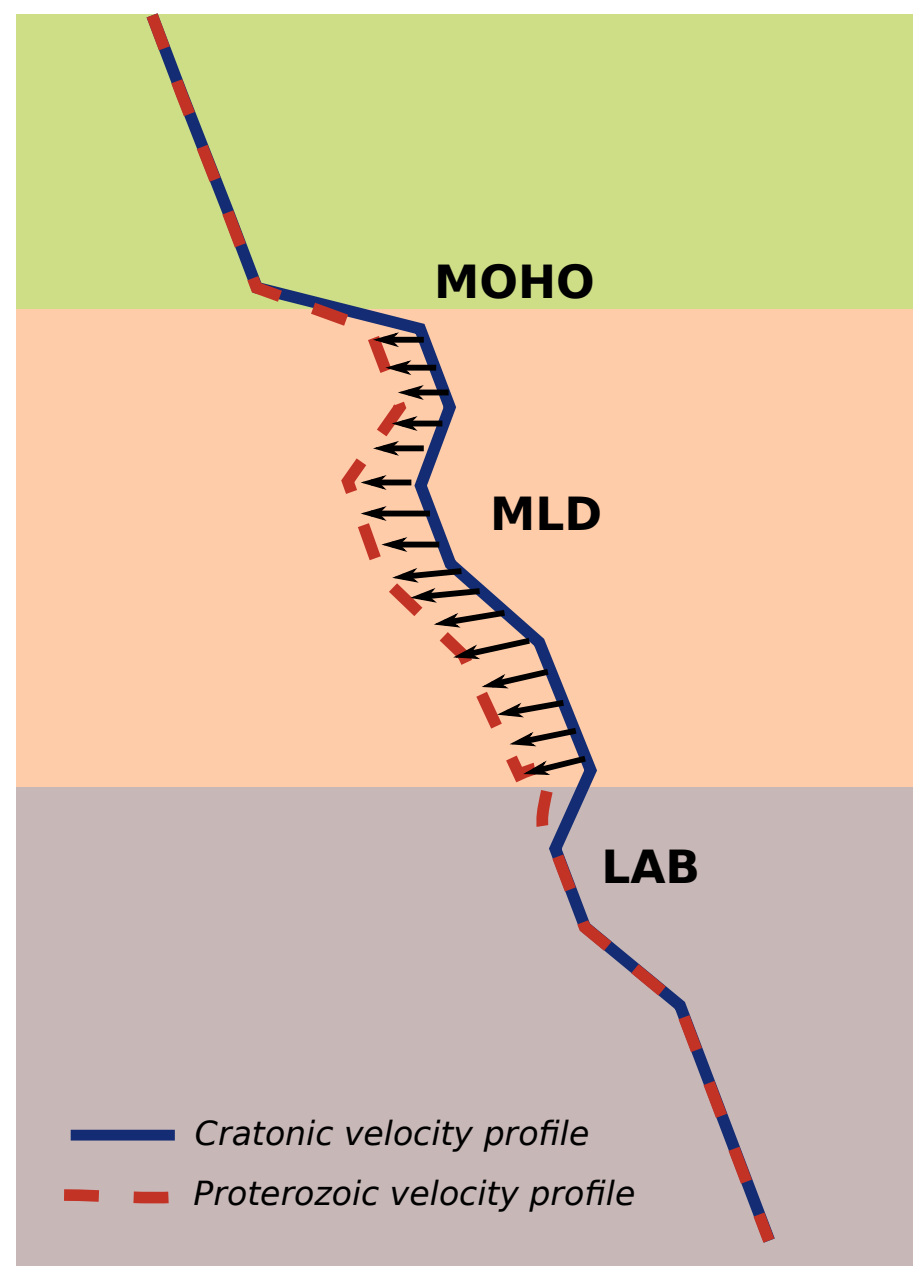

Figure 3.20: Schema for lithospheric structure in areas with lower and higher heat flow. For colder lithospheres the phase conversion at the LAB is stronger, while at hotter areas this conversion tends to be weaker, being not noticeable at SRF. 
Chapter 4

\section{D a-priori velocity model for South American Platform}

In this chapter, we present the methodology followed to build a 3D velocity model for the South American platform (SAP), combining the detailed information of crustal thickness obtained in Chapter 2 with other global and regional geophysical studies, enabling to assemble a model that captures the most important heterogeneities of the crust and upper mantle. This work was carried out under the supervision of the researcher Yvonne Font, Ph.D. at Geoázur Laboratory-Observatoire de la Côte d'Azur (France), from the Research Institute for Development (IRD).

\subsection{Introduction}

Despite more than $90 \%$ of the earthquakes occur in the limits of tectonic plates, the stable area of South America, mainly Brazil, has an important seismicity (Figure 4.1), whose origin is still not well understood. Earthquakes are distributed throughout Brazil, being the northeastern part one of the most active areas; yearly it is observed at least two events of magnitude $4.0 \mathrm{mb}$ and it is expected one of magnitude $5 \mathrm{mb}$ every five years (Bianchi et al., 2018). Most of these events are initially located using 1D standard velocity models (e.g. IASP91, AK135) and the associated uncertainties do not permit correlating the epicenters with geological information. Another model used routinely for locating earthquakes is a 1D model, self-entitled NewBR and used by the USP seismological group for local and regional events of major significance. This model tries to mimic regional travel times (Assumpção et al., 2010). 
The use of $3 \mathrm{D}$ velocity models significantly improves the earthquake location on a regional scale since they capture the velocity heterogeneities mainly of the crust and upper mantle and better predict the travel times. The error in travel time prediction at regional scale when using 1D velocity models could exceed 8 seconds (Myers et al., 2010). Despite the advantage of using 3D velocity models to locate accurately regional earthquakes, the travel time calculation is easier for 1D velocity models, which makes it more convenient for monitoring systems; nevertheless, many studies have focused to relocate regional or local seismicity with regional and local 3D velocity models (Font et al., 2003; Wu et al., 2008; Lin, 2013; Nugraha et al., 2018).

The global 3D RSTT model (Myers et al., 2010) and the iLoc algorithm (Bondár and Storchak, 2011) have been used successfully to relocate regional events in areas such as Hungary (Bondár et al., 2018). In South America, Neves et al. (2018) also relocated an event of magnitude $3.8 \mathrm{mb}$, well located by a 3D seismic array in the offshore Campos Basin in Brazil, obtaining satisfactory results. Nevertheless, when we attempted to use this 3D velocity model and the $i L o c$ algorithm to relocate the well-known Aiquile Andean earthquake, we did not obtain the expected result, as previously presented in the introduction (Figure 1.1), and was the main initial motivation of the project.

With the growth of the Brazilian Permanent Network (RSBR) and the temporary deployment of the XC subnet, many studies have been carried out by the Seismology group of the USP and UnB obtaining local and regional P- and S-wave velocity models for the crust and upper mantle. Unfortunately, the local P-wave velocity models derived from tomographies cover mainly only the area of the Pantanal, Paraná, and Chaco Basins, and do not have enough information of sediments and crustal velocities (Dragone and Bianchi, 2019; Rocha et al., 2019). A prominent regional P- and S-wave velocity model for South America is under development by adjoint tomography (Ciardelli et al., 2019), the preliminary version of this model shows better resolution at crustal depths, but it still has some inconsistencies as velocity inversion with the depth; however, it shows a good fit with mantle discontinuities. Finally, the local S-wave velocity model obtained by ambient noise tomography (Shirzad et al., 2020) that covers the southwestern part of Brazil, did not show a good fit with the known sedimentary layer given by (Laske et al., 2013).

Knowing the need to construct a regional 3D velocity model for earthquake locations, 
we have built a 3D a-proiri velocity model for the South American platform, also including the Andean region (Figure 4.1), using: (1) structural information (surface topography variations, sediment basement, and Moho depth determined in Chapter 2), (2) a set of regionalized relations for sediment and crystalline crustal velocities, and (3): a well established 3D velocity model for the mantle, the LLNL-G3Dv3 (Simmons et al., 2012).

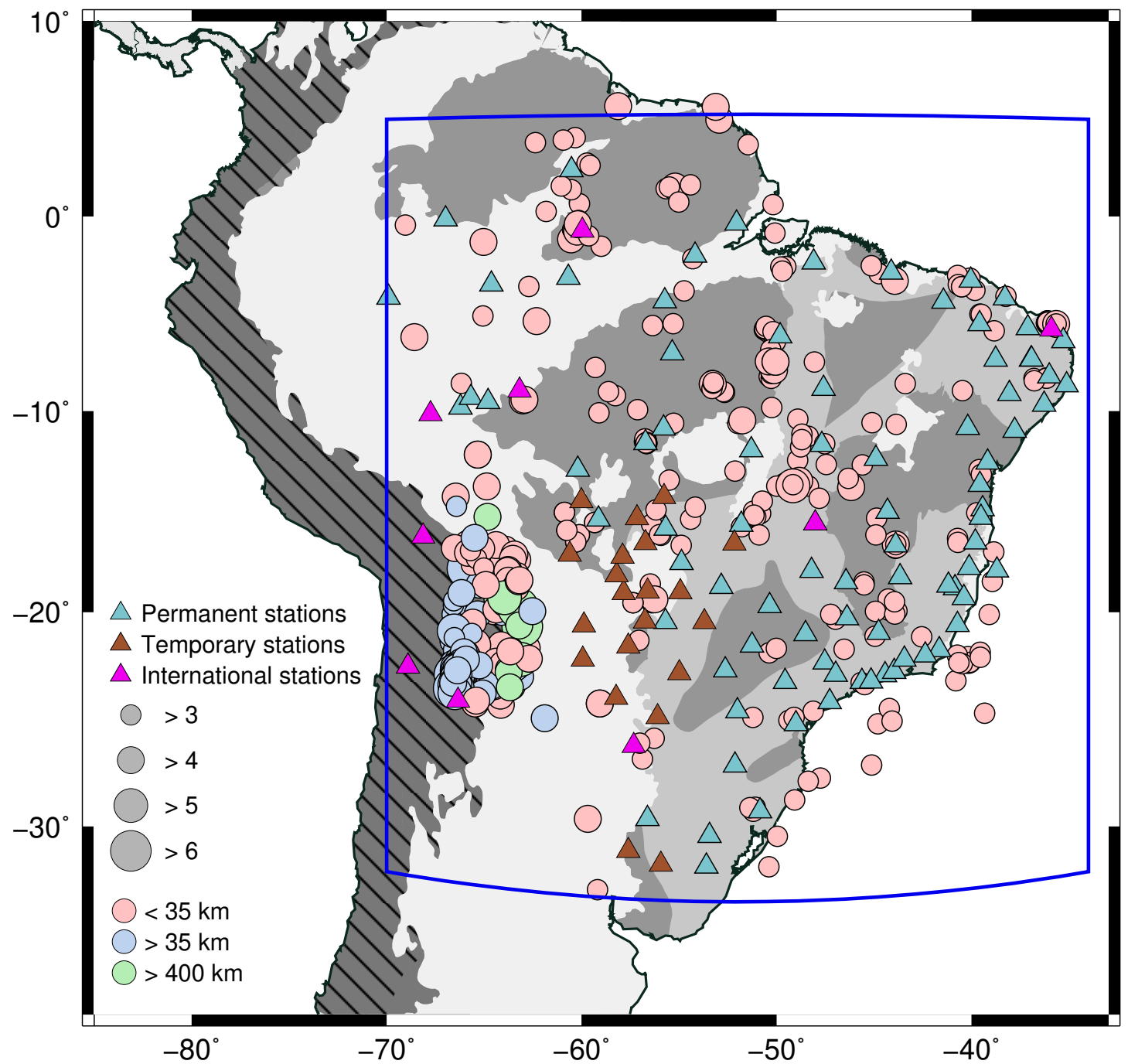

Figure 4.1: Delimitation of a 3D velocity model area (blue rectangle), seismicity of South American platform from the uniform catalog of the USP from 1955 to February 2021, filtered considering the detection thresholds in (Bianchi et al., 2018). Andean seismicity from 2010 to 2020, taken from the raw catalog of the USP. Pink circles: earthquakes up to $35 \mathrm{~km}$ depth. Light blue circles: earthquakes between $35 \mathrm{~km}$ and $300 \mathrm{~km}$ depth. Green circles: Earthquakes with a depth greater than $300 \mathrm{~km}$. The size of circles represents the event's magnitude. RSBR stations (turquoise triangles), XC temporary deployment (brown triangles), and IRIS international stations (purple triangles). 
This model was tested relocating the well-known Aiquile Andean earthquake, and other two recent earthquakes occurred in the stable platform using the NonLinLoc (NLLoc) routine, developed by Lomax et al. (2009), that has been used satisfactorily in regional and local relocations using 3D velocity models (Béthoux et al., 2016; Lomax, 2020). This method uses efficient global sampling algorithms to obtain the a-posteriori probability density function (PDF) over possible solutions, quantifying the agreement between predicted and observed arrival times to all uncertainties and forms a complete probabilistic solution (Lomax and Curtis, 2001).

This 3D velocity model can serve as a reference for the next generations of models to be used for South American earthquake locations using regional stations. Besides, it could be updated as soon as new consistent tomography studies are settled.

\subsection{Model Construction}

To facilitate the 3D model construction, we have taken into account the most important structural information on a crustal scale. Because the velocity models obtained by the research groups do not cover our area of interest in its entirety, and neither have enough resolution in depth, we have elaborated velocity laws from already published relevant data for the sediments and crystalline crust.

\subsubsection{Structural data}

We considered two first-order structures on a crustal scale (sedimentary layer and the crystalline crust) that can be described by three interfaces. Those interfaces are:

- Topography/bathymetry surface: We used detailed topographic information, given by the ETOPO1 model (NOAA National Geophysical Center, 2009). This is a 1-arc minute global relief model of Earth's surface that integrates land topography and ocean bathymetry. In our study area, the topography varies from $\sim 6 \mathrm{~km}$ amsl in the Andean region to $\sim 5 \mathrm{~km}$ below the sea level in the oceanic area (Figure $4.2 \mathrm{a}$ ).

- Sedimentary basement interface: knowing the role of sedimentary layer thickness in the hypocenter location, we used the sediment information of the CRUST1.0 model 
in most of our study area (Laske et al., 2013). In Paraná Basin, we used refined sedimentary data from the IAG database (Figure 4.2b).

- Moho discontinuity: it is the most important discontinuity at crustal scale because of the high velocity contrast and relevant depth variations, we used the updated crustal thickness map of South America, presented in Chapter 2, that maps in detail the Moho thickness of the Chaco, Paraná, and Pantanal Basins, and the northern portion of South America.

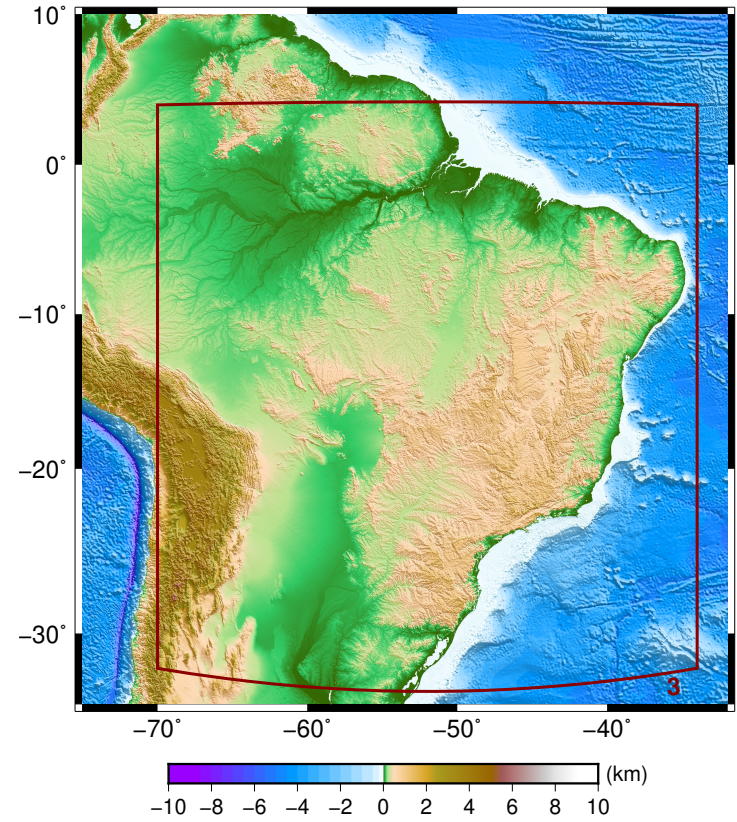

(a)

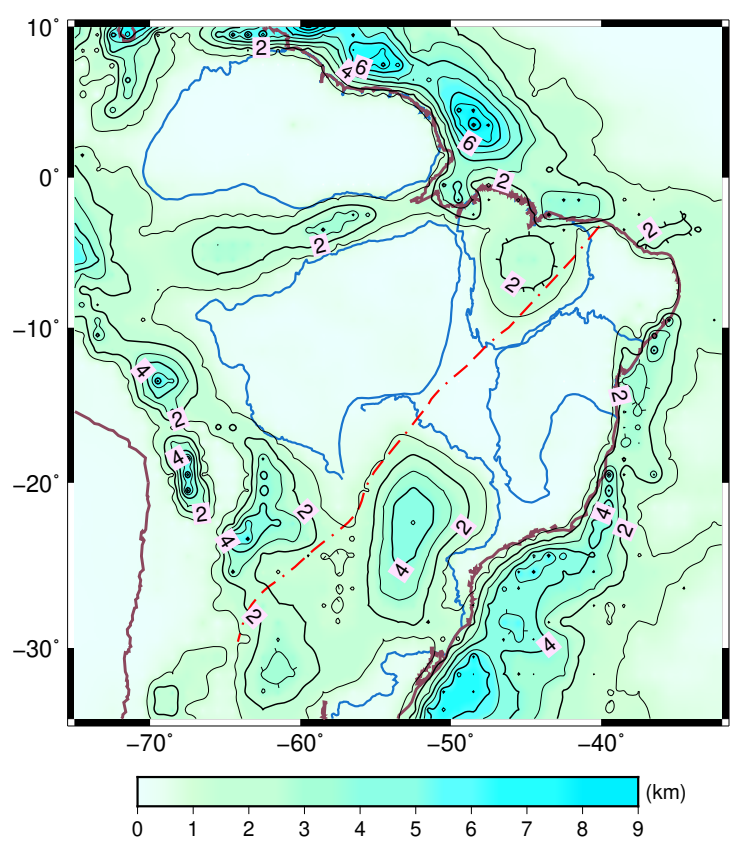

(b)

Figure 4.2: (a)Topography of the South American platform from NOAA National Geophysical Center (2009), and the delimited area for 3D velocity model construction (red rectangle). (b) Sediment thickness map of the South American platform from CRUST1.0 model (Laske et al., 2013), showing the most important geologic features (blue lines) and the Transbrasiliano Lineament (red dotted line).

\subsubsection{Sedimentary and Crustal velocities}

To obtain the velocity laws, both for sediments and crystalline crust, we compiled velocity information from the literature, giving preference to active seismic experiments data because a seismic source controlled in terms of time and position gives more accurate information of seismic velocities than other techniques, as receiver function or tomography. The predicted velocity law was obtained by fitting a polynomial regression from the average 
of the velocities released in the literature. The curve obtained presents a velocity gradient that depends on the depth.

Figure 4.3a shows the velocity law for sediments, obtained from velocity gradients of sedimentary basins and wells around the world, since we had no access to regional scale data in a consistent manner. We collected data from Los Angeles Basin (Süss and Shaw, 2003), the Indian Bengal Basin (Krishna and Rao, 2005; Damodara et al., 2017), Indian Palashi well (Murty et al., 2008), Norwegian-Danish Basin (Sandrin and Thybo, 2008), and Po Plain Basin in Italy (Molinari et al., 2015). The resulting velocity law obtained varies between $1.7 \mathrm{~km} / \mathrm{s}$ at the top of the sedimentary layer and goes up to $5 \mathrm{~km} / \mathrm{s}$, the velocity increases rapidly at shallower depths of $\sim 4 \mathrm{~km}$, and downwards the gradient is lower. Only the Po Plain Basin velocity structure does not present the same pattern; in this case, the velocity slightly increases up to $5 \mathrm{~km}$ depth, and at that depth there is an important velocity jump. On the other hand, the velocity structure of the Bengal Basin reported by Krishna and Rao (2005) presents velocities higher than $5 \mathrm{~km} / \mathrm{s}$ from $3 \mathrm{~km}$ depth downwards, these values correlate more with crustal velocities than with sediment velocities.

For crustal velocity law, we have considered two different tectonic areas:

- South American platform: we collected Brazilian available data of the central part (Soares et al., 2006) and northeastern region Lima et al. (2019); we considered the averages for platforms given by Christensen and Mooney (1995); and crustal velocity structures from the East European Craton (Starostenko et al., 2013), Siberian Craton (Cherepanova et al., 2013), China Craton (Wang et al., 2014), the Chinese southern region (Zhu et al., 2018), Dominican Republic (Núñez et al., 2019), the Eastern Piedmont Guo et al. (2019), and Cadiz gulf (Lozano et al., 2020). The crustal velocity law obtained varies between $5.7 \mathrm{~km} / \mathrm{s}$ and $7.1 \mathrm{~km} / \mathrm{s}$, without any variation from $37 \mathrm{~km}$ downwards and it is agree with the global average for platforms given by Christensen and Mooney (1995), the largest difference is the higher velocity at shallower depths up to $12 \mathrm{~km}$ observed in our predicted law. Nevertheless, the data available for Brazil (Soares et al., 2006; Lima et al., 2019) shows higher velocities at shallower depths (Figure 4.3b). All bibliography reviewed presents a similar pattern of velocity gradient with the depth; however, the crustal velocities at Cadiz Gulf 
and China Craton seem to be lower in approximately $1 \mathrm{~km} / \mathrm{s}$ up to $\sim 25 \mathrm{~km}$, while Dominican Republic presents higher crustal velocities, being the Moho at shallower depth than in the other areas.

- The Andes highlands: Considering the thicker crust under the Andes (up to $\sim 70 \mathrm{~km}$ ), and the different velocity gradient due to their tectonic evolution (Beck and Zandt, 2002), we calculated another law for this region, considering the global average for orogens from Christensen and Mooney (1995), and active seismic studies in the region (Beck and Zandt, 2002; Oncken et al., 2003; Chulick et al., 2013). The predicted velocity law shown in Figure $4.3 \mathrm{c}$ ranges from $5.7 \mathrm{~km} / \mathrm{s}$ to $7.1 \mathrm{~km} / \mathrm{s}$ and it does not vary significantly after $40 \mathrm{~km}$ down. It is also very similar to the global average for orogens, being the larger difference the low velocity zone between $10 \mathrm{~km}$ and $20 \mathrm{~km}$ depth, also found in previous works.

Figure 4.3d compares the velocity laws for the platform and the Andes; for the upper layers, both laws present very similar velocities; nevertheless, from $10 \mathrm{~km}$ down the Andean profile shows lower velocities reaching the same velocity again at the bottom of each model, at the Moho discontinuity. Also, it is important to remark that the velocity at the bottom of the sediments $(5 \mathrm{~km} / \mathrm{s})$ is lower than the velocity at the top of the crust $(5.8 \mathrm{~km} / \mathrm{s})$. This ensures that in the transition from sediments to crust, there is a significant velocity increase. 


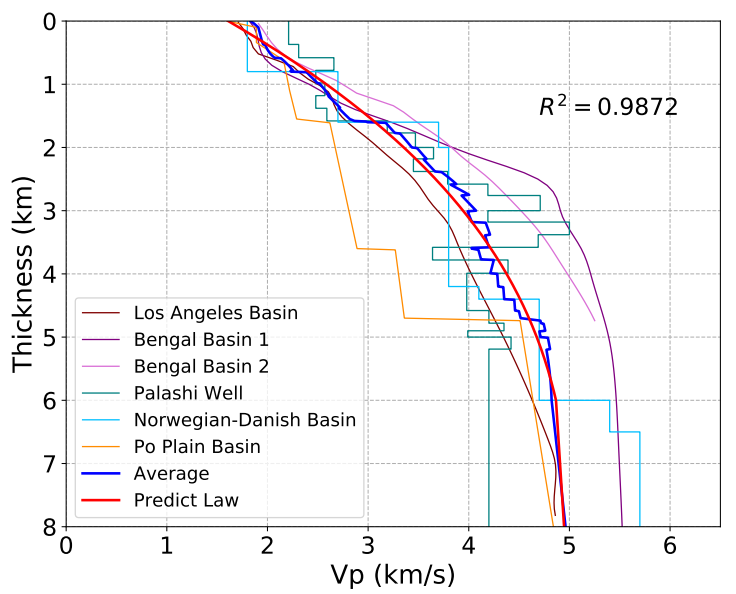

(a)

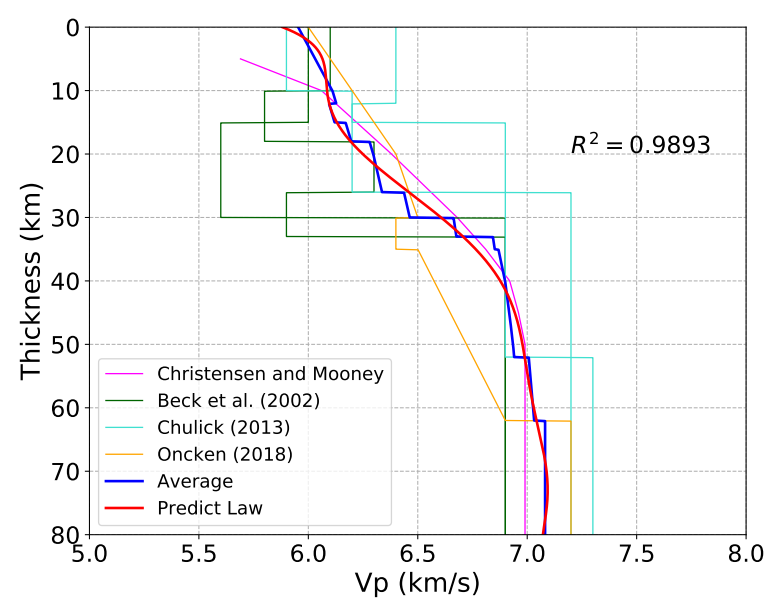

(c)

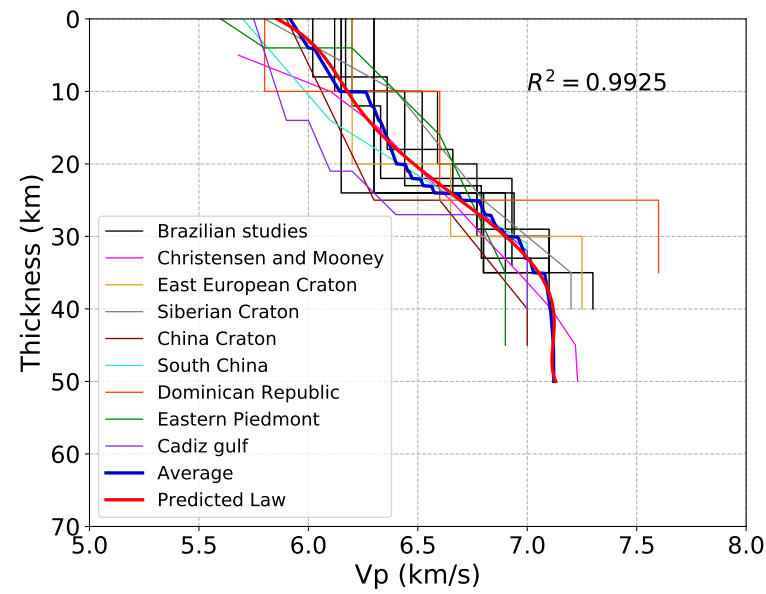

(b)

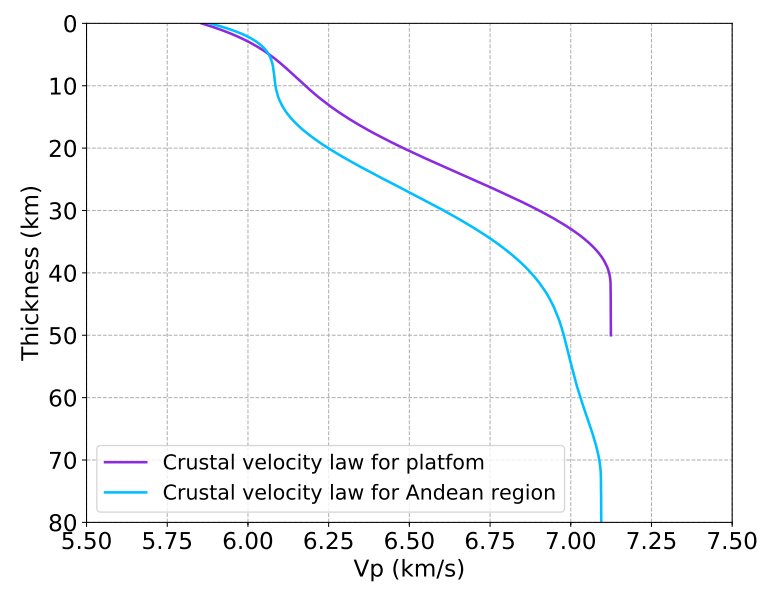

(d)

Figure 4.3: Velocity laws for the sediment layer (a), platform crust (b) and (c) Andean crust. Blue line is the average velocity from data collected, and the red curve is the polynomial regression that adjusts the blue line. (d) Comparison between velocity laws for platform and Andean region.

\subsubsection{Mantle velocities}

For the mantle, we used the LLNL-G3Dv3 global P-wave 3D velocity model (Simmons et al., 2012), consistent with global discontinuities at $\sim 420$ and $\sim 660 \mathrm{~km}$ depth, and most importantly, with the position of Nazca slab under the Andean and Sub-Andean region according to Portner et al. (2020), as shown in Figure 4.4a. As we commented before, the regional P-wave velocity model developed by Ciardelli et al. (2019) also shows consistency at mantle depths with global discontinuities; however, in the unfinished version tested, it was not possible to observe a velocity variation in the surrounded area of Nazca Slab (Figure 4.4b). 
As the LLNL-G3Dv3 is a 3D velocity model heterogeneously distributed with a horizontal resolution of $1^{\circ}$ on a global scale, we proceeded to sample the mantle velocities from it and adjust them at the upper mantle position in our model, respecting the geographical position. The lowest mantle velocity is $7.8 \mathrm{~km} / \mathrm{s}$, mainly under the ocean area, and the highest crustal velocity is $\sim 7.1 \mathrm{~km} / \mathrm{s}$, ensuring a consistent velocity jump at Moho discontinuity.

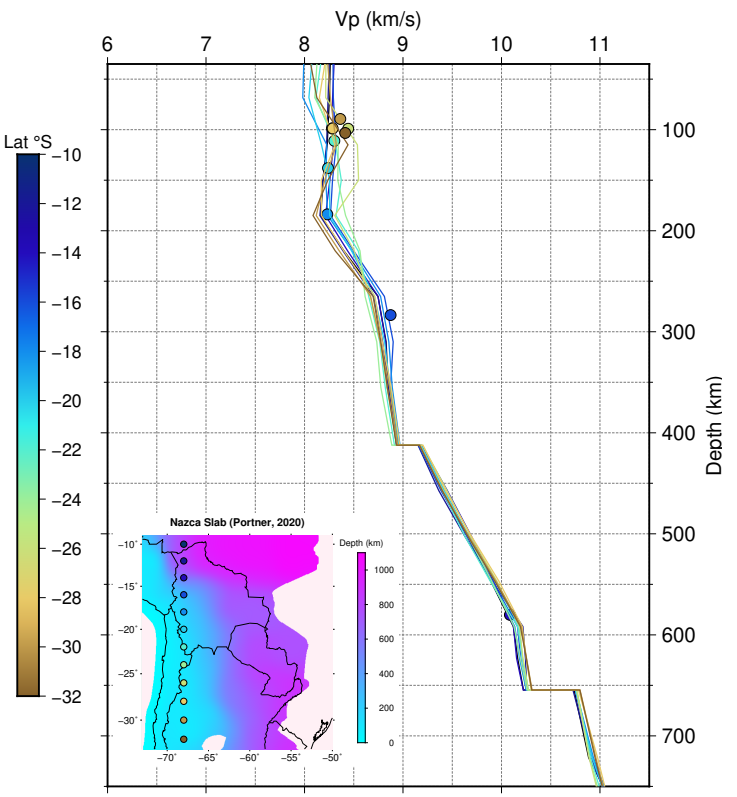

(a)

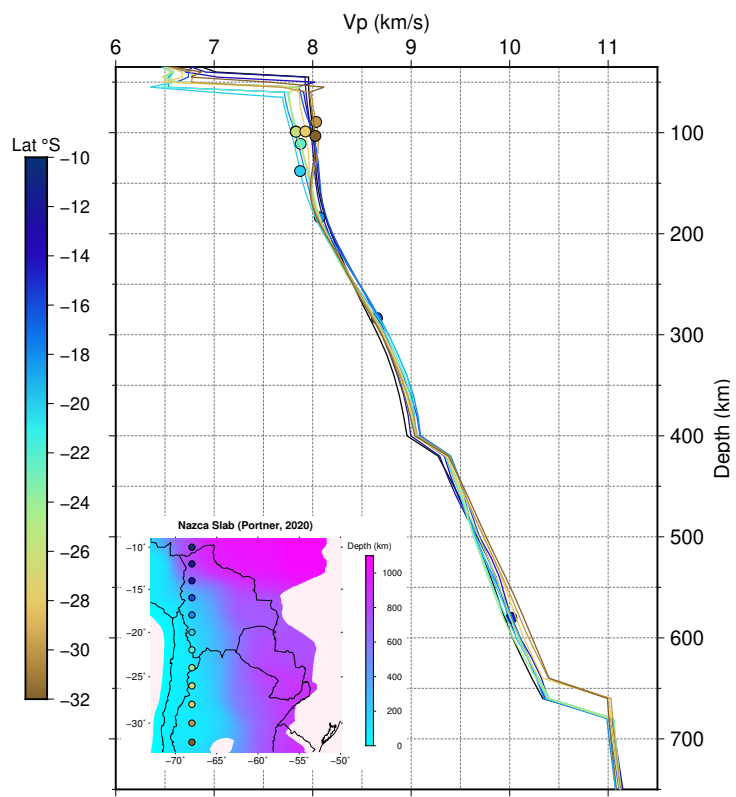

(b)

Figure 4.4: Mantle velocity profile at $68^{\circ} \mathrm{W}$. (a) Global-scale LLNL-G3Dv3 P-wave velocity model. Circles represent the depth of the Nazca slab according to Portner et al. (2020), whose model is shown in the inset pictures. (b) P-wave velocity model from adjoint tomography (Ciardelli et al., 2019).

\subsubsection{Parametrization and Model construction}

Considering that the topography reaches up to $6 \mathrm{~km}$ amsl in our study area, we considered starting our model at $7 \mathrm{~km}$ above sea level. To know how deep our model has to be, we have taken as reference the theoretical ray paths of the IASP91 model (Kennett and Engdahl, 1991), which shows that for regional distances up to $30^{\circ}$, the rays do not go deeper than $900 \mathrm{~km}$, even for hypocenters deeper than $600 \mathrm{~km}$, like those of deep Andean earthquakes (Figure 4.5).

The total volume of the study area goes from $7 \mathrm{~km}$ amsl to $900 \mathrm{~km}$ depth (Figure 4.6a). Because of the resolution of the available data, and the depth of our model; we have defined a horizontal discretization of $0.5^{\circ}$, while the vertical discretization has different 
values depending on the depth: shallower than $10 \mathrm{~km}$ is $1 \mathrm{~km}$ due to the higher velocity gradient of the sediment velocity law; between 10 and $50 \mathrm{~km}$, the resolution is $2 \mathrm{~km}$, and finally at mantle depths is $5 \mathrm{~km}$, because of the reduced velocity variation.

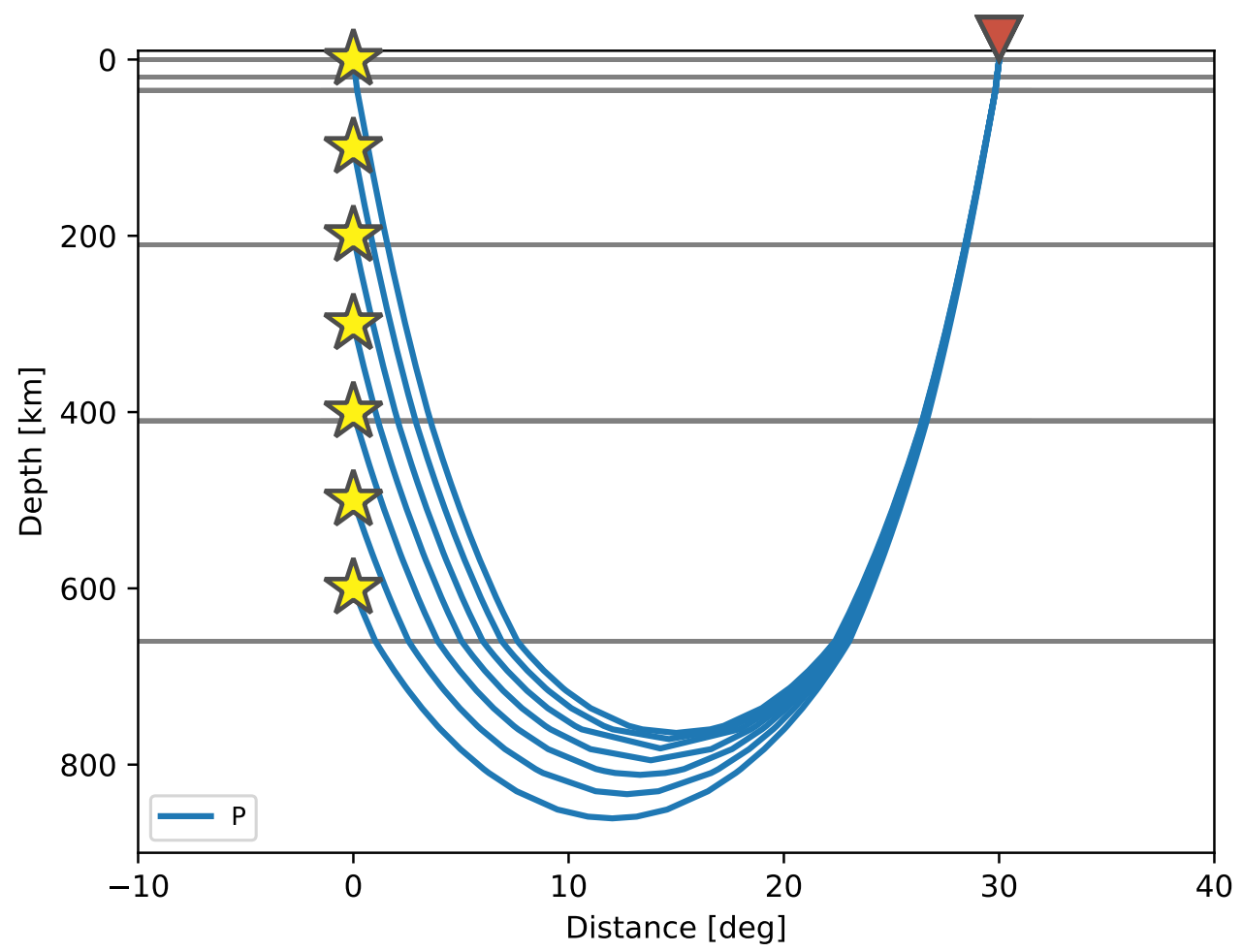

Figure 4.5: Theoretical P-wave ray paths computed using the IASP91 model Kennett and Engdahl (1991), for regional events up to $30^{\circ}$ distance and up to $600 \mathrm{~km}$ depth.

The area of interest was divided into blocks of the size of horizontal and vertical discretization previously defined, a simplification of that is shown in Figure 4.6b, each block edge or node (red circles) represents the average velocity of the column below. As we have started the model at $7 \mathrm{~km}$ amsl there are areas where there is only air, in these cases we filled the node with a velocity of $0.3 \mathrm{~km} / \mathrm{s}$. When the topography relief begins we started to fill each node with the corresponding velocity according to the structural information and velocity laws obtained.

Independently of the vertical discretization of the blocks, we have calculated the velocity at each $0.1 \mathrm{~km}$ for sedimentary layer and crust, and every $1 \mathrm{~km}$ for the mantle; after we averaged the sampled velocities between each node at depth (using its slowness) and placed the result at the top nodes (red circle in Figure 4.6b). When one of the discontinuities 
considered (sediment basement or Moho depth) is in the middle of two nodes, the velocities of the two types of structure were averaged.

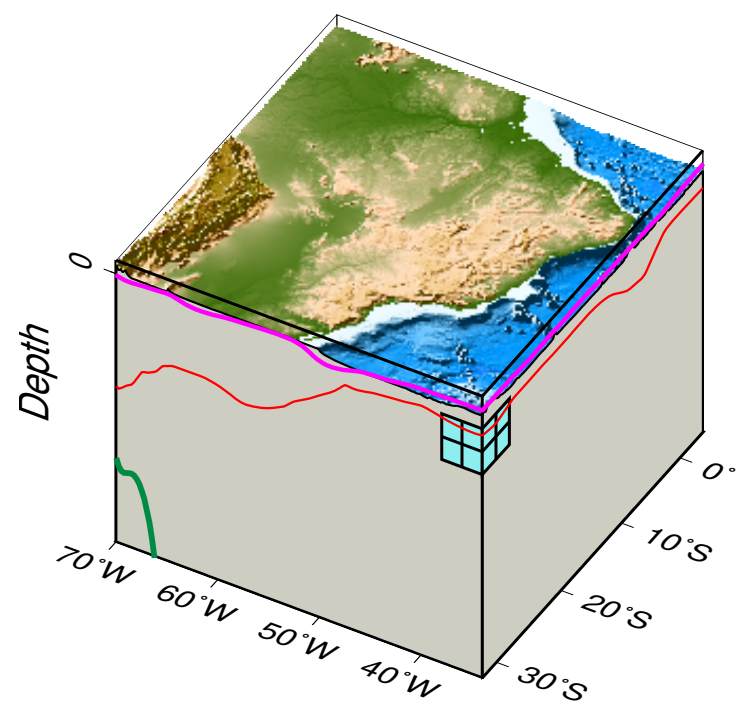

(a)

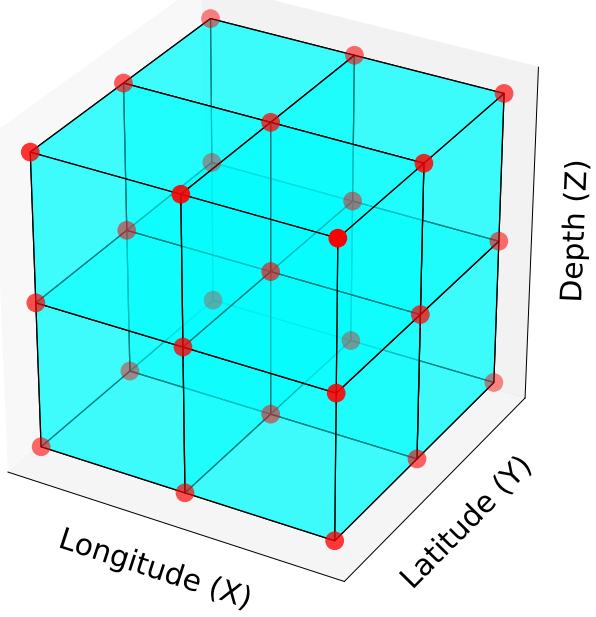

(b)

Figure 4.6: (a) 3D representation of the study area for 3D model construction, which goes from $7 \mathrm{~km}$ amsl to $900 \mathrm{~km}$ depth. The vertical scale is not proportional to the horizontal scale. Fuchsia line: Sediment basement. Red line: Moho depth. Green line: Nazca Slab. A simplification of the discretization of the area is shown as light blue blocks. (b) Representation of the discretization in blocks, each node (red dot) contains velocity information of the column below.

To ensure the transition between the velocity laws of the South American platform and the Andes highlands, we first delimited the Andean region considering a height higher than 1500 amsl in the west and east border. At the central axis of this delimited area it was used the Andean velocity law, and in the following nodes, closer to the stable platform, the two laws were weighted considering the distance of the node to both regions. This reduced any abrupt change in velocity in two contiguous nodes.

The 3D velocity model constructed contains 1108432 nodes. Two vertical W-E crosssections at $12^{\circ} \mathrm{S}$ and $20^{\circ} \mathrm{S}$ are presented in Figure 4.7 as examples of lateral and depth velocity variations. In both, we observe a clear velocity difference between the sediment layer, the crust, and mantle, without any velocity inversion with the depth in any structure. Lateral velocity variations are observed, depending on the presence of sedimentary basins (gray line) and the Moho depth (black line). In oceanic areas, the mantle velocities are lower than in continental areas. Black points represent nodes with velocities of $0.3 \mathrm{~km} / \mathrm{s}$, due to there is only air or water (ocean regions). 
Figure $4.7 \mathrm{a}$ shows the vertical cross-section at $12^{\circ} \mathrm{S}$, where the topography is almost about the sea level in the continental area, a sediment layer of $\sim 3 \mathrm{~km}$ is observed at the western border and another one at the eastern border (at the seafloor), with velocities up to $\sim 4.5 \mathrm{~km} / \mathrm{s}$. On the other hand, the vertical cross-section at $20^{\circ} \mathrm{S}$ (Figure $4.7 \mathrm{~b}$ ) presents three continental basins, one of them located on the Andes, and the other two are the Chaco at $\sim 63^{\circ} \mathrm{W}$ and Paraná at $\sim 53^{\circ} \mathrm{W}$, with a clear lower velocity than the crustal area. The Andean region, characterized by a high topography, has a slightly lower velocity compared with the platform area, at the same depths. The color scale used allows observing important velocity changes, mainly at discontinuities; however, the smaller velocity variation due to the Nazca Slab is not noticeable.

Horizontal sections at $4 \mathrm{~km}$ amsl, $4 \mathrm{~km}, 36 \mathrm{~km}$, and $55 \mathrm{~km}$ depth are shown in Figure 4.8. The Andean region is delimited by a turquoise line and the limit between continent and ocean by a green line. At $4 \mathrm{~km}$ amsl, only the Andean region has velocity information, mainly of sediments. At $4 \mathrm{~km}$ depth, most of the continental area presents crustal velocities $(\sim 6 \mathrm{~km})$, and it is still noticeable the lower sediment velocities of $\sim 4.5 \mathrm{~km} / \mathrm{s}$ in the Paraná Basin, as expected the ocean region presents velocities corresponding to sedimentary layer, being higher in areas closer to the continent.

The horizontal section at $36 \mathrm{~km}$ depth (Figure 4.8) shows mainly crustal velocities about $\sim 6.5 \mathrm{~km} / \mathrm{s}$ in the continent; besides, the Sub-Andean region and Pantanal Basin present velocities corresponding to the mantle, since these areas have a thinner crust (Rivadeneyra-Vera et al., 2019). Finally, at $55 \mathrm{~km}$ depth, only the Andean region presents crustal velocities, with no significant variation in the mantle velocities in the rest of the area.

Although the model presented shows a coherent velocity variation at the continentocean margin, we did not use a special velocity law for this region, as according to the literature the velocity structure of this transition is similar to that of the stable platform. This could be a point of improvement for a next version, especially when we start to deploy OBS stations on the platform. 


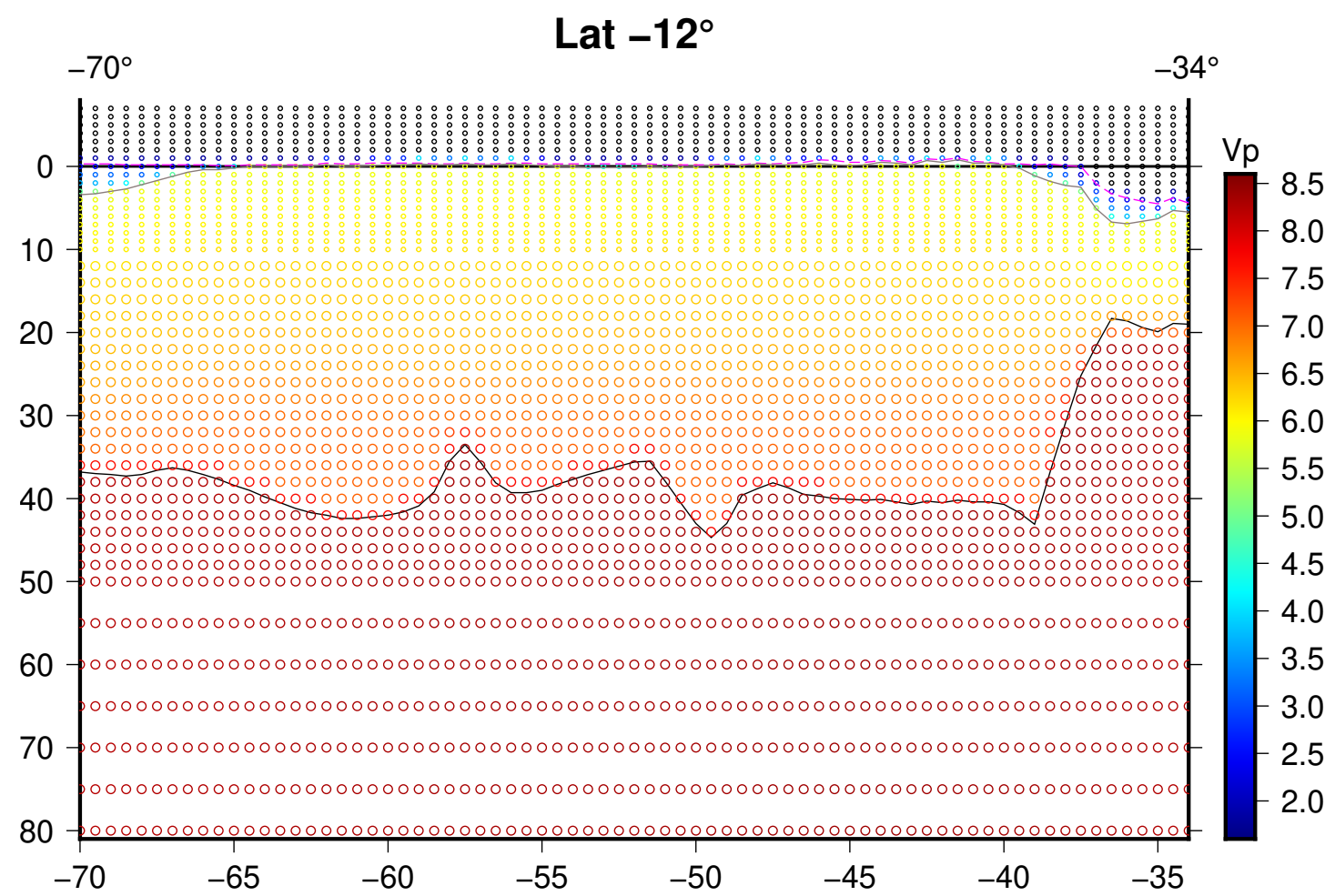

(a)

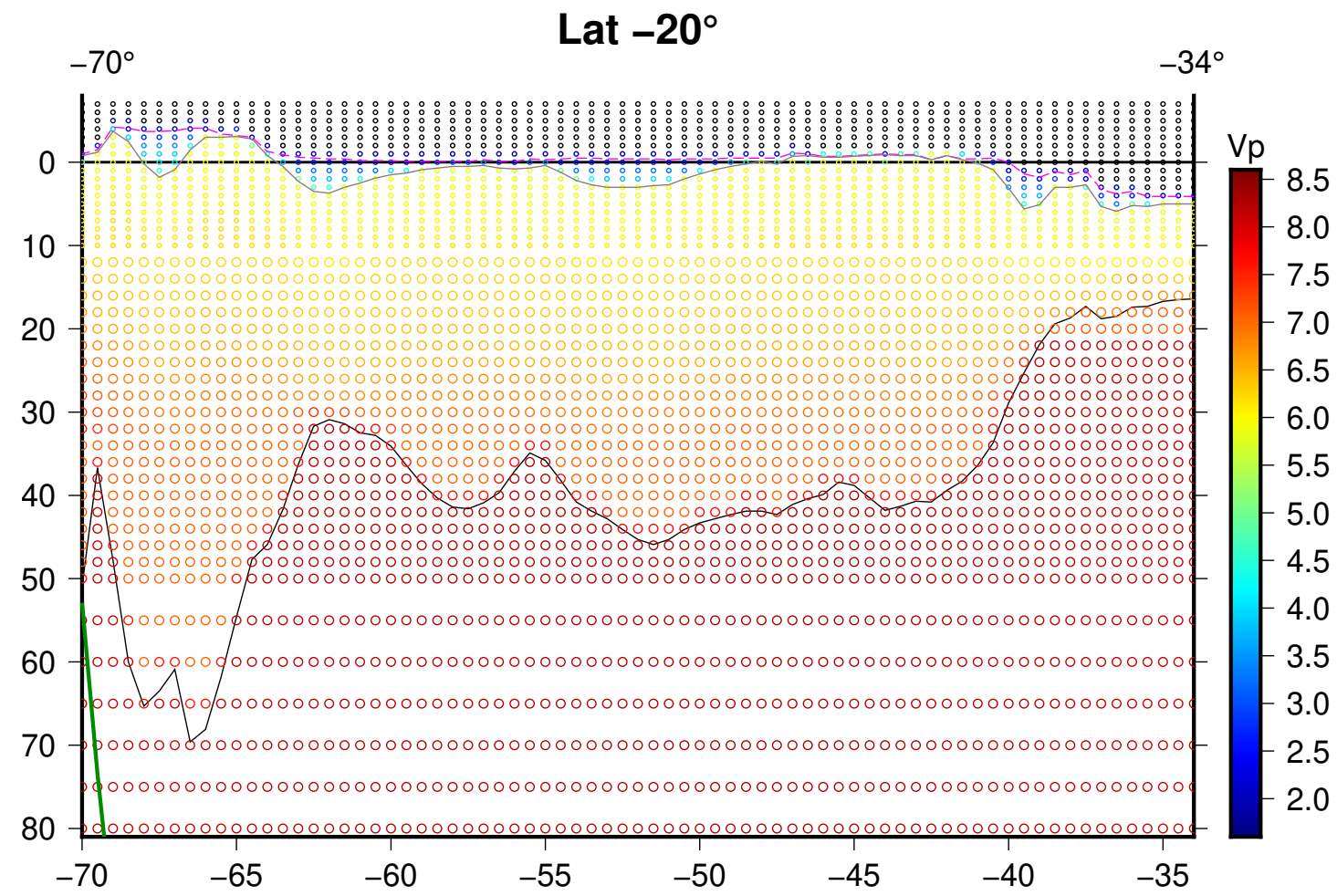

(b)

Figure 4.7: Vertical cross-section at (a) $12^{\circ} \mathrm{S}$ and (b) $20^{\circ} \mathrm{S}$, from $7 \mathrm{~km}$ a.m.s.l to $80 \mathrm{~km}$ depth. Fuchsia line: Topography relief. Gray line: Sediment basement. Black line: Moho depth. Green line: Nazca Slab. Black points represent nodes with velocities of $0.3 \mathrm{~km} / \mathrm{s}$, due to there is only air or water (ocean regions) 

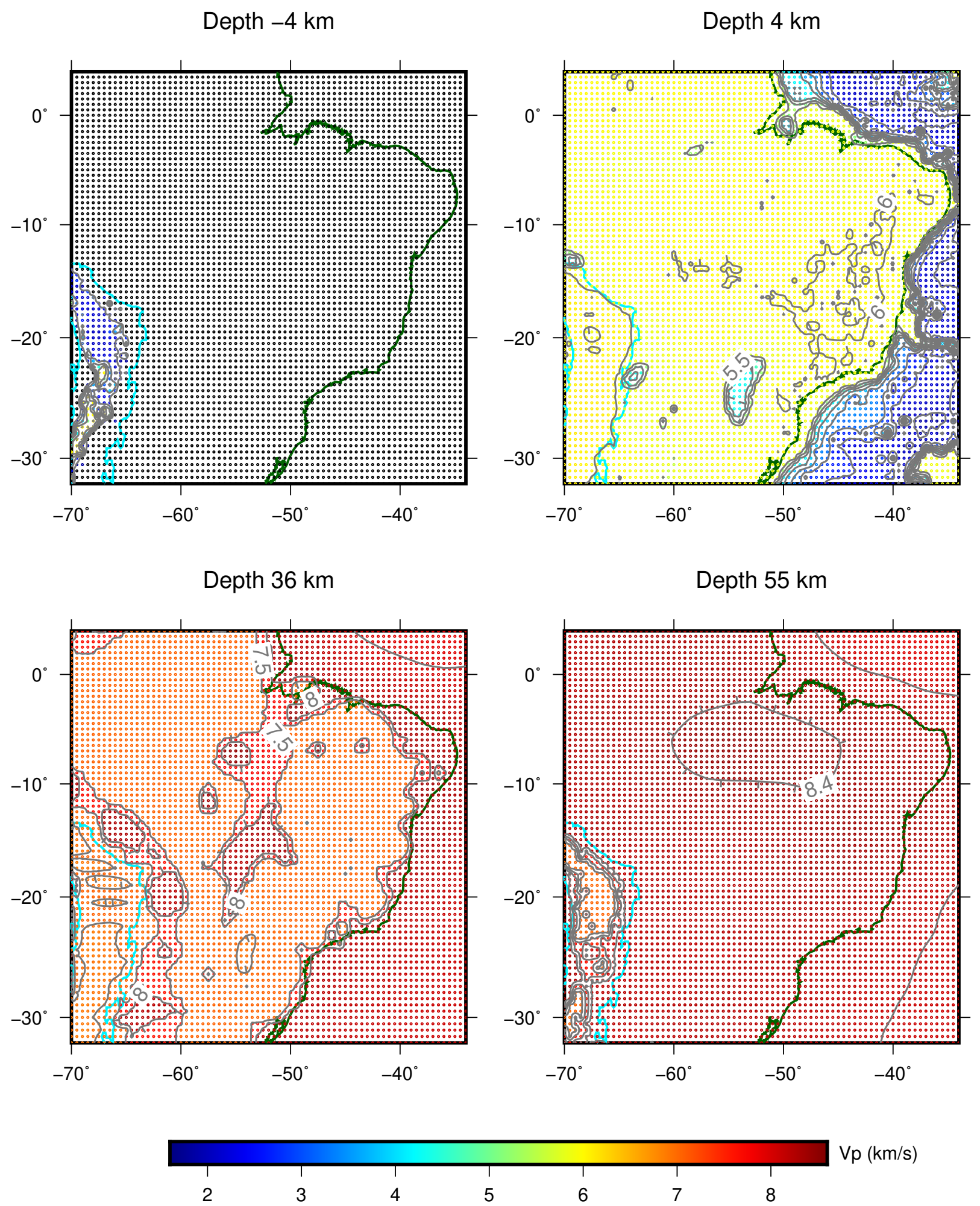

Figure 4.8: Horizontal section at $4 \mathrm{~km}$ a.m.s.l., $4 \mathrm{~km}, 36 \mathrm{~km}$ and $55 \mathrm{~km}$ depth. Turquoise line: Andes limits. Green line: Continent-ocean margin. Gray lines: Velocity isolines. 


\subsection{Travel Time computation}

To know how the expected travel times vary using $1 \mathrm{D}$ and $3 \mathrm{D}$ velocity models, we used the sub-routine of NonLinLoc (NLLoc) to calculate the travel times from AMBA station to any node of our model. Figure 4.9 shows horizontal sections of the absolute wave travel time from the AMBA station to each point of the model, considering $1 \mathrm{D}$ and $3 \mathrm{D}$ velocity models, for a depth of $0 \mathrm{~km}$. The most significant difference is observed at the west border (toward the Andean region). Since the absolute travel time is much larger than the expected difference it is hard to observe any other difference for the computed times in this figure.

Figure 4.10 shows a vertical W-E cross-section of the difference in travel times using $3 \mathrm{D}$ and $1 \mathrm{D}$ velocity models. When it is used the 3D velocity model, the predicted travel times are higher, increasing notably toward the Andean region due to the notably thicker crust, and therefore lower velocities than its surroundings, when is observed a difference up to $\sim 8$ seconds (Myers et al., 2010). Close to the station, we observe negative travel time differences mainly because of the proximity of two different sedimentary basins at each side of the station. 
1D AK135 model

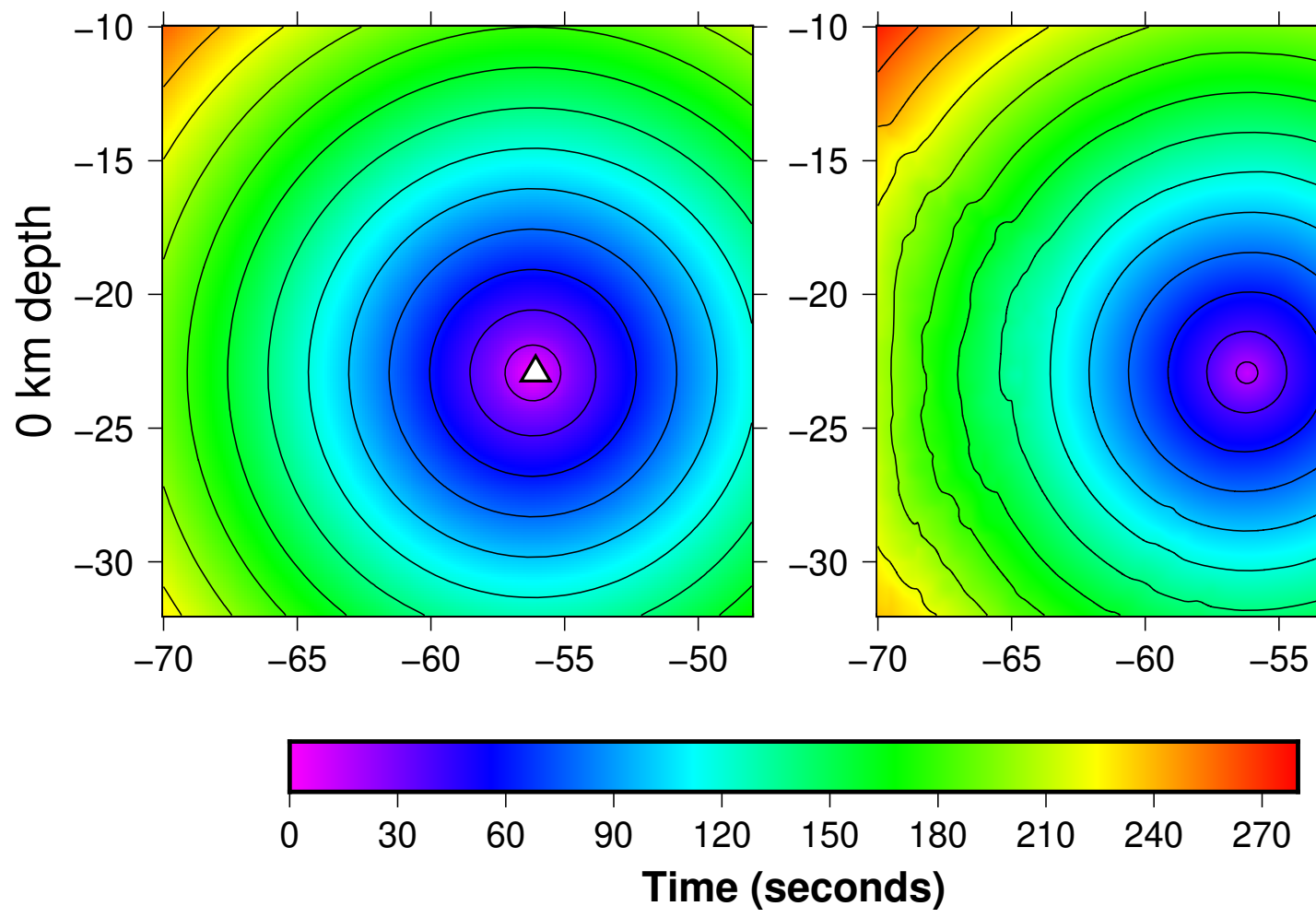

Figure 4.9: Regional travel time using 1D AK135 velocity model and a 3D velocity model, at $0 \mathrm{~km}$ and $20 \mathrm{~km}$ depth. White triangle: AMBA station of $\mathrm{XC}$ temporary deployment

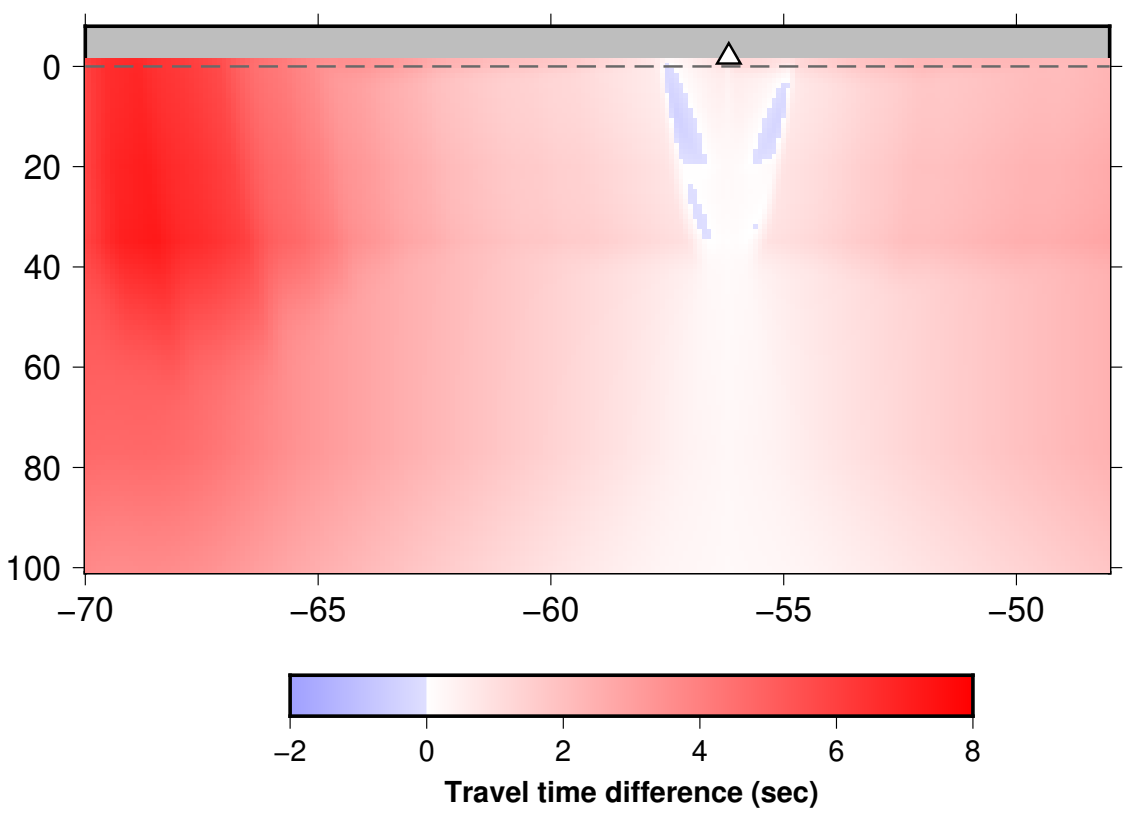

Figure 4.10: Travel time difference using 1D global and 3D regional velocity models. White triangle: AMBA station of XC temporary deployment. Dotted line: $0 \mathrm{~km}$ depth. 


\subsection{Example of earthquakes location}

To test our 3D velocity model we relocated the well-known Aiquile Andean earthquake and other two more recent events that occurred in the stable platform, using the NonLinLoc (NLLoc) routine which returns two solutions: (1) the PDF (probability density function) which corresponds to the best point in the cloud solution (minimum misfit) and quantifies the agreement between predicted and observed arrival times to all uncertainties forming a complete probabilistic solution; and (2) the Expected that includes the hypocentral coordinates and uncertainty given by the Gaussian expectation and covariance matrix measures of the PDF.

On our tests, we let the NLLoc sample a certain fixed depth range, normally correlated to the expected depth. To simplify of the process, we opted to execute the test using a simple geographic coordinate transformation that could yield additional uncertainties.

\subsubsection{Aiquile Andean earthquake}

As commented before, the Aiquile earthquake was accurately located by Funning et al. (2005) using SAR interferometry (InSAR); nevertheless, we did not have satisfactory results trying to relocate it using the 3D RSTT global model. We relocated this event with our model and $14 \mathrm{P}$-wave arrivals up to $15^{\circ}$, mostly belonging to the Bolivian network, located mainly in the Andean region, to the west of the event; and existing an important azimuthal gap at the east (inset picture in Figure 4.11); this distribution of stations leads to a large uncertainty $(\sim 20 \mathrm{~km})$ to the northeast.

Despite the large uncertainty, all stations considered presented residuals less than 1 second, even the stations located in the Andean region that generally present higher residual values; the final RMS is 0.53 seconds. The Expected and PDF solutions, obtained using the proposed 3D model, are the closest to the accurate epicenter ( $\sim 5 \mathrm{~km}$ away) given by Funning et al. (2005) as shown in Figure 4.11. 


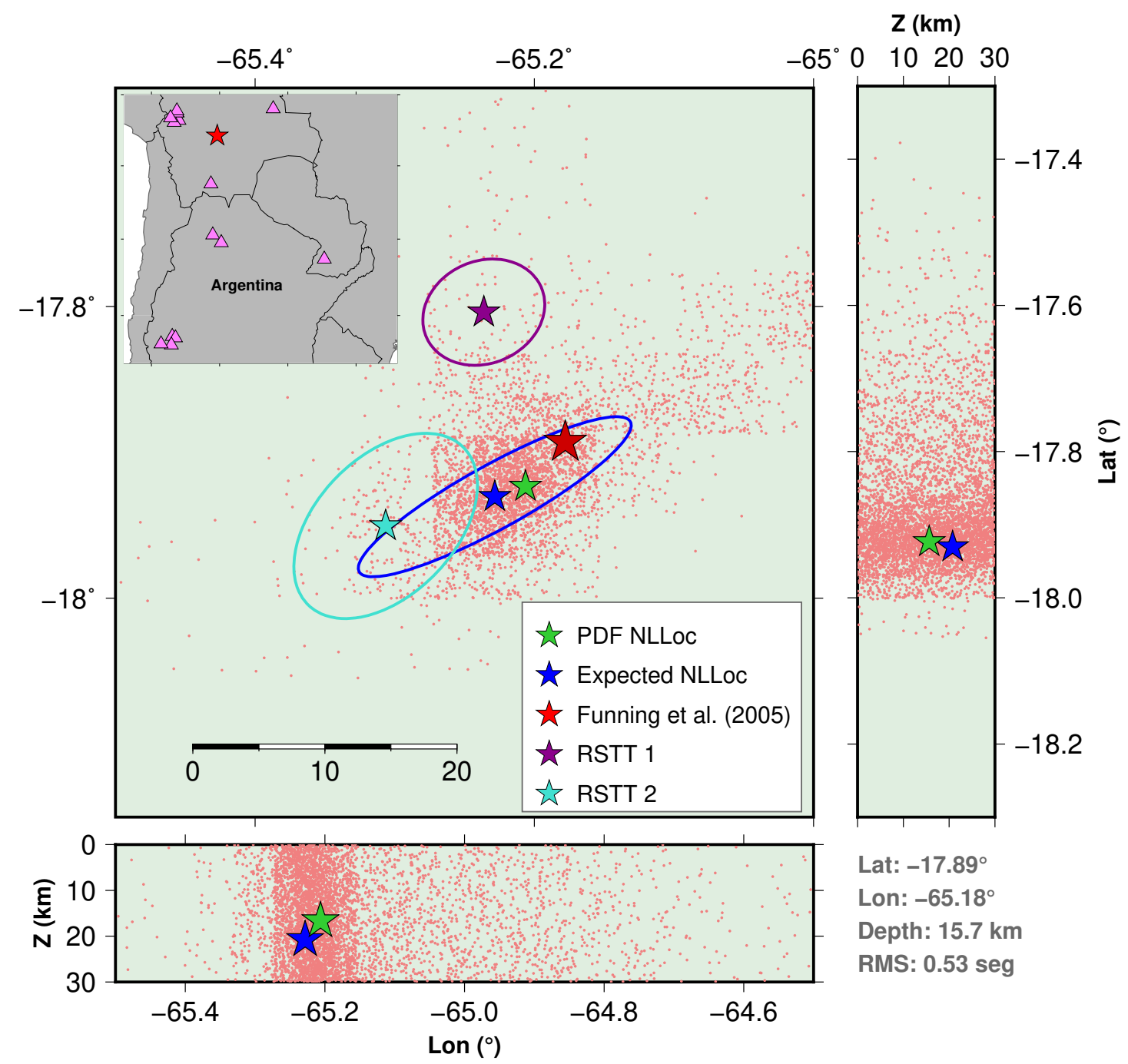

Figure 4.11: Aiquile earthquake relocation using NLLoc routine and the 3D velocity model (blue and green stars). Red star is the well-known epicenter given by Funning et al. (2005). RSTT 1: Epicenter determined with stations up to $90^{\circ}$ and corrected with RSTT model up to $15^{\circ}$. RSTT 2: Epicenter determined with stations corrected with RSTT model up to $15^{\circ}$. Stations used are shown as purple triangles in the embedded picture.

\subsubsection{Platform earthquakes}

We also relocated other two recent important events that occurred at the South American stable platform. In both cases, our solution was satisfactory, showing a final RMS lower than 0.8 seconds when using stations up to $15^{\circ}$. The first event was the Amargosa 2020-08-30 10:44:28 UTC earthquake, located in northeast Brazil with a magnitude of 4.2 mR. This particular event had aftershocks well located by a local network (red stars in Figure 4.12). Also, using RSBR data, two epicenters were obtained, one using the NewBR model with the Hypo71 routine (orange star) and the other, is the standard solution of 
the USP/RSBR, shown by the purple star. Again in that specific case, our solution was the closest one to the known epicenter location $(\sim 2.5 \mathrm{~km}$ away).

\section{$\mathbf{Z}(\mathbf{k m})$}
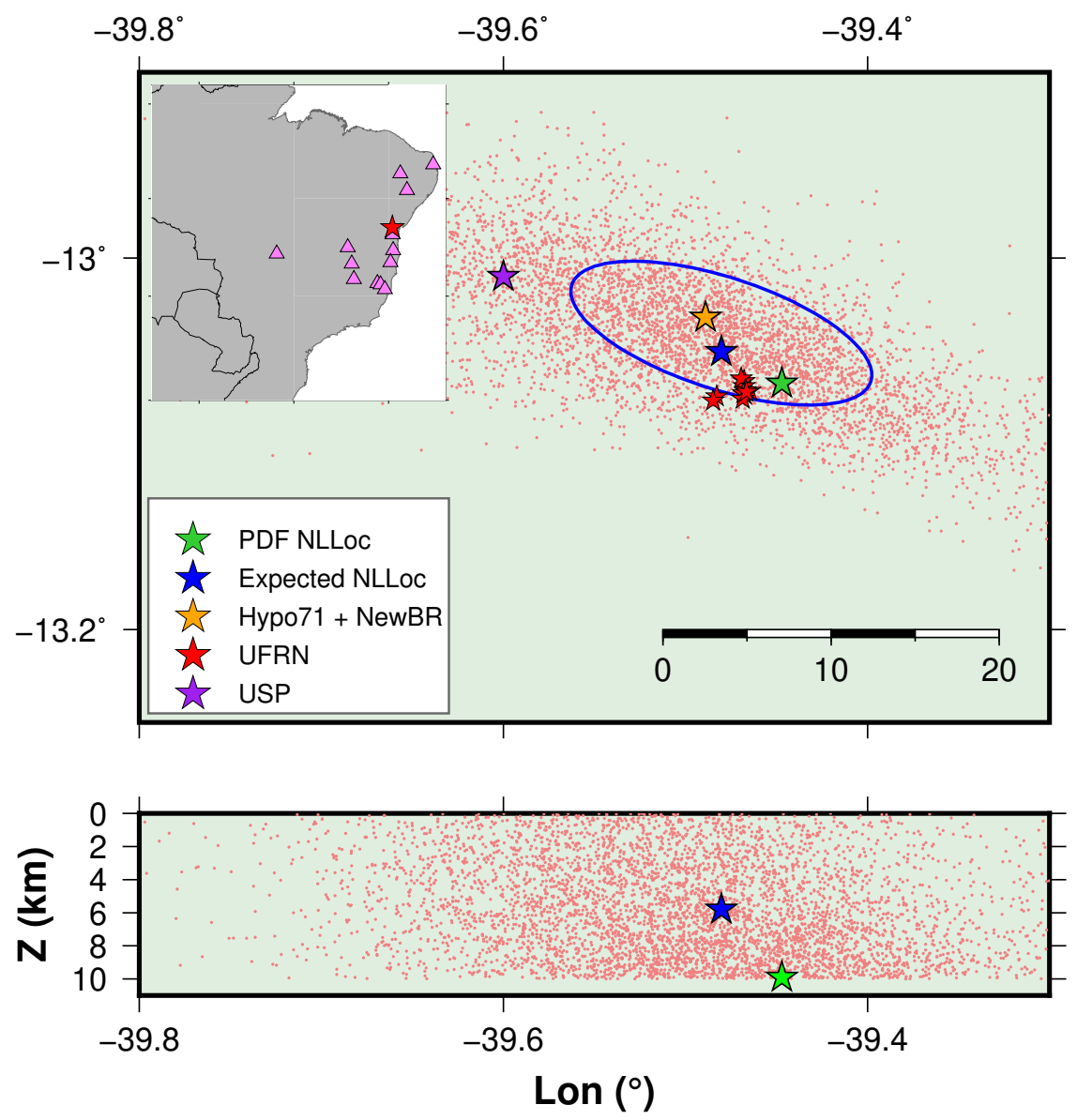

0246810

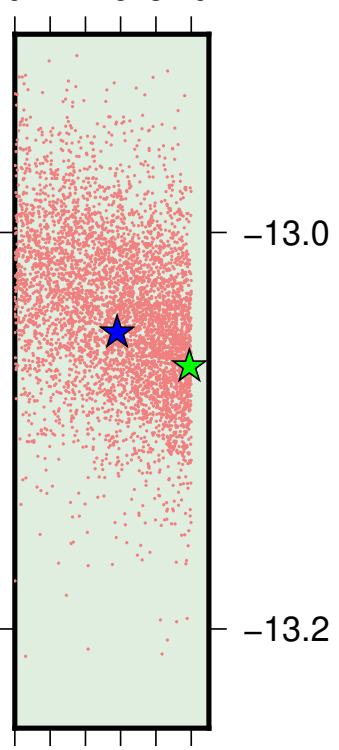

Lat: $-13.068^{\circ}$

Lon: $-39.447^{\circ}$

Depth: 9.9 km

RMS: $0.7 \mathrm{seg}$

Figure 4.12: Amargosa earthquake relocation using NLLoc routine and the 3D velocity model (blue and green stars). Red stars are aftershocks well located by a local network operated by the UFRN. Orange star: Epicenter determined using the NewBR model and Hypo71 routine. Stations used are shown as purple triangles in the embedded picture.

The last performed test was done using readings from the very recent Guayana 202101-31 19:05:13 UTC earthquake (Figure 4.13). This was the largest event (Mag. 5.7 $\mathrm{mb}$ ) in the South American platform recorded by the Brazilian Seismographic Network so far. In this example, the large uncertainty in the northeast direction is due to the event being at the limit of our model, which limits the use of stations to the north of the event. Again, depths were hard to constrain; however, our solution was similar to the USP/RSBR solution; considering the uncertainty given by the determined PDF. 


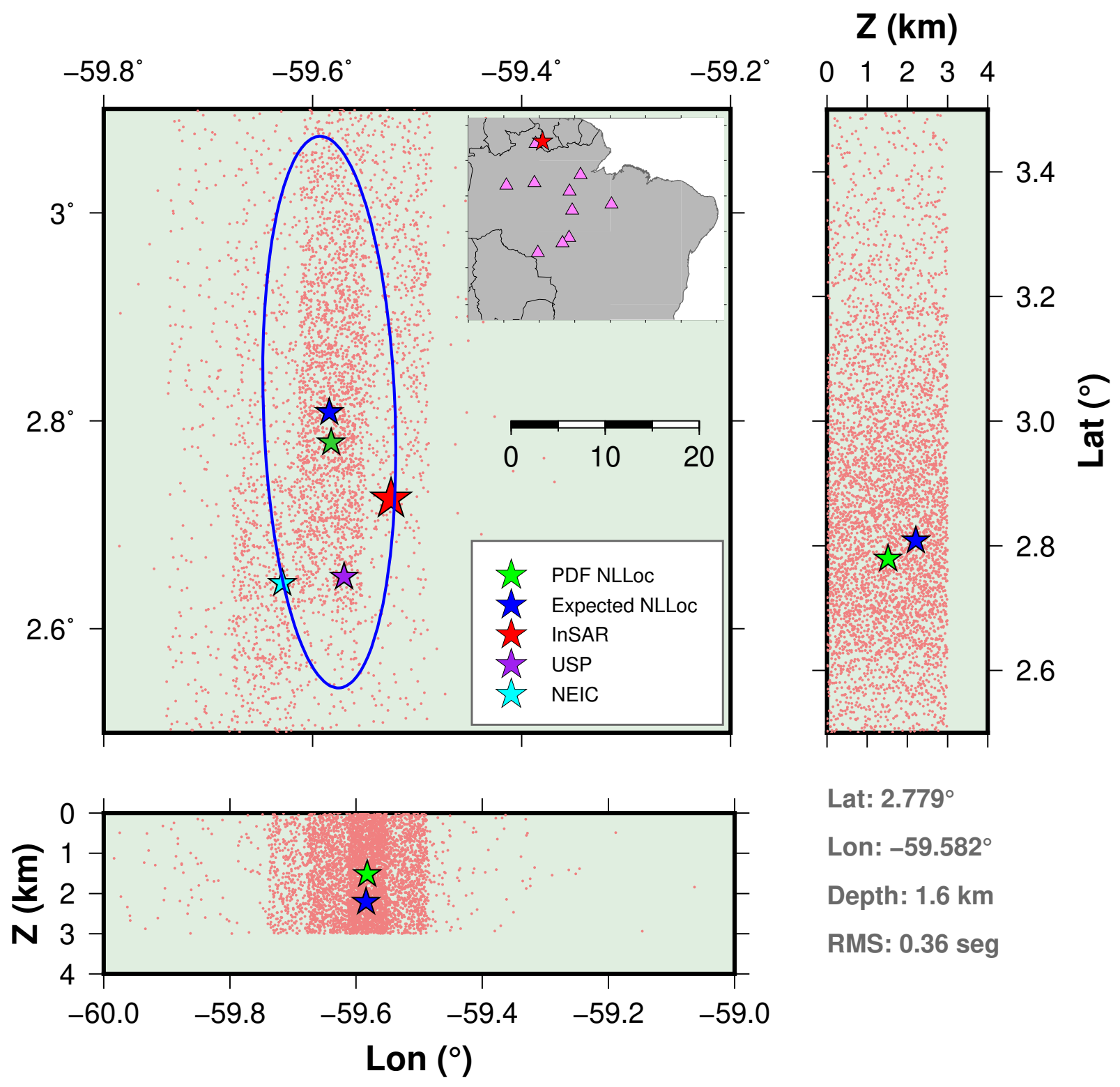

Figure 4.13: Guyana earthquake relocation using NLLoc routine (blue and green stars). Red star is the best epicenter given by InSAR (personal communication). Purple and turquoise stars are RSBR and USGS/NEIC locations. Stations used are shown as purple triangles in the embedded picture.

Although the use of our 3D velocity model has given satisfactory results in the relocation of one Andean and two platform earthquakes, more tests are necessary to confirm the reliability of the model, such as testing the relocation of events that share readings in stations split between the Andean and the stable area. Moreover, another step is to build an S-wave counterpart model to improve the depth's solutions. 
Chapter 5

\section{Conclusions}

The results obtained in the present work have improved the knowledge of the crustal and lithosphere structure in the South American platform, allowing to correlate the crustal thickness and LAB depth with different tectonic units. We also built a 3D velocity model for the South American platform that showed reliability to locate a regional event. We present below the most important findings in each topic approached.

\subsection{Crustal thickness in the South America platform}

The modified H-k stacking is a reliable method to obtain accurate values of crustal thickness and $V_{p} / V_{s}$ ratio, with smaller uncertainties than the conventional one. Nevertheless, it is necessary to have huge data at each station to obtain reliable results.

Using a large permanent and temporary seismographic network, we have better characterize the crustal structure of southwest Brazil. The eastern edge of the Pantanal Basin presents a thin crust, while the west part tends to be thicker. The Chaco Basin also has a normal to thick crust, making the thinner crust of the Sub-Andean region narrower than proposed by previous studies. We confirmed the thinner crust of Borborema Province and along the coastal margin, as well as the thicker crust at the northern of Paraná Basin. The average crustal thickness of our observations is $40.5 \mathrm{~km}$, close to the worldwide average for platforms $(41.5 \mathrm{~km})$, and the average $V_{p} / V_{s}$ ratio is 1.73 .

With these new measurements and published results of other works, we have presented an updated crustal thickness map for South America, with a better resolution mainly in the Amazon region and western part of Brazil; which will be useful for future regional studies. 
We also mapped the $V_{p} / V_{s}$ ratio over the South American platform, finding normal values consistent with a felsic crust, and slightly higher values in Paraná Basin possibly related to the mafic underplating in the lower crust, as proposed by previous studies.

\subsection{Lithosphere-Asthenosphere boundary under Brazil}

The LAB depth estimated tends to vary with the tectonic units, we have confirmed the thinner lithosphere of $\sim 80 \mathrm{~km}$ at Borborema and coastal area of the Mantiqueira Province; both studied before using only one station, while at the coastal part of São Franciso Craton it is observed a thicker lithosphere. In the Amazon region, the thicker lithosphere reaches values up to $\sim 180 \mathrm{~km}$, thinning to Pantanal Basin. Finally, Paraná Basin is characterized by an average lithosphere thickness of $\sim 120 \mathrm{~km}$, being notably thicker close to the cratonic block.

In cratonic and older areas we observed two negative arrivals, interpreting the first one as the MLD which presents an average depth of $\sim 90 \mathrm{~km}$, and the second one as the deeper LAB. Nevertheless, there does not seem to be a clear correlation between the heat flow, MLD and LAB together. We believe that in areas with higher heat flow the lithospheric mantle is hotter, having a lower velocity contrast at the LAB, which disappears from the SRF traces. Nevertheless, we found a good correlation between intraplate higher seismicity with regions of thinner lithosphere (up to $100 \mathrm{~km}$ thick). As expected thinner lithospheres are related to the concentrations of the stress in the upper part of the crust, which favors the occurrence of earthquakes.

The S-wave receiver function method can resolve discontinuities on lithospheric scale, but it needs a good quantity of data due to the weaker signal of the conversions, which could be misinterpreted with noise. Even, due to the geographic location of South America, the number of adequate events to use this method is scarce, then is needed a database for at least three years in each station.

\subsection{D velocity model for South American platform}

The 3D velocity model elaborated shows a realistic velocity variation with the main important interfaces, as sedimentary basement, Moho depth, the Nazca slab (when is 
pertinent), and the global mantle discontinuities at $\sim 420$ and $\sim 660 \mathrm{~km}$. As expected, the travel times are up to 8 seconds highest in the Andean region, when using a 3D velocity model that takes into account local and regional crustal heterogeneities.

Using our 3D velocity model, we have successfully relocated the well-known Aiquile Andean earthquake, as well as two platform events. Despite the epicenter has a good agreement with the accurate location in all cases, it is still necessary to improve the solution in depth and reduce the associated error, which will be achieved with the construction of the S-wave counterpart model.

The way that the model is built allows for improvement when accurate seismic and seismological studies for the South American platform and Andean region are available. Because of the very scarce ground-truth events in the South American platform, we suggest the use of tomography to refine and validate the model whenever it is possible.

Also, as previously suggested we think that the next steps to be followed would be to generate an S-wave counterpart model, test it with more well-known local events, and try to accommodate the location of Andean events recorded by the RSBR network. 


\section{Bibliography}

Agurto-Detzel, H., M. Assumpção, M. Bianchi, and M. Pirchiner (2015), Intraplate seismicity in mid-plate South America: correlations with geophysical lithospheric parameters, Geological Society, London, Special Publications, 432(1), 73-90, https: //doi.org/10.1144/SP432.5.

Albuquerque, D. F., G. S. França, L. P. Moreira, M. Assumpção, M. Bianchi, L. V. Barros, C. C. Quispe, and M. E. Oliveira (2017), Crustal structure of the amazonian craton and adjacent provinces in brazil, Journal of South American Earth Sciences, 79, 431-442, https://doi.org/10.1016/j.jsames.2017.08.019.

Alkmim, F. d. (2004), O que faz de um cráton um cráton? o cráton do são francisco e as revelações almeidianas ao delimitá-lo, Geologia do continente Sul-Americano: evolução da obra de Fernando Flávio Marques de Almeida, pp. 17-34.

Almeida, F. F. M., B. B. de Brito Neves, and C. Dal Ré Carneiro (2000), The origin and evolution of the South American Platform, Earth-Science Reviews, 50(1), 77 - 111, https://doi.org/10.1016/S0012-8252(99)00072-0.

Anderson, D. L. (1995), Lithosphere, asthenosphere, and perisphere, Reviews of Geophysics, 33(1), 125-149, https://doi.org/10.1029/94RG02785.

Assine, M. L., E. R. Merino, F. N. Pupim, L. V. Warren, R. L. Guerreiro, and M. M. McGlue (2016), Geology and geomorphology of the pantanal basin, in Dynamics of the Pantanal wetland in South America, pp. 23-50, Springer, https://doi.org/10.1007/ 698_2015_349. 
Assumpção, M., J. Ardito, and J. R. Barbosa (2010), An improved velocity model for regional epicentre determination in brazil, in IV Simpósio Brasileiro de Geofísica, pp. cp197, European Association of Geoscientists \& Engineers, https://doi.org/10.3997/ 2214-4609-pdb.197.SBGF_2245.

Assumpção, M., P. A. Azevedo, M. P. Rocha, and M. B. Bianchi (2017), Lithospheric features of the São Francisco Craton, in São Francisco Craton, Eastern Brazil, pp. 1525, Springer, https://doi.org/10.1007/978-3-319-01715-0_2.

Assumpção, M., D. James, and A. Snoke (2002), Crustal thickness in SE Brazilian Shield by receiver function analysis: Implications for isostatic compensation, Journal of Geophysical Research, 107(B1,2006), https://doi.org/10.1029/2001JB000422.

Assumpção, M., M. Schimmel, C. Escalante, J. Roberto Barbosa, M. Rocha, and L. V. Barros (2004), Intraplate seismicity in SE Brazil: stress concentration in lithospheric thin spots, Geophysical Journal International, 159(1), 390-399, https://doi.org/10. $1111 / j \cdot 1365-246 \mathrm{X} .2004 .02357 . \mathrm{x}$.

Assumpção, M., M. Feng, A. Tassara, and J. Juliá (2013), Models of crustal thickness for South America from seismic refraction, receiver functions and surface wave tomography, Tectonophysics, 609, 82-96, https://doi.org/10.1016/j.tecto.2012.11.014.

Beck, S., and G. Zandt (2002), The nature of orogenic crust in the central Andes, Journal of Geophysical Research - Solid Earth, 107(B10), https://doi.org/10.1029/ 2000 JB000124.

Béthoux, N., T. Theunissen, M.-O. Beslier, Y. Font, F. Thouvenot, J.-X. Dessa, S. Simon, G. Courrioux, and A. Guillen (2016), Earthquake relocation using a 3d a-priori geological velocity model from the western alps to corsica: Implication for seismic hazard, Tectonophysics, 670, 82-100, https://doi.org/10.1016/j.tecto.2015.12.016.

Bianchi, M., M. Assumpção, H. Agurto-Detzel, J. Carvalho, M. Rocha, S. Drouet, S. Fontes, J. Ferreira, A. Nascimento, and J. Veloso (2015), The Brazilian Seismographic Network: Historical overview and current status, Summary of the Bulletin of the International Seismological Centre, 49(1-6), 70-90, https://doi.org/10.5281/zenodo. 998851. 
Bianchi, M. B., M. Assumpção, M. P. Rocha, J. M. Carvalho, P. A. Azevedo, S. L. Fontes, F. L. Dias, J. M. Ferreira, A. F. Nascimento, M. V. Ferreira, and I. S. L. Costa (2018), The Brazilian Seismographic Network (RSBR): Improving Seismic Monitoring in Brazil, Seismological Research Letters, 89(2A), 452-457, https://doi.org/10.1785/ 0220170227.

Bianchi, M. B. d. (2008), Variações da estrutura da crosta, litosfera e manto para a plataforma Sul Americana através de funções do receptor para ondas P e S, Ph.D. thesis, Universidade de São Paulo, 10.11606/T.14.2008.tde-22092008-121708.

Bird, P. (2003), An updated digital model of plate boundaries, Geochemistry, Geophysics, Geosystems, 4(3), https://doi.org/10.1029/2001GC000252.

Blanco, J. F., C. A. Vargas, and G. Monsalve (2017), Lithospheric thickness estimation beneath northwestern south america from an s-wave receiver function analysis, Geochemistry, Geophysics, Geosystems, 18(4), 1376-1387, https://doi.org/10.1002/ 2016 GC006785.

Bondár, I., and D. Storchak (2011), Improved location procedures at the International Seismological Centre, Geophysical Journal International, 186, 1220-1244, https://doi. org/10.1111/j.1365-246X.2011.05107.x.

Bondár, I., S. Myers, R. Engdahl, and A. Bergman (2004), Epicentre accuracy based on seismic network criteria, Geophysical. J. Int, 156, 483-496, https://doi.org/10.1111/ j.1365-246X.2004.02070.x.

Bondár, I., P. Mónus, C. Czanik, M. Kiszely, Z. Gráczer, Z. Wéber, and the AlpArrayWorking Group (2018), Relocation of Seismicity in the Pannonian Basin Using a Global 3D Velocity Model, Seismological Research Letters, 89(6), 2284-2293, https://doi.org/10.1785/0220180143.

Brown, G., and A. Mussett (1993), The inaccessible Earth: An integrated view of its structure and composition, 275 pp., Chapman and Hall.

Cassidy, J. (1992), Numerical experiments in broadband receier function analysis, Bulletin of the Seismological Society of America, 82(3), 1453-1474. 
Cherepanova, Y., I. M. Artemieva, H. Thybo, and Z. Chemia (2013), Crustal structure of the Siberian craton and the West Siberian basin: An appraisal of existing seismic data, Tectonophysics, 609, 154-183, https://doi.org/10.1016/j.tecto.2013.05.004.

Christensen, N. I. (1996), Poisson's ratio and crustal seismology, Journal of Geophysical Research: Solid Earth, 101(B2), 3139-3156, https://doi.org/10.1029/95JB03446.

Christensen, N. I., and W. D. Mooney (1995), Seismic velocity structure and composition of the continental crust: A global view, Journal of Geophysical Research: Solid Earth, 100(B6), 9761-9788, https://doi.org/10.1029/95JB00259.

Chulick, G. S., S. Detweiler, and W. D. Mooney (2013), Seismic structure of the crust and uppermost mantle of South America and surrounding oceanic basins, Journal of South American Earth Sciences, 42, 260 - 276, http://dx.doi.org/10.1016/j. jsames. 2012.06.002.

Ciardelli, C., S. Van der Lee, E. Bozdag, and M. Assumpção (2019), Adjoint tomography of South America based on 3d spectral-element seismic wave simulations, in AGU Fall Meeting Abstracts, vol. 2019, pp. T21F-0380, 2019AGUFM.T21F0380C.

Cleveland, M., and C. Ammon (2013), Precise relative earthquake location using surface waves, Journal of Geophysical Research: Solid Earth, 118, 2893-2904, https://doi. org/10.1002/jgrb. 50146.

Coelho, D. L., J. Julià, V. Rodríguez-Tribaldos, and N. White (2018), Deep crustal architecture of the Parnaíba basin of NE Brazil from receiver function analysis: implications for basin subsidence, Geological Society, London, Special Publications, 472(1), 83-100, https://doi.org/10.1144/SP472.8.

Condori, C. (2016), Estudo da estrutura da crosta no norte do peru usando a função do receptor, Master's thesis, Universidade de Brasilia, https://repositorio.unb.br/ handle/10482/21417.

Condori, C., G. S. França, H. J. Tavera, D. F. Albuquerque, B. T. Bishop, and S. L. Beck (2017), Crustal structure of north Peru from analysis of teleseismic receiver functions, Journal of South American Earth Sciences, 76, 11-24, https://doi.org/10.1016/j. jsames. 2017.02.006. 
Cordani, U., V. Ramos, L. Fraga, M. Cegarra, I. Delgado, K. Souza, F. Gomes, and C. Schobbenhaus (2016), Tectonic map of South America= Mapa tectônico da América do Sul, CGMW-CPRM-SEGEMAR.

Cordani, U. G. (1984), Estudo preliminar de integração do Pré-Cambriano com os eventos tectônicos das bacias sedimentares brasileiras, Bol. Ciênc. Técn. Petról., 15, 1-70.

Costa, T. N. (2006), Estudo de espessura sedimentar na bacia do paraná com funcão do receptor de alta frequência, Master's thesis, Universidade de São Paulo.

Damodara, N., V. V. Rao, K. Sain, A. Prasad, and A. Murty (2017), Basement configuration of the West Bengal sedimentary basin, India as revealed by seismic refraction tomography: its tectonic implications, Geophysical Journal International, 208(3), 14901507, https://doi.org/10.1093/gji/ggw461.

Davies, J. H. (2013), Global map of solid earth surface heat flow, Geochemistry, Geophysics, Geosystems, 14(10), 4608-4622, https://doi.org/10.1002/ggge. 20271.

Dragone, G. N. (2018), A litosfera das Bacias do Chaco-Paraná e Paraná integrando gravimetria e sondagens magnetotelúricas: novos vínculos à tectônica do Gondwana Sul-Ocidental, Ph.D. thesis, Universidade de São Paulo, 10.11606/T.14.2019. tde-28012019-215255.

Dragone, I., and M. Bianchi (2019), P-wave tomography sensibility test applied to the Chaco-Paraná, Paraná and Pantanal basins inversion, in Reports from the 3rd Brazilian Seismology Symposium Fall Meeting, vol. 2019, p. 93, 10.5281/zenodo. 2656790.

Eaton, D. W., F. Darbyshire, R. L. Evans, H. Grütter, A. G. Jones, and X. Yuan (2009), The elusive lithosphere-asthenosphere boundary (LAB) beneath cratons, Lithos, 109, 1-22, https://doi.org/10.1016/j.lithos.2008.05.009.

Farra, V., and L. Vinnik (2000), Upper mantle stratification by P and S receiver functions, Geophysical Journal International, 141(3), 699-712, https://doi.org/10.1046/ j.1365-246x.2000.00118.x.

Feng, M., M. A. ao, and S. V. der Lee (2004), Group-velocity tomography and lithospheric S-velocity structure of the South American continent, Physics of the Earth and Planetary Interiors, 147(4), 315-331, http://dx.doi.org/10.1016/j.pepi.2004.07.008. 
Feng, M., S. Van der Lee, and M. Assumpção (2007), Upper mantle structure of South America from joint inversion of waveforms and fundamental mode group velocities of Rayleigh waves, Journal of Geophysical Research: Solid Earth, 112(B4), https://doi. org/10.1029/2006JB004449.

Filho, J. V. L., R. A. Fuck, A. S. Ruiz, E. L. Dantas, J. B. Rodrigues, and J. E. Scandolara (2020), Rio apa block: A juvenile crustal fragment in the southwest amazonian craton and its implications for columbia supercontinent reconstitution, The Journal of Geology, 128(5), 415-444, https://doi.org/10.1086/710999.

Fischer, K. M., H. A. Ford, D. L. Abt, and C. A. Rychert (2010), The LithosphereAsthenosphere Boundary, Annual Review of Earth and Planetary Sciences, 38, 551-575, https://doi.org/10.1146/annurev-earth-040809-152438.

Font, Y., H. Kao, C.-S. Liu, and L.-Y. Chiao (2003), A comprehensive 3d seismic velocity model for the eastern taiwan southernmost ryukyu regions, Terrestrial Atmospheric and Oceanic Sciences, 14(2), 159-182.

Fowler, C. M. R. (2005), The Solid Earth: An introduction to Global Geophysics, second edition ed., Cambridge University Press.

França, G. S., and M. Assumpção (2004), Crustal structure of the Ribeira fold belt, SE Brazil, derived from receiver functions, Journal of South American Earth Sciences, 16(8), 743-758, https://doi.org/10.1016/j.jsames.2003.12.002.

Funning, G. J., R. M. Barke, S. H. Lamb, E. Minaya, B. Parsons, and T. J. Wright (2005), The 1998 Aiquile, Bolivia earthquake: A seismically active fault revealed with InSAR, Earth and Planetary Science Letters, 232(1-2), 39-49, https://doi.org/10.1016/j. eps1.2005.01.013.

Guo, W., S. Zhao, F. Wang, Z. Yang, S. Jia, and Z. Liu (2019), Crustal structure of the eastern Piedmont and Atlantic coastal plain in North Carolina and Virginia, eastern North American margin, Earth, Planets and Space, 71(1), 1-22, https://doi.org/10. $1186 /$ s40623-019-1049-z.

Hansen, S., A. A. Nyblade, and J. Julia (2009), Estimates of crustal and lithospheric 
thickness in Sub-Saharan Africa from S-wave receiver functions, South African Journal of Geology, 112(3-4), 229-240, https://doi.org/10.2113/gssajg.112.3-4.229.

Heit, B., F. Sodoudi, X. Yuan, M. Bianchi, and R. Kind (2007), An S receiver function analysis of the lithospheric structure in South America, Geophysical Research Letters, 34(14), https://doi.org/10.1029/2007GL030317.

Heit, B., M. Bianchi, X. Yuan, S. Kay, E. Sandvol, P. Kumar, R. Kind, R. Alonso, L. Brown, and D. Comte (2014), Structure of the crust and the lithosphere beneath the southern Puna plateau from teleseismic receiver functions, Earth and Planetary Science Letters, 385, 1 -11, https://doi.org/10.1016/j.eps1.2013.10.017.

Julià, J., M. Assumpção, and M. Rocha (2008), Deep crustal structure of the Paraná Basin from receiver functions and Rayleigh-wave dispersion: Evidence for a fragmented cratonic root, Journal of Geophysical Research, 113(B08318), https://doi.org/10. 1029/2007 JB005374.

Kennett, B. L. N., and E. Engdahl (1991), Traveltimes for global earthquake location and phases identification, Geophysical Journal International, 105, 429-465, https://doi. org/10.1111/j.1365-246X.1991.tb06724.x.

Kind, R., and X. Yuan (2018), Perspectives of the S-Receiver-Function Method to Image Upper Mantle Discontinuities, in Lithospheric Discontinuities, pp. 139-154, John Wiley \& Sons, https://doi.org/10.1002/9781119249740.ch8.

Kind, R., X. Yuan, and P. Kumar (2012), Seismic receiver functions and the lithosphereasthenosphere boundary, Tectonophysics, 536, 25-43, https://doi.org/10.1016/j. tecto.2012.03.005.

Krishna, V., and V. V. Rao (2005), Processing and modelling of short-offset seismic refraction-coincident deep seismic reflection data sets in sedimentary basins: an approach for exploring the underlying deep crustal structures, Geophysical Journal International, 163(3), 1112-1122, https://doi.org/10.1111/j.1365-246X.2005.02792.x.

Kumar, P., X. Yuan, R. Kind, and G. Kosarev (2005a), The lithosphere-asthenosphere boundary in the Tien Shan-Karakoram region from S receiver functions: Evidence for 
continental subduction, Geophysical Research Letters, 32(7), https://doi.org/10. 1029/2004GL022291.

Kumar, P., R. Kind, W. Hanka, K. Wylegalla, C. Reigber, X. Yuan, I. Woelbern, P. Schwintzer, K. Fleming, T. Dahl-Jensen, et al. (2005b), The lithosphere-asthenosphere boundary in the North-West Atlantic region, Earth and Planetary Science Letters, 236(1-2), 249-257, https://doi.org/10.1016/j.epsl.2005.05.029.

Kumar, P., R. Kind, K. Priestley, and T. Dahl-Jensen (2007), Crustal structure of Iceland and Greenland from receiver function studies, Journal of Geophysical Research: Solid Earth, 112(B3), https://doi.org/10.1029/2005JB003991.

Kumar, P., R. Kind, X. Yuan, and J. Mechie (2012), USArray receiver function images of the lithosphere-asthenosphere boundary, Seismological Research Letters, 83(3), 486-491, https://doi.org/10.1785/gssr1.83.3.486.

Langston, C. (1979), Structure under Mount River, Washington, inferred from teleseismic body waves, Journal of Geophysical Research, 84(B9), 4749-4762, https://doi.org/ 10.1029/JB084iB09p04749.

Laske, G., G. Masters, Z. Ma, and M. Pasyanos (2013), Update on CRUST1.0 a 1-degree global model of Earth's crust, in Geophys. res. abstr, vol. 15, p. 2658, https : //igppweb . ucsd.edu/ gabi/crust1/laske-egu13-crust1.pdf.

Ligorría, J., and C. Ammon (1999), Iterative deconvolution and receiver-function estimation, Bulletin of the Seismological Society of America, 89(5), 1395-1400.

Lima, M. V. A., R. A. Stephenson, J. E. P. Soares, R. A. Fuck, V. C. de Araújo, F. T. Lima, and F. A. Rocha (2019), Characterization of crustal structure by comparing reflectivity patterns of wide-angle and near vertical seismic data from the Parnaíba Basin, Brazil, Geophysical Journal International, 218(3), 1652-1664, https: //doi.org/10.1093/gji/ggz227.

Lin, G. (2013), Three-Dimensional Seismic Velocity Structure and Precise Earthquake Relocations in the Salton Trough, Southern California, Bulletin of the Seismological Society of America, 103(5), 2694-2708, https://doi.org/10.1785/0120120286. 
Liu, Z., J. Park, and S.-i. Karato (2016), Seismological detection of low-velocity anomalies surrounding the mantle transition zone in japan subduction zone, Geophysical Research Letters, 43(6), 2480-2487, https://doi.org/10.1002/2015GL067097.

Lloyd, S., S. Van der Lee, G. Sand, and M. Assumpção (2010), Moho map of South America from receiver functions and surface waves, Journal of Geophysical Research, 115(115), B11,315, https://doi.org/10.1029/2009JB006829.

Lomax, A. (2020), Absolute Location of 2019 Ridgecrest Seismicity Reveals a Shallow Mw 7.1 Hypocenter, Migrating and Pulsing Mw 7.1 Foreshocks, and Duplex Mw 6.4 Ruptures, Bulletin of the Seismological Society of America, 110(4), 1845-1858, https: //doi.org/10.1785/0120200006.

Lomax, A., and A. Curtis (2001), Fast, probabilistic earthquake location in 3d models using oct-tree importance sampling, in Geophys. Res. Abstr, vol. 3, p. 955.

Lomax, A., A. Michelini, A. Curtis, and R. Meyers (2009), Earthquake location, direct, global-search methods, Encyclopedia of complexity and systems science, 5, 2449-2473.

Lozano, L., J. V. Cantavella, and J. Barco (2020), A new 3-D P-wave velocity model for the Gulf of Cadiz and adjacent areas derived from controlled-source seismic data: application to nonlinear probabilistic relocation of moderate earthquakes, Geophysical Journal International, 221(1), 1-19, https://doi.org/10.1093/gji/ggz562.

Lutgens, F. K., E. J. Tarbuck, and D. G. Tasa (2012), Essentials of geology, Pearson Higher Ed.

Luz, R. M. N., J. JuliÂA, and A. F. do Nascimento (2015), Crustal structure of the eastern borborema province, ne brazil, from the joint inversion of receiver functions and surface wave dispersion: Implications for plateau uplift, Journal of Geophysical Research: Solid Earth, 120(5), 3848-3869, https://doi.org/10.1002/2015JB011872.

Mantovani, M., M. Quintas, W. Shukowsky, and B. d. Brito Neves (2005), Delimitation of the paranapanema proterozoic block: a geophysical contribution, EpisodesNewsmagazine of the International Union of Geological Sciences, 28(1), 18-22. 
Marshak, S., and B. A. Van Der Pluijm (2004), Earth structure: An introduction to structural geology and tectonics, WW Norton.

Milani, E. J., and V. A. Ramos (1998), Orogenias paleozóicas no domínio sul-ocidental do gondwana e os ciclos de subsidência da bacia do paraná, Revista Brasileira de Geociências, 28(4), 473-484.

Milani, E. J., and A. Thomaz Filho (2000), Sedimentary basins of south america, Tectonic Evolution of South America, 31, 389-449.

Molinari, I., A. Argnani, A. Morelli, and P. Basini (2015), Development and testing of a 3D seismic velocity model of the Po Plain sedimentary basin, Italy, Bulletin of the Seismological Society of America, 105(2A), 753-764, https://doi.org/10.1785/0120140204.

Murty, A., K. Sain, and B. R. Prasad (2008), Velocity structure of the West-Bengal sedimentary basin, India along the Palashi-Kandi profile using a travel-time inversion of wide-angle seismic data and gravity modeling-An update, Pure and applied geophysics, 165(9), 1733-1750, https://doi.org/10.1007/s00024-008-0398-5.

Myers, S., M. Begnaud, S. Ballard, M. Pasyanos, W. Phillips, A. Ramirez, M. Antolik, K. Hutchenson, J. Dwyer, C. Rowe, and G. Wagner (2010), A crust and upper-mantle model of Eurasia and North Africa for Pn travel-time calculation, Bulletin of the Seismological Society of America, 100, 640-656, https://doi.org/10.1785/0120090198.

Neves, F. A., M. Assumpção, J. C. Dourado, F. Le Diagon, and A. Ortolan (2018), Improved epicentral relocation in the offshore Campos basin, SE Brazil, with the RSTT 3D model, Journal of South American Earth Sciences, 85, 121-125, https: //doi.org/10.1016/j.jsames.2018.05.002.

NOAA National Geophysical Center (2009), Etopo1 1 arc-minute global relief model, Tech. rep., NOAA National Centers for Environmental Information.

Nugraha, A. D., H. A. Shiddiqi, S. Widiyantoro, C. H. Thurber, J. D. Pesicek, H. Zhang, S. H. Wiyono, M. Ramdhan, Wandono, and M. Irsyam (2018), Hypocenter Relocation along the Sunda Arc in Indonesia, Using a 3D Seismic-Velocity Model, Seismological Research Letters, 89(2A), 603-612, https://doi.org/10.1785/0220170107. 
Núñez, D., D. Córdoba, and E. Kissling (2019), Seismic structure of the crust in the western Dominican Republic, Tectonophysics, 773, 228,224, https://doi.org/10.1016/j. tecto.2019.228224.

Oncken, O., G. Asch, C. Haberland, J. Metchie, S. Sobolev, M. Stiller, X. Yuan, H. Brasse, S. Buske, P. Giese, et al. (2003), Seismic imaging of a convergent continental margin and plateau in the central Andes (Andean Continental Research Project 1996 (ANCORP'96)), Journal of Geophysical Research: Solid Earth, 108(B7), https: //doi.org/10.1029/2002JB001771.

O'Reilly, S. Y., and W. L. Griffin (2010), The continental lithosphere-asthenosphere boundary: Can we sample it?, Lithos, 120(1-2), 1-13, https://doi.org/10.1016/j.lithos. 2010.03 .016$.

Owens, T., G. Zand, and S. Taylor (1984), Seismic evidence for an ancient rift beneath the Cumberland Plateau, Tennessee: A detailed analysis of broadband teleseismic P waveforms, Journal of Geophysical Research, 89(B9), 7783-7795, https://doi.org/ 10.1029/JB089iB09p07783.

Pasyanos, M. E., T. G. Masters, G. Laske, and Z. Ma (2014), Litho1. 0: An updated crust and lithospheric model of the Earth, Journal of Geophysical Research: Solid Earth, 119(3), 2153-2173, https://doi.org/10.1002/2013JB010626.

Pavão, C., G. França, G. Marotta, P. Menezes, G. Neto, H. Roig, et al. (2012), Spatial interpolation applied a crustal thickness in Brazil, Journal of Geographic Information System, 4(2), 11-24, https://doi.org/10.4236/jgis.2012.42019.

Portner, D. E., E. E. Rodríguez, S. Beck, G. Zandt, A. Scire, M. P. Rocha, M. B. Bianchi, M. Ruiz, G. S. França, C. Condori, and P. Alvarado (2020), Detailed structure of the subducted nazca slab into the lower mantle derived from continent-scale teleseismic p wave tomography, Journal of Geophysical Research: Solid Earth, 125(5), e2019JB017,884, https://doi.org/10.1029/2019JB017884.

Priestley, K., D. McKenzie, and T. Ho (2018), A Lithosphere-Asthenosphere Boundary - A global model derived from multimode surface-wave tomography and petrology, in 
Lithospheric Discontinuities, pp. 111-124, John Wiley \& Sons, https://doi.org/10. 1002/9781119249740.ch6.

Rivadeneyra-Vera, C., M. Bianchi, M. Assumpção, V. Cedraz, J. Julià, M. Rodríguez, L. Sánchez, G. Sánchez, L. Lopez-Murua, G. Fernandez, R. Fugarazzo, and T. .-B. P. Team (2019), An updated crustal thickness map of central south america based on receiver function measurements in the region of the chaco, pantanal, and paraná basins, southwestern brazil, Journal of Geophysical Research: Solid Earth, 124(8), 8491-8505, https://doi.org/10.1029/2018JB016811.

Rocha, E., and E. O. Cristallini (2015), Controls on structural styles along the deformation front of the Subandean zone of southern Bolivia, Journal of Structural Geology, 73, 8396, https://doi.org/10.1016/j.jsg.2015.02.010.

Rocha, M., M. Assumpção, G. Affonso, P. Azevedo, and M. Bianchi (2019), Teleseismic p wave tomography beneath the Pantanal, Paraná, and Chaco-Paraná Basins, SE South America: Delimiting lithospheric blocks of the SW Gondwana assemblage, Journal of Geophysical Research: Solid Earth, 124(7), 7120-7137, https://doi.org/10.1029/ $2018 J B 016807$.

Rocha, M. P., P. A. de Azevedo, G. S. Marotta, M. Schimmel, and R. Fuck (2016), Causes of intraplate seismicity in central Brazil from travel time seismic tomography, Tectonophysics, 680,1-7, https://doi.org/10.1016/j.tecto.2016.05.005.

Rosa, M. L., B. Collaço, M. A. ao, N. Sabbione, and G. Sánchez (2016), Thin crust beneath the chaco-paraná basin by surface-wave tomography, Journal of South American Earth Sciences, 66, 1 -14, http://dx.doi.org/10.1016/j.jsames.2015.11.010.

Rychert, C. A., and P. M. Shearer (2009), A global view of the Lithosphere-Asthenosphere Boundary, Science, 324(5926), 495-498, https://doi.org/10.1126/science.1169754.

Sandrin, A., and H. Thybo (2008), Seismic constraints on a large mafic intrusion with implications for the subsidence history of the Danish Basin, Journal of Geophysical Research: Solid Earth, 113(B9), https://doi.org/10.1029/2007 JB005067.

Selway, K. (2018), Electrical discontinuities in the continental lithosphere imaged with 
magnetotellurics, in Lithospheric Discontinuities, pp. 89-110, John Wiley \& Sons, https://doi.org/10.1002/9781119249740.ch5.

Shen, Y., C. J. Wolfe, and S. C. Solomon (2003), Seismological evidence for a mid-mantle discontinuity beneath Hawaii and Iceland, Earth and Planetary Science Letters, 214(12), 143-151, https://doi.org/10.1016/S0012-821X(03)00349-2.

Shirzad, T., M. Assumpção, and M. Bianchi (2020), Ambient seismic noise tomography in west-central and Southern Brazil, characterizing the crustal structure of the ChacoParaná, Pantanal and Paraná basins, Geophysical Journal International, 220(3), 20742085, https://doi.org/10.1093/gji/ggz548.

Silva, L. C., N. J. McNaughton, R. Armstrong, L. A. Hartmann, and I. R. Fletcher (2005), The neoproterozoic mantiqueira province and its african connections: a zircon-based u-pb geochronologic subdivision for the brasiliano/pan-african systems of orogens, Precambrian Research, 136(3), 203 - 240, https://doi.org/10.1016/j .precamres. 2004. 10.004 .

Simmons, N. A., S. C. Myers, G. Johannesson, and E. Matzel (2012), LLNL-G3Dv3: Global $\mathrm{P}$ wave tomography model for improved regional and teleseismic travel time prediction, Journal of Geophysical Research: Solid Earth, 117(B10), https://doi.org/10.1029/ 2012JB009525.

Soares, J. E., J. Berrocal, R. A. Fuck, W. D. Mooney, and D. B. Ventura (2006), Seismic characteristics of central Brazil crust and upper mantle: A deep seismic refraction study, Journal of Geophysical Research: Solid Earth, 111(B12), https://doi.org/10.1029/ 2005 JB003769.

Soares, J. E., R. Stephenson, R. A. Fuck, M. V. De Lima, V. C. De Araújo, F. T. Lima, F. A. Rocha, and C. R. Da Trindade (2018), Structure of the crust and upper mantle beneath the Parnaíba Basin, Brazil, from wide-angle reflection-refraction data, Geological Society, London, Special Publications, 472(1), 67-82, https://doi.org/10.1144/ SP472.9.

Starostenko, V., T. Janik, K. Kolomiyets, W. Czuba, P. Środa, M. Grad, I. Kovács, R. Stephenson, D. Lysynchuk, H. Thybo, et al. (2013), Seismic velocity model of 
the crust and upper mantle along profile PANCAKE across the Carpathians between the Pannonian Basin and the East European Craton, Tectonophysics, 608, 1049-1072, https://doi.org/10.1016/j.tecto.2013.07.008.

Sun, D., E. Tan, D. Helmberger, and M. Gurnis (2007), Seismological support for the metastable superplume model, sharp features, and phase changes within the lower mantle, Proceedings of the National Academy of Sciences, 104(22), 9151-9155, https: //doi.org/10.1073/pnas.0608160104.

Sun, W., B. Kennett, L. Zhao, and L.-Y. Fu (2018), Continental lithospheric layering beneath stable, modified and destriyed cratons from seismic daylight imaging, in Lithospheric Discontinuities, pp. 155-176, John Wiley \& Sons, https://doi.org/10.1002/ $9781119249740 \cdot \operatorname{ch} 9$.

Süss, M. P., and J. H. Shaw (2003), P wave seismic velocity structure derived from sonic logs and industry reflection data in the Los Angeles basin, California, Journal of Geophysical Research: Solid Earth, 108(B3), https://doi.org/10.1029/2001JB001628.

Ussami, N., S. Shiraiwa, and J. M. L. Dominguez (1999), Basement reactivation in a subAndean foreland flexural bulge: The Pantanal wetland, SW Brazil, Tectonics, 18(1), 25-39, https://doi.org/10.1029/1998TC900004.

Van der Meijde, M., J. Julià, and M. Assumpção (2013), Gravity derived Moho for South America, Tectonophysics, 609, 456-467, https://doi.org/10.1016/j.tecto. 2013.03 .023$.

Wang, S., F. Wang, J. Zhang, S. Jia, C. Zhang, J. Zhao, and B. Liu (2014), The Pwave velocity structure of the lithosphere of the North China Craton-Results from the Wendeng-Alxa Left Banner deep seismic sounding profile, Science China Earth Sciences, 57(9), 2053-2063, https://doi.org/10.1007/s11430-014-4903-7.

Ward, K. M., R. C. Porter, G. Zandt, S. L. Beck, L. S. Wagner, E. Minaya, and H. Tavera (2013), Ambient noise tomography across the Central Andes, Geophysical Journal International, 194(3), 1559-1573, https://doi.org/10.1093/gji/ggt166.

Wu, Y.-M., C.-H. Chang, L. Zhao, T.-L. Teng, and M. Nakamura (2008), A Comprehensive 
Relocation of Earthquakes in Taiwan from 1991 to 2005, Bulletin of the Seismological Society of America, 98(3), 1471-1481, https://doi.org/10.1785/0120070166.

Yeck, W. L., A. F. Sheehan, and V. Schulte-Pelkum (2013), Sequential H-k Stacking to Obtain Accurate Crustal Thicknesses beneath Sedimentary Basins, Bulletin of the Seismological Society of America, 103(3), 2142-2150, https://doi .org/10.1785/0120120290.

Yu, Y., J. Song, K. H. Liu, and S. S. Gao (2015), Determining crustal structure beneath seismic stations overlying a low-velocity sedimentary layer using receiver functions, Journal of Geophysical Research: Solid Earth, 120(5), 3208-3218, https://doi.org/10. 1002/2014JB011610.

Yuan, H., and B. Romanowicz (2018), Introduction - Lithospheric discontinuities, in Lithospheric Discontinuities, pp. 1-4, John Wiley \& Sons, https://doi.org/10.1002/ $9781119249740 \cdot \operatorname{ch} 0$.

Yuan, X., R. Kind, X. Li, and R. Wang (2006), The S receiver functions: synthetics and data example, Geophysical Journal International, 165(2), 555-564, https://doi.org/ $10.1111 / j .1365-246 X .2006 .02885 . x$.

Zandt, G., S. Myers, and T. Wallace (1995), Crust and mantle structure across the Basin and Range-Colorado Plateau boundary at $37^{\circ} \mathrm{n}$ latitude and implications for cenozoic extensional mechanism, Journal of Geophysical Research, 100(B6), https://doi.org/ $10.1029 / 94 J B 03063$

Zelt, B., and R. Ellis (1999), Receiver-function studies in the Trans-Hudson orogen, Saskatchewan, Canadian Journal of Earth Sciences, 36(4), 585-603, https://doi .org/ 10.1139/e98-109.

Zhang, J., and C. A. Langston (1995), Constraints on oceanic lithosphere structure from deep-focus regional receiver function inversions, Journal of Geophysical Research: Solid Earth, 100(B11), 22,187-22,196, https://doi.org/10.1029/95JB02512.

Zheng, T., L. Zhao, and L. Chen (2005), A detailed receiver function image of the sedimentary structure in the Bohai Bay Basin, Physics of the Earth and Planetary Interiors, 152(3), 129 -143, https://doi.org/10.1016/j.pepi.2005.06.011. 
Zhu, J., H. Xu, X. Qiu, C. Ye, and S. Li (2018), Crustal structure and rifting of the northern South China Sea margin: Evidence from shoreline-crossing seismic investigations, Geological Journal, 53(5), 2065-2083, https://doi.org/10.1002/gj. 3034.

Zhu, L., and H. Kanamori (2000), Moho depth variation in southern California from teleseismic receiver functions, Journal of Geophysical Research, 105, 2969-2980, https: //doi.org/10.1029/1999JB900322. 